\title{
Monitoring Barnegat Inlet, New Jersey, South Jetty Realignment
}

William C. Seabergh, Mary A. Cialone, John W. McCormick, Keith D. Watson, and Monica A. Chasten

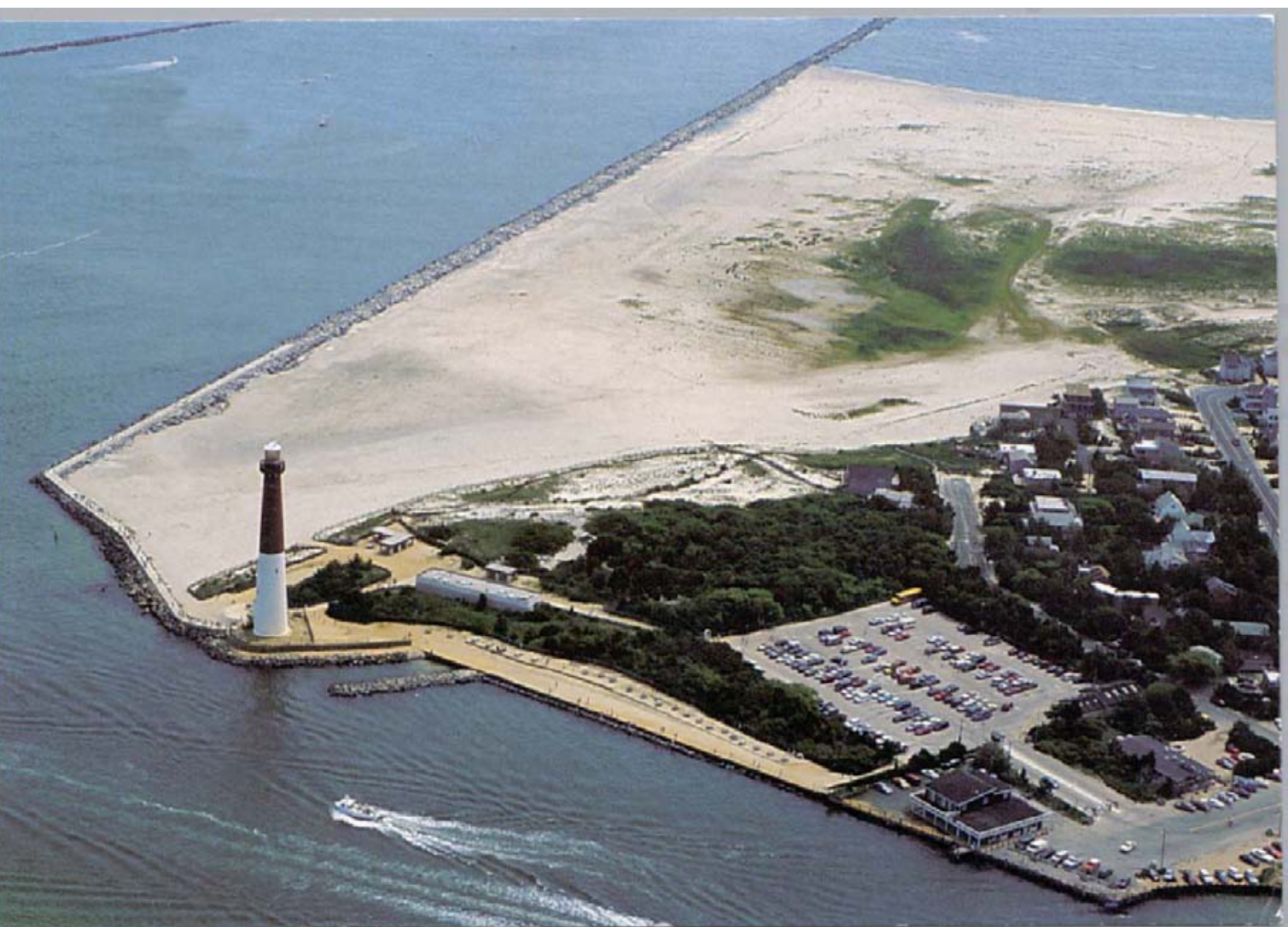




\title{
Monitoring Barnegat Inlet, New Jersey, South Jetty Realignment
}

\author{
William C. Seabergh, Mary A. Cialone \\ Coastal and Hydraulics Laboratory \\ U.S. Army Engineer Research and Development Center \\ 3909 Halls Ferry Road \\ Vicksburg, MS 39180-6199 \\ John W. McCormick \\ U.S. Army Engineer District, Wilmington \\ 69 Darlington Avenue \\ Wilmington, NC 28403 \\ Keith D. Watson, Monica A. Chasten \\ U.S. Army Engineer District, Philadelphia \\ Wanamaker Building \\ 100 Penn Square East \\ $2^{\text {nd }}$ and Chestnut Street \\ Philadelphia, PA 19107-3390
}

Final report

Approved for public release; distribution is unlimited.

\footnotetext{
Prepared for U.S. Army Corps of Engineers

Washington, DC 20314-1000

Under MCNP Work Unit IIM-9
} 


\begin{abstract}
The objective of this monitoring at Barnegat Inlet was to determine the response of the inlet system to a new south jetty completed in 1991 that essentially parallels the existing north jetty. Barnegat Inlet is accessed by a large number of commercial, sport fishing, and recreational vessels each year. An unstable navigation channel and numerous accidents and deaths at Barnegat Inlet led to the construction of the new south jetty. The response of the new south jetty and inlet system was determined by data collection and monitoring and compared with design predictions. This new knowledge will contribute to improved jetty and inlet system design guidance, enhance construction of rubble-mound jetties, and develop better maintenance techniques for tidal inlets. The monitoring plan evaluated four fundamental hypotheses of the project design objectives: (a) the new south jetty and new channel alignment will not adversely affect tidal hydraulic response or high tide level in the inlet by system (i.e., no flooding problem), and prototype hydraulic response will be as predicted by a previous physical model evaluation; (b) the new south jetty realignment will improve navigation safety by stabilizing the navigation channel and depth between the jetties and over the outer bar (ebb tidal shoal), and will eliminate dredging in these regions; (c) the new south jetty will be structurally stable; and (d) the jetty system realignment will not adversely affect upcoast or downcoast beaches.
\end{abstract}

DISCLAIMER: The contents of this report are not to be used for advertising, publication, or promotional purposes. Citation of trade names does not constitute an official endorsement or approval of the use of such commercial products. All product names and trademarks cited are the property of their respective owners. The findings of this report are not to be construed as an official Department of the Army position unless so designated by other authorized documents.

DESTROY THIS REPORT WHEN IT IS NO LONGER NEEDED. DO NOT RETURN TO THE ORIGINATOR. 


\section{Contents}

Preface. . $\mathrm{x}$

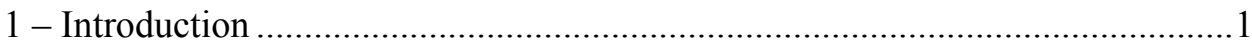

Monitoring Completed Navigation Projects (MCNP) Program.......................1

Barnegat Inlet, NJ, Navigation Project .....................................................2

Problem Statement. .....................................................................................

Historical Development of Barnegat Inlet .................................................. 7

Summary of Engineering Activities at Barnegat Inlet ..................................12

Objectives of MCNP Monitoring at Barnegat Inlet ..................................... 13

Study Approach and Monitoring Plan .................................................... 14

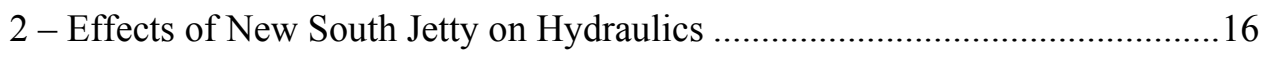

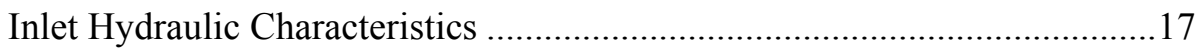

MCNP Hydraulic Measurements ............................................................19

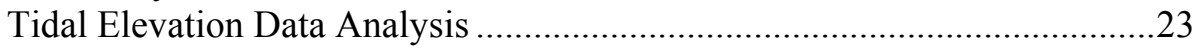

Short-term Tidal Current Data Analysis .................................................27

One-month Tidal Current Data Analysis ..........................................................

Summary of New South Jetty Effects on Hydraulics ..................................45

3 - Effects of New South Jetty on Channel Stability and Dredging ...................50

Impact of Structures on Inlet Channel Location ..........................................50

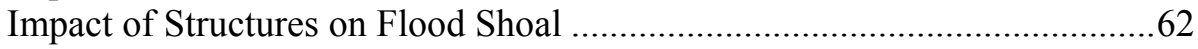

Impact of Structures on Navigation Safety and Dredging ............................71

Summary of New South Jetty Effects on Channel Stability and Dredging ...73

4 - Barnegat Inlet New South Jetty Structure Stability .....................................77

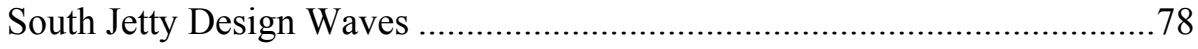

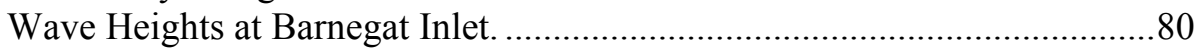

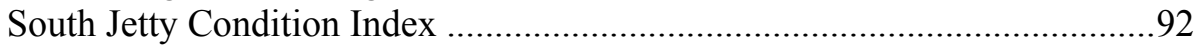

Summary of New South Jetty Structure Stability .......................................103

5 - Effects of New South Jetty on Upcoast and Downcoast Beaches ................105

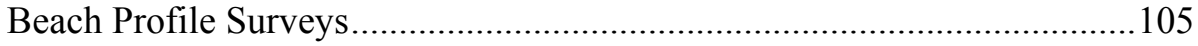

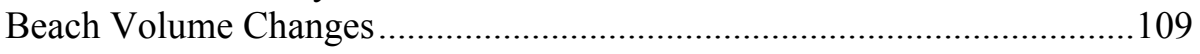


Summary of Effects of New South Jetty on Upcoast and Downcoast

Beaches

6 - Summary and Conclusions

Introduction 115

Effects of New South Jetty on Hydraulics

Effects of New South Jetty on Channel Stability and Dredging

Barnegat Inlet New South Jetty Structure Stability

Effects of New South Jetty on Upcoast and Downcoast Beaches

Conclusions

References

Appendix A: Historical photos of Barnegat Inlet, NJ, Change Chronology

Appendix B: Beach Profiles at Island Beach State Park and Long Island Beach, Adjacent to Barnegat Inlet, NJ

Appendix C: Beach Sand Volume Above Various Contours for Island Beach State Park and Long Island Beach Profiles for Years 1993, 1994, 1995, 1996, and 1997

SF 298

\section{List of Figures}

Figure 1. Barnegat Inlet, NJ, MCNP study area showing locations of tide gauges and wind anemometer. 2

Figure 2. Arrowhead jetties constructed at Barnegat Inlet, NJ, 1939-1940, and sand dike constructed in 1943, photo August 1944

Figure 3. Barnegat Inlet, NJ, and flood shoal inside the inlet, after new south jetty construction was completed in June 1991, photo December 1992.

Figure 4. Barnegat Inlet, NJ, bathymetry, November-December 1993 (the project configuration monitored by the MCNP program)

Figure 5. Barnegat Inlet, NJ, 1994, showing MCNP instrument locations, transect locations, and the new south jetty location with respect to the old south jetty, photo June 1994.

Figure 6. Measured ocean tide 1 mile seaward of jetties, Coast Guard Station tide just inside inlet, and bay tides at Bayshore and Loveladies

Figure 7. Tidal constituents elevation amplitude at the Coast Guard Station tide gauge for the 1985 preproject condition, and the 1993-94 postproject condition. 
Figure 8. Tidal elevation constituent amplitude and phase changes at the Coast Guard Station between the 1985 preproject and the 1993-94 postproject condition

Figure 9. Elevation differences and corresponding wind speed across length of Barnegat Inlet, measured between tide gauges at Loveladies and Mantoloking

Figure 10. Velocity distributions across Transects A, B, and C for maximum ebb and flood discharges for 1993, 1994, and 1995, looking seaward.....

Figure 11. Average peak flood and ebb velocities at Transects A, B, and $\mathrm{C}$ for spring and mean tide conditions.

Figure 12. Peak average currents taken on a vertical line through the water column at Transect $\mathrm{C}$ and adjusted to represent the entire transect.

Figure 13. Velocity profiles from bottom-mounted ADCP located at Transect C

Figure 14. Mean peak velocity profiles for ebb and flood tide conditions as determined through analysis of a complete lunar cycle of ADCP data

Figure 15. Water level, depth-averaged velocities, and direction for bottom-mounted ADCP for a 3-day period in June 1994 36

Figure 16. Tidal prisms derived from 34-day bottom-mounted ADCP data, and wind speed and direction blowing over Barnegat Inlet.

Figure 17. Hourly discharges at Transect $\mathrm{C}$ versus tide elevation derived from the 34-day bottom-mounted ADCP current data collection ...38

Figure 18. Discharge curve for one tidal cycle versus tide elevation for Transect C .38

Figure 19. Tidal elevations measured at the Bayshore gauge showing the fortnightly rise in bay water surface .39

Figure 20. Power spectral density versus frequency for Bayshore hourly water elevations between Day 50 and Day 207 of 1994 .40

Figure 21. Ebb and flood tidal prism variation with tide range at Barnegat Inlet during May-June 1994 .41

Figure 22. Duration of ebb and flood flow, and the ebb and flood tide range, during May-June 1994 at Barnegat Inlet .41

Figure 23. Variation of ebb and flood duration versus tide range during May-June 1994 at Barnegat Inlet, NJ . .42

Figure 24. Tidal prism and minimum flow area between 1932 and 1995 ........43

Figure 25. Spring tide conditions at Transect C............................................44 
Figure 26. Neap tide conditions at Transect C, Days 151 through 154 of the 34-day ADCP data acquisition, showing velocity time-series and corresponding direction of transport, and sediment transport time-series

Figure 27. Arrowhead jetties at high tide level, the sand dike across the channel south of the flood shoal, and the new channel dredged through the flood shoal, photo August 1944.

Figure 28. Sand spit accumulation between arrowhead jetties, photo October 1964

Figure 29. Filling of dredged channel through the flood shoal, and reformation of the flood shoal, immediately before construction of new south jetty, photo March 1988 .52

Figure 30. Flood shoal and entrance channel alignment after construction of new south jetty, photo October 1991 52

Figure 31. Extensive flood shoal, and waves being reformed by the ebb shoal in the ocean in front of the inlet, photo June 1992 53

Figure 32. Physical model study flowlines for ebb and flood currents.............54

Figure 33. Barnegat Inlet channel bathymetry, 1937-1943 …..........................56

Figure 34. Barnegat Inlet channel bathymetry, 1946-1959 ............................57

Figure 35. Barnegat Inlet channel bathymetry, 1962-1975 ...........................59

Figure 36. Barnegat Inlet channel bathymetry, 1979-1986 .............................60

Figure 37. Average channel depths between jetties, 1991-1994 .......................61

Figure 38. Average channel area between jetties, 1991-1994 .........................62

Figure 39. Barnegat Inlet flood shoal closest to the inlet throat looking seaward, photo December 1992 .63

Figure 40. Cross sections taken through flood shoal, 1992 and 1997.

Figure 41. Fill and eroded areas where cross sections were taken through flood shoal, 1992 and 1997 .65

Figure 42. Cross-section A-A looking seaward ............................................65

Figure 43. Cross-section B-B looking seaward ...............................................66

Figure 44. Cross-section C-C looking seaward .............................................66

Figure 45. Thalweg depths through the Barnegat Inlet flood shoal.................67

Figure 46. Flood shoal contour plot for 1992 NAVD 88 datum .......................68

Figure 47. Flood shoal contour plot for 1997 NAVD 88 datum........................68

Figure 48. Plan view area above the 0-ft NAVD 88 contour............................69

Figure 49. Plan view area above the -3.3 -ft NAVD 88 contour ......................69

Figure 50. Percent reduction in flood shoal volume above -1.6-, -3.3-, $-6.6-,-9.8-$, and $-13.1-\mathrm{ft}$ contours ................................................ 70

Figure 51. Boat wakes traversing Barnegat Inlet channel ..............................72 
Figure 52. Dredging volumes at Barnegat Inlet, years 1986 through 2000 ......73

Figure 53. Waves being refracted by nearshore bathymetry and tidal currents in the vicinity of Barnegat Inlet jetties, photo April 1993

Figure 54. Instrumentation locations used in determining wave transformation at Barnegat Inlet jetties for ascertaining structural stability

Figure 55. Occurrences of wave height by direction of approach, DWG, May 1994-June 1995.

Figure 56. Occurrences of wave period by direction of approach, DWG, May 1994-June 1995.

Figure 57. Wave height ratio versus DWG wave height

Figure 58. Wave height ratio versus DWG wave height (35-day average) ......84

Figure 59. Wave height ratio versus DWG wave height (variation with period)

Figure 60. Wave height ratio versus DWG wave height (variation with direction)

Figure 61. Barnegat Inlet ebb shoal bathymetry from Scanning Hydrographic Operational Airborne Lidar Survey June-July 1994 survey

Figure 62. Standard (nonstorm) numerical simulation model results for 7.4-ft $(2.25-\mathrm{m})$ wave height and $15-\mathrm{sec}$ wave period .87

Figure 63. Wave height ratio versus DWG for both numerical simulation model and prototype. .88

Figure 64. Wave height at the jetty and wave height ratio versus direction of approach, wave period, and water level

Figure 65. Wave height at DWG for storm of 22-23 September 1994 .90

Figure 66. November 1994 storm time-series. .90

Figure 67. Wave height prototype and numerical simulation model comparisons at Seapac location.

Figure 68. Nondimensional energy change between DWG and Seapac wave gauge

Figure 69. Typical rubble-mound breakwater or jetty cross-section features

Figure 70. Barnegat Inlet new south jetty cross section showing unique design features

Figure 71. Barnegat Inlet new south jetty and fill region between new south jetty and old arrowhead jetty .95

Figure 72. Barnegat Inlet new south jetty and fill region adjacent to new south jetty 
Figure 73. Sediment passing through the permeable upper layer of armor stone due to core loss above the impermeable core section.

Figure 74. Sediment passing through the structure where corestone has washed out

Figure 75. Dye passing through voids in the new south jetty resulting from loss of corestone

Figure 76. Dye dispersing into the channel after passing through voids in the new south jetty created by loss of corestone

Figure 77. Water beginning to move through the south jetty on rising tide .....99

Figure 78. Water continuing to pass through the south jetty on rising tide ......99

Figure 79. Meandering channels along landside of new south jetty, allowing sediment movement through the structure into the channel on falling tide as a result of loss of corestone

Figure 80. Armor stone settling and displacement on landside of new south jetty, exposing large voids between armor stone and loss of corestone.....

Figure 81. Armor stone displacement and slope steepening on channel side of new south jetty, resulting from combined wave energy and tidal currents

Figure 82. Indentations in structure channel side slope resulting from loss of armor stone and steepening of structure slope

Figure 83. Large gaps and cracks between armor stone on crest of new south jetty near oceanward end, resulting from high-energy wave activity

Figure 84. Cracking of armor stone from rocking and settling following loss of corestone 102

Figure 85. Location of beach profiles along Island Beach State Park and Long Island Beach, near Barnegat Inlet, NJ .. 106

Figure 86. Typical beach profile change for Island Beach State Park, Profile IB 8 112

Figure 87. Beach volume changes along Island Beach State Park, Profile IB 8

Figure 88. Typical beach profile change for Long Island Beach,

Profile LB 14 113

Figure 89. Beach volume changes along Long Island Beach, Profile LB 14 113

Figure 90. New south jetty constructed entirely within the confines of the old arrowhead jetty system. 


\section{List of Tables}

Table 1. Relationships Among Vertical Datums at Barnegat Inlet, NJ, Referenced to the North American Vertical Datum of 1988 (NAVD 88)

Table 2. Barnegat Inlet, NJ, Historical Engineering Activities, Channel Velocities, and Tidal Prisms.

Table 3. Coast Guard Station Gauge Tide Ranges ........................................24

Table 4. Changes in Tide Range at Barnegat Bay Tide Gauges....................24

Table 5. Pre- and Post-Project M2 and M4 Tidal Constituents at

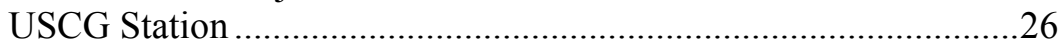

Table 6. Average Peak Velocities...............................................................29

Table 7. Statistical Results of 34 Days of Bottom-Mounted ADCP

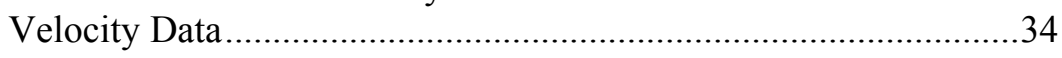

Table 8. Volume, cu m, above $-0.5,-1.0,-2.0,-3.0$, and -4.0 NAVD 88 Contours.......................................................... 70

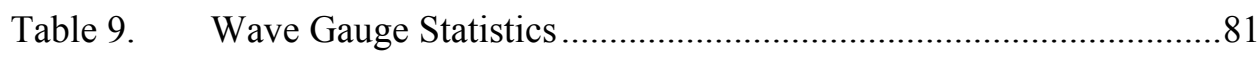

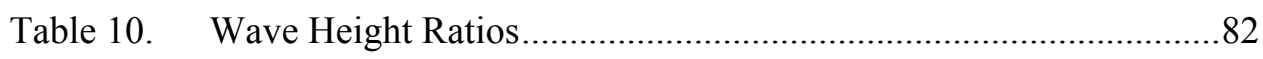

Table 11. Representative Wave Conditions for Numerical Model

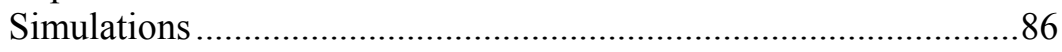

Table 12. Structural Index Scale for Coastal Structures .................................99 


\section{Preface}

The studies reported herein were conducted as part of the Monitoring Completed Navigation Projects (MCNP) program (formerly Monitoring Completed Coastal Projects (MCCP) program). Work was conducted under MCNP Work Unit No. 11M-9, "Barnegat Inlet, New Jersey," during the period October 1992 - September 1997. Overall program management of the MCNP is provided by Headquarters, U.S. Army Corps of Engineers (HQUSACE). The Coastal and Hydraulics Laboratory (CHL), Vicksburg, MS, U.S. Army Engineer Research and Development Center (ERDC), is responsible for technical and data management and support for HQUSACE review and technology transfer. Program monitors for the MCNP program are Messrs. Barry W. Holliday, Charles B. Chesnutt, and David B. Wingerd, HQUSACE. MCNP Program Managers during the conduct of this MCNP Barnegat Inlet study were Ms. Carolyn M. Holmes and Messrs. E. Clarke McNair and Robert R. Bottin, CHL.

The studies reported herein that were funded by the MCNP were conducted by Ms. Mary A. Cialone and Mr. William C. Seabergh, CHL, Vicksburg, MS; Ms. Monica A. Chasten, U. S. Army Engineer District, Philadelphia (formerly of CHL); and Messrs. John W. McCormick, U. S. Army Engineer District, Wilmington (formerly of CHL); and Keith D. Watson, U. S. Army Engineer District, Philadelphia. Other supplemental studies that contributed significantly to this investigation were conducted by the Philadelphia District. This work was performed under the general supervision of Dr. James R. Houston, former Director, CHL; Mr. Thomas W. Richardson, Director, CHL; Mr. Bruce A. Ebersole, Chief, Coastal Processes Branch, CHL; and Mr. Dennis G. Markle, Chief, Coastal Harbors and Structures Branch, CHL. Ms. Cialone and Mr. Seabergh were the Principal Investigators for this MCNP work unit. The MCNP Team Member from the Philadelphia District was Mr. Watson. This report was compiled by Dr. Lyndell Z. Hales and Ms. Donna L. Richey, CHL.

Commander and Executive Director of ERDC was COL James R. Rowan, EN. Director was Dr. James R. Houston. 


\section{Introduction}

\section{Monitoring Completed Navigation Projects (MCNP) Program}

The goal of the Monitoring Completed Navigation Projects (MCNP) program (formerly the Monitoring Completed Coastal Projects program) is the advancement of coastal and hydraulic engineering technology. The program is designed to determine how well projects are accomplishing their purposes and are resisting attacks by their physical environment. These determinations, combined with concepts and understanding already available, will lead to (a) creating more accurate and economical engineering solutions to coastal and hydraulic problems, (b) strengthening and improving design criteria and methodology, (c) improving construction practices and cost-effectiveness, and (d) improving operation and maintenance techniques. Additionally, the monitoring program will identify where current technology is inadequate or where additional research is required.

To develop direction for the program, the U.S. Army Corps of Engineers established an ad hoc committee of engineers and scientists. The committee formulated the objectives of the program, developed its operation philosophy, recommended funding levels, and established criteria and procedures for project selection. A significant result of their efforts was a prioritized listing of problem areas to be addressed. This is essentially a listing of the areas of interest of the program.

Corps offices are invited to nominate projects for inclusion in the monitoring program as funds become available. The MCNP program is governed by Engineer Regulation 1110-2-8151 (Headquarters, U.S. Army Corps of Engineers (HQUSACE) 1977)). A selection committee reviews and prioritizes the nominated projects based on criteria established in the regulation. The prioritized list is reviewed by the Program Monitors at HQUSACE. Final selection is based on this prioritized list, national priorities, and the availability of funding.

The overall monitoring program is under the management of the Coastal and Hydraulics Laboratory (CHL), U.S. Army Engineer Research and Development Center (ERDC), with guidance from HQUSACE. An individual monitoring project is a cooperative effort between the submitting District and/or Division office and CHL. Development of monitoring plans and conduct of data collection and analyses are dependent upon the combined resources of CHL and the District and/or Division. 


\section{Barnegat Inlet, NJ, Navigation Project}

\section{Background}

Barnegat Inlet is a stabilized inlet centrally located on the New Jersey coast approximately 50 miles $(80 \mathrm{~km})$ south of Sandy Hook and 70 miles $(112 \mathrm{~km})$ northeast of Cape May (Figure 1). The overall orientation of the New Jersey coastline changes in this area from northeast to north-northeast. The inlet separates Island Beach State Park to the north from Long Beach Island to the south and serves as the primary link between the Atlantic Ocean and Barnegat Bay. There are no major rivers contributing to the bay system. The beach area

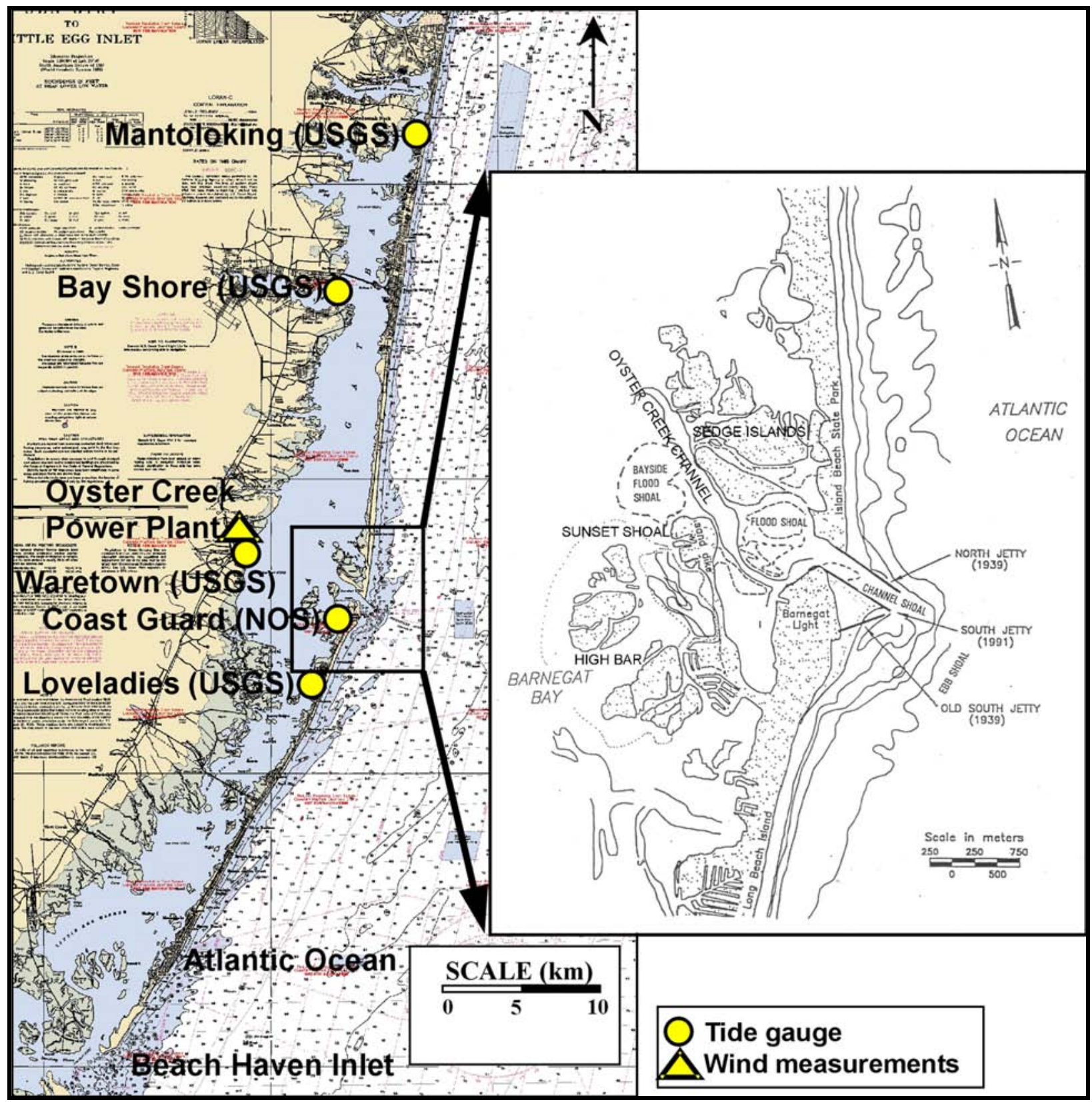

Figure 1. Barnegat Inlet, NJ, MCNP study area showing locations of tide gauges and wind anemometer 
from the Barnegat Lighthouse south to the Brigantine National Wildlife Refuge is heavily structured with 110 groins. Net transport is $100,000 \mathrm{cu}$ yd per year (76,500 cu m per year) to the south (Caldwell 1966). Prior to the initial inlet stabilization in 1939-1940, the inlet migrated to the south at an average rate of 20 $\mathrm{ft}$ per year (6 $\mathrm{m}$ per year) (Caccese and Spies 1977). Barnegat Inlet is used by a large number of commercial and recreational vessels. Boaters contend that it is one of the most hazardous inlets on the East Coast (U.S. Army Engineer District, Philadelphia, 1984).

In 1939-1940, two rubble-mound jetties were constructed in an arrowhead configuration as part of a Federal navigation project (Figure 2). As constructed, the north jetty (length $=4,900 \mathrm{ft}(1,495 \mathrm{~m})$ ) and the south jetty (length $=2,950 \mathrm{ft}$ $(900 \mathrm{~m}))$ were $3,500 \mathrm{ft}(1,070 \mathrm{~m})$ apart at the landward end, and were spaced much closer together at the seaward end $(1,000 \mathrm{ft}(305 \mathrm{~m}))$. Jetty elevations were $+8 \mathrm{ft}(+2.4 \mathrm{~m})$ mean low water $(\mathrm{mlw})$ at the landward end and $+2 \mathrm{ft}(+0.6 \mathrm{~m})$ mlw at the seaward end. (Table 1 shows the relationships among the various datums used in the vicinity of Barnegat Inlet over the years, referenced to the

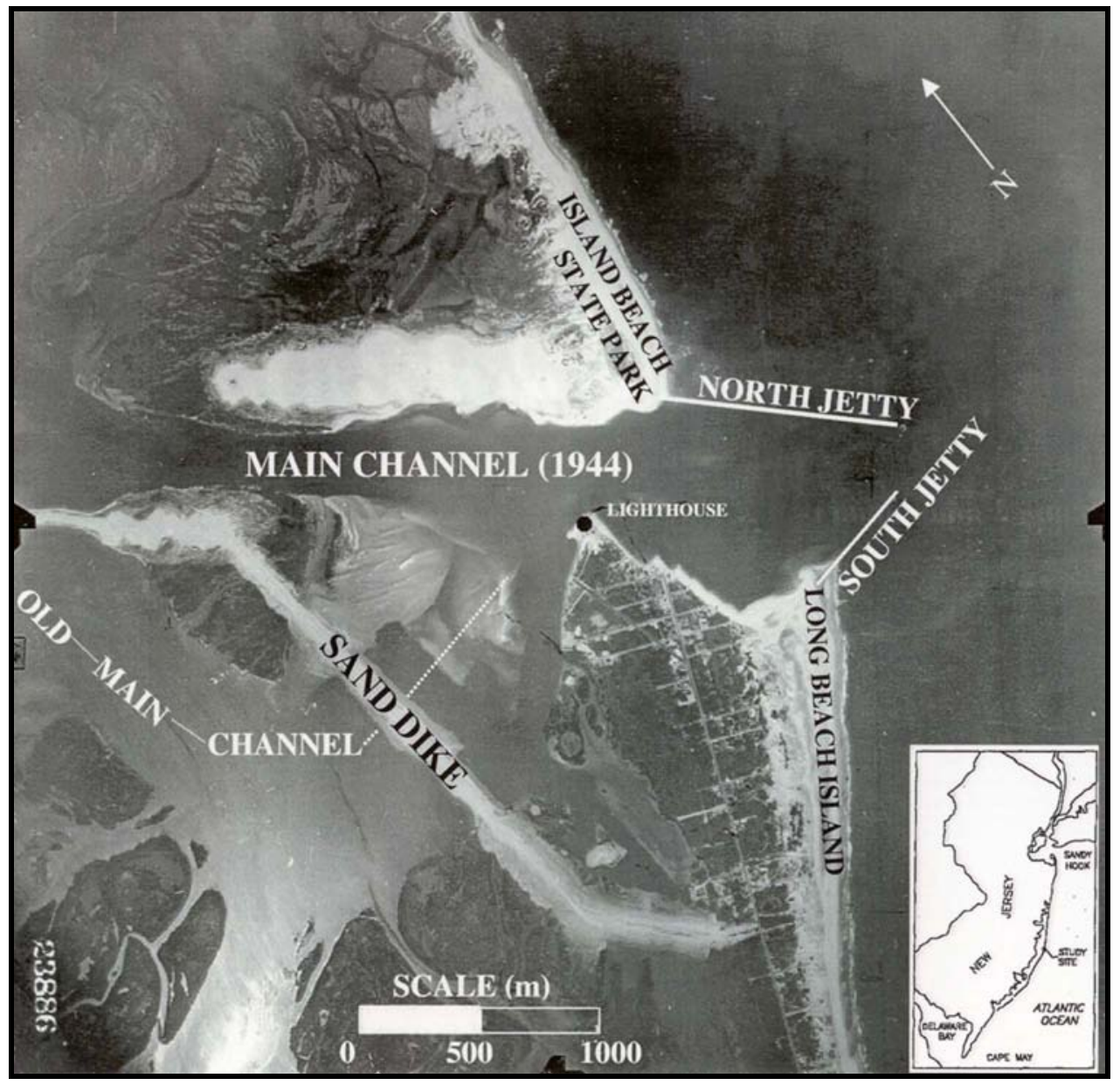

Figure 2. Arrowhead jetties constructed at Barnegat Inlet, NJ, 1939-1940, and sand dike constructed in 1943, photo August 1944 


\begin{tabular}{|c|c|c|}
\hline \multicolumn{3}{|c|}{$\begin{array}{l}\text { Table } 1 \\
\text { Relationships among Vertical Datums at Barnegat Inlet, NJ, } \\
\text { Referenced to the North American Vertical Datum of } 1988 \text { (NAVD 88) }\end{array}$} \\
\hline Vertical Datum & $\begin{array}{l}\text { Bay Gauge Elevations, } \\
\mathrm{ft}(\mathrm{m}) \text {, at Coast Guard } \\
\text { Station (see Figure 1) }\end{array}$ & $\begin{array}{l}\text { Ocean Gauge Elevations } \\
\mathrm{ft}(\mathrm{m})\end{array}$ \\
\hline Mean higher high water (mhhw) & $1.22(0.37)$ & $1.80(0.55)$ \\
\hline Mean high water (mhw) & $0.97 \quad(0.30)$ & $1.49(0.45)$ \\
\hline NAVD88 & $0.00(0.00)$ & $0.00 \quad(0.00)$ \\
\hline $\begin{array}{l}\text { Mean water line }(\mathrm{mwl})=\text { mean tide } \\
\text { level }(\mathrm{mtl})\end{array}$ & $-0.25(-0.08)$ & $-0.57(-0.17)$ \\
\hline $\begin{array}{l}\text { National Geodetic Vertical Datum } \\
\text { (NGVD) }\end{array}$ & $-1.26(-0.38)$ & $-1.26(-0.38)$ \\
\hline Mean low water (mlw) & $-1.47(-0.45)$ & $-2.63(0.80)$ \\
\hline Mean lower low water (mllw) & $-1.61(-0.49)$ & $-2.94(-0.90)$ \\
\hline
\end{tabular}

North American Vertical Datum of 1988 (NAVD 88)). The arrowhead configuration was selected to provide flow convergence promoting scour and maintaining the desired channel depth in the inlet throat. However, the arrowhead jetty configuration did not confine the ebb and flood tidal flows, possibly due to a mean tidal level elevation of the jetties (discussed later). The low elevation permitted sand to enter the inlet, resulting in several channels developing between the jetties. There was not a single stable navigation channel through the inlet, and the depths of the navigation channels were inadequate.

Several modifications were made to the jetties following their initial construction (Smith 1988). In 1944, the shoreward $100 \mathrm{ft}(30 \mathrm{~m})$ of the south jetty was lowered to promote sand deposition on the critically eroding beach south of the inlet (Sager and Hollyfield 1974). In 1950 and 1954, repairs were made to the seaward end of the north jetty and shoreward portion of the south jetty, respectively. In 1972-1974, the shoreward 3,700 ft $(1,130 \mathrm{~m})$ of the north jetty was raised to $+8 \mathrm{ft}(+2.4 \mathrm{~m}) \mathrm{mlw}$ and made impermeable. The center line of the repaired section was offset $12 \mathrm{ft}(3.7 \mathrm{~m})$ toward the inlet from the existing section to make the structure impermeable.

Numerous dredging projects were performed throughout the history of the project in an attempt to straighten or stabilize the channel, but all were unsuccessful. In 1943, a sand dike, shown in Figure 2, was constructed on the bay side of the inlet to eliminate one of the two major channels and stabilize the flow through the inlet, but this was also unsuccessful. In response to the channel stability problem, hydraulic model studies were conducted at the U. S. Army Engineer Waterways Experiment Station (Sager and Hollyfield 1974) to develop a recommended plan of improvement with respect to maintaining an effective navigation channel. The model study concluded that the construction of a new south jetty parallel to the existing north jetty and a 300-ft- $(91-\mathrm{m}-)$ wide dredged channel (depth $=10 \mathrm{ft}(3 \mathrm{~m})$ ) would provide inlet and channel stability.

A survey study for Barnegat Inlet was completed in September 1974 (U.S. Army Engineer District, Philadelphia, 1974). Based on the findings of that study, a plan of improvement consisting of modifications to the existing navigation project was recommended. Subsequent authorization for a Phase I advanced 
engineering and design study in 1976 was based on that recommendation (U.S. Army Engineer District, Philadelphia, 1976). The Phase I study recounted the survey study plan of improvement, with some changes to the channel alignment and dredge disposal locations. The Phase I General Design Memorandum was completed in September 1981 and approved in January 1983. The Phase II design study (U.S. Army Engineer District, Philadelphia, 1984) refined the Phase I design plan while retaining the same functional purposes of inlet stabilization and channel improvement. The recommended plan included (a) the construction of a new south jetty 4,270 ft $(1,300 \mathrm{~m})$ long along an alignment generally parallel to the existing north jetty to extend from an existing groin at the base of the Barnegat Lighthouse (Figure 2) to the tip of the existing south jetty; (b) the dredging and maintenance of a navigation channel $300 \mathrm{ft}(91 \mathrm{~m})$ wide dredged to a depth of $-10 \mathrm{ft}(-3 \mathrm{~m}) \mathrm{mlw}$, extending from the outer ocean bar to the Barnegat Lighthouse; (c) the removal of a shoal located between the proposed navigation channel and the existing north jetty; and (d) construction of a walkway (sport fishing facility) and installation of a steel railing at the inlet end of the south jetty.

\section{Present project}

The new south jetty was constructed during the period December 1987 through June 1991 parallel to the existing north jetty, extending from the base of the Barnegat Lighthouse to the end of the existing south jetty (Figure 3 ). The total length of the new south jetty is $4,270 \mathrm{ft}(1,300 \mathrm{~m})$. The jetty cross section consists of a bedding layer, mat stone, core stone, and a double layer of capstone. However, the design was revised, replacing the bottom layer of capstone at the center with core stone to prevent sand migration through the pervious capstone layer. The old south jetty was not removed upon completion of the new south jetty.

Initial dredging of the 300-ft- (91-m-) wide by 10-ft- (3-m-) deep channel and other minor project features (i.e., sport fishing facility, walkway, railing, handicap access) were completed in early 1992. All material dredged during the south jetty construction was placed between the old and new south jetties. The material from the initial channel dredging was placed on the ocean beaches south of the inlet project area. It was anticipated that subsequent maintenance dredging would be placed on either the north or south ocean beaches adjacent to the inlet, depending on the apparent need.

\section{Problem Statement}

Barnegat Inlet, NJ, is accessed by a large number of commercial, sport fishing, and recreational vessels each year. An unstable navigation channel and numerous accidents and deaths at Barnegat Inlet led to the construction of a new interior south jetty rubble-mound structure completed in 1992 that essentially parallels the existing north jetty. The response of the inlet system to this new jetty construction needed to be determined by data collection and monitoring and compared with design predictions. 


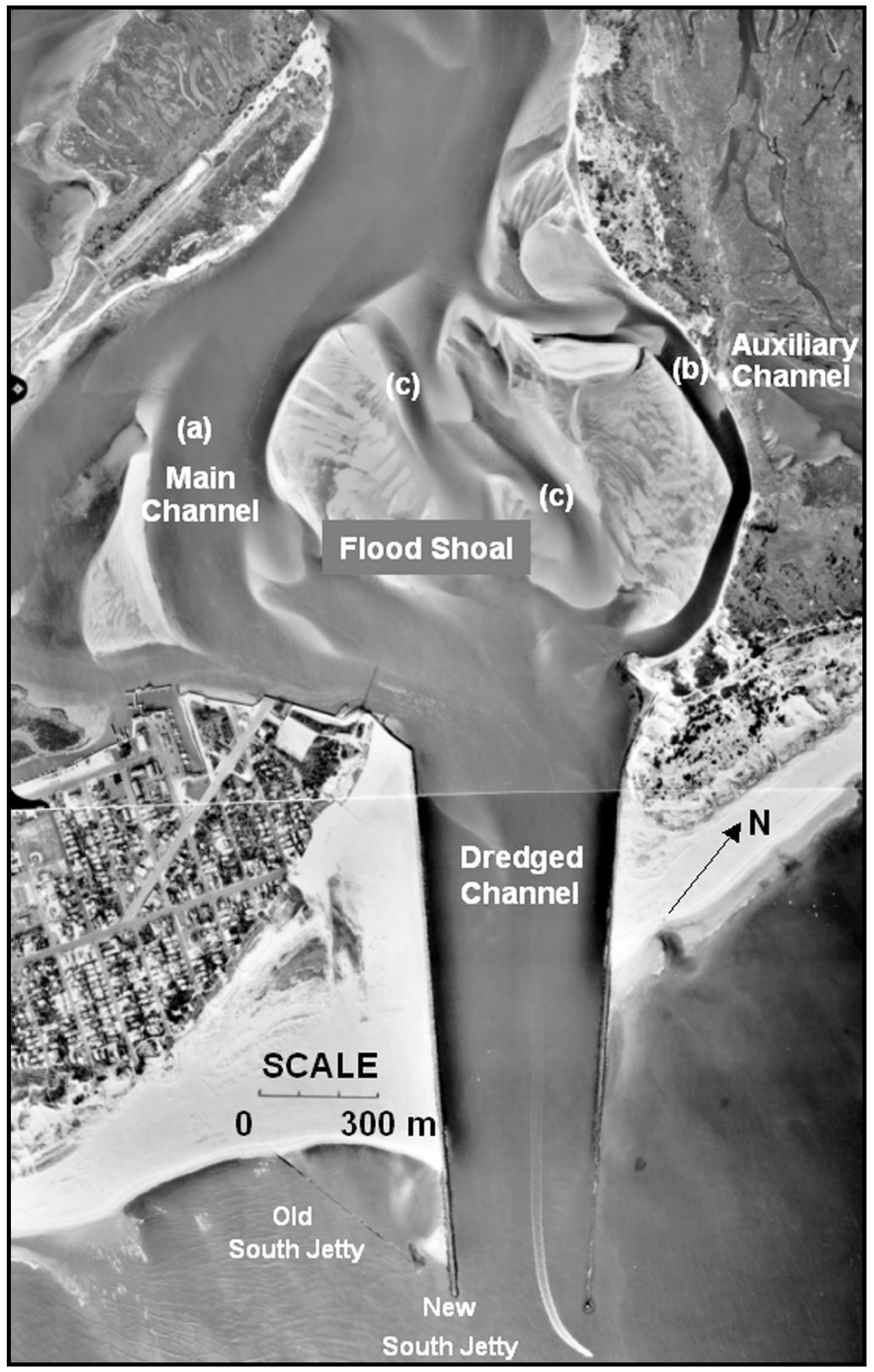

Figure 3. Barnegat Inlet, $\mathrm{NJ}$, and flood shoal inside the inlet, after new south jetty construction was completed in June 1991 (main channel is now on the left side of the flood shoal looking upstream), photo December 1992 


\section{Historical Development of Barnegat Inlet ${ }^{1}$}

The earliest depiction of Barnegat Inlet can be traced back to a Dutch map from the 1600s (Lucke 1934). The first detailed maps of Barnegat Inlet, prepared by the U.S. Coast and Geodetic Survey, showed that prior to 1812 numerous small inlets to the north of Barnegat Inlet opened for brief periods and then closed. Cranberry Inlet (12 miles $(19.3 \mathrm{~km})$ to the north) was the last small inlet to close in 1812, leaving the principal inlets of Manasquan and Shark River, which are presently stabilized. Maps that date from 1839 to 1932 show a southerly migration of Barnegat Inlet. The greatest movement occurred between 1839 and 1866, when the inlet migrated to the south a distance of 2,500 ft $(762 \mathrm{~m})$, or an average of $92 \mathrm{ft}(28 \mathrm{~m})$ per year (U.S. Army Shore Protection Board 1933). Between 1866 and 1874 the north and south barrier islands migrated toward each other, causing a narrowing of the inlet. From 1874 to 1932 the inlet continued to migrate southward for a distance of 1,200 ft $(366 \mathrm{~m})$, or an average of $20 \mathrm{ft}(6 \mathrm{~m})$ annually (U.S. Army Shore Protection Board 1933). Thus, in the century following 1838, Barnegat Inlet migrated southward a distance of 1 mile $(1.6 \mathrm{~km})$.

During this time, the migration rates of the barrier islands to the north and south of Barnegat Inlet were not equal. Most shoreline change maps indicate that the northern island migrated at a faster rate than the southern island. As a result, the inlet became increasingly narrower with a decreasing cross-sectional area (U.S. Army Engineer District, Philadelphia, 1936).

In 1926 the State of New Jersey began a program to prevent migration along the southern shore of Barnegat Inlet. In 1928 a stone and timber core groin $310 \mathrm{ft}$ (94.5 m) long was built to the east of Barnegat Lighthouse. Three timber groins 75 to $110 \mathrm{ft}$ ( 23 to $34 \mathrm{~m}$ ) long were constructed in 1929 on the bay-side beach to the west of Barnegat Lighthouse. In 1930 two timber and steel groins $175 \mathrm{ft}(53 \mathrm{~m})$ long were built south of Barnegat Lighthouse near Fourth Street with a timber and steel bulkhead between them (U.S. Army Engineer District, Philadelphia, 1981). Some of these structures have since been destroyed during storms.

During the early migration of the inlet from 1839 to 1932 , prior to significant modification by man, the main channel maintained relatively the same configuration. The navigation channel from Barnegat Bay to the inlet ran eastsoutheast through Oyster Creek Channel, and on the western side of Sedge Island the channel was deflected to flow past the west side of Sunset Shoal. To the north of High Bar, the channel turned northeast to flow past the bay side of Long Beach Island. The channel continued in this direction until it passed the southern tip of Island Beach where it turned to the southeast to enter the ocean.

Thus, in 1932 the main channel entered the ocean in a southerly direction. In 1935 the channel migrated to enter the ocean in an easterly direction, and by 1939 it had once again migrated to the southerly position.

In 1934 erosion resulting from continued inlet migration endangered the tip of Long Beach Island. At this time, the State of New Jersey built a steel sheetpile bulkhead $205 \mathrm{ft}$ ( $62 \mathrm{~m}$ ) long on the western and northern sides of Barnegat Lighthouse. In 1938 the Federal government added a timber and stone groin

\footnotetext{
${ }^{1}$ This section is extracted essentially verbatim by permission from Fields (1984).
} 
$180 \mathrm{ft}(55 \mathrm{~m})$ long to the west of Barnegat Lighthouse (U.S. Army Engineer District, Philadelphia, 1981). Despite these efforts to stabilize the southern shore of the inlet, $200 \mathrm{ft}(61 \mathrm{~m})$ of northerly migration occurred between 1935 and 1939.

The channel leading from the inlet throat to Oyster Creek Channel was dredged during the period November 1938 to March 1939. Dredged material was placed on the marsh along the southern tip of Island Beach. On the southern side of the channel, material was placed on Sunset Shoal and in a line parallel with the channel extending back into the bay. The north jetty, measuring approximately 4,870 ft (1,484 m) long, was completed in December 1939. Construction of the south jetty, measuring about 2,950 ft (899 m) long, was completed in September 1940. Both jetties terminated at the 8-ft- (2.4-m-) depth contour instead of the 12-ft- (3.7-m-) depth contour (Sager and Hollyfield 1974). As stated previously, these jetties were constructed in an arrowhead configuration (Figure 2) in an unsuccessful attempt to concentrate the flow to produce channel scouring for the purpose of reducing or eliminating channel dredging.

A few years after construction of the arrowhead jetties, it became apparent that the navigation problems had not been completely solved. The channel in the intra-jetty region migrated from a southerly location in 1940 to a position parallel to the north jetty by 1943 . Because the jetties were not providing the desired channel improvements, a sand dike was built from Sunset Shoal across High Bar to the bay side of Long Beach Island. The dike was constructed from dredged material during maintenance of the main channel. It was hoped that the dike would create a permanent straight channel from Oyster Creek to the inlet by blocking off flow through the old channel (U.S. Army Engineer District, Philadelphia, 1981).

The volume of the tidal prism at Barnegat Inlet was estimated by the U.S. Army Corps of Engineers during several different stages of the Federal navigation project development. Tidal prism is defined as the total volume of water that flows into a harbor or estuary, or out again with movement of the tide, excluding any freshwater flow (Shore Protection Manual 1984). In June 1932, prior to construction of the jetties, the tidal prism was estimated to be about 30 million cubic yards (Mcy) (23 million cubic meters (Mcm)) (U.S. Army Engineer District, Philadelphia, 1981). After stabilization of the inlet in September 1940, the tidal prism was estimated to be about $42 \mathrm{Mcy}$ (32 Mcm). This represents an increase of $12 \mathrm{Mcy}(9 \mathrm{Mcm})$. By the time the sand dike was completed in September 1943, the tidal prism had decreased to 27 Mcy $(21 \mathrm{Mcm})$. The trend of inlet cross-sectional area changes corresponds to that predicted by the change in tidal prism (U.S. Army Engineer District, Philadelphia, 1981).

These tidal prism values had been calculated from the equilibrium flow area equation of O'Brien $(1931,1969)$. O'Brien's equation was based primarily on data from Pacific coast inlets where the cross-sectional area of the entrance channel was measured below mean sea level and the tidal prism corresponded to the diurnal or spring range of tide. O'Brien (1976) stated later that the data should be reworked to relate the flow area to the tidal prism on a mean tidal range. Jarrett (1976) confirmed that this second hypothesis would be appropriate. 
Current velocity measurements collected near the inlet throat prior to emplacement of the sand dike indicate ebb-dominant inlet flow. Data recorded in 1932 (Lucke 1934) show maximum ebb and flood velocities of $5.1 \mathrm{ft}$ per sec $(156 \mathrm{~cm}$ per sec) and $3.6 \mathrm{ft}$ per sec $(111 \mathrm{~cm}$ per sec), respectively. Current velocity measurements collected in 1936 by the National Ocean Survey indicate maximum ebb velocities of $4.2 \mathrm{ft}$ per sec $(129 \mathrm{~cm}$ per sec) and maximum flood velocities of $3.5 \mathrm{ft}$ per sec (107 cm per sec) (Jarrett 1976). The U.S. Army Corps of Engineers collected data in July 1945, 2 years after construction of the sand dike, finding nearly equal ebb and flood velocities of $3.1 \mathrm{ft}$ per sec $(94 \mathrm{~cm}$ per $\mathrm{sec}$ ) and $3.3 \mathrm{ft}$ per sec $(100 \mathrm{~cm}$ per sec), respectively (U.S. Army Engineer District, Philadelphia, 1981).

In the years 1943 and 1944, severe erosion took place along the intra-jetty beach of Long Beach Island. As a result, in 1943 the Federal government built three timber groins $165 \mathrm{ft}(50 \mathrm{~m})$ long to the south of Barnegat Lighthouse. Further measures were taken to restore the beach in January 1944 when $100 \mathrm{ft}$ $(30 \mathrm{~m})$ of the inshore end of the south jetty were lowered. It was hoped that lowering the jetty would facilitate sand movement from the south into this critically eroded area (Johnson 1969).

Despite maintenance dredging of the channel between 1943 and 1944, navigational conditions continued to deteriorate due to shoaling. Between 1943 and 1950, the channel in the intra-jetty area migrated from a position parallel to the north jetty to a position in the center of the inlet. By July 1950, a large sand body had grown in the inlet throat, forming a narrow passageway. In the bay area between the end of the sand dike and Barnegat Lighthouse, the main channel eroded a broad curve into the dredged material deposit along the southern shore of Island Beach. In addition, a small flood-tidal delta had begun to form in this area, representing a seaward migration of the site of active flood delta deposition from the pre-dike (1934) location of Sunset Shoal.

Navigational conditions at Barnegat Inlet continued to worsen, and by November 1955, the channel passed through the center of the inlet throat and was deflected toward the end of the south jetty where it entered the ocean. The sand body at the inlet throat grew larger between 1950 and 1955, and a large subaqueous shoal developed along the length of the north jetty. The flood-tidal delta in the bay area grew to a volume of about $220,000 \mathrm{cu}$ yd $(168,000 \mathrm{cu} \mathrm{m})$ by 1955, a significant increase since 1950. At the same time, the channel shoaled, with depths through the inlet decreasing from 8.9 to $3.0 \mathrm{ft}$ ( 2.7 to $0.9 \mathrm{~m}$ ) (U.S. Army Engineer District, Philadelphia, 1981). Current velocity measurements taken at this time by the Corps of Engineers indicated flood-dominant flow with maximum flood and ebb velocities of $3.5 \mathrm{ft}(107 \mathrm{~cm})$ per sec) and $3.2 \mathrm{ft}(98 \mathrm{~cm})$ per sec), respectively (U.S. Army Engineer District, Philadelphia, 1981).

In an attempt to remedy the extensive shoaling, a dredging program was initiated in 1955. A straight channel was to be dredged along the north jetty in the belief that once the channel was created, a flushing action would keep it open (Caccese and Spies 1977). A fixed dredging plant was set up and about $475,000 \mathrm{cu}$ yd $(365,000 \mathrm{cu} \mathrm{m})$ of material was removed from the channel (U.S. Army Engineer District, Philadelphia, 1981). Despite this effort, little progress was made toward creating a permanent channel, and hazardous water conditions finally forced the dredge to shut down. 
During 1956, severe erosion was once again a problem along the intra-jetty beach of Long Beach Island. Prior to this time, the outer end of the 308-ft(94-m-) long groin built in 1928 to the east of Barnegat Lighthouse had been destroyed by waves. In 1956 the groin was rebuilt and extended to a length of $505 \mathrm{ft}(154 \mathrm{~m})$. In addition, a timber bulkhead was constructed to the west of Barnegat Lighthouse, and four groins 200 to $350 \mathrm{ft}$ (61 to $107 \mathrm{~m}$ ) long were added to the south of Barnegat Lighthouse.

Subsequent to 1955 , southerly migration of the intra-jetty channel continued, and by April 1968 Barnegat Inlet was impassable at low water to anything other than small outboard motor boats (Caccese and Spies 1977). The main channel ran south along the intra-jetty beach of Long Beach Island, and then turned to follow the south jetty out to the ocean. Reports indicate that the channel followed so closely to the jetty that parts of the jetty were in danger of being undermined (U.S. Army Engineer District, Philadelphia, 1981). The large sand body extending southward from Island Beach into the inlet throat was approximately the same size as in 1955, although it had reached its largest proportions in August 1962 when the throat was in danger of closing.

In May 1968 the tidal prism at the inlet was estimated to be about 18 Mcy $(14 \mathrm{Mcm})$, a significant decrease since construction of the sand dike in September 1943 (U.S. Army Engineer District, Philadelphia, 1981). Between 1955 and 1968, three channels developed in the bay area between Barnegat Lighthouse and the sand dike. The main navigational channel held the northernmost position, and continued to scour into the southern shore of Island Beach. The second channel maintained a straight path from the inlet throat to the end of the sand dike, and the third channel followed a southwest direction past Barnegat Lighthouse where it turned to the northwest toward the end of the sand dike. Two flood-tidal deltas developed in association with these three channels. A smaller delta with a volume of about $210,000 \mathrm{cu}$ yd $(161,000 \mathrm{cu} \mathrm{m})$ was deposited between the two southern channels, and a larger delta with a volume of about $434,000 \mathrm{cu}$ yd $(332,000 \mathrm{cu} \mathrm{m})$ accumulated in the middle of the main channel.

Maintenance dredging was conducted at the seaward end of the jetties during the years 1968 to 1971 (U.S. Army Engineer District, Philadelphia, 1981). This was done in response to channel migration and shoaling in this area (Caccese and Spies 1977). Between 1939 and 1968, the channel at the mouth of the inlet and through the ebb-tidal delta had maintained a relatively stable position and depth.

In September 1972, the Corps of Engineers began a program of sidecast dredging at Barnegat Inlet on an annual or semiannual basis (U.S. Army Engineer District, Philadelphia, 1981). As part of the program, a straight channel was dredged from the inlet throat to the ends of the jetties. However, shoaling reoccurred and the channel had to be abandoned. As a result, navigation resumed through the old channel running parallel to the south jetty.

Plans were developed to modify the north jetty in 1972 due to the deteriorating conditions both seaward of and between the jetties. During the period 1973 to 1974 , the inner $3,700 \mathrm{ft}(1,128 \mathrm{~m})$ of the north jetty were raised from an elevation of 2.0 to $7.9 \mathrm{ft}(0.6$ to $2.4 \mathrm{~m}) \mathrm{mlw}$. The jetty was also made impermeable (U.S. Army Engineer District, Philadelphia, 1981). These changes were aimed at stopping movement of sand from the north over the jetty and into the inlet throat. 
Even prior to completion of work on the north jetty, improvements in the channel alignment were evidenced by a migration away from the south jetty. By January 1976, the channel had moved to a position nearly parallel with the north jetty, and the sand body in the inlet throat had decreased considerably in size. The northern flood-tidal delta increased to a volume of about 520,000 cu yd $(397,000 \mathrm{cu} \mathrm{m})$. Following modifications to the north jetty, significant changes also occurred in the morphology and size of the ebb-tidal delta. The volume had increased from about $38,000 \mathrm{cu}$ yd $(29,000 \mathrm{cu} \mathrm{m})$ in 1968 to about $64,000 \mathrm{cu}$ yd $(49,000 \mathrm{cu} \mathrm{m})$ in 1975 . The position of the ebb delta shifted from north of the north jetty in 1975 to seaward of the sends of the jetties by 1976.

By May 1978, the accumulation of sand at the inlet throat had completely eroded away, and the main channel closely followed the north jetty. A linear subaerial shoal accumulated on the south side of the channel, probably the result of sidecast dredging in the channel. Several smaller subaqueous shoals developed between the channel and Barnegat Lighthouse. The northern floodtidal delta increased to a volume of about $830,000 \mathrm{cu}$ yd $(634,000 \mathrm{cu} \mathrm{m})$, while the southern delta had completely eroded away. With the exception of changes in channel depth due to dredging, few changes occurred in the intra-jetty region between 1978 and 1982.

The most significant changes at Barnegat Inlet between 1978 and 1982 related to the size and position of the ebb-tidal delta. Between September 1977 and May 1978, the ebb delta grew in volume from about 130,000 cu yd $(98,000 \mathrm{cu} \mathrm{m})$ to about $240,000 \mathrm{cu}$ yd $(183,000 \mathrm{cu} \mathrm{m})$, and a large portion of the delta became subaerially exposed. In addition, the delta shifted from the 1976 position directly seaward of the ends of the jetties to a position south of the south jetty. Because the ebb-tidal delta blocked the entrance to the open ocean in 1978, the main channel was deflected along the outside of the south jetty to enter the ocean through a break in the ebb-tidal delta.

During the spring and summer of 1979, the Corps of Engineers conducted an emergency beach nourishment project along the northern end of Long Beach Island. Approximately 130,000 cu yd (100,000 cu m) of sediment were dredged from the main channel at Barnegat Inlet seaward along an east-southeast line. The material was pumped to critically eroded beaches from Barnegat Lighthouse south to Loveladies (Ashley and Halsey 1982).

By September 1979, the volume of the ebb-tidal delta had increased to about $265,000 \mathrm{cu}$ yd $(201,000 \mathrm{cu} \mathrm{m})$, and by February 1980 the volume was about $310,000 \mathrm{cu}$ yd $(238,000 \mathrm{cu} \mathrm{m})$. The position of the delta also began to change at this time, such that by June 1980 a small portion of the delta had migrated past the south jetty into the inlet. In November 1980, landward migration caused the feature to weld onto Long Beach Island directly south of the south jetty. In March 1980, the Corps of Engineers estimated the tidal prism at Barnegat Inlet at about 15.3 Mcy $(11.7 \mathrm{Mcm})$, a decrease of about 2.8 Mcy $(2.1 \mathrm{Mcm})$ since 1968. The cross-sectional area was estimated to be $12,000 \mathrm{sq} \mathrm{ft}(1,115 \mathrm{sq} \mathrm{m})$. By May 1982, the accumulation of sediment on the ebb-tidal delta had migrated onshore and completely separated from the ebb delta. Beginning at this time, the sediment behaved more like an attachment bar migrating in response to longshore currents.

In 1987, Ashley (1987) conducted a field study to determine the spring tidal prism at Barnegat Inlet for both ebb and flood tidal flow. The flood tidal prism was about 16.2 Mcy (12.4 Mcm), and the ebb tidal prism was about 14.2 Mcy 
(10.9 Mcm). The minimum cross-sectional area was about 10,450 sq ft (972 sq $\mathrm{m}$ ) for these conditions. This was the last known tidal prism study conducted prior to the construction of the new south jetty. Postconstruction tidal prisms were determined by the authors of this MCNP report from extensive data collection in 1993, 1994, and 1995, and are reported herein.

\section{Summary of Engineering Activities at Barnegat Inlet}

The continued southward migration of the inlet was prevented initially by construction of a groin near the Barnegat Lighthouse (south side of the inlet), then by the construction of two converging (arrowhead) rubble-mound jetties in 1939-1940 as part of a Federal navigation project (Figure 2). The north jetty was $4,900 \mathrm{ft}(1,485 \mathrm{~m})$ long, and the south jetty was $2,950 \mathrm{ft}(900 \mathrm{~m})$ long. Jetty elevations were $+8.0 \mathrm{ft}(+2.4 \mathrm{~m}) \mathrm{mlw}$ at the landward end, sloped to $+2.0 \mathrm{ft}$ $(+0.6 \mathrm{~m}) \mathrm{mlw}$ at the shoreline, and continued at this elevation to the seaward end. With an ocean mean tide range of $+4.2 \mathrm{ft}(+1.3 \mathrm{~m})$, there was tidal flow over the jetties when water elevation was above mean tide level. The jetties were 3,500 ft $(1,065 \mathrm{~m})$ apart at the landward end, and were spaced much closer together at $1,000 \mathrm{ft}(305 \mathrm{~m})$ at the seaward end. The arrowhead configuration was selected to provide flow convergence, thus promoting scour to maintain the desired channel depth in the inlet throat and seaward

In 1939, an 8-ft- (2.4-m-) deep, 200-ft- (61-m-) wide channel was dredged through the flood shoal (Main Channel, Figure 2) to provide a navigable waterway from Barnegat Bay to the Atlantic Ocean. However, the channel soon began its long history of meandering. The arrowhead jetty configuration did not confine the ebb and flood tidal flows, resulting in several channels developing between the jetties. There was not a single stable navigation channel through the inlet, and the depths of the channels were inadequate. In 1943, a sand dike (Figure 2) was built to eliminate one of the two major channels in an attempt to train the tidal flow to follow a straighter path through the remaining channel. Numerous dredging projects were performed throughout the history of the project in an attempt to straighten or stabilize the channel, but all were unsuccessful. A straight channel, parallel to the north jetty, was dredged in 1956. By 1968, erosion of the north beach and deposition inside the channel as a result of sediment movement over and through the deteriorating mean tide level north jetty resulted in southward channel migration until the channel became inaccessible at low water (Caccese and Spies 1977). The channel was dredged on an annual or semiannual basis between 1972 and 1981 (Fields 1984).

Several modifications were also made to the jetties since their initial construction (Smith 1988). In 1944, the shoreward $100 \mathrm{ft}(30.5 \mathrm{~m})$ of the south jetty was lowered to promote sand deposition on the critically eroding beach south of the inlet but inside the south jetty (Sager and Hollyfield 1974). In 1950 and 1954, repairs were made to the seaward end of the north jetty and shoreward portion of the south jetty, respectively (Smith 1988). The center line of the repaired north jetty was offset $12 \mathrm{ft}(3.7 \mathrm{~m})$ toward the inlet from the existing section. In 1972-74, the shoreward 3,700 ft $(1,130 \mathrm{~m})$ of the north jetty was raised to $+8 \mathrm{ft}(+2.4 \mathrm{~m}) \mathrm{mlw}$ and made impermeable to prevent sand from entering from the north and possibly closing the inlet. 
In response to the channel stability problem, hydraulic model studies were conducted at the U.S. Army Engineer Waterways Experiment Station during the period 1968 through 1974 to develop a recommended plan of improvement with respect to maintaining an effective navigation channel (Sager and Hollyfield 1974). The model study concluded that the construction of a new south jetty essentially parallel to the existing north jetty and a 300-ft- (91-m-) wide, 10-ft(3-m-) deep channel would provide inlet and channel stability. The jetty would extend from an existing groin at the base of the Barnegat Lighthouse to the tip of the existing south jetty.

Sager and Hollyfield (1974) recommended that the construction sequence for improvements at Barnegat Inlet be as follows:

a. Remove existing south jetty, working landward from the ocean end and leaving a short section of the jetty for beach stabilization.

$b$. Concurrent with $a$, construct the new south jetty. Use stone from old jetty in new jetty if it is economical.

c. Prior to closure of the south channel by construction of the jetty, begin dredging a navigation channel $300 \mathrm{ft}(91 \mathrm{~m})$ wide and $8 \mathrm{ft}(2.4 \mathrm{~m})$ deep at $\mathrm{mlw}$ on a line from deep water in the throat to a point midway between the ocean end of the existing jetties.

d. Raise north jetty to $+8 \mathrm{ft}(+2.4 \mathrm{~m})$ from the beach to a point $1,200 \mathrm{ft}$ $(365 \mathrm{~m})$ from the ocean end of the jetty.

e. Dredge a 300-ft- (91-m-) wide interior channel to a depth of $10 \mathrm{ft}(3 \mathrm{~m})$ on a line favoring deep water at the throat of the inlet bayward to deep water at the north end of the existing sand dike.

$f$. Consider, in sequence, the groin field and sand dike, should the interior channel subsequently prove to require excessive maintenance.

Economic analyses determined that it was not practical to remove the old south jetty. The new 4,270-ft- (1,300-m-) long, impermeable south jetty (Figure 3) was constructed to an elevation of $+8 \mathrm{ft}(+2.4 \mathrm{~m})$ ) mlw between December 1987 and June 1991, and was built nearly parallel to the north jetty (U.S. Army Engineer District, Philadelphia, 1984). The region between the old south jetty and the new south jetty was filled with sediment excavated for the new south jetty foundation. Initial dredging of the navigation channel was completed in early 1992. Figure 4 shows the basic bathymetric configuration in 1993, including the intra-jetty shoal with the navigation channel located on the north side and the large flood shoal to the northwest of the jetties. The performance of this project was monitored and evaluated by the MCNP program.

\section{Objectives of MCNP Monitoring at Barnegat Inlet}

The effectiveness of the new south jetty at Barnegat Inlet, NJ, on the inlet system needed to be evaluated to provide improved inlet and jetty system design guidance, to enhance construction of rubble-mound jetties, and to develop better maintenance techniques for tidal inlets. The project performance was assessed with regard to providing a stable navigation channel and a stable rubble-mound jetty structure, and was then compared with project design, physical model predictions, and other design criteria. 


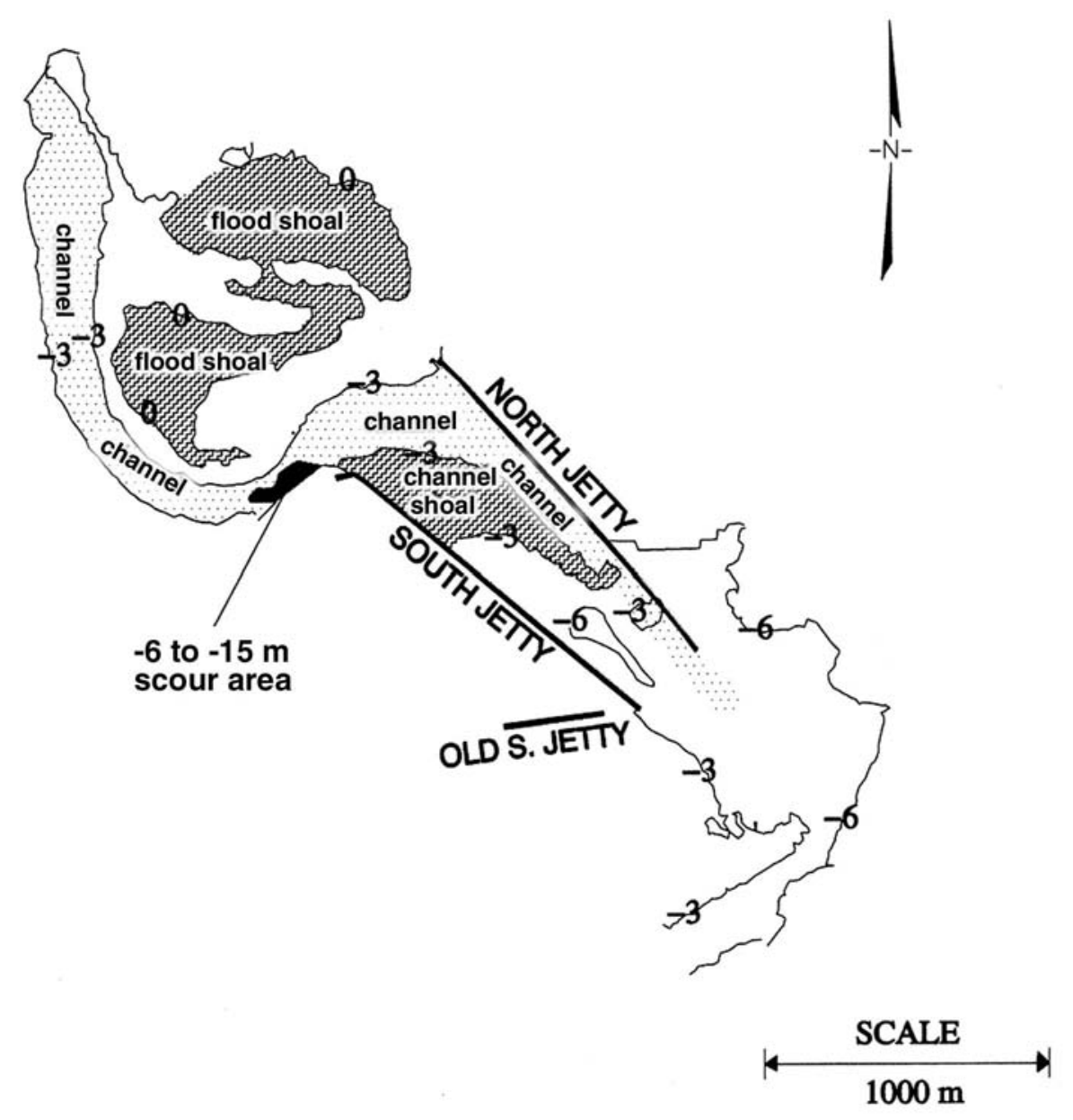

Figure 4. Barnegat Inlet, NJ, bathymetry, November-December 1993 (the project configuration monitored by the MCNP program)

\section{Study Approach and Monitoring Plan}

This MCNP study gathered and analyzed data to develop an improved understanding of the physical processes at Barnegat Inlet to evaluate the performance of the project. The monitoring plan evaluated four fundamental hypotheses of the project design objectives (U.S. Army Engineer District, Philadelphia, 1984).

Hypothesis 1: The new south jetty and new channel alignment will not adversely affect tidal hydraulic response or high tide level in the inlet bay system (i.e., no flooding problem).

Tide, current, and hydrographic survey data were used to evaluate this hypothesis. Tidal prisms were calculated using current and bathymetric data to compare to previous tidal prism studies (PRC Harris 1980; Ashley 1987). Tide range differences caused by the project were determined. Comparison of model and prototype velocities indicated the predictive capability of the physical model. 
Hypothesis 2: The new south jetty realignment will improve navigation safety by stabilizing the navigation channel location and depth between the jetties and over the outer bar (ebb tidal shoal), and will eliminate dredging in these regions. The new south jetty will help maintain interior channel location (bayward of Barnegat Lighthouse on the edge of the flood tidal shoal), with a channel shoaling rate of $60,000 \mathrm{cu}$ yd $(46,000 \mathrm{cu} \mathrm{m})$ per year. Sediment placement in the area between the old and new south jetties during construction of the new south jetty does not affect channel shoaling.

Wave and current data, hydrographic and profile survey data, video photography, and surveys of vessel captains and Coast Guard were used as input to test this hypothesis. The positions of the channel and ebb shoal were defined by quarterly hydrographic surveys. Wave (offshore and nearshore) and current data were analyzed to determine the frequency of occurrence of conditions detrimental to navigation. Video of vessels navigating through the inlet was taken to examine typical vessel pathways and to evaluate potential navigation difficulties. Pre- and post-project hydrographic and profile surveys were compared using the Contour Plotting System and the Interactive Survey Reduction Program (ISRP) to examine changes in the inlet channel and the area between the old and new south jetties. Dredging records were examined. Annual current data were analyzed using Acoustic Doppler Current Profiler (ADCP) software and compared to previous studies (PRC Harris 1980; Ashley 1987), and from year to year. These data were used to examine the forces driving channel processes (e.g., development of scour holes) and to investigate relative channel stability.

Hypothesis 3: The new south jetty will be structurally stable.

Structural Condition Index (SCI) inspections, side-scan sonar surveys, wave gauge data, and center-line surveys were conducted and used to test this hypothesis. SCI inspections provided an annual rating of the condition of the jetty. Side-scan sonar records were analyzed to examine the toe of the south jetty, and to identify areas of possible jetty instability. Offshore and nearshore wave gauge data provided wave heights in the vicinity of the south jetty to evaluate the design wave conditions. Comparison of semiannual center-line surveys were used to indicate any settlement of the structure.

Hypothesis 4: The jetty system realignment will not adversely affect upcoast or downcoast beaches.

Profile surveys and aerial photographs were assimilated to evaluate this hypothesis. Profile data were entered into the Corps ISRP and analyzed using various profile analysis programs. Pre- and post-project surveys and erosion/ accretion rates were compared to examine shoreline trends since jetty construction. Aerial photography was visually examined to complement the profile data. 


\section{Effects of New South Jetty on Hydraulics}

As part of the MCNP studies, field data were collected during the period 1993 through 1997 to evaluate the project design hypotheses and performance of the new south jetty and navigation channel at Barnegat Inlet, New Jersey. To understand the effects of the new Barnegat Inlet south jetty on the hydraulics of the entire system, and to evaluate project design Hypothesis 1, the data collected included tide and wave measurements, currents in the inlet throat and near the flood shoal, time-lapse video photography of the channel and flood shoal, aerial photography, bathymetric surveys, beach and offshore profiles, and structural inspections of the new south jetty. Additionally, a Scanning Hydrographic Operational Airborne Lidar Survey (SHOALS) system survey of the entire Barnegat Inlet system was conducted in July 1994 by the U.S. Army Engineer District, Philadelphia, to supplement the MCNP bathymetric survey data and project monitoring. Jetty construction and channel dredging change the flow characteristics at tidal inlets; however, there have been no studies that have documented the hydraulic and hydrodynamic changes following inlet modifications.

Project design Hypothesis 1 states that the new south jetty and new channel alignment will not adversely affect tidal hydraulic response or high tide level in the inlet bay system. Prototype hydraulic response will be as predicted by the physical model evaluation (Sager and Hollyfield 1974).

Nearly continuous tidal records at five locations in Barnegat Bay were analyzed by Seabergh et al. (in preparation) to determine changes in tidal constituents and bay tide range since completion of the project. The effects of wind on Barnegat Bay tide elevations were also examined. Short-term (13- and 25 -hr duration) measurements of tidal current in the inlet throat and near the flood shoal were used to determine flow patterns. A longer-term (34-day) tidal current data collection effort at a single point in the inlet throat was conducted and correlated with short-term measurements to understand variations in discharge and tidal prism over a lunar month. A historical examination of tidal prism was compared to the tidal prism computed from this data collection effort. In addition, the effects of lunar variation on ebb and flood tide flow duration, phase lags, and flow dominance were examined. 


\section{Inlet Hydraulic Characteristics}

\section{Tidal elevations}

An intuitive explanation of Barnegat Inlet hydraulics, including tidal elevations and tidal currents, was first presented by Lucke (1934) when the inlet was in its natural state. Lucke visualized the inlet as a narrow slit that is deep relative to the bay depth. In this configuration, when the ocean high tide is reached, the large bay is still not filled; and when the ocean tide is low, the bay cannot drain to the level of the ocean. Also, if the slit is considered to be wider at the top, water in the bay at higher tide elevations will be closer to ocean elevations than at low tide elevations due to freer passage for flow at higher tide stages. From this explanation one would expect a bay that does not fill completely and has a mean elevation higher than the average ocean level. Observations of water levels in 1931-32 indicated an average estimated ocean tide range of $4 \mathrm{ft}(1.2 \mathrm{~m})$. Actual (measured) average tide ranges at the inlet throat were $2.7 \mathrm{ft}(0.8 \mathrm{~m})$ on the ocean side, and $2.0 \mathrm{ft}(0.6 \mathrm{~m})$ just inside the inlet. The tide range was 0.48 to $0.42 \mathrm{ft}(0.15$ to 0.13$)$ at a distance of 2 to 7 miles ( 3.2 to $11.3 \mathrm{~km})$, respectively, into the bay. The average mean tide level inside the inlet throat was 0.42 to $0.49 \mathrm{ft}(0.13$ to $0.15 \mathrm{~m})$ above the ocean mean tide level.

\section{Tidal currents, ebb/flood dominance, and flow duration}

The early preproject data described previously provide an insight into the basic inlet hydraulics of Barnegat Inlet. The very low ratio of bay-to-ocean tide range (approximately 0.1) indicates that the bay is maintained at nearly a constant elevation, and that the ocean water level oscillates above and below that level with tidal periodicity. There is a time lag of about 2 to $4 \mathrm{hr}$ between high water (or low water) in the ocean and slack water in the channel, ending flood (or ebb) flow. This type of long phase lag produces interesting flow conditions in the inlet channel where maximum flood current occurs near high water elevation and maximum ebb current occurs near low water. Lucke (1934) observed this phenomenon, as did more recent authors (Fields 1984; Ashley 1987). If, for a typical 12.42-hr tidal cycle, the time for ebb and flood flow were equally split, ebb currents would be expected to be faster due to flow through a smaller cross section at low water elevations. Typically ebb duration is a little longer than half a tidal cycle due to increased frictional effects for ebb flow, so the predominance of ebb current magnitude is less pronounced but still greater than flood current magnitude.

Early current measurements appear to support ebb flow predominance; i.e., ebb current maximums were greater than flood current maximums (Lucke 1934). However, the early current measurements were obtained at point locations, so they may not represent the inlet flow predominance precisely. They were, however, obtained at the deepest regions of the inlet entrance, and therefore probably represent a composite of the inlet as a whole. Lucke (1934) made measurements near Barnegat City (in the vicinity of this MCNP study Transect A (Figure 5)), and near the junction of Oyster and Mud Creek channels for a 10-hr period on July 19, 1932. He found ebb velocities exceeded flood velocities at both locations, with the current magnitude significantly greater closer to the inlet, 


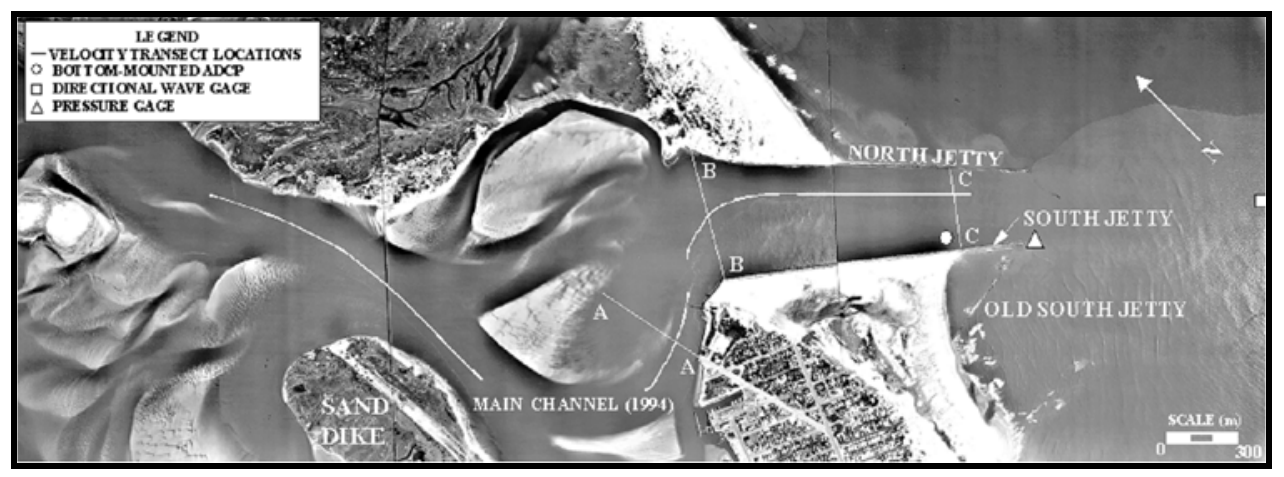

Figure 5. Barnegat Inlet, NJ, 1994, showing MCNP instrument locations, transect locations, and the new south jetty location with respect to the old south jetty, photo June 1994

as expected. A maximum ebb velocity of $5.1 \mathrm{ft}$ per $\mathrm{sec}(156 \mathrm{~cm}$ per $\mathrm{sec})$ and maximum flood velocity of $3.6 \mathrm{ft}$ per sec $(111 \mathrm{~cm}$ per sec) were reported. Lucke observed the large phase lag between high tide in the ocean and slack water in the channel, and stated that maximum ebb velocities nearly coincided with mean low water.

The locations of Lucke's measurements were in long-term ebb-dominant channels and may not necessarily indicate that the inlet as a whole is ebb dominant. After the inlet had been stabilized with jetties in 1939-1940 and the interior sand dike had been constructed in 1943, others (PRC Harris 1980; Fields and Ashley 1987; Ashley 1987) also found that flood velocities exceeded ebb velocities near the minimum inlet cross section at Barnegat Inlet, indicating flood dominance. This was likely due to increased frictional effects, since the inlet channel connecting the ocean and the bay was effectively lengthened by a factor of three from the preproject condition. A long friction-dominated channel connecting a large open bay to the ocean would be expected to be flood dominant (Aubrey and Speer 1985).

PRC Harris (1980) conducted a tidal prism study for the Corps of Engineers, measuring tidal velocities at five stations along an inlet transect near this MCNP study Transect B (Figure 5). Hourly readings were obtained at the five stations for a 13-hr period on March 20, 1980. In general, flood velocities exceeded ebb velocities except at station 2, approximately $590 \mathrm{ft}(180 \mathrm{~m})$ from the southern side of the inlet. Peak flood velocities were about $2.6 \mathrm{ft}$ per sec $(80 \mathrm{~cm}$ per sec), and peak ebb velocities were about $2.2 \mathrm{ft}$ per sec $(67 \mathrm{~cm}$ per sec). The duration of the ebb tide was slightly longer than flood tide.

Fields and Ashley (1987) collected velocity data at Barnegat Inlet during 19821983 at one location in the inlet throat and at four locations in the shallow area south of the channel. The velocity data in the channel indicated flood dominance of flow (peak flood velocities of $3.3 \mathrm{ft}$ per sec $(100 \mathrm{~cm}$ per sec) versus peak ebb velocities of $2.2 \mathrm{ft}$ per $\mathrm{sec}(67 \mathrm{~cm}$ per sec) $)$. Fields and Ashley found that maximum ebb velocity occurs $1.33 \mathrm{hr}$ before low tide, and maximum flood velocity occurs $0.58 \mathrm{hr}$ before high tide. The duration of ebb flow was about $1 \mathrm{hr}$ longer than flood flow duration.

Ashley (1987) collected tidal elevation and tidal current data at Barnegat Inlet on September 23, 1987, for $13 \mathrm{hr}$ to determine the spring tidal prism. Data were 
collected at three locations near Transect B (Figure 5). Current profiles were measured every $30 \mathrm{~min}$ with a Marsh-McBirney electromagnetic current meter. Peak flood velocities of $3.6 \mathrm{ft}$ per sec $(111 \mathrm{~cm}$ per sec) exceeded peak ebb velocities of $3.3 \mathrm{ft}$ per sec $(100 \mathrm{~cm}$ per sec). The interval between high or low tide elevation and slack water in the channel was $2.5 \mathrm{hr}$.

\section{Tidal prism}

The tidal prism for Barnegat Inlet has varied considerably throughout its recorded history (Table 2). Fields and Ashley (1987) indicate that the entrance channel area was as large as $37,800 \mathrm{sq} f t(3,510 \mathrm{sq} \mathrm{m})$ in the $1800 \mathrm{~s}$ when the inlet was migrating along the coastline. Using O'Brien's (1969) equation (Shore Protection Manual 1984) that relates tidal prism to entrance channel area, a tidal prism of nearly 1,700 Mcf (48 Mcm) was estimated by Fields and Ashley (1987). This is a reasonable value for that time period when the ultimate storage capacity of the bay was larger. Since then, bay infilling on the mainland side due to human intervention and community development has reduced the bay volume (Fields and Ashley 1987).

In 1932, Lucke (1934) measured velocities near the inlet throat with an inlet cross-sectional area of 14,397 sq ft (1,340 sq m). Based on these data, an average mean tidal prism of $800 \mathrm{Mcf}(23 \mathrm{Mcm})$ was computed after adjusting for tide conditions (U.S. Army Engineer District, Philadelphia, 1981). After the arrowhead jetties were constructed and the channel dredged in 1939-1940, there was a noticeable increase in the mean tidal prism to 1,200 $\operatorname{Mcf}(35 \mathrm{Mcm})$, probably due to the increased cross-sectional area (U.S. Army Engineer District, Philadelphia, 1981).

Soon the channel began to shoal. In 1943 a sand dike was built (Figure 2) to straighten the interior channel and train the interior flow. However, it effectively lengthened the channel and increased flow resistance through friction, thereby causing more shoaling. The mean tidal prism was reduced to $750 \mathrm{Mcf}(21 \mathrm{Mcm})$ by 1943, and then further reduced to $490 \mathrm{Mcf}(14 \mathrm{Mcm})$ by 1968 (U.S. Army Engineer District, Philadelphia, 1981) as the minimum cross-sectional area decreased due to shoaling. In an attempt to reduce channel shoaling, the north jetty was raised and sand-tightened in 1972, and channel dredging on an annual or semiannual basis began at that time. By 1980, the mean tidal prism was $410 \mathrm{Mcf}$ (12 Mcm) (PRC Harris 1980).

Ashley (1987) conducted the last known tidal prism study prior to this MCNP investigation. Ashley determined the spring tidal prism at Barnegat Inlet for both ebb and flood tidal flow. The spring flood tidal prism was $440 \mathrm{Mcf}(12.4 \mathrm{Mcm})$, and the spring ebb tidal prism was $380 \mathrm{Mcf}(11 \mathrm{Mcm})$. The minimum crosssectional area was $10,460 \mathrm{sq} \mathrm{ft}(972 \mathrm{sq} \mathrm{m})$ for these conditions.

\section{MCNP Hydraulic Measurements}

The hydraulic data collected for the MCNP project included tidal elevations, currents, waves, wind, and bathymetry. Tidal elevation, current, wind, and hydrographic survey data were used to characterize the hydraulics of Barnegat Inlet and evaluate the hydraulic response of the inlet system to the project. Current data and tidal prisms were compared with those of previous studies 
(Lucke 1934; PRC Harris 1980; Fields and Ashley 1987; and Ashley 1987); and year-to-year comparisons were made with these MCNP study data.

\begin{tabular}{|c|c|c|c|c|c|c|c|c|c|c|c|c|}
\hline \multicolumn{13}{|c|}{$\begin{array}{l}\text { Table } 2 \\
\text { Barnegat Inlet, NJ, Historical Engineering Activities, Channel Velocities, and Tidal } \\
\text { Prisms }\end{array}$} \\
\hline $\begin{array}{l}\text { Measure- } \\
\text { ment } \\
\text { Year }\end{array}$ & $\begin{array}{l}\text { Measured } \\
\text { Channel } \\
\text { Area, } \mathrm{m}^{2} \\
\end{array}$ & $\begin{array}{l}\text { Equili- } \\
\text { brium } \\
\text { Area, } \\
\mathrm{m}^{2}\end{array}$ & \multicolumn{3}{|c|}{$\begin{array}{l}\text { Peak } \\
\text { Ebb Velocity } \\
\text { cm/sec }\end{array}$} & \multicolumn{3}{|c|}{$\begin{array}{l}\text { Peak Flood } \\
\text { Velocity, cm/sec }\end{array}$} & $\begin{array}{l}\text { Tidal } \\
\text { Prism } \\
10^{6} \mathrm{~m}^{3}\end{array}$ & $\begin{array}{l}\text { Ebb } \\
\text { Tidal } \\
\text { Prism } \\
10^{6} \mathrm{~m}^{3} \\
\end{array}$ & $\begin{array}{l}\text { Flood } \\
\text { Tidal } \\
\text { Prism } \\
10^{6} \mathrm{~m}^{3}\end{array}$ & \multirow{2}{*}{$\begin{array}{l}\text { Source } \\
\text { Lucke } 1934\end{array}$} \\
\hline 1839 & 3512 & & & & & & & & & & & \\
\hline 1866 & 3326 & & & & & & & & & & & \\
\hline 1874 & 2230 & & & & & & & & & & & \\
\hline 1932 & 1338 & 1627 & 156 & & & 111 & & & $\begin{array}{l}22.9 \\
\text { (mean) }\end{array}$ & & & \\
\hline 1936 & & & & & & & & & $\begin{array}{l}17.7 \\
\text { (spring) }\end{array}$ & & & \\
\hline $1939 / 40$ & \multicolumn{12}{|c|}{ Jetties constructed and bayside main channel dredged (note dramatic increase in prism) } \\
\hline $12 / 1940$ & 1487 & 2167 & & & & & & & $\begin{array}{l}32.1 \\
\text { (mean) }\end{array}$ & & & \multirow[t]{3}{*}{ Dredging } \\
\hline $4 / 1941$ & 1519 & 2305 & & & & & & & $\begin{array}{l}34.5 \\
\text { (mean }\end{array}$ & & & \\
\hline 11/1941 & 1507 & 2224 & & & & & & & $\begin{array}{l}33.1 \\
\text { (mean }\end{array}$ & & & \\
\hline 1943 & \multicolumn{12}{|c|}{ Sand dike built to train the flow (channel is longer with more friction and more sedimentation) } \\
\hline 9/1943 & 1010 & 1524 & & & & & & & $\begin{array}{l}21.2 \\
\text { (mean) }\end{array}$ & & & \\
\hline 6/1945 & 1243 & 1455 & 94 & & & 100 & & & $\begin{array}{l}20.1 \\
\text { (mean) }\end{array}$ & & & \\
\hline 1955 & & & 98 & & & 107 & & & & & & \\
\hline May 1968 & 709 & 1061 & & & & & & & $\begin{array}{l}13.9 \\
\text { (mean) }\end{array}$ & & & \\
\hline 1972 & \multicolumn{12}{|c|}{ Raised inner portion of north jetty to reduce sedimentation in channel; began annual dredging } \\
\hline 1980 & 1115 & 922 & \multicolumn{3}{|l|}{67} & \multicolumn{3}{|l|}{81} & $\begin{array}{l}11.7 \\
\text { (mean) }\end{array}$ & $\begin{array}{l}11.6 \\
\text { (mean) }\end{array}$ & $\begin{array}{l}11.0 \\
\text { (mean) }\end{array}$ & $\begin{array}{l}\text { PRC Harris } \\
1980\end{array}$ \\
\hline $1982-1983$ & & & \multicolumn{3}{|l|}{67} & \multicolumn{3}{|l|}{100} & & & & $\begin{array}{l}\text { Fields/ } \\
\text { Ashley } \\
1987\end{array}$ \\
\hline 1987 & 972 & 916 & \multicolumn{3}{|l|}{100} & \multicolumn{3}{|l|}{111} & & $\begin{array}{l}10.9 \\
\text { (spring) }\end{array}$ & $\begin{array}{l}12.4 \\
\text { (spring) }\end{array}$ & $\begin{array}{l}\text { Ashley } \\
1987\end{array}$ \\
\hline 1991 & \multicolumn{12}{|c|}{ New south jetty constructed and "straight " channel dredged } \\
\hline & & & \multicolumn{6}{|c|}{ Transect } & & & & \\
\hline & & & A & B & $\mathbf{C}$ & $\mathbf{A}$ & B & C & & & & \\
\hline 1993 & & & 119 & 88 & 102 & 76 & 80 & 127 & & $\begin{array}{l}21.4 \\
\text { (spring) }\end{array}$ & $\begin{array}{l}29.6 \\
\text { (spring) }\end{array}$ & \multirow[t]{3}{*}{ MCNP } \\
\hline 1994 & 1386 & & 131 & 95 & 104 & 76 & 82 & 122 & & $\begin{array}{l}19.3 \text { and } \\
20.9 \\
\text { (spring) }\end{array}$ & $\begin{array}{l}32.4 \text { and } \\
12.6 \\
\text { (spring) } \\
\end{array}$ & \\
\hline 1995 & & & 108 & 73 & 92 & 70 & 75 & 81 & & $\begin{array}{l}13.5 \\
\text { (mean) }\end{array}$ & $\begin{array}{l}21.9 \\
\text { (mean) }\end{array}$ & \\
\hline
\end{tabular}




\section{Tidal elevations}

Tidal data were collected throughout the bay at Mantoloking, Bayshore, Waretown, and Loveladies by the Water Resources Division of the U.S. Geological Survey (USGS), and just inside Barnegat Inlet near the U.S. Coast Guard (USCG) Station (Figure 1). A USCG gauge was installed by the National Oceanic and Atmospheric Administration (NOAA), National Ocean Survey (NOS), before the start of the project so tidal constituent data (harmonic constants) were available for pre- and post-project conditions. The location of the gauge just inside the inlet permits an examination of the effect of the newly constructed south jetty on the tide as it enters the bay. Average water levels at the other bay gauges were obtained from USGS for pre- and post-project conditions. Figure 6 shows the variation in tide range from the ocean to the bay for a 2-day period in 1994. The attenuation of the tide from the ocean through the inlet and into the bay is easily discernable from this data display.

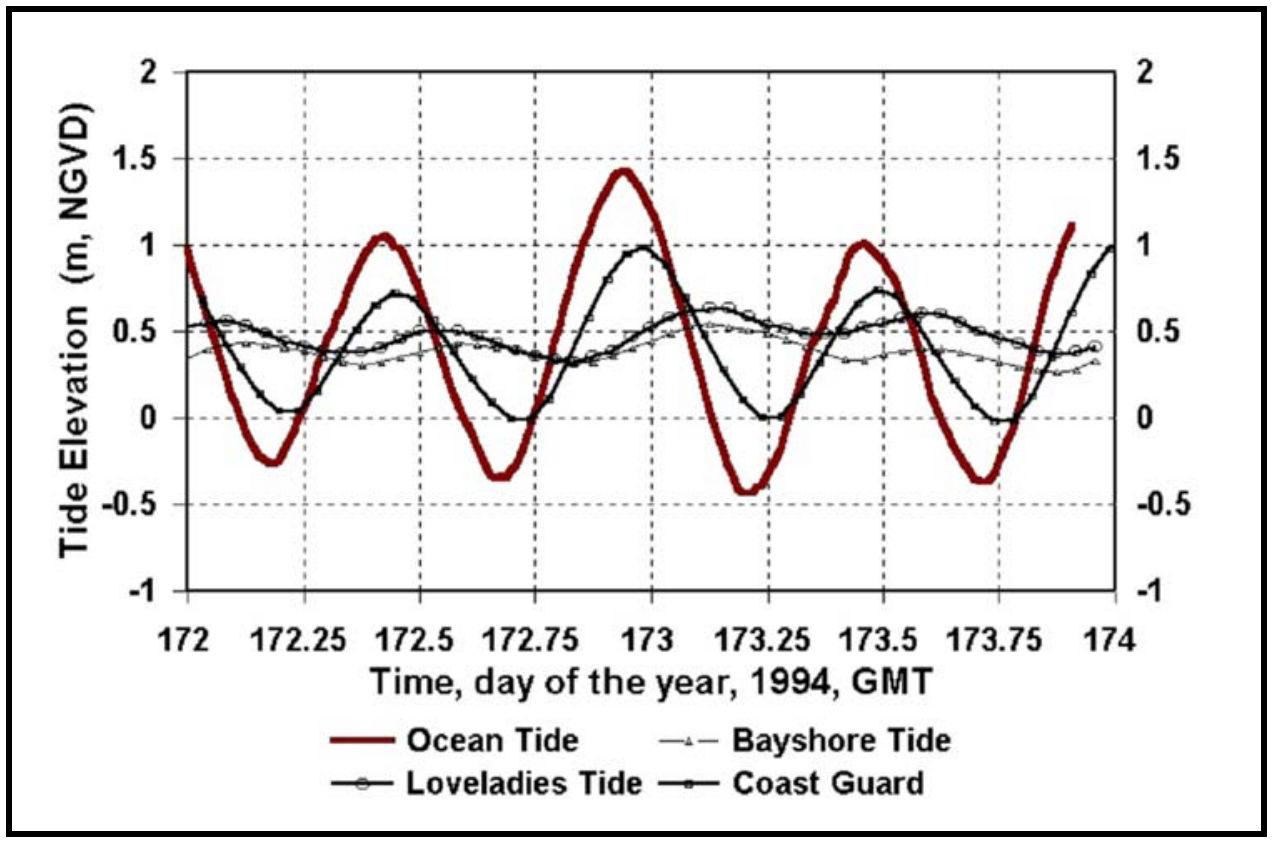

Figure 6. Measured ocean tide 1 mile $(1.6 \mathrm{~km})$ seaward of jetties, Coast Guard Station tide just inside inlet, and bay tides at Bayshore and Loveladies, illustrating attenuation of tide range and increase of phase lag when progressing from ocean to bay

\section{Tidal currents}

Both short- and long-term tidal current measurements were made using broadband ADCPs. These instruments operate on the principle of Doppler shift to measure water velocity distribution. The ADCP transmits sound bursts through the water that are scattered by particles in the water column. The motion of particles in the water relative to the ADCP causes the return signal, or echo, to change in frequency. The ADCP measures this change, referred to as the Doppler shift, to obtain the water velocity. The Doppler shift in the return signals from different depths gives the vertical distribution of velocity. 
Short-term tide gauges installed during data collection were positioned close to ADCP locations for quick data retrieval and analysis.

Short-term ADCP data. Short-term measurements of tidal currents in the inlet were collected using a broad-band ADCP. The instrument was operated near the water surface, facing downward to measure the vertical velocity distribution. The ADCP was mounted to a boat that repeatedly traversed the inlet, measuring the vertical velocity distribution at approximately 4-sec intervals. Each of these vertical slices is called an ensemble. Within each ensemble, each depth cell where the average velocity is computed is called a bin. For this MCNP study, each bin measured $1.6 \mathrm{ft}(0.5 \mathrm{~m})$ in height. With the boat traveling across the inlet in a short (3-5 $\mathrm{min})$ time period, the entire velocity cross section was computed. However, the topmost bin in each ensemble was located 1.6 to $2.0 \mathrm{ft}(0.5$ to $0.6 \mathrm{~m})$ below the head of the ADCP instrument (about $3.9 \mathrm{ft}$ $(1.2 \mathrm{~m})$ below the water surface), and the lowest bin was located at a distance above the bottom approximately equal to 15 percent of the water depth. Therefore, no velocity measurements were made in the surface and bottom layers of each cross section. The surface current was assumed to be equal to the velocity in the topmost bin, and an exponential decay function was applied in the bottom boundary layer.

ADCP data collection was repeated at three locations for a $13-\mathrm{hr}$ period on June 2, 1993, a 25-hr period in 1994 (June 21 and 22), and two 13-hr periods in 1995 (June 6 and 7), providing hourly cross-sectional velocity distributions at three locations through five tidal cycles. Typically a cross section is described by 900 velocity data values. Mean tide conditions were chosen for ADCP data collection in 1995 to contrast with spring tide conditions for data collection in previous surveys (1993 and 1994). Variations in cross-channel distribution from the higher flow conditions of a spring tide to the lower flow conditions of a mean tide could thus be determined.

The three transect locations, or ranges, traversed the 1994 main channel (Figure 5). In this figure it is apparent that the flood shoal formation has caused the main channel to swing south. Transect A was located south of the flood shoal, Transect B was located at the bayward end of the parallel jetties (near the base of Barnegat Lighthouse), and Transect $\mathrm{C}$ was located in the inlet throat. For each of the ranges, the velocity cross-sectional distribution, velocity contour plots, velocity tracks, and discharges were generated for each hour of data collection. Integration of discharge for a tidal cycle was used to compute the tidal prism.

Long-term ADCP data. A bottom-mounted ADCP was placed in the inlet between the jetties in an upward-looking position from May 18, 1994, through June 23, 1994. The instrument was located $200 \mathrm{ft}(61 \mathrm{~m})$ from the south jetty along Transect $\mathrm{C}$ (Figure 5). Velocity magnitude and direction for each bin were recorded every $10 \mathrm{~min}$. Data were collected every $1.6 \mathrm{ft}(0.5 \mathrm{~m})$ beginning $4.9 \mathrm{ft}$ $(1.5 \mathrm{~m})$ off the bottom and extending to $1.6 \mathrm{ft}(0.5 \mathrm{~m})$ below the water surface. The data collection period covered a full lunar tide cycle, including two spring tide conditions. The last spring tide cycle that was measured corresponded with the ADCP transect data collection effort. A correlation between the long-term and short-term instruments was determined, and long-term estimates of discharge and tidal prism were derived and are subsequently discussed. 


\section{Wave and wind conditions}

A directional wave gauge (DWG) was placed 1 mile $(1,600 \mathrm{~m})$ seaward of Barnegat Inlet in water depth of approximately $40 \mathrm{ft}(12 \mathrm{~m})$ to measure wave height, period, and direction, as well as water surface elevation for 2 years (Figure 5). The DWG was deployed in May 1994, with maintenance and data retrieval occurring every 6 months. Also in May 1994, a nondirectional pressure wave gauge was placed $61 \mathrm{~m}(200 \mathrm{ft})$ southeast of the south jetty in approximately $5 \mathrm{~m}(16 \mathrm{ft})$ of water to measure wave height and water surface elevation adjacent to the structure for approximately 1 year (Figure 5). Wave data from this instrument were used in the new south jetty structural stability analysis and to evaluate the structural design parameters. The average significant wave height was $2.4 \mathrm{ft}(0.75 \mathrm{~m})$, and the average peak period was $8.9 \mathrm{sec}$. Typically, when ocean waves were less than $3.3 \mathrm{ft}(1.0 \mathrm{~m})$, the two gauges indicated similar heights. As the incident wave increased in height, the wave height measured at the jetty gauge was attenuated relative to the ocean gauge, and appeared to be somewhat dependent on tide stage and incident wave approach. Reductions in wave height at high water were in the 10 to 30 percent range, while at low water, wave height reduction was as high as 40 to 50 percent.

Wind data were collected at the Oyster Creek Power Station, GPU Nuclear Corporation (Figure 1), at a nearly continuous hourly rate during the MCNP data collection period. Prevailing winds approach from the south, west, and northwest, and dominant winds approach from the northeast (Fields 1984).

\section{Tidal Elevation Data Analysis}

\section{Change in tidal constituents due to the project}

The distortion of the tide as it propagates through an inlet is due to friction, nonlinear advection, interaction with channel geometry, and bay surface area variation with tide elevation (Aubrey and Speer 1985). These effects create tidal harmonics such as M4 and M6 (shallow water overtides) of the dominant M2 (principal lunar semidiurnal) component. Figure 7 shows that at the USCG station, the major tidal constituent, M2, increased 30 percent after project completion. N2 (larger lunar elliptic semidiurnal), K1 (lunisolar diurnal), and S2 (principal solar semidiurnal) constituents had similar percentage increases after project completion, indicating greater admittance of tide, probably due to the straighter, deeper channel alignment and larger cross section dredged through the shoal near Barnegat Lighthouse (1987 area of 970 sq $\mathrm{m}$ versus 1994 area of $1,390 \mathrm{sq} \mathrm{m})$. The M4 constituent, though small in magnitude, is an indicator of frictional effects in the system. It decreased 49 percent, also indicating an increase in efficiency of the inlet system after project completion. The M6 constituent, also small in magnitude, showed little change. The various postproject project tide ranges (twice the tidal amplitude, and including mean, spring, neap, perigean, and apogean ranges) at the USCG station showed a consistent 30 percent increase (Table 3 ).

Constituent information was not available at bay interior gauges, but average tide ranges are shown in Table 4 . The percent increase in bay tide range generally increased from south (Loveladies) to north (Bayshore) along the length 


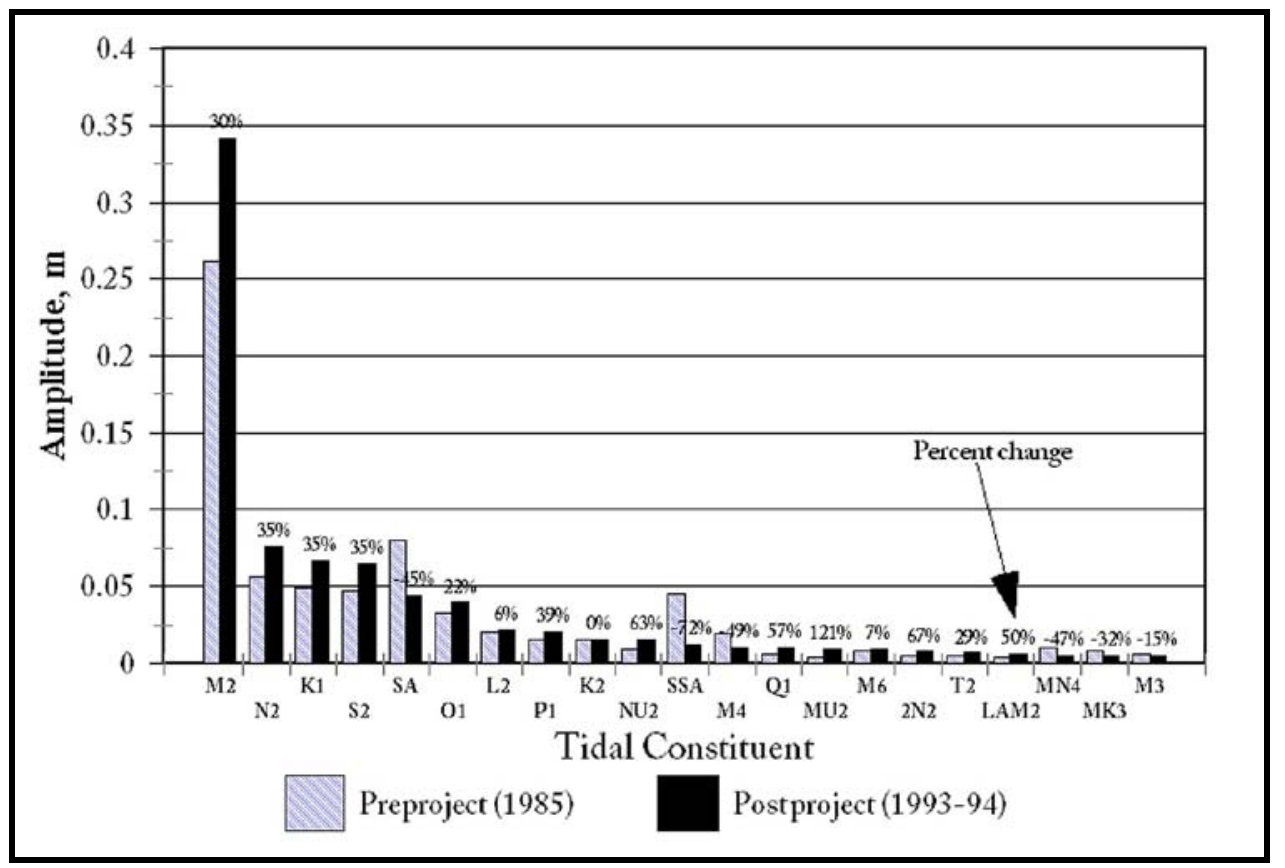

Figure 7. Tidal constituents elevation amplitude at the USCG station tide gauge for the 1985 preproject condition, and the 1993-94 postproject condition

\begin{tabular}{|l|l|l|l||}
\hline \hline $\begin{array}{l}\text { Table 3 } \\
\text { Coast Guard Station Gauge Tide Ranges }\end{array}$ & Percent Change \\
\hline \hline $\begin{array}{l}\text { Type of Tide } \\
\text { Range Change }\end{array}$ & $\begin{array}{l}1985 \text { (Pre-New } \\
\text { South Jetty }\end{array}$ & $\begin{array}{l}1993-94 \\
\text { (Postproject) }\end{array}$ & +30 \\
\hline \hline $\begin{array}{l}\text { Mean range } \\
(2.2 \mathrm{M} 2)\end{array}$ & $0.58 \mathrm{~m}$ & $0.75 \mathrm{~m}$ & +31 \\
\hline $\begin{array}{l}\text { Spring range } \\
2.1 \times(\mathrm{M} 2+\mathrm{S} 2)\end{array}$ & $0.65 \mathrm{~m}$ & $0.85 \mathrm{~m}$ & +29 \\
\hline $\begin{array}{l}\text { Neap range } \\
2.1 \times(\mathrm{M} 2+\mathrm{S} 2)\end{array}$ & $0.58 \mathrm{~m}$ & $0.75 \mathrm{~m}$ & +31 \\
\hline $\begin{array}{l}\text { Perigean range } \\
2.2 \times(\mathrm{M} 2+\mathrm{S} 2)\end{array}$ & $0.70 \mathrm{~m}$ & $0.92 \mathrm{~m}$ & +29 \\
\hline $\begin{array}{l}\text { Apogean range } \\
(2.2 \times \mathrm{M} 2)-(1.7 \times \\
\text { N2) }\end{array}$ & $0.48 \mathrm{~m}$ & $0.62 \mathrm{~m}$ & \\
\hline \hline
\end{tabular}

\begin{tabular}{|c|c|c|c|}
\hline \multicolumn{4}{|c|}{$\begin{array}{l}\text { Table } 4 \\
\text { Changes in Tide Range at Barnegat Bay Tide Gauges }\end{array}$} \\
\hline Gauge Location & $\begin{array}{l}\text { Tide Range, 1977-78 } \\
\text { (Preproject) }\end{array}$ & $\begin{array}{l}\text { Tide Range, } 1993 \\
\text { (Postproject) }\end{array}$ & Percent Change \\
\hline Mantoloking & $0.10 \mathrm{~m}$ & $0.14 \mathrm{~m}$ & +40 \\
\hline Bayshore & $0.11 \mathrm{~m}$ & $0.16 \mathrm{~m}$ & +45 \\
\hline Waretown & $0.12 \mathrm{~m}$ & $0.16 \mathrm{~m}$ & +33 \\
\hline Loveladies & $0.14 \mathrm{~m}$ & $0.17 \mathrm{~m}$ & +21 \\
\hline
\end{tabular}


of the bay. (This may be due to the rather short period of time in 1993 for which the averages were determined.) Averages were computed for a 2-month period in the summer when southerly winds are more prevalent, increasing the water level gradient south to north along the bay. The Waretown gauge, closest to the USCG gauge and central along the longitudinal axis of the bay, had nearly the same percentage increase as the USCG gauge.

The change in tidal constituents can also be used to examine change in tidal elevation curve distortion (which determines whether an inlet is flood dominant or ebb dominant), and the change in tidal curve distortion depends on magnitude and relative phasing of the M4 and M2 tidal constituents (Aubrey and Speer 1985). The amount of change for both tidal constituent amplitudes and phases is shown in Figure 8. Barnegat Inlet had been determined to be flood dominant in the early 1940s (after arrowhead jetty construction) (Fields and Ashley 1987). If the phasing difference between M2 and M4 is from 0 to $180 \mathrm{deg}$, the resulting tide curve is that of a flood-dominant inlet, with the rising tide curve steeper (shorter duration) than the falling tide curve. Calculations for pre- and postproject conditions at Barnegat Inlet (Table 5) show an increase in phasing difference from 33 to $69 \mathrm{deg}$. This indicates an increase in falling tide duration (Zetler 1959), thus enhancing flood dominance; however, the decrease in the M4/M2 ratio indicates reduced friction effects. Thus, the postproject inlet enhances flood dominance, but the decrease in the M4/M2 ratio indicates some reduction in friction effects making the increase in flood dominance less pronounced (due to reduction in distortion of the tide curve from symmetry).

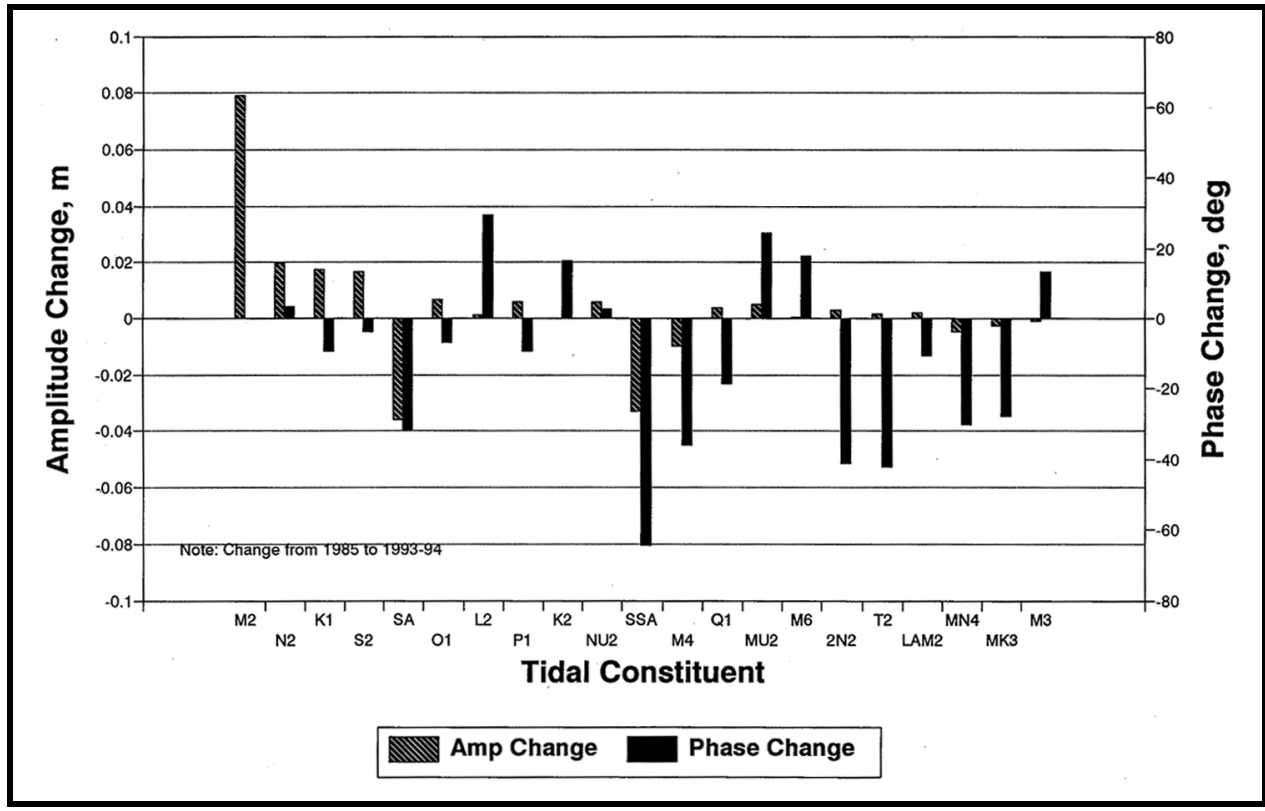

Figure 8. Tidal elevation constituent amplitude and phase changes at the USCG station between the 1985 preproject and the 1993-94 postproject condition 


\begin{tabular}{|c|c|c|}
\hline \multicolumn{3}{|c|}{$\begin{array}{l}\text { Table } 5 \\
\text { Pre- and Post-Project M2 and M4 Tidal Constituents at USCG Station }\end{array}$} \\
\hline Constituent Information & 1985 (Prepoject) & 1993-94 (Postproject) \\
\hline "M2 Amplitude/Phase $\left(\theta_{1}\right)$ & $0.26 \mathrm{~m} / 217.9 \mathrm{deg}$ & $0.34 \mathrm{~m} / 218.0 \mathrm{deg}$ \\
\hline M4 Amplitude/ Phase $\left(\theta_{2}\right)$ & $0.02 \mathrm{~m} / 42.9 \mathrm{deg}$ & $0.01 \mathrm{~m} / 7.0 \mathrm{deg}$ \\
\hline M4/M2 Amplitude Ratio & 0.076 & 0.029 \\
\hline Phase Difference $\Phi=2 \theta_{1}-\theta_{2}$ & $33 \mathrm{deg}$ & $69 \mathrm{deg}$ \\
\hline Result of Phasing & Flood Dominance & Flood Dominance \\
\hline
\end{tabular}

\section{Effects of wind on bay tide}

In the large, open Barnegat Bay, the effect of wind stress on the water surface can be significant. It was observed that maximum head differences along the length of the bay for a 40-day period in May-June 1994 corresponded to strong wind events (Figure 9). The Loveladies tide gauge is about 3.1 miles $(5 \mathrm{~km})$ south of the inlet, and the Mantoloking tide gauge is at the far north end of the bay, about 16.8 miles $(27 \mathrm{~km})$ from the inlet (Figure 1). When wind was from the south and southwest, the elevation at Mantoloking was higher than at Loveladies. Winds nearing $30 \mathrm{ft}$ per sec $(9 \mathrm{~m}$ per sec) create about a $1.3-\mathrm{ft}(40$ $\mathrm{cm})$ difference in elevation between the two gauges. These locations have average tide ranges less than $0.4 \mathrm{ft}(12 \mathrm{~cm})$, so the wind-induced head difference is significant. Winds from the north, northeast, and northwest reversed the head difference, producing head differences as much as $0.8 \mathrm{ft}(24 \mathrm{~cm})$, with northeast winds producing the greatest response for a given wind magnitude.

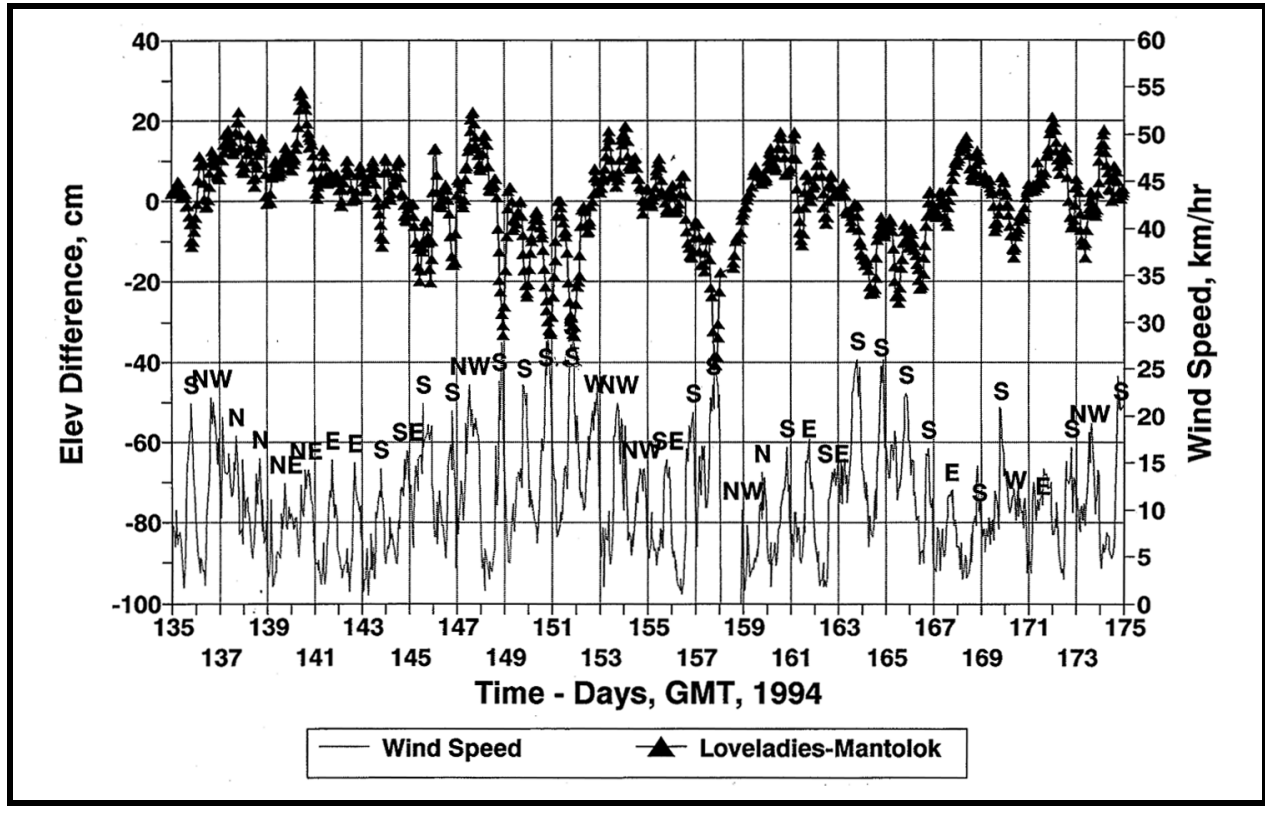

Figure 9. Elevation differences and corresponding wind speed across length of Barnegat Inlet, measured between tide gauges at Loveladies and Mantoloking 


\section{Short-term Tidal Current Data Analysis}

\section{General trends}

Comparisons of the 1993 and 1994 spring tide current data and 1995 mean tide current data were made. Velocity distributions for a given transect were shown to be consistent from year to year (Figure 10); however, velocities were significantly higher during spring tide as would be expected. Flood flow was distributed fairly uniformly across Transect C (Figure 10f), with somewhat higher velocities in the central and southern portions of the inlet. This was due to flow over the low (mean tide level) outer portion of the north jetty entering almost perpendicular to the channel. Also, the asymmetrical ebb shoal impedes flood flow from the south relative to flood flow from the north side. These factors combine to force flood flow toward the south side at Transect C. At Transect B (Figure 10e), peak flood velocities shifted to slightly north of the central portion of the inlet. A secondary peak in flood velocities occurred at the extreme southern end of Transect B (near the base of the Barnegat Lighthouse). Flood velocities were stronger on the northern side of Transect A. On ebb, the trends were reversed, with the southern side of Transects A and B having stronger ebb velocities (Figures 10a and 10b), and the northern side of Transect $\mathrm{C}$ having stronger ebb velocities (Figure 10c). Flood flow tended to have peak velocities that followed the natural navigation channel, whereas peak ebb velocities were located over the shoals.

\section{Spring tide velocity comparison (1993-1994)}

Data were collected for similar spring tide conditions in 1993 and 1994. Comparing the flood flow data shows the variation in velocity distributions for spring tides in consecutive years (Figures 10d-f). At Transect C, flood velocities were similar for the two data collection time periods; however, the 1993 distribution was somewhat more uniform across Transect C, whereas the 1994 distribution showed a stronger flow on the southern side of the inlet due to deepening in this area. Flood velocities along a $262-\mathrm{ft}-(80-\mathrm{m}-)$ stretch of the midsection of Transect B were $1.0 \mathrm{ft}$ per sec $(30 \mathrm{~cm}$ per sec) higher in 1993 than in 1994. These differences were closely associated with a long, fingerlike shoal that developed through the inlet throat (Figure 3). The more elongated shoal configuration observed in 1994 diverted flood flow, allowing less flow to reach the midsection of Transect B, hence, the lower velocities in 1994. Flood velocities were similar for the two data collection time periods, with the 1993 distribution slightly higher on the southern side of Transect A.

Comparison of the 1993 and 1994 spring tide ebb flows shows 1994 ebb velocities greater than those for 1993 at Transect A. There was a noticeable difference between the ebb velocity distributions for Transect $B$ along the same 262-ft- (80-m-) stretch in the midsection for which flood flows differed. Again, the channel shoal influenced the flow in this region. The 1994 velocities were $1.0 \mathrm{ft}$ per sec $(30 \mathrm{~cm}$ per sec) faster than the 1993 velocities in this region. When the shoal was located directly at Transect B (1993), ebb flow was diverted around it and velocities were lower. In 1994, the shoal elongated in the seaward direction and did not have as strong an effect on ebb flow as in 1993. Velocity 


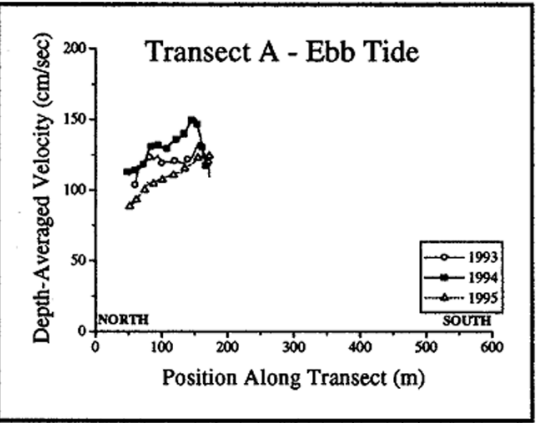

(a)

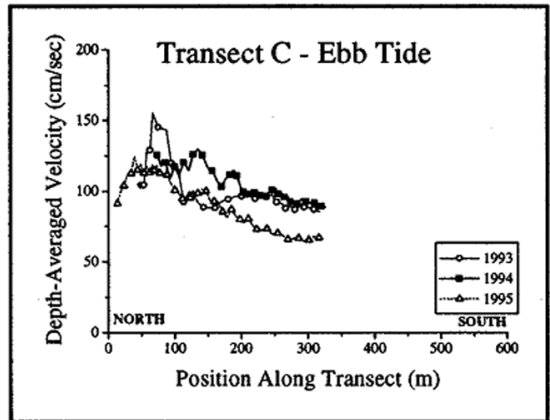

(c)

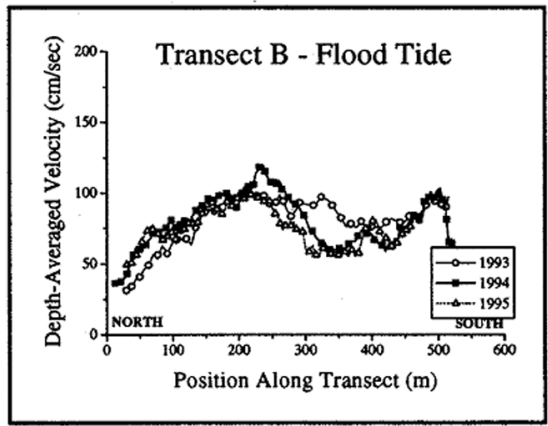

(e)

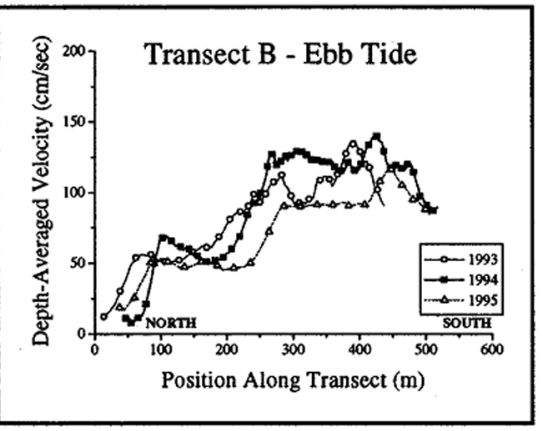

(b)

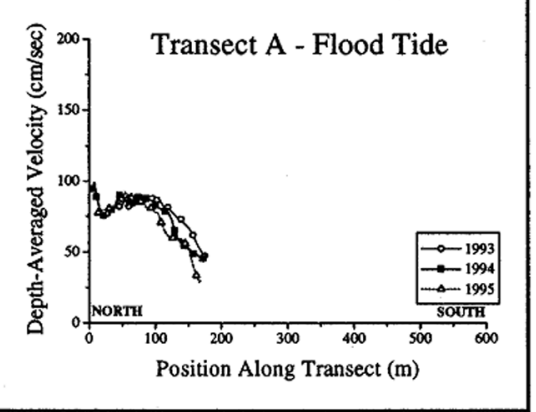

(d)

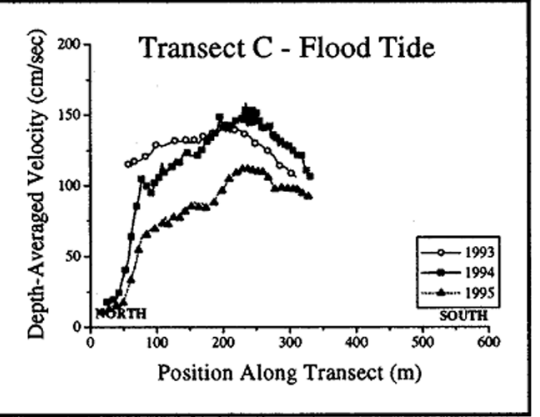

(f)

Figure 10. Velocity distributions across Transects A, B, and C for maximum ebb and flood discharges for 1993, 1994, and 1995, looking seaward

vectors indicate that ebb currents were not perpendicular to Transect $\mathrm{B}$, but made a 40-deg angle with the transect normal. Flood velocity vectors were nearly normal to Transect B. Ebb velocities showed a similar difference along a $295-\mathrm{ft}-$ (90-m-) stretch of Transect C. The 1994 velocities were about 1.3 to $1.6 \mathrm{ft}$ per $\mathrm{sec}(40$ to $50 \mathrm{~cm}$ per sec) faster than the 1993 velocities in this region, probably due to bathymetric changes. 


\section{Spring-to-mean tide comparison (1994-1995)}

Comparing 1994 with 1995 data shows the variation in velocity distribution from a spring tide to a mean tide. The distribution of flow for a given transect was generally the same from year to year; however, velocities were significantly higher during spring tide as would be expected. At Transect $C$, flood velocities were about 1.3 to $1.5 \mathrm{ft}$ per sec ( 40 to $45 \mathrm{~cm}$ per sec) higher during spring tide, and ebb velocities were about $0.3 \mathrm{ft}$ per sec $(10 \mathrm{~cm}$ per sec) higher (Table 6; Figure 11). At Transect B, there was a discernible difference in flood velocity of only $0.7 \mathrm{ft}$ per sec $(20 \mathrm{~cm}$ per sec) along a $164-\mathrm{ft}-(50-\mathrm{m}-)$ portion of the central part of the inlet. On ebb, the difference between spring tide velocities and mean tide velocities at Transect B was more significant, averaging $62 \mathrm{ft}$ per sec $(19 \mathrm{~cm}$ per sec) higher for spring tide for the entire transect. At Transect A, flood velocities were slightly higher by $0.3 \mathrm{ft}$ per $\mathrm{sec}(10 \mathrm{~cm}$ per sec) along a $246-\mathrm{ft}-$ $(75-\mathrm{m}-)$ portion of the transect, and were actually lower at the extreme southern end of the transect. The average spring tide flood velocity at Transect A was $0.2 \mathrm{ft}$ per sec $(6 \mathrm{~cm}$ per sec) higher than the average mean tide flood velocity. On ebb, spring velocities were about $0.6 \mathrm{ft}$ per sec $(17 \mathrm{~cm}$ per sec) higher than mean velocities.

\section{Table 6}

Average Peak Velocities, cm/sec

\begin{tabular}{||l|l|l|l|l|l|l||}
\hline \multirow{3}{*}{ Year } & \multicolumn{2}{|c|}{ Transect A } & \multicolumn{2}{c|}{ Transect B } & \multicolumn{2}{c||}{ Transect C } \\
\cline { 2 - 7 } & Ebb & Flood & Ebb & Flood & Ebb & Flood \\
\hline \hline 1993 & 119 & 76 & 76 & 78 & 98 & 119 \\
\hline 1994 & 131 & 76 & 78 & 79 & 102 & 115 \\
\hline 1995 & 108 & 70 & 62 & 72 & 92 & 93 \\
\hline \hline
\end{tabular}

\section{Flow distribution at primary flood shoal}

The velocity distribution for each transect was collected for several tidal cycles in 1993, 1994, and 1995. The tidal discharge time series also recorded by the ADCP were integrated to determine flow volume (tidal prism) at the three transect locations (Figure 5). From these data, the distribution of flow in the vicinity of the flood shoal was examined. For both spring and mean tide conditions, the distribution of ebb flow was consistent. Approximately twothirds (64 to 71 percent) of the ebb flow was through the navigation channel and one-third (29 to 36 percent) was over the shoal. Flood flow for mean tide conditions indicated that about 56 percent of the flow traversed the flood shoal region and 44 percent moved through the navigation channel adjacent to the Barnegat Lighthouse. This compared to 65 percent over the flood shoal and 35 percent through the channel for spring tide conditions. This change was attributable to the smaller mean tide range; i.e., the rising mean tide did not reach as high an elevation as spring tide to permit as much flow over the flood shoal. Ebb flow velocity distribution was not affected by changes in tide range since ebb flow begins at about midtide on the falling tide curve when flow over the shoal is cut off by the emerging shoal. This analysis indicates that flow over the flood shoal is flood dominant, and flow through the interior navigation channel is ebb dominant, similar to the segregation of flow attributed to time-velocity 

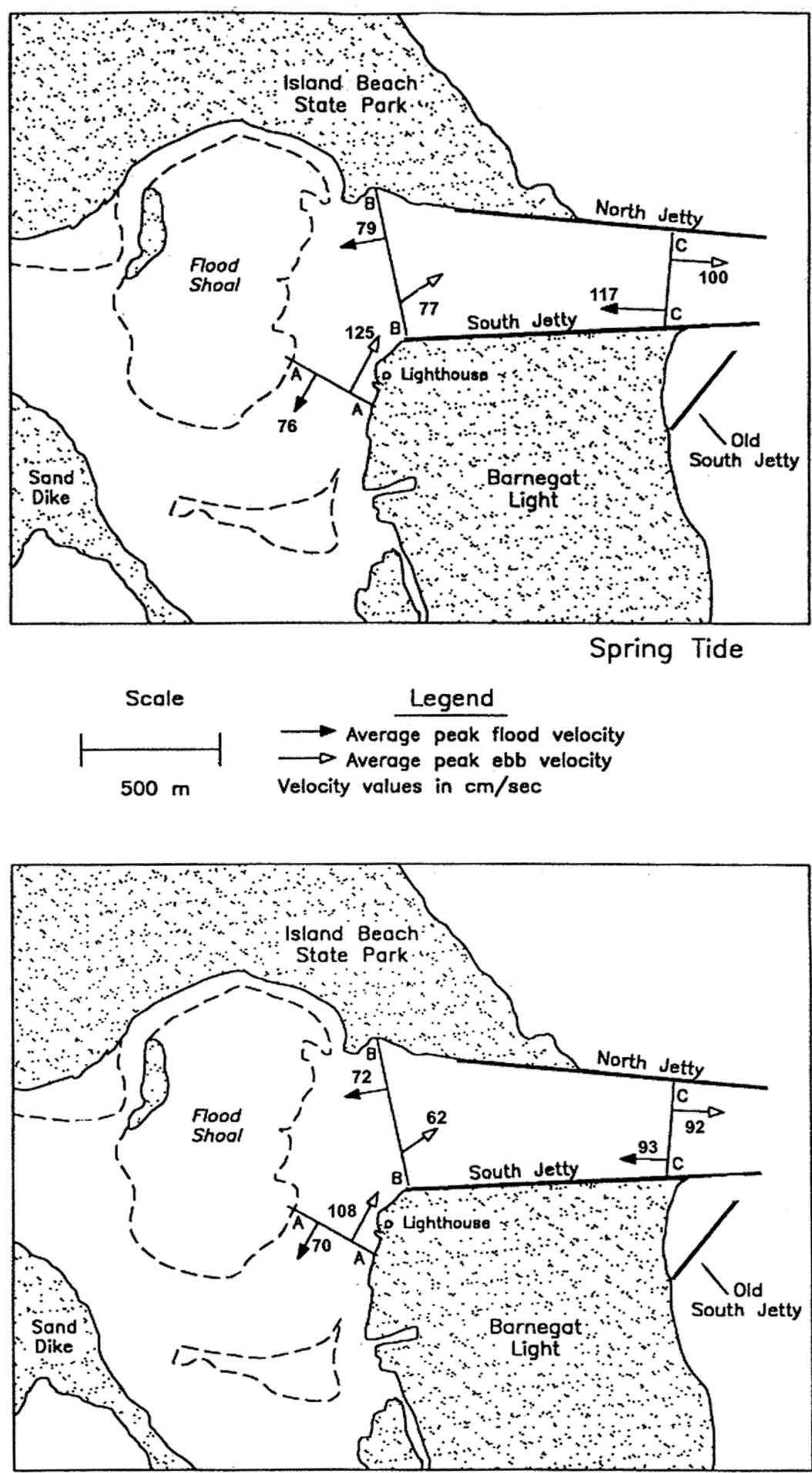

Mean Tide

Figure 11. Average peak flood and ebb velocities at Transects A, B, and C for spring and mean tide conditions 
asymmetry noted by Boothroyd and Hubbard (1975). Bathymetric data analysis (Cialone et al. 1999) has indicated a reduction in elevation of the seaward face of the flood shoal creating the potential for channel development through this area.

\section{Flow dominance}

Average peak flood velocities were higher than peak ebb velocities at Transect C (Figures 10c and 10f), indicating flood-dominant conditions during spring tide (Table 6). Mean tide conditions indicate Transect $\mathrm{C}$ is fairly balanced. The month-long current data (discussed later) also showed that Transect $\mathrm{C}$ was flood-dominated for spring tide conditions and ebb-dominated during mean and neap tide conditions (Figure 12). The higher velocities during spring tide indicated that this location experienced an overall flood dominance. The distribution of flow indicated clear flood dominance on the south side of Transect $\mathrm{C}$ and ebb dominance on the north side of Transect $\mathrm{C}$. The highest velocities at Transects $\mathrm{A}$ and $\mathrm{B}$ occurred for ebb flow. The most extreme difference between ebb and flood flow was observed at Transect A where ebb velocities were approximately $1.6 \mathrm{ft}$ per sec $(50 \mathrm{~cm}$ per sec $)$ higher than flood velocities (Figures 10a and 10d). The entire ebb velocity magnitude curve was greater than the flood velocity magnitude curve. The ebb dominance observed at Transect $\mathrm{A}$ is attributed to the emergence of the flood shoal at low water, and to the diversion of flow into the channel on ebb tide.

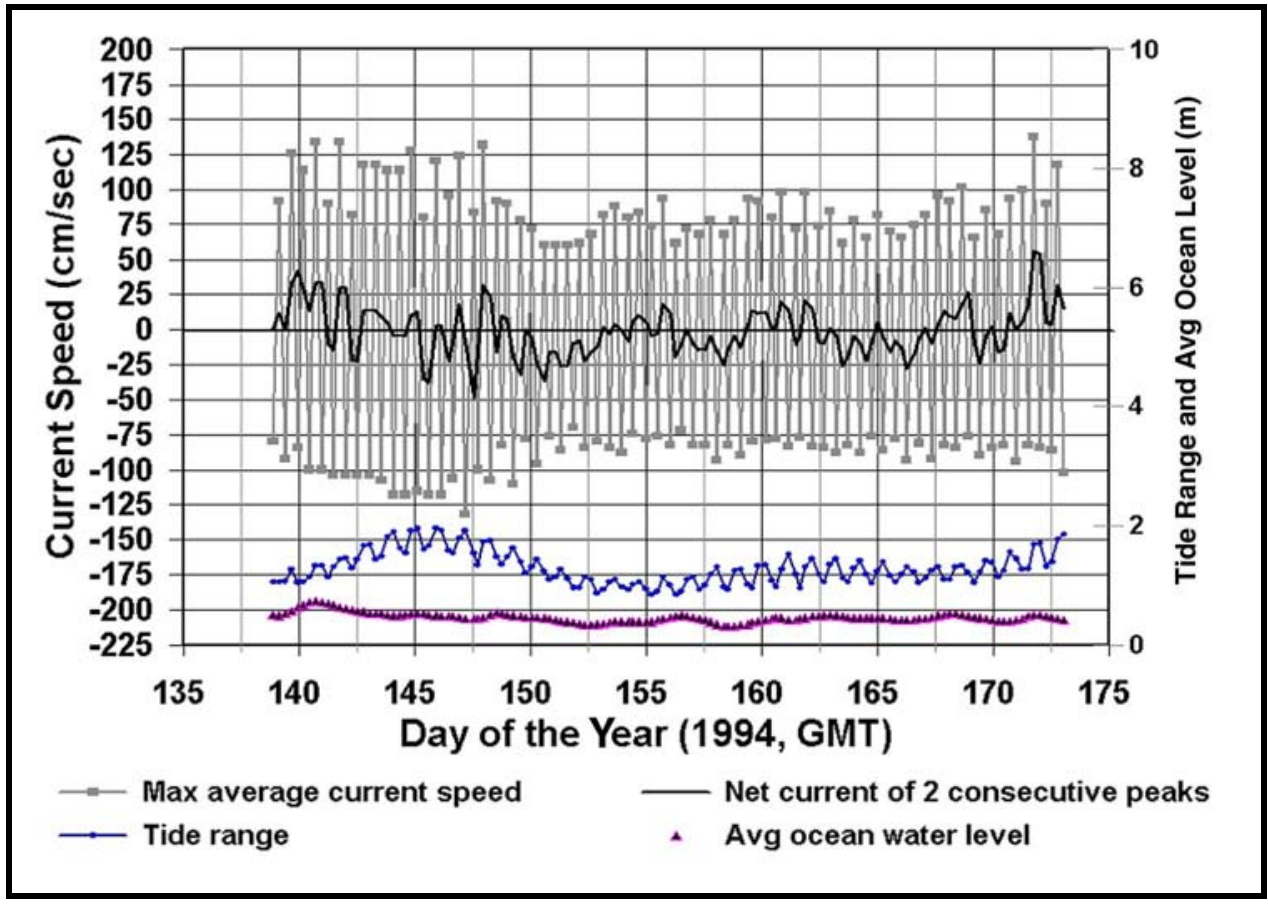

Figure 12. Peak average currents taken on a vertical line through the water column at Transect $C$ and adjusted to represent the entire transect. Data were collected over a 34-day period with an ADCP on the bottom of the channel. Also shown are net current values determined by averaging consecutive ebb (or flood) maximum current values 
Large differences in velocity from peak flood to peak ebb occurred at Transect B, but the difference was due to a shift in the location of maximum velocity (Figures $10 \mathrm{~b}$ and 10e). The influence of the channel shoal and flood shoal on the velocity distribution at Transect $B$ was definitive. The north side of Transect B had stronger flood velocities and the south side had stronger ebb velocities. Flood velocities tended to follow the navigation channel and were diverted around the elongated shoal in the inlet throat leading to the north main peak and the southern secondary peak (Figure 10e). On ebb, the flood shoal influenced the flow and velocity distributions at Transect B. A large percentage (65 percent) of the ebb flow was diverted around the flood shoal through the channel to the south and flowed into the inlet throat at Transect B. The proximity of the transect to the navigation channel on the south side of the flood shoal and the navigation channel near the north jetty means Transect $B$ was a crossover point for maximum ebb velocities. The direction of flow was angled from the navigation channel on the south side of the flood shoal toward the north jetty navigation channel. Velocity vectors indicate that ebb currents were not perpendicular to the transect, but made a 40-deg angle with the transect-normal (flood velocity vectors were nearly normal to the transect).

Transect B is fairly balanced for spring tide conditions, and shows a slight flood dominance for mean tide conditions. Although the physical configuration of the inlet was different, two preproject studies indicated greater average flood velocities than ebb velocities near the present Transect B location (PRC Harris 1980; Ashley 1987).

In summary, for spring tide conditions Transect $C$ had higher average peak flood velocities (indicating flood dominance), and Transect B had higher average peak ebb velocities (indicating ebb dominance). These findings support flow convergence in the intra-jetty region. Transect $\mathrm{A}$ had higher ebb velocities, indicating that location is ebb-dominated; however, it is not considered in the analysis of flow dominance for the entire inlet because it receives only 35 65 percent of the flood and ebb flow. Overall mean conditions were nearly balanced, with a slight flood dominance. However, the strong spring tide flood dominance indicates that Barnegat Inlet is a flood-dominated inlet.

\section{Transect B historical comparison}

Two studies conducted prior to project construction included velocity data collection at several points near the present MCNP Transect B (PRC Harris 1980; Ashley 1987). Both studies indicated greater average flood velocities than ebb velocities in this location prior to project construction. The present MCNP study, however, showed an average peak flood velocity of $2.7 \mathrm{ft}$ per sec $(81 \mathrm{~cm}$ per sec) and an average peak ebb velocity of $3.0 \mathrm{ft}$ per $\mathrm{sec}(92 \mathrm{~cm}$ per sec) for spring tide conditions. For mean tide conditions, the average peak flood and ebb velocities were nearly equal at 2.5 and $2.4 \mathrm{ft}$ per sec ( 75 and $73 \mathrm{~cm}$ per sec), respectively, with flood velocities slightly higher. The proximity of Transect B to Transect A influenced the flow dominance as inferred from measurements at Transect B. Had the Transect B been shifted slightly seaward of its present location, flood dominance would have been observed. Looking at the distribution of flow across Transect B, the Ashley (1987) data clearly show higher flood velocities on the north side of the inlet and higher ebb velocities on the south side of the inlet, as was indicated in the present study. PRC Harris (1980) showed one location on 
the south side of the inlet where flood velocities were lower, and fairly uniform ebb velocities with slightly higher velocities on the south side.

\section{One-month Tidal Current Data Analysis}

For a 1-month period, continuous velocity data were collected with the bottommounted ADCP on the south side of Transect C (Figure 5). From these data, discharge, tidal prism, ebb and flood flow duration, and potential sediment transport information were derived.

\section{Velocity profile description}

Velocity profile plots are shown in Figure 13 for selected maximum flood and ebb flows during spring and neap tides at Transect $\mathrm{C}$. A vertical velocity profile consisted of 10 bins, but also with more bins available for high water conditions and fewer for low water. Transect $\mathrm{C}$ (Figure 5) is a flood-dominant region, as noted by comparing Figures 10c and 10f. Velocity profile plots for selected maximum flood and ebb flows during spring and neap tides show a more uniform (linear) distribution for lower velocities and a more logarithmic distribution for larger velocities (Figure 13). The most noticeable difference in the structure of the velocity profile is between spring flood and ebb. The flood flow shows a strong logarithmic structure, and the larger magnitude clearly indicates flood dominance. There was not significant shear, only minor observances during low flow conditions. Figure 14 shows mean peak velocity profiles calculated by averaging the maximum ebb profiles and flood profiles for the entire 34-day ADCP data set. These profiles also show a more logarithmic structure for the higher velocity (flood) profile, and a more linear lower velocity (ebb) profile (Figure 13). These profiles are representative of only one location, and that is in a flood-dominant zone of the inlet.

\section{Depth-averaged velocities}

Depth-averaged velocity magnitude and direction were computed for each time-step from the individual bins. The resulting time-histories (e.g., Figure 15) were analyzed, along with water level data from the nearshore wave gauge, to identify peak velocities, mean directions, durations, and phase lags associated with each tidal cycle. Phase lag is defined as the time between high or low tide elevation in the ocean and zero velocity in the inlet channel. Tide ranges for this time period were $4.1 \pm 0.9 \mathrm{ft}(1.25 \pm 0.27 \mathrm{~m})$. Further statistical analyses were performed on each parameter for the range of tide conditions to obtain insight into average conditions over a complete lunar cycle.

As seen in Table 7, flood tide conditions result in significantly larger average velocities of $1.0 \mathrm{ft}$ per sec $(30 \mathrm{~cm}$ per sec) greater, but ebb flow durations are nearly 30 min longer on average. Mean directions of ebb and flood currents indicate that they are about 17 deg out of alignment from being purely bidirectional (180 deg). The main axis of the south jetty has an azimuth of $130 \mathrm{deg}$, or 310 deg relative to true north (TN). It appears that flood flow is directed $10 \mathrm{deg}$ toward the new south jetty, and ebb flow is directed 7 deg toward the new south jetty. 

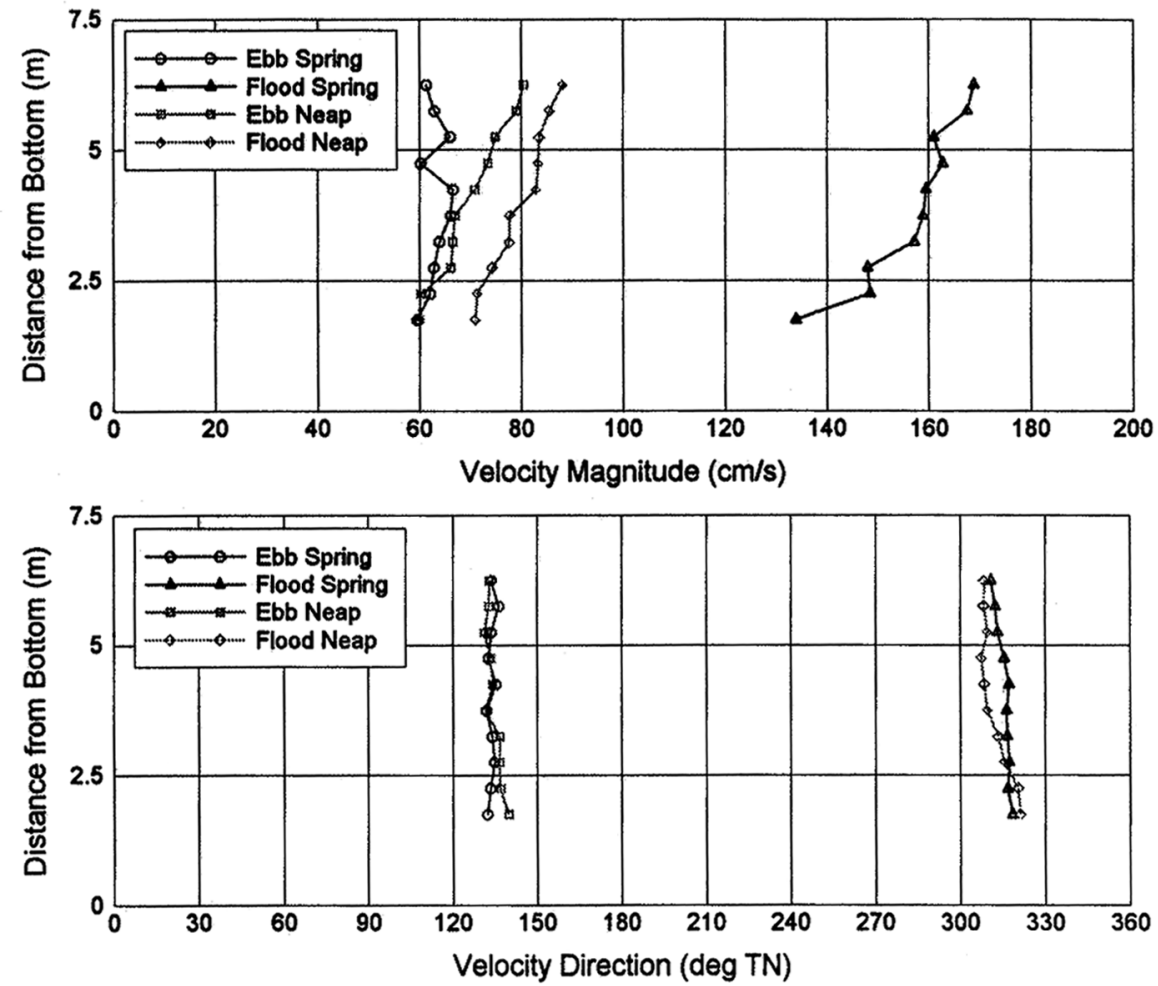

Figure 13. Velocity profiles from bottom-mounted ADCP located at Transect C. Flood and ebb velocity profile magnitude and direction profiles for June 1, 1994 (neap tide conditions) and June 20, 1994 (spring tide conditions)

\section{Table 7 \\ Statistical Results of 34 Days of Bottom-Mounted ADCP Velocity Data}

\begin{tabular}{||l|l|l|l||}
\hline \hline Parameter & All Cycles & Flood Cycles & Ebb Cycles \\
\hline \hline Peak velocities & $90 \pm 25 \mathrm{~cm} / \mathrm{sec}$ & $105 \pm 25 \mathrm{~cm} / \mathrm{sec}$ & $75 \pm 15 \mathrm{~cm} / \mathrm{sec}$ \\
\hline Mean directions & N/A & $300.0 \pm 2.8 \mathrm{deg} \mathrm{TN}$ & $137.0 \pm 1.6 \mathrm{TN}$ \\
\hline Duration & $6.21 \pm 0.77 \mathrm{hr}$ & $5.99 \pm 0.82 \mathrm{hr}$ & $6.44 \pm 0.66 \mathrm{hr}$ \\
\hline $\begin{array}{l}\text { Phase lag from } \\
\text { high/low tide }\end{array}$ & $3.40 \pm 0.47 \mathrm{hr}$ & $\begin{array}{l}3.18 \pm 0.39 \mathrm{hr} \text { after } \\
\text { ocean high water }\end{array}$ & $\begin{array}{l}3.61 \pm 0.45 \mathrm{hr} \text { after } \\
\text { ocean low water }\end{array}$ \\
\hline
\end{tabular}

\section{Individual velocity bin analysis}

For each bin, statistical properties of velocity magnitude and direction were computed. As expected, velocities decrease with depth. Ebb durations are longer near the bottom, and flood durations are longer near the water surface. This is probably due to momentum effects of the more channelized ebb flow directed seaward, while flood surface currents approaching the inlet over the shallow ebb shoal and on the inlet flanks begin flooding earlier than the deeper 


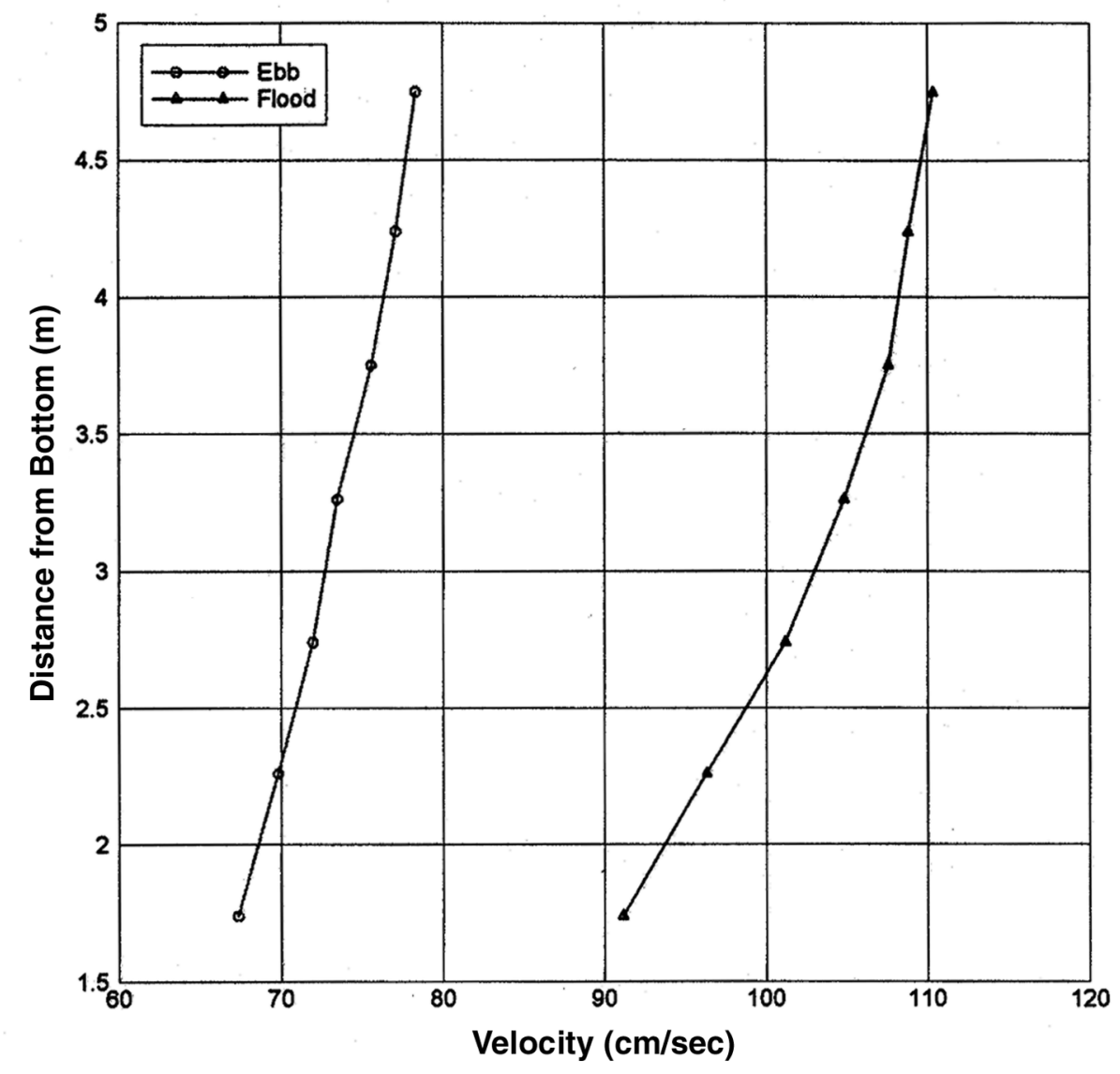

Figure 14. Mean peak velocity profiles for ebb and flood tide conditions as determined through analysis of a complete lunar cycle of ADCP data

channel currents. The mean flow direction is not strictly bidirectional. Flood flow is directed toward the south jetty, with the topmost bins directed most toward the jetty ( $12 \mathrm{deg}$ ). This supports the assumption that flow over the weir section of the north jetty at elevated water levels (flood flow) causes a shift in the mean direction to the south. Flood flow in the lower bins is also directed slightly toward the south jetty ( $5 \mathrm{deg}$ ), but is more closely aligned with the main channel axis than the topmost bins. Analysis of the ebb flow directions indicates flows are also directed toward the south jetty, with flows directed more southerly toward the jetty with increasing depth. Ebb flows appear to be controlled by the bathymetry. The presence of the channel shoal affects (diverts) flow in the bottom bins whereas the topmost layers are able to flow over the shoal. Thus, surface ebb flow at the ADCP location is aligned with the channel while bottom bins of the ADCP receive flow that has come around the channel shoal and flows into the lee of the shoal. This bottom ebb flow then approaches the ADCP location on a line that intercepts the south jetty by about 7 to $9 \mathrm{deg}$. 

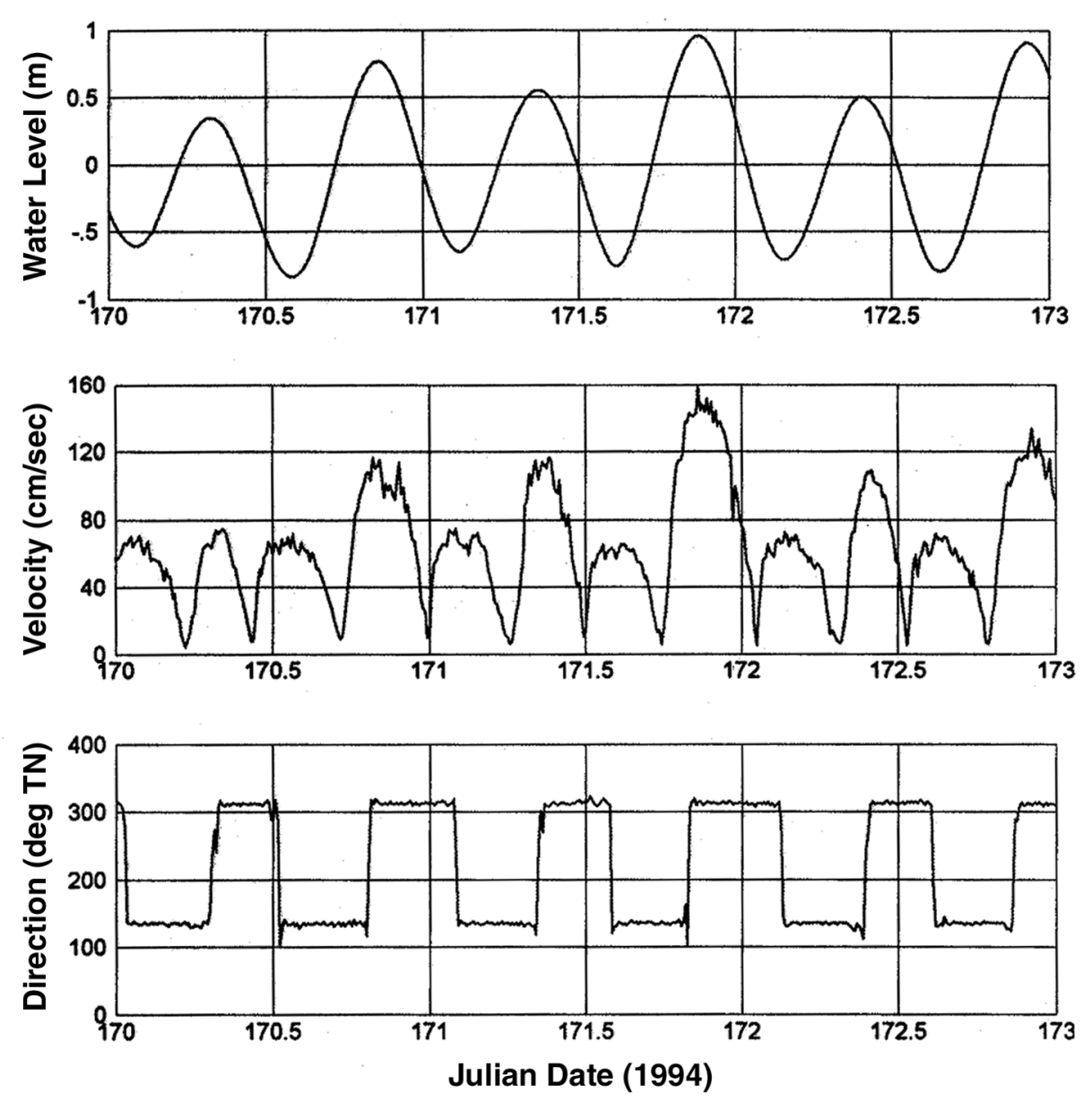

Figure 15. Water level, depth-averaged velocities, and direction for bottommounted ADCP for a 3-day period in June 1994

\section{Derivation of discharge and tidal prism data}

The bottom-mounted, depth-averaged velocity data were correlated to flood and ebb cross-sectional flow distributions at Transect $\mathrm{C}$ for spring tide conditions to provide a representative velocity for the cross section. Velocity distribution varied for ebb and flood current magnitudes, but distribution was similar for various tide ranges. Using a representative velocity for the entire cross section, estimates of discharge were calculated and tidal prism variation for the month was determined by integration of the discharges (Figure 16). Comparison of the prisms for the 2-day, full cross-section ADCP velocity data collection at Transect $\mathrm{C}$ and the estimated prisms from the bottom-mounted ADCP indicated close comparison. For two consecutive tidal cycles, percentage differences between the bottom-mounted and full cross-section ADCP tidal prism measurements were -10 percent (ebb), -6 percent, (flood), +2 percent (ebb), and +24 percent (flood). The large ( 24 percent) difference in the last flood condition was caused by a flow reversal (eddy) adjacent to the weir section, reducing flood flow. This difference occurred for a lower flood tide range and may be related to the interaction of flow over the weir with swell wave conditions. 


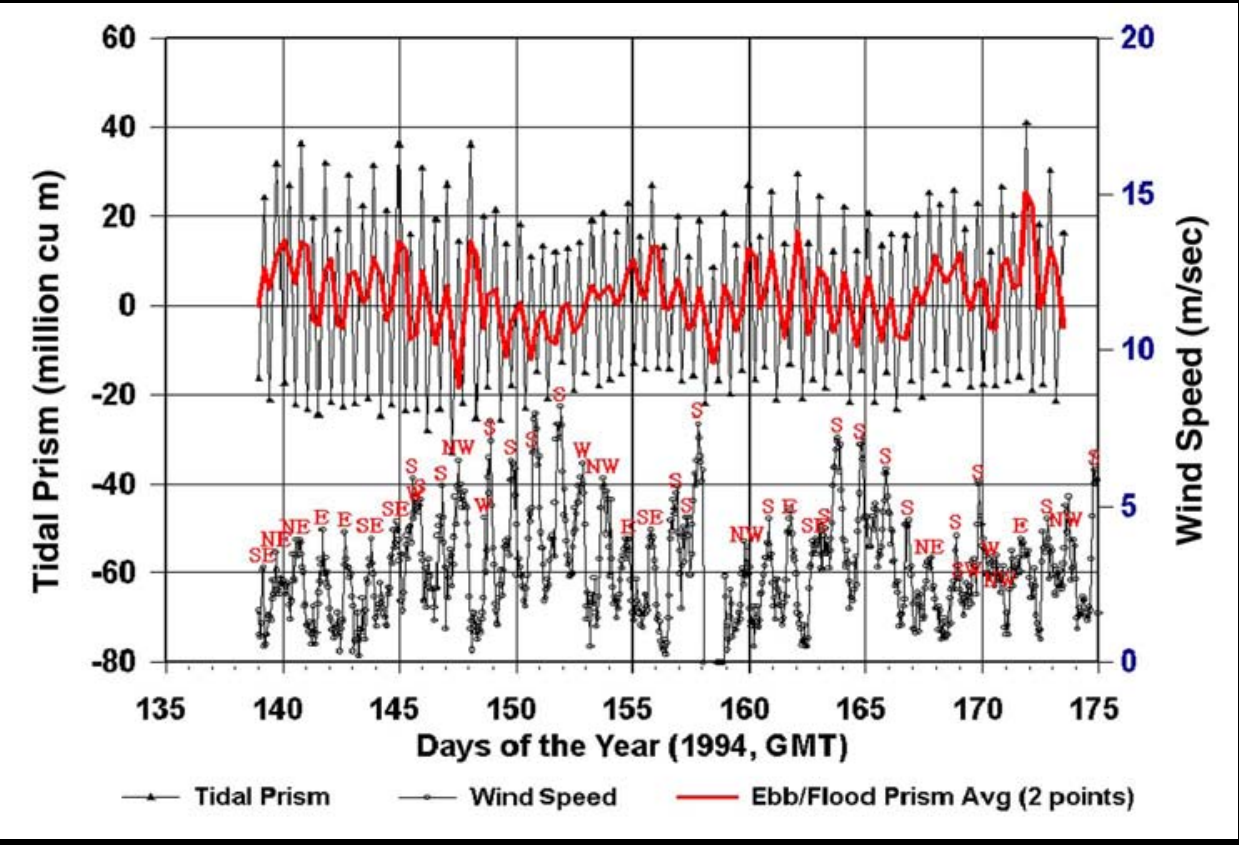

Figure 16. Tidal prisms derived from 34-day bottom-mounted ADCP data, and wind speed and direction blowing over Barnegat Inlet

\section{Month-long tidal discharges}

Figure 17 shows the hourly cross-sectional discharges calculated from the 34-day velocity record. From this plot it is interesting to note the relatively large number of similar values at maximum ebb flow. A limiting value of discharge was reached, compared to the positive maximums (flood tide flow) that varied widely depending on the phase in the lunar cycle. Figure 18 shows a plot of hourly discharge during a single tidal cycle plotted against water surface elevation. Ebb discharge remained about the same value of $45,900 \mathrm{cu} \mathrm{ft}$ $(1,300 \mathrm{cu} \mathrm{m})$ as the water surface fell from -1.0 to $-3.0 \mathrm{ft}(-0.3$ to $-0.9 \mathrm{~m})$ referred to National Geodetic Vertical Datum (NGVD), again indicating a friction-limited value for ebb discharge. Maximum flood discharge reached a larger discharge value but had a sharper peak. It is important to note from this plot that maximum discharges occur near the maximum and minimum tidal elevations.

\section{Month-long tidal prisms}

Integrating the month-long tidal discharge curves produced the month-long tidal cycle flow volumes (tidal prisms). Figure 16 shows the calculated tidal prisms for the month, plus summations of consecutive ebb and flood tidal prisms $\left(\mathrm{V}_{\mathrm{ebb}}+\mathrm{V}_{\text {flood }}\right)$ (i.e., the net flow). Also plotted are wind magnitude and direction during the time period. Analysis of these data indicated that generally southerly wind events tended to be associated with negative ebb/flood averages, indicating net ebb flow through the inlet. The maximum ebb prism of $11.7 \times 10^{8} \mathrm{cu} \mathrm{ft}$ $\left(33.0 \times 10^{6} \mathrm{cu} \mathrm{m}\right)$ was at spring tide on Day 147 with strong northwest wind (blowing seaward along the inlet channel) following $0.1 \mathrm{ft}(0.03 \mathrm{~m})$ of local 


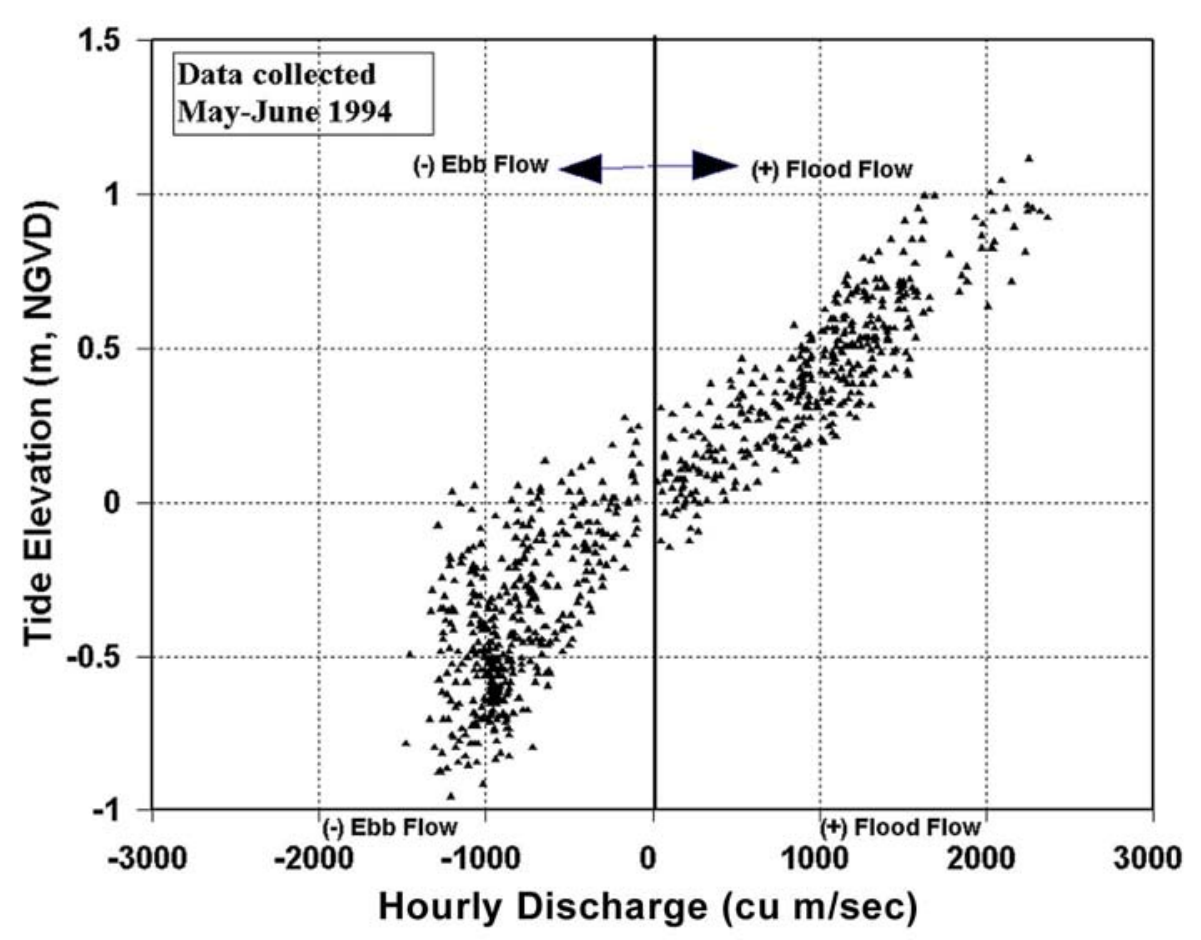

Figure 17. Hourly discharges at Transect $C$ versus tide elevation derived from the 34-day bottom-mounted ADCP current data collection. Ebb flow occurs at much lower elevations than flood flow, and peak flood discharges are larger than peak ebb discharges

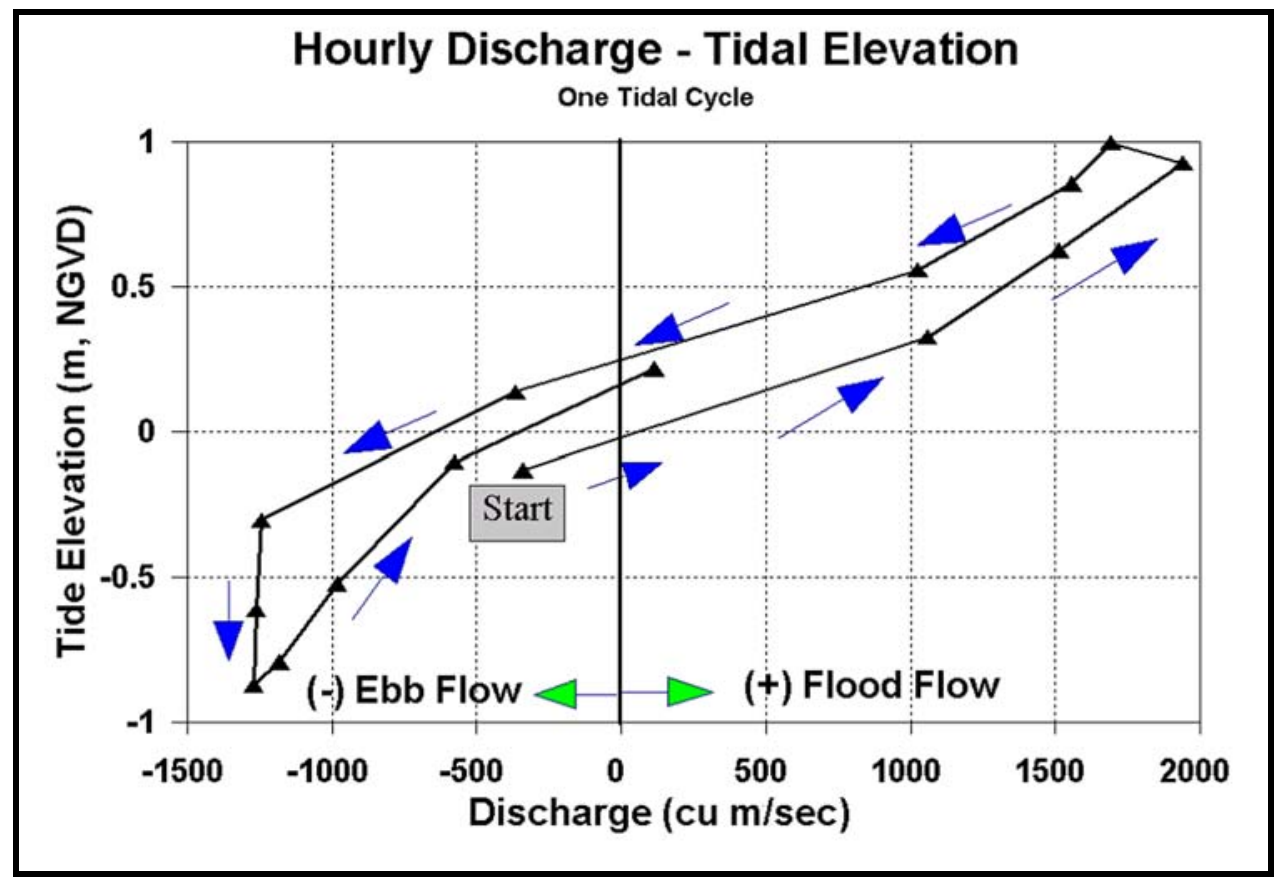

Figure 18. Discharge curve for one tidal cycle versus tide elevation for Transect $C$ 
rainfall. The minimum ebb prism of $4.4 \times 10^{8} \mathrm{cu} \mathrm{ft}\left(12.5 \times 10^{6} \mathrm{cu} \mathrm{m}\right)$ was at neap tide on Day 152 when strong southerly winds caused northerly bay setup that impeded ebb flow. The maximum flood prism of $14.6 \times 10^{8} \mathrm{cu} \mathrm{ft}$ $\left(41.3 \times 10^{6} \mathrm{cu} \mathrm{m}\right)$ occurred during spring tide on Day 172 with a strong wind from the east. The minimum flood prism of $11.7 \times 10^{8} \mathrm{cu} \mathrm{ft}\left(8.9 \times 10^{6} \mathrm{cu} \mathrm{m}\right)$ occurred during mean tide conditions on Day 158 during strong southerly winds and bay tide levels that were about $1 \mathrm{ft}(0.3 \mathrm{~m})$ higher than usual.

There was a general trend for an accumulation of water in the bay, or net flood flow, as tide range increased approaching spring tide, followed by a reduction of this accumulation (or release) as neap tides were approached. Flood flows tended to be more efficient due to greater depths, and friction effects on maximum ebb flow limited the amount of water that could leave the bay, leading to an accumulation of water during spring tides. This effect is noted in the net flows but can also be seen in the tidal record. Figure 19 shows the increasing tide elevation at Bayshore as spring tide is approached (smoothed by a 7-day running average). The large bumps in the curve occur about every 2 weeks during spring tides (the general rising trend of this curve is associated with the annual cycle of sea level increase until autumn (Harris 1981)).

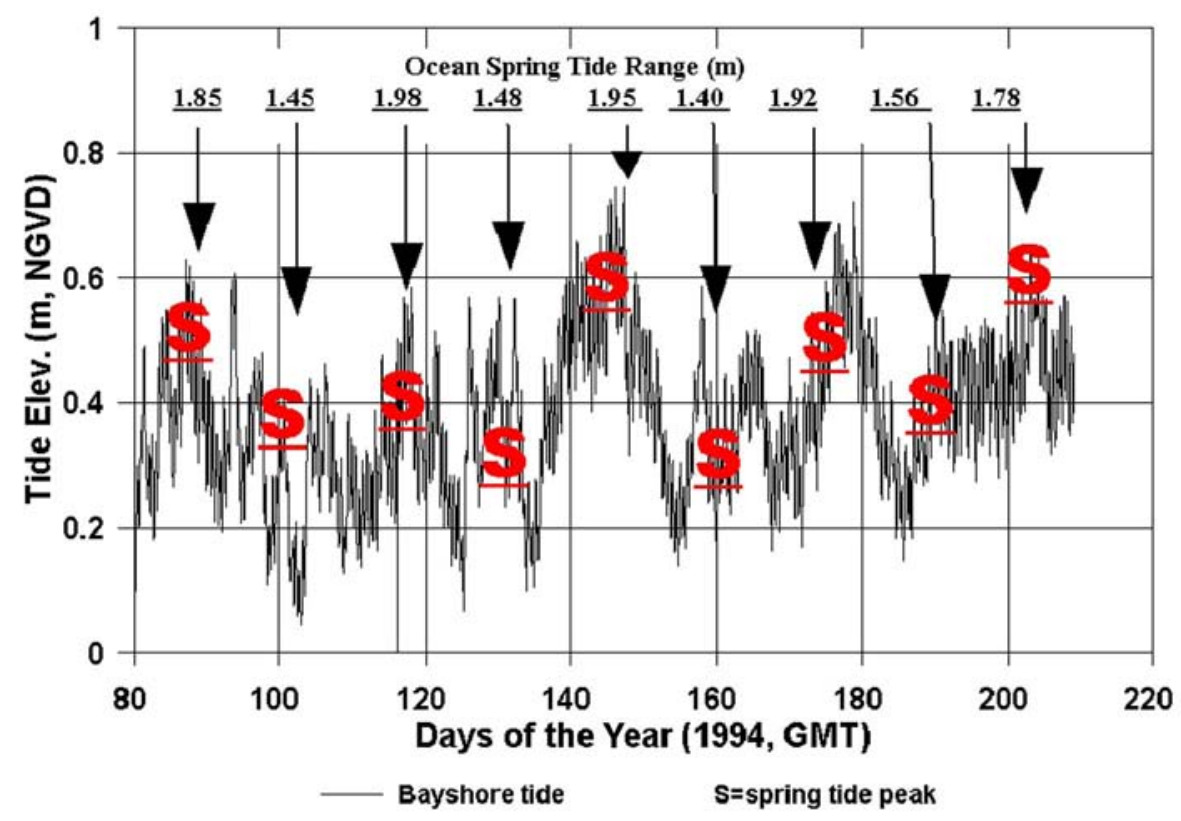

Figure 19. Tidal elevations measured at the Bayshore gauge showing the fortnightly rise in bay water surface

The largest bay rise occurred for the largest spring tides on a monthly basis. A Fast Fourier Transform of the data from Day 50 to Day 207 supports this, with highest energy density at about the 28-day spring-neap cycle lunar monthly cycle $(\mathrm{Mm})$ component, about equal to the energy at the 12.42-hr normal lunar semidiurnal cycle (M2) component (Figure 20). This accumulation appears to 


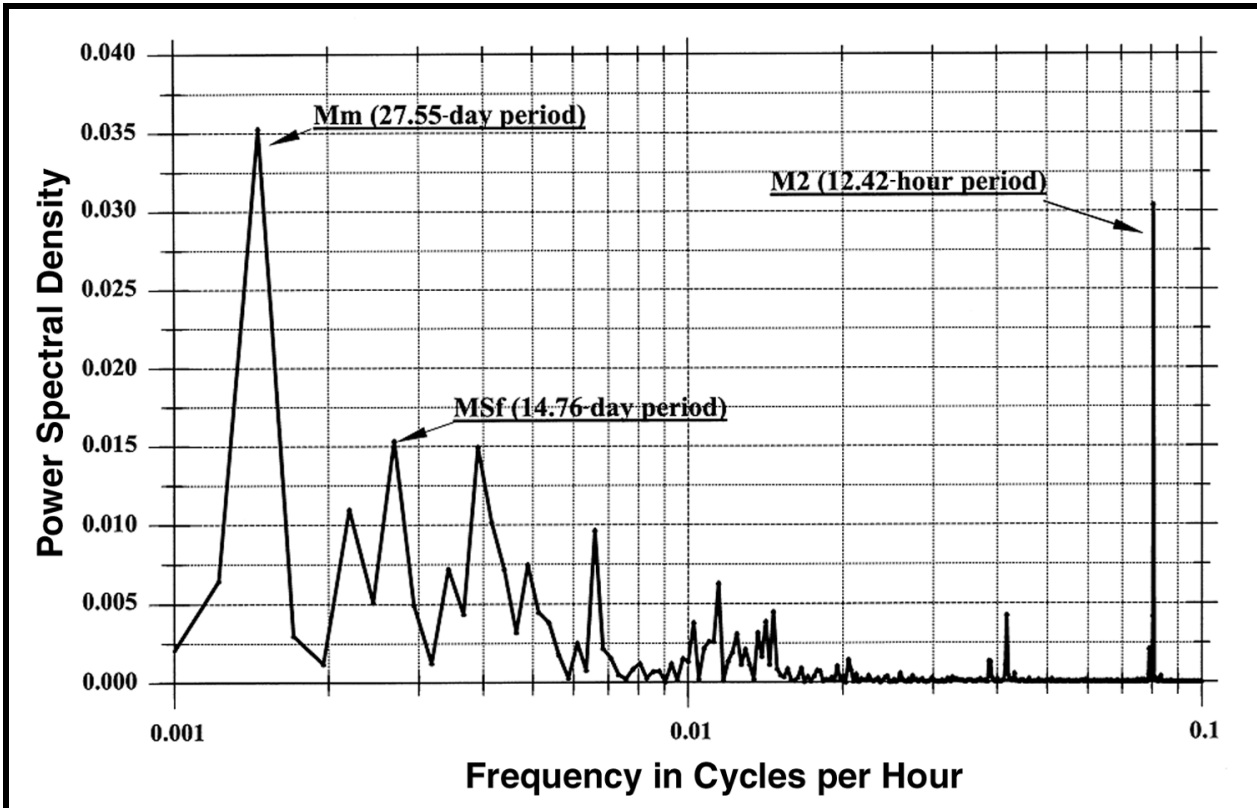

Figure 20. Power spectral density versus frequency for Bayshore hourly water elevations between Day 50 and Day 207 of 1994

be related to the limitation of ebb flow discharge through the channel during spring tides. Friction effects on maximum ebb flow limit the amount of water that can leave the bay. Since flood flows tend to be more efficient due to greater depths, with peak flood flow occurring at high water as shown in Figure 18, this combination of events leads to an accumulation of water during spring tides. This is also noted from spectral analysis of the tidal elevation record, the lunisolar synodic fortnightly lunar long-period cycle $\left(\mathrm{MS}_{\mathrm{f}}\right)$ component (Figure 20). The $\mathrm{MS}_{\mathrm{f}}$ component has a period of 14.76 days and a power density of about 50 percent of the M2 component. Others have seen this response in inlets that have a fairly high attenuation of the bay tide (Robinson et al. 1983; Aubrey and Speer 1985; Hill 1994). This may be one of several factors that cause bay superelevation.

Figure 21 shows ebb and flood tidal prism variation with tide range. The ebb curve has a flatter slope than the flood curve due to the friction limitation on ebb tidal prism. The ebb curve also shows stronger correlation between tidal prism and tide range (ebb correlation is 0.66 and flood correlation is 0.39 ). This can be attributed to greater variation in ocean high water to bay elevation that drives flood currents, and to less variation in ocean low water to bay elevation that drives ebb currents. The tabulation in Figure 21 shows that average spring flood prisms are greater than ebb while mean conditions have balanced prisms, and neap flood prisms are slightly greater than ebb (due to a significant wind event affecting the average).

\section{Ebb and flood flow duration}

Analysis of the 34-day velocity data set provided information on ebb and flood flow duration. Figure 22 shows the ebb and flood durations along with tide 


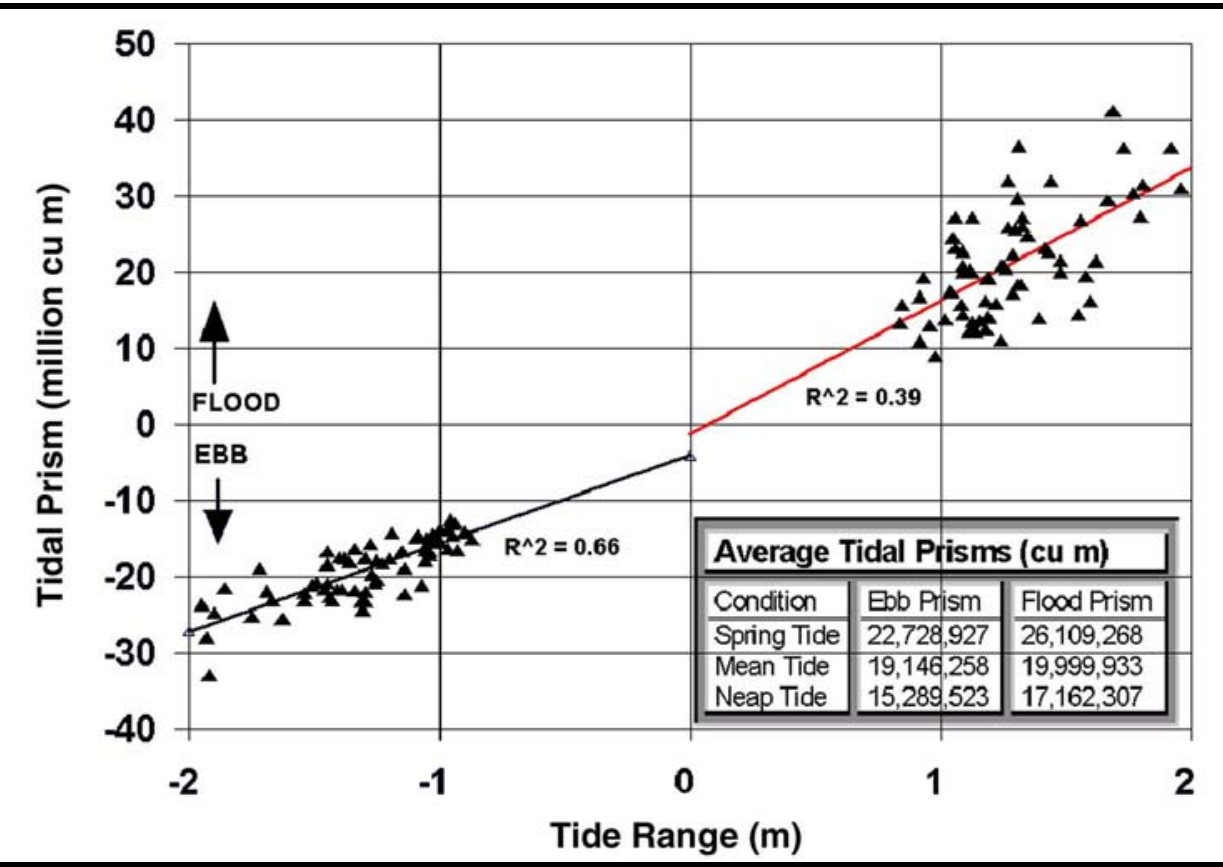

Figure 21. Ebb and flood tidal prism variation with tide range at Barnegat Inlet during May-June 1994

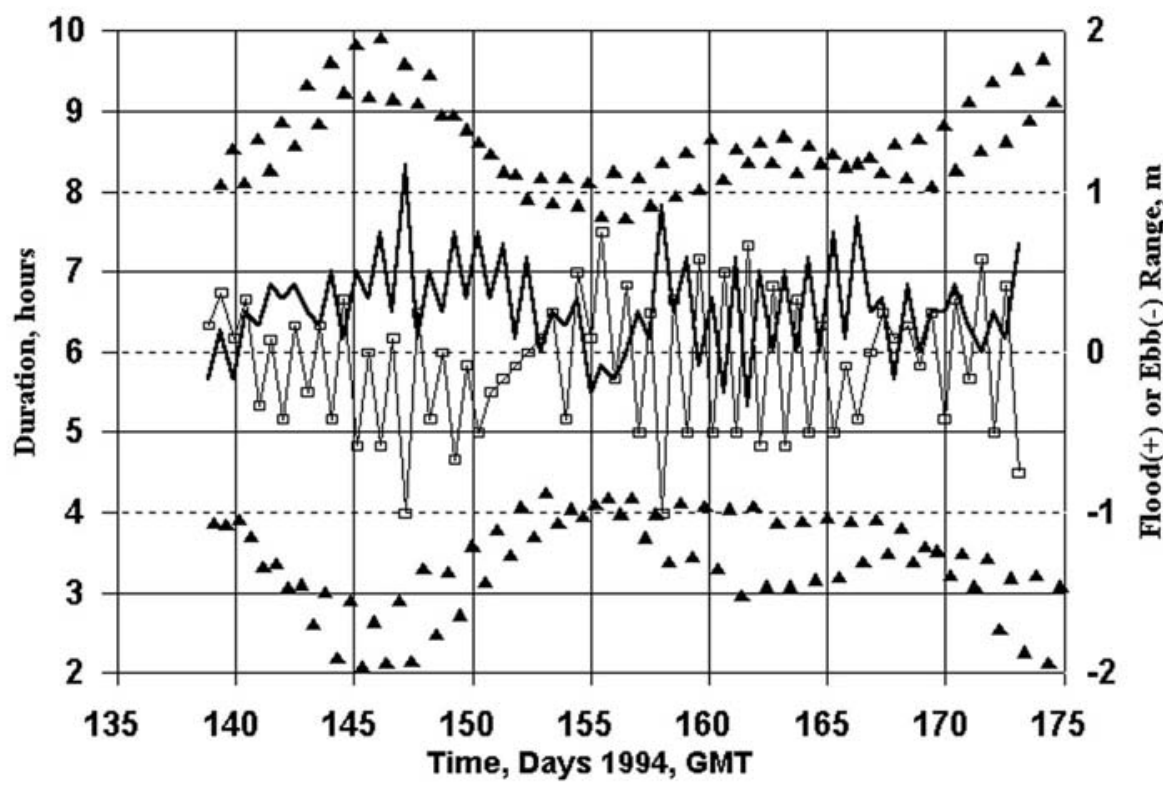

Ebb Duration,hrs $\rightarrow$ Flood Duration,hrs \ Ebb/Flood Range, $m$

Figure 22. Duration of ebb and flood flow and range of ebb and flood tide, during May-June 1994 at Barnegat Inlet 
range. Ebb flow durations are typically longer than the more efficient flood flow. Average ebb duration is $6.44 \mathrm{hr}$, and average flood duration is $5.99 \mathrm{hr}$. Flood and ebb durations varied with tide range. The longest ebbs and shortest flood flows occur at spring tides, and longer floods and shorter ebbs are more likely to occur at neap tides. This variation was not strongly dependent on the winds, but wind effects can create longer ebbs or floods.

Figure 23 shows that ebb flow duration correlated fairly well $\left(\mathrm{R}^{2}=0.41\right)$ with tide range while flood flow duration was not very well correlated $\left(\mathrm{R}^{2}=0.03\right)$ $\left(\mathrm{R}^{2}\right.$ is the statistical correlation coefficient). This again relates to the greater ebb duration with increasing tide range while flood duration is more dependent on other factors such as winds and the larger variability of high water elevations. The ebb phase lag (time between low water in the ocean and slack water in the inlet entrance channel) averaged $3.61 \mathrm{hr}$, while the flood phase lag was $3.18 \mathrm{hr}$. Note that phase lag varied with tide range, with spring tides having maximum ebb phase lags (over $4 \mathrm{hr}$ ), and spring flood phase lags being occasionally lower than $2.5 \mathrm{hr}$. At neap tide, the trend was reversed, with flood phase lag sometimes greater than ebb phase lag (with flood lag values over $4 \mathrm{hr}$ and ebb phase lags as low as $2.75 \mathrm{hr}$ ).

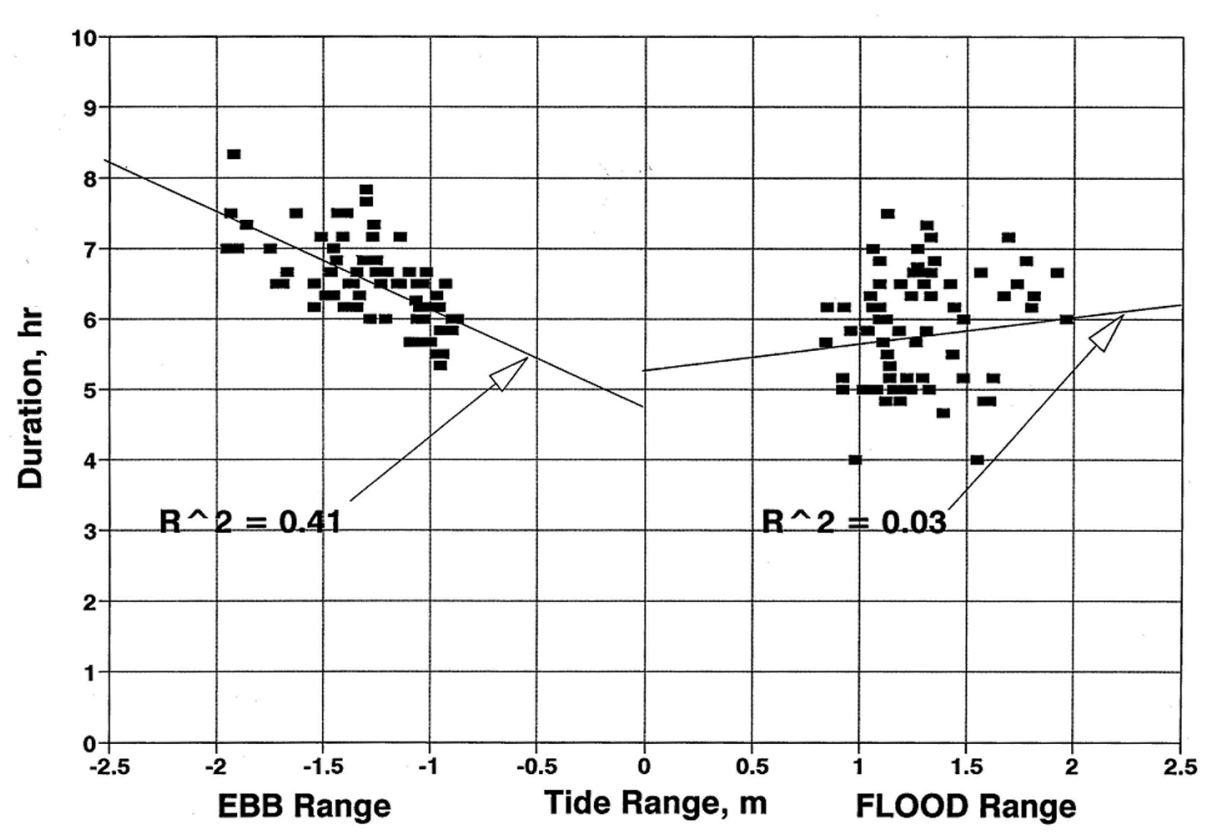

Figure 23. Variation of ebb and flood duration versus tide range during MayJune 1994 at Barnegat Inlet, NJ

\section{Comparison to historical tidal prism}

Tidal prisms computed from this MCNP data collection effort were compared with historical spring or mean tidal prisms (Table 2; Figure 24). Here can be seen the large variation in tidal prism and inlet cross-sectional area for the engineered history of the inlet. Note that each of these values is a tidal prism measurement for 1 day in the spring-neap cycle and, therefore, represents only 


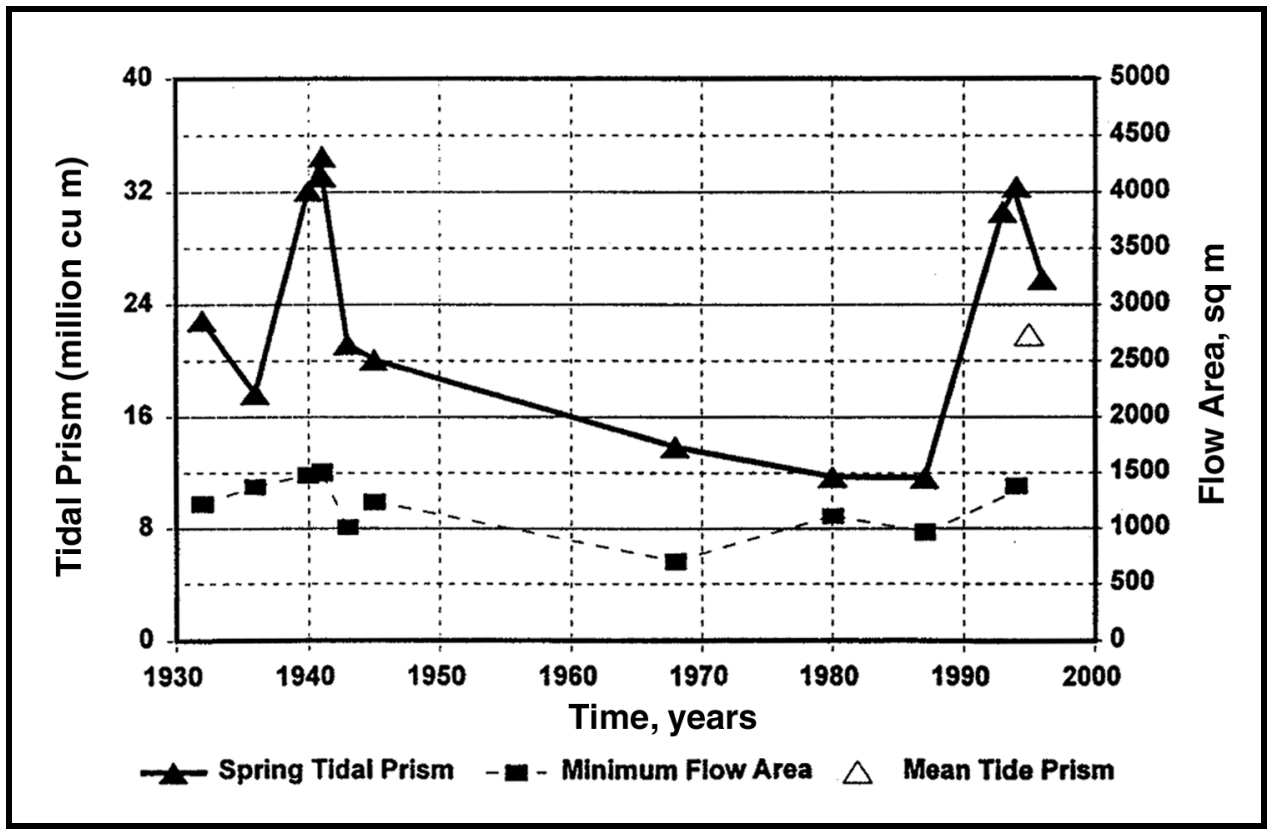

Figure 24. Tidal prism and minimum flow area between 1932 and 1995

the prism on that particular day. Also the areas presented are at the location of measurements, and are reasonably close to the minimum or control area. Historically, after construction of the jetties in 1939-40, there was a dramatic 81 percent increase in tidal prism, probably due to the increased cross-sectional area dredged for the project. After construction of the sand dike in 1943, there was a decrease in tidal prism because flow through the old main channel was cut off (Figure 2). This MCNP data collection and analysis indicate that the inlet cross-sectional area and tidal prism have returned to values similar to those of the early engineered history of the project, 28 to $42 \times 10^{6} \mathrm{cu}$ yd ( 21 to $32 \times 10^{6} \mathrm{cu}$ $\mathrm{m})$. The increase in tidal prism is due to the increased cross-sectional area dredged for the project and to channel straightening. The longer term velocity data collection was used to determine the range of tidal prisms for 34 days, and indicated that the tidal prism measured on 21 June 1994 was one of the most extreme spring tidal prisms, $54 \times 10^{6} \mathrm{cu}$ yd $\left(41 \times 10^{6} \mathrm{cu} \mathrm{m}\right)$. The average spring tidal prism from the longer term data collected was $34 \times 10^{6} \mathrm{cu}$ yd $\left(26 \times 10^{6} \mathrm{cu}\right.$ $\mathrm{m})$ for flood, and $29.7 \times 10^{6} \mathrm{cu}$ yd $\left(22.7 \times 10^{6} \mathrm{cu} \mathrm{m}\right)$ for ebb. The longer term averages all indicated that there was an increase in tidal prism since completion of the most recent project. Averages of the spring, mean, neap, and all tidal prisms for the long-term data set are higher than the 1987 (preproject) spring tidal prism determined by Ashley (1987).

\section{Potential sediment transport analysis}

The depth-averaged velocity time-series was analyzed to determine if the sediment transport of the inlet was ebb- or flood-dominated. Assuming an average grain size of approximately $0.25 \mathrm{~mm}$ for inlet channel sediments (Stauble and Cialone 1995), and using Shields criteria, the minimum velocity to induce bedload transport is $0.4 \mathrm{ft}$ per $\sec (12 \mathrm{~cm}$ per $\mathrm{sec})$. Furthermore, assuming 
sediment transport is proportional to velocity squared $\left(Q \propto V^{2}\right)$, a sediment transport time-series can be computed from the velocity time-series. Figure 25 shows, for a spring tide condition at Transect $\mathrm{C}$, the entire 34-day ADCP velocity time-series (Figure 25a) and the corresponding entire sediment transport timeseries (Figure 25c). Figures 25b and 25d are enlargements of Days 170 through 173 from Figures $25 \mathrm{a}$ and $25 \mathrm{c}$, respectively. Figure 26 depicts the velocity timeseries, the direction of transport, and the sediment transport time-series for a neap tide condition (Days 151 through 154) during the same 34-day ADCP data acquisition time period.

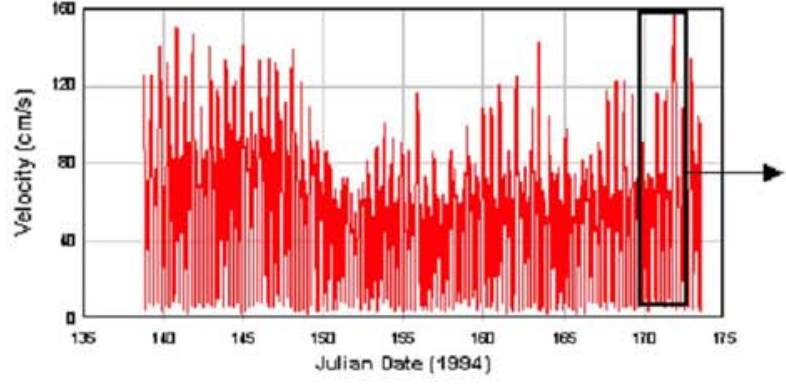

a. Entire 34-day velocity time-history of bottom-mounted ADCP

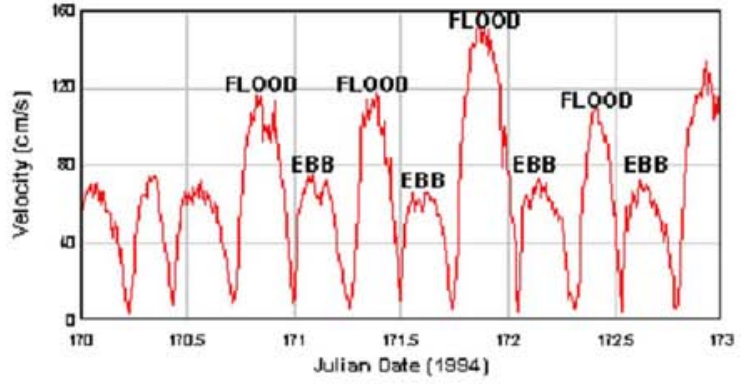

b. Enlargement of the velocity time-history for Days 170 to 173

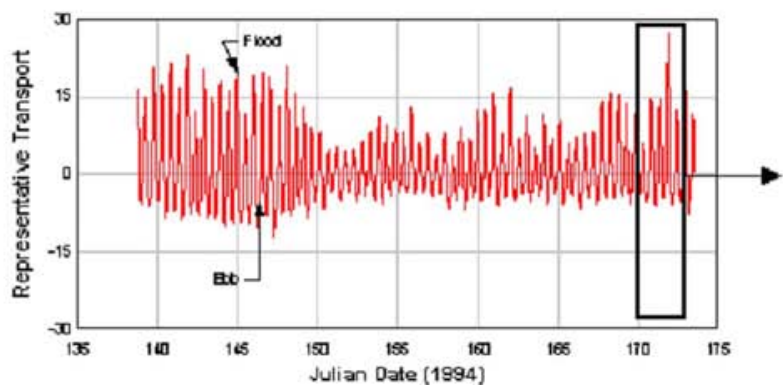

c. Corresponding entire 34-day sediment transport time-history

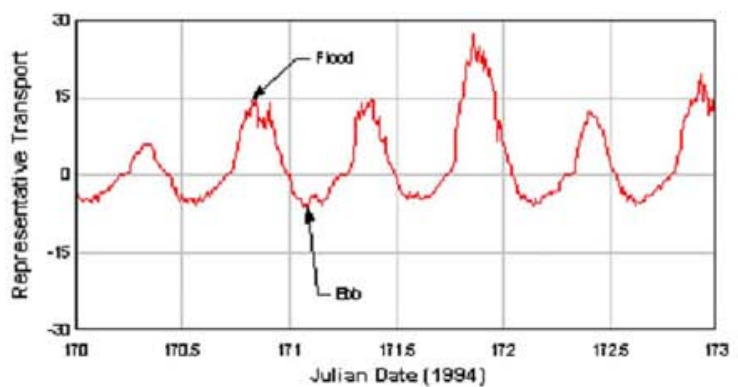

d. Enlargement of the sediment transport timehistory for Days 170 to 173

Figure 25. Spring tide conditions at Transect C

During spring tide, where flood velocities greatly exceed ebb velocities, flood dominance of sediment transport is observed. During neap conditions, where flows are more nearly in balance, sediment transport is more evenly distributed and net transport is slightly ebb-dominated due to longer ebb durations. Analysis of the entire 34-day record indicates that the cumulative sediment transport is flood-dominated at the location of the meter. It is interesting to note that residual velocities (or average velocity vectors) computed from the depth-averaged timeseries and from each bin show a slight ebb residual of $0.2 \mathrm{ft}$ per $\mathrm{sec}(6 \mathrm{~cm}$ per $\mathrm{sec})$; however, ebb velocities are lower and therefore less able to transport sediment. 

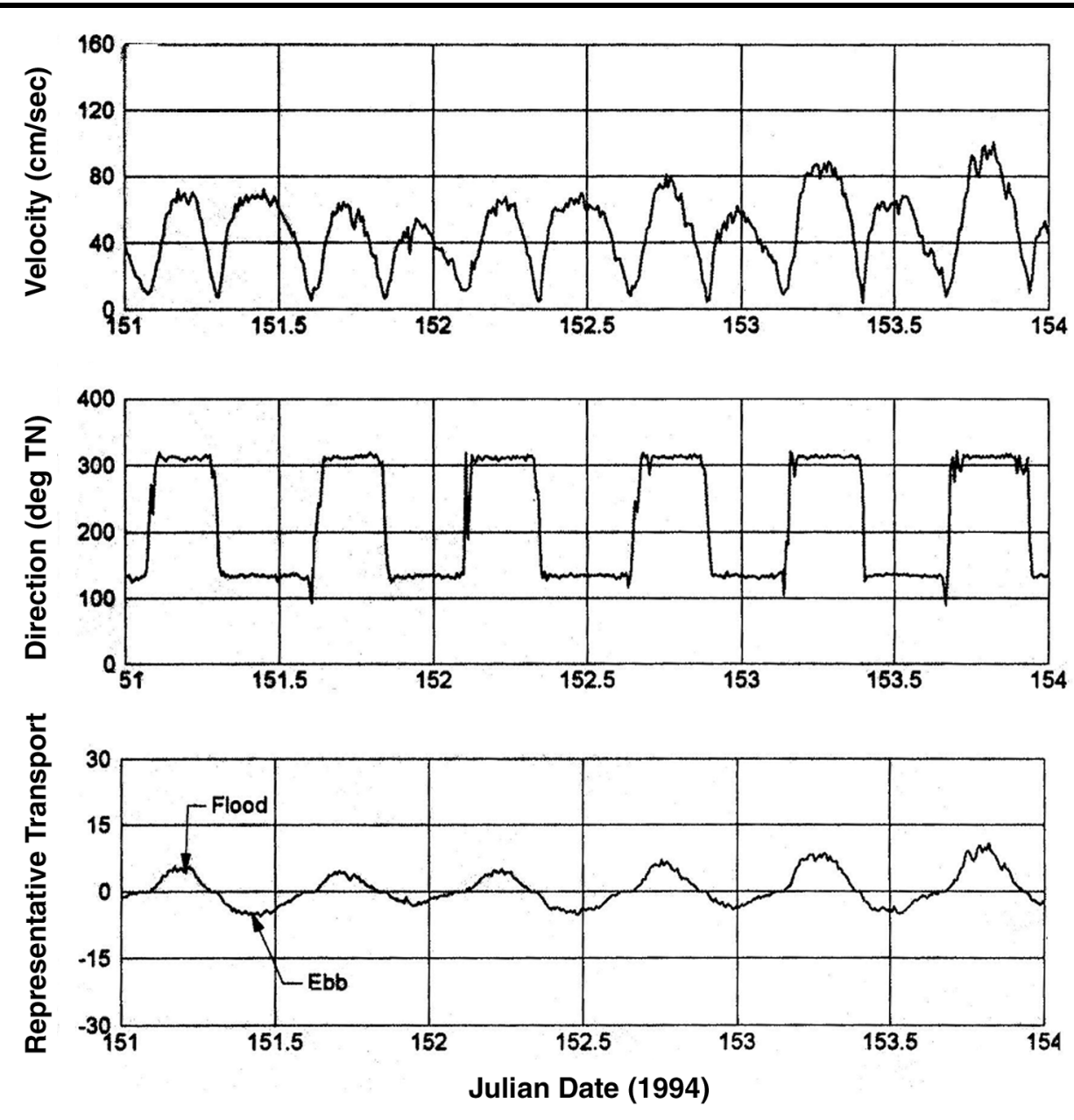

Figure 26. Neap tide conditions at Transect C, Days 151 through 154 of the 34-day ADCP data acquisition, showing velocity time-series, corresponding direction of transport, and sediment transport time-series

\section{Summary of New South Jetty Effects on Hydraulics}

\section{Engineering activities}

Engineering activities have significantly affected the dynamics of Barnegat Inlet, New Jersey. Mean tide level arrowhead jetties were completed in 1939-40. In 1943 a sand dike eliminated one interior channel, reduced flow through the inlet, and reduced the minimum cross-sectional area. The north jetty was raised and made impermeable in 1974. Numerous dredging activities in the 1970s and 1980s were needed to keep the inlet navigable. More recently a new south jetty was constructed parallel to the north jetty in 1991. 


\section{Tidal prisms}

Tidal prisms based on velocity measurements in the 1990s indicate that the inlet has returned to prism magnitudes measured in the preproject 1930s and early project years of the 1940s. Detailed, short-term ADCP measurements indicate that spring tide prisms range up to $42.4 \times 10^{6} \mathrm{cu}$ yd $\left(32.4 \times 10^{6} \mathrm{cu} \mathrm{m}\right)$. Early $1940 \mathrm{~s}$ measurements were as high as $45 \times 10^{6} \mathrm{cu}$ yd $\left(34.5 \times 10^{6} \mathrm{cu} \mathrm{m}\right)$. This agreement follows naturally from the similarity between the $1930 \mathrm{~s}$ and 1990 s bay tide range measurements. In contrast, late 1960s to 1980 s prisms measured 14 to $18 \times 10^{6} \mathrm{cu}$ yd ( 11 to $14 \times 10^{6} \mathrm{cu} \mathrm{m}$ ) when the inlet was more choked. This change in prism from the 1980s to the 1990s is accounted for by a 40 percent increase in minimum channel cross-sectional area due to dredging for the present project, and to the raised jetties limiting longshore sediment from entering the channel. The oceanward side of the inlet gorge between the jetties is much deeper for the high parallel jetty system (keeping sediment out and promoting channel efficiency through higher velocities) than for the lowelevation arrowhead jetty system of the $1960-80$ s. In contrast, late 1960 s to 1980s prisms were much smaller due to sediment influx over the low arrowhead jetties that reduced the minimum cross-sectional area.

The 34-day tidal prism data derived from an ADCP moored on the channel bottom in an upward-facing direction indicates that a fairly wide range of tidal prism magnitudes can occur, depending on the tide range and wind conditions. Variation for ebb tidal prisms was between 16 and $43 \times 10^{6} \mathrm{cu}$ yd (12.5 and $\left.33.0 \times 10^{6} \mathrm{cu} \mathrm{m}\right)$, and for flood prisms was between 11.6 and $54.0 \times 10^{6} \mathrm{cu} \mathrm{yd}$ $\left(8.9\right.$ and $\left.41.3 \times 10^{6} \mathrm{cu} \mathrm{m}\right)$. Wind conditions were a factor in all the extreme cases. Strong winds along the channel axis (northwest and southwest) contributed to maximum extremes in tidal prism. Strong southerly winds along the longitudinal bay axis existed for each minimum tidal prism.

\section{Tidal constituents}

Tidal constituents at the USCG station on the bay side of the jetty system indicate an increase in flood dominance and greater admittance into Barnegat Bay since completion of the new south jetty compared with the arrowhead jetty configuration. This is due to an increase in minimum cross-sectional area in the jetty region and to channel straightening and deepening. However, when the most recent jetty configuration is compared to the prestabilized inlet tides (1932), bay tide ranges for the present conditions are very similar, being in the range of 0.4 to $0.6 \mathrm{ft}(0.13$ to $0.17 \mathrm{~m})$. Bay tide range decreased when the arrowhead (mean tide level crest elevation) jetties and sand dike were constructed, then increased after jetty elevations were raised and the minimum cross-sectional area increased by dredging. A Fast Fourier Transform of the bay tide indicates that the strongest periodicity occurs monthly, in phase with the largest monthly maximum spring tide. The secondary spring tide energy (14.5-day periodicity) is nearly equal in magnitude to the bay semidiurnal tide energy.

\section{Inlet dynamics}

The hydraulic condition at Barnegat Inlet indicates a small bay tide range of 0.3 to $0.7 \mathrm{ft}$ ( 0.1 to $0.2 \mathrm{~m}$ ) relative to the ocean tide, due to the large bay size in relation to the inlet cross-sectional area at the throat. Maximum flood flow in the entrance channel occurs near ocean high water elevations, and maximum ebb 
flow occurs near ocean low water elevations. This leads to ebb flow that is longer in duration than flood flow due to the increase in friction for ebb flow moving through a smaller, shallower cross-sectional area. This effect is even larger for spring tide conditions since the extreme low and high water elevations reduce ebb flow to a larger degree and enhance flood flow, respectively. Friction attenuates ebb velocities, creating a limiting discharge value of about $45,900 \mathrm{cu} \mathrm{ft}$ per sec $(1,300 \mathrm{cu} \mathrm{m}$ per sec). In contrast, the predominant flood currents have greater variability. Maximum flood flows are as much as 60 percent greater than maximum ebb flow discharges. As neap tide ranges are approached, ebb predominance occurs as flood flow falls below the ebb threshold. Water stored in the bay during spring tide is gradually released to the ocean during the transition from spring to neap tide. The flood flow predominance of spring tides and accompanying inability to fully drain during ebb flow due to the maximum discharge capacity of the channel create a net storage in the bay until the transition from spring to neap tide. At that time there is a net outflow. The duration of ebb flow typically reaches its maximum during spring tide, as the increased superelevation of the bay creates a greater bay-to-ocean elevation gradient for a greater portion of the tidal cycle than exists during neap tides.

\section{Wind effects}

The effect of wind can change the typical trends for ebb and flood flow duration, net bay inflow and outflow, and tidal prism magnitude. Winds along the channel axis can enhance bay inflows and outflows. Winds from the southeast and east enhance flood tidal prism and extend duration. Winds from the south can enhance ebb tidal prism and duration, possibly introducing some water from the south (through the intracoastal waterway and surrounding marshy regions). However, winds from the south can also minimize ebb tidal prism if the tidal phasing and southerly wind duration are such that northerly bay setup and wind stress on the bay impede ebb flow. Winds from the northwest increase ebb tidal prism. Variation for ebb tidal prisms was between 16.3 and $43.1 \times 10^{6}$ cu yd $\left(12.5\right.$ and $\left.33.0 \times 10^{6} \mathrm{cu} \mathrm{m}\right)$, and for flood prisms was between 11.6 and $54.0 \times 10^{6} \mathrm{cu}$ yd $\left(8.9\right.$ and $\left.41.3 \times 10^{6} \mathrm{cu} \mathrm{m}\right)$. Wind conditions were a factor in all the extreme prism events. Strong winds along the channel axis (northwest and southwest) contributed to maximum extremes in tidal prism. Strong southerly winds along the longitudinal bay axis existed for each minimum tidal prism.

The effects of winds on the bay tide elevations can also be significant, especially considering that the average bay tide range is only $0.4 \mathrm{ft}(0.12 \mathrm{~m})$. When winds were from the south and southwest, the northern portion of Barnegat Bay was superelevated by as much as $0.40 \mathrm{~m}(1.3 \mathrm{ft})$. Winds from the north, northeast, and northwest reverse the head difference, elevating the southern portion of Barnegat Bay up to $0.8 \mathrm{ft}(0.24 \mathrm{~m})$.

\section{Flow distribution}

Flow distribution through the navigation channel and over the flood shoal are similar for mean and spring conditions. Approximately two-thirds of the ebb flow exited through the interior navigation channel and one-third exited over the flood shoal. Flood flow entering into the bay for mean tide conditions indicated about 56 percent of the flow entered over the flood shoal, and 44 percent moved through the interior navigation channel adjacent to Barnegat Lighthouse. This 
compares with 65 percent entering over the flood shoal and 35 percent entering through the channel for spring tide flood flow conditions. Flood flows at the seaward end of the inlet are strongest near the south jetty. Near the inner part of the intra-jetty area, flood flows are strongest on the north side of the inlet. On ebb the trends are reversed. For spring tide, flow in the intra-jetty region showed higher average peak flood velocities, indicating local flood dominance. Overall mean conditions were nearly balanced, with a slight flood dominance.

\section{Flood and ebb currents}

Analysis of the 34-day bottom-mounted ADCP data showed that the lower magnitude ebb velocities are more uniform over depth (linear distribution), whereas the higher flood velocities have a logarithmic distribution over the same depth range. Flood tide conditions resulted in significantly larger average velocities of $1.0 \mathrm{ft}(0.3 \mathrm{~m})$ per sec greater. Flood and ebb velocities are directed somewhat toward the south jetty due to structural and bathymetric controls. The weir section at the oceanward end of the north jetty and greater adjacent seaward depths relative to the south approach to the inlet help direct flood flow toward the south side of the intra-jetty region. Ebb currents exiting through the intra-jetty region from the bay, once past this region, expand seaward of the intra-jetty shoal and are somewhat directed toward the south jetty.

\section{Sediment transport}

During spring tide, where flood velocities greatly exceed ebb velocities, flood dominance of potential sediment transport is implied. During neap conditions, where flows are more nearly in balance, sediment transport magnitude estimates are more evenly distributed, and net transport is slightly ebb-dominated due to longer ebb durations. Analysis of the entire 34-day record indicates that the cumulative sediment transport potential is flood-dominated.

\section{Flood flow dominance}

Flow dominance has been characterized in a number of ways. Through harmonic analysis of tidal elevation and through the relative magnitude of M2 and M4 components, a gross resultant of dominance can be determined. Through detailed current measurements at a control cross section (e.g., minimum crosssectional area of inlet), a flow dominance characterization also can be determined that will be dependent on state of the tide (spring, mean, neap), and possibly on whether it is in an ascending or descending mode. A continual current data collection period (at least a fortnightly period of time) combined with a sediment transport model will produce a better examination of flow dominance at an inlet. Analysis of the entire 34-day record indicates that the cumulative sediment transport at the gauge location is flood-dominated. However, even with this characterization of flow and sediment dominance, care must be taken in evaluation due to flow field variation across the cross section combined with locations or sources of sediment being introduced into the inlet.

Short-term ADCP data collection and analysis conducted since completion of the project showed that the distributions of velocities are consistent for mean and spring conditions. Approximately two-thirds (64-71 percent) of the ebb flow exited through the interior navigation channel, and one-third (29-36 percent) exited over the flood shoal. Flood flow entering the bay for mean tide conditions 
indicated about 56 percent of the flow entered over the flood shoal region, and about 44 percent entered through the interior navigation channel adjacent to Barnegat Lighthouse. This compares with 65 percent over the flood shoal and 35 percent through the channel for spring tide flood flow conditions. Flood flows at the seaward end of the inlet (Transect $\mathrm{C}$ ) are strongest near the south jetty. Flood velocities near the inner part of the intra-jetty area (base of Barnegat Lighthouse, Transect B) are strongest on the north side of the inlet. Flood velocities at Transect $\mathrm{A}$ are strongest close to the flood shoal. This trend shows that flood velocities follow the navigation channel. On ebb, however, the trends are reversed: the southern side of Transects $\mathrm{A}$ and $\mathrm{B}$ and the northern side of Transect $\mathrm{C}$ have stronger velocities.

For spring tide conditions, Transect $\mathrm{C}$ has higher average peak flood velocities (indicating local flood dominance), and Transect B has higher average peak ebb velocities (indicating local ebb dominance). Overall mean conditions are nearly balanced, with a slight ebb dominance. The strong flood dominance at Transect $\mathrm{C}$ for spring tide conditions indicates the potential for sediment movement into the intra-jetty region. However, Transect B showed ebb dominance, also indicating the potential for sediment movement into the intra-jetty region. These findings support shoal development in the intra-jetty region. The strong spring tidal flood dominance indicates that Barnegat Inlet is a flood-dominated inlet. 


\section{Effects of New South Jetty on Channel Stability and Dredging}

Barnegat Inlet, New Jersey, has undergone a variety of structural changes in an attempt to provide a navigable channel from bay to ocean. These structures have included shoreline revetments, arrowhead jetties with their crest elevation at mean water level, a sand dike to better align interior channel flow, a raised impermeable north jetty, and finally a new south jetty essentially parallel with the north jetty. Each of these structures has had significant influence on inlet hydraulics and sedimentation, which in turn has impacted channel location (Seabergh et al. 1996).

Project design Hypothesis 2 states that the new south jetty will improve navigation safety by stabilizing the navigation channel location and depth between the jetties and over the outer bar (ebb tidal shoal), and will eliminate dredging in these regions. The new south jetty will help maintain interior channel location (bayward of Barnegat Lighthouse on the edge of the flood tidal shoal), with a channel shoaling rate of $60,000 \mathrm{cu}$ yd $(46,000 \mathrm{cu} \mathrm{m})$ per year. Sediment placement in the area between the old and new south jetties during construction of the new south jetty does not affect channel shoaling.

\section{Impact of Structures on Inlet Channel Location}

The arrowhead jetties were constructed in the late 1930s, followed in 1943 by a sand dike in the adjacent bay that caused a redirection of flow from the channel south of the flood shoal. Important in understanding the response of the inlet channel in this time frame were the low crest elevations of the jetties at mean tide level. These jetties were functioning as weir jetties, which allowed tidal flow, wave-generated currents, and sand to be transported over these inlet structures. This resulted in creation of sand spits at the inlet gorge and became a new control for channel location, withstanding many dredging attempts to control channel position. During a 20-year period, the sinuous channel was completely inverted as this new regime interacted with structural controls. The aerial photography of Figure 27, taken in August 1944, shows the arrowhead jetties at high tide level, the sand dike across the channel south of the flood shoal, and the new channel dredged through the flood shoal. Figure 28 (aerial photograph taken in October 1964) shows the formation of the sand spit between the arrowhead jetties. 


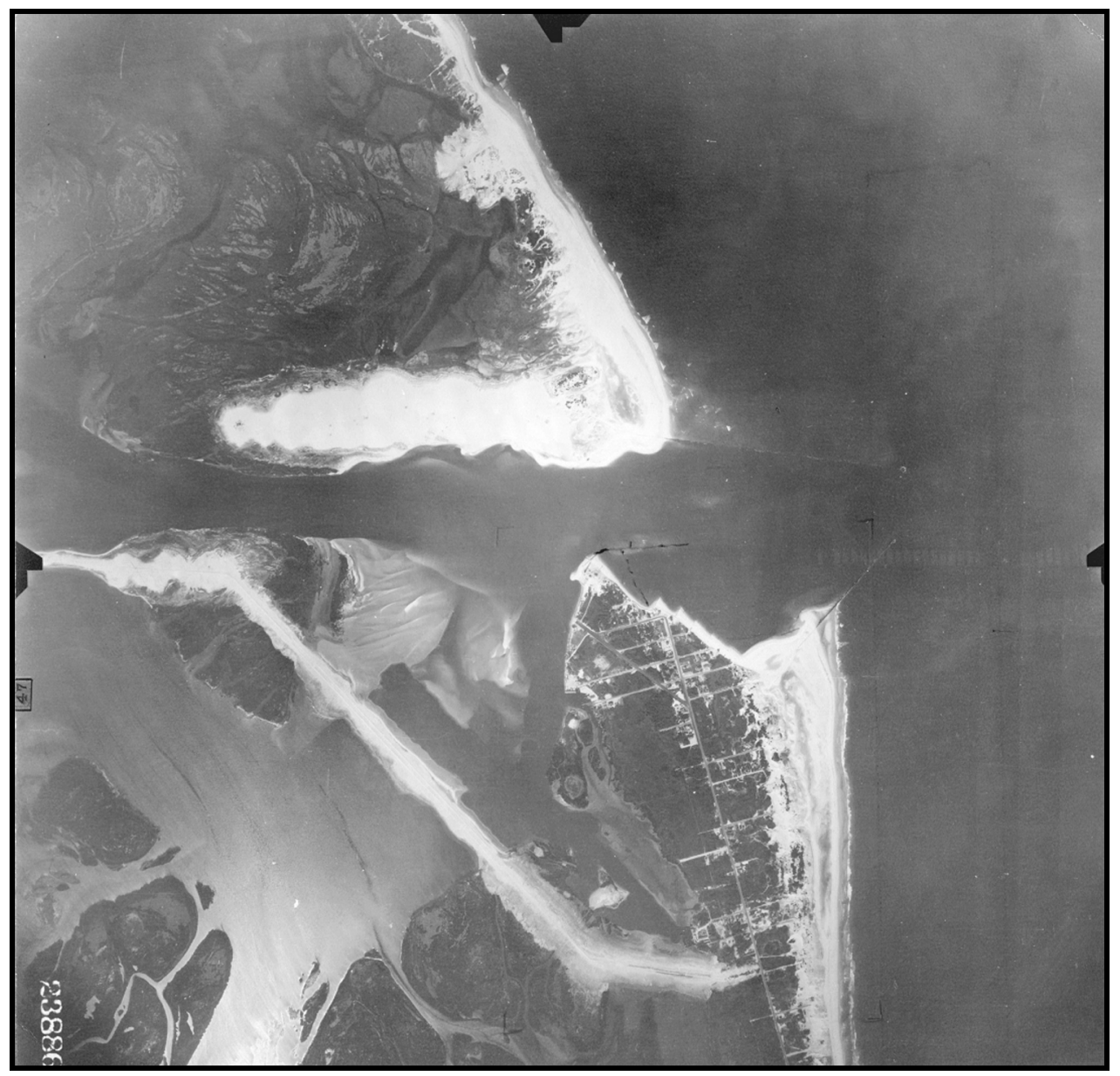

Figure 27. Arrowhead jetties at high tide level, the sand dike across the channel south of the flood shoal, and the new channel dredged through the flood shoal, photo August 1944

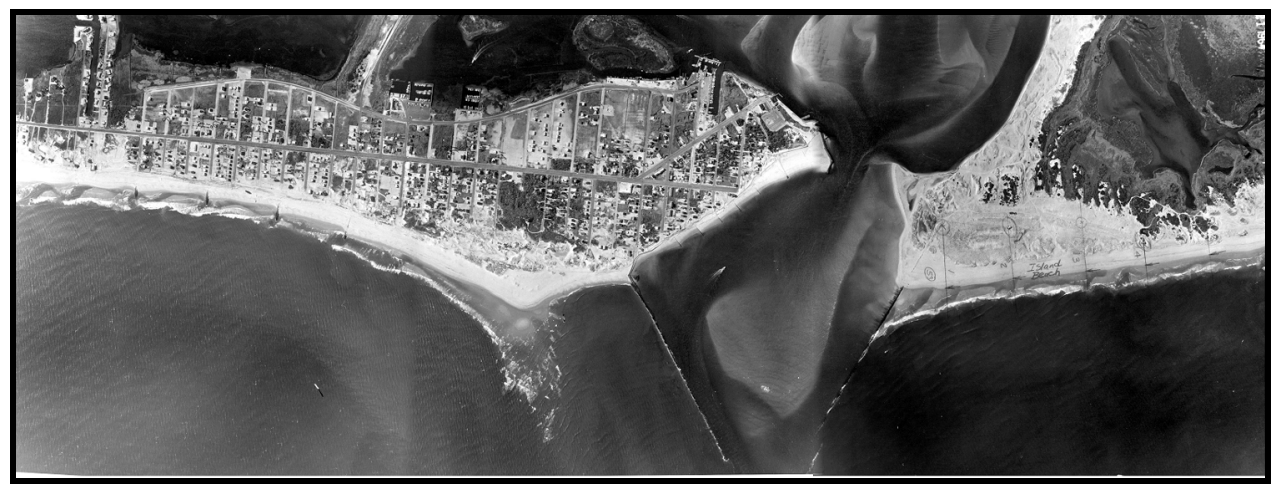

Figure 28. Sand spit accumulation between arrowhead jetties, photo October 1964 
In the 1970s, a sequence of steps to improve channel dynamics was developed from a physical model study (Sager and Hollyfield 1974), which included raising the north jetty and making it impermeable, plus the addition of a new south jetty essentially paralleling the existing north jetty. In 1972-74, the north jetty was raised $5.9 \mathrm{ft}(1.8 \mathrm{~m})$. Sand was diverted offshore along the impermeable jetty, and growth of the ebb shoal resulted. The channels adjusted to a reduction of sediment from the north beach. Figure 29 (aerial photograph taken in March 1988 before construction of the new south jetty) shows the manner in which the dredged channel through the flood shoal has filled and the shoal reformed.

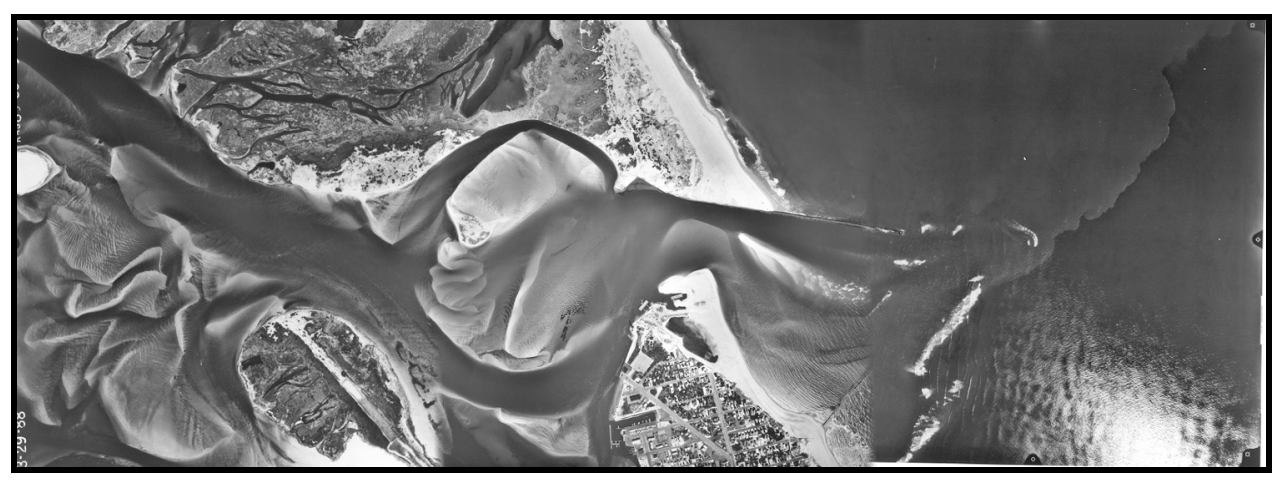

Figure 29. Filling of dredged channel through the flood shoal and reformation of the flood shoal immediately before construction of new south jetty, photo March 1988

A significant amount of dredging was done in the late 1970s to maintain the channel at the inlet throat. However, the increase in ebb shoal volume created additional maintenance dredging in that location. Another phase suggested by the model study was implemented beginning in 1989, with the construction of a new south jetty located within the arrowhead system. Figure 30 (aerial photograph taken in October 1991) shows the new south jetty and the flood

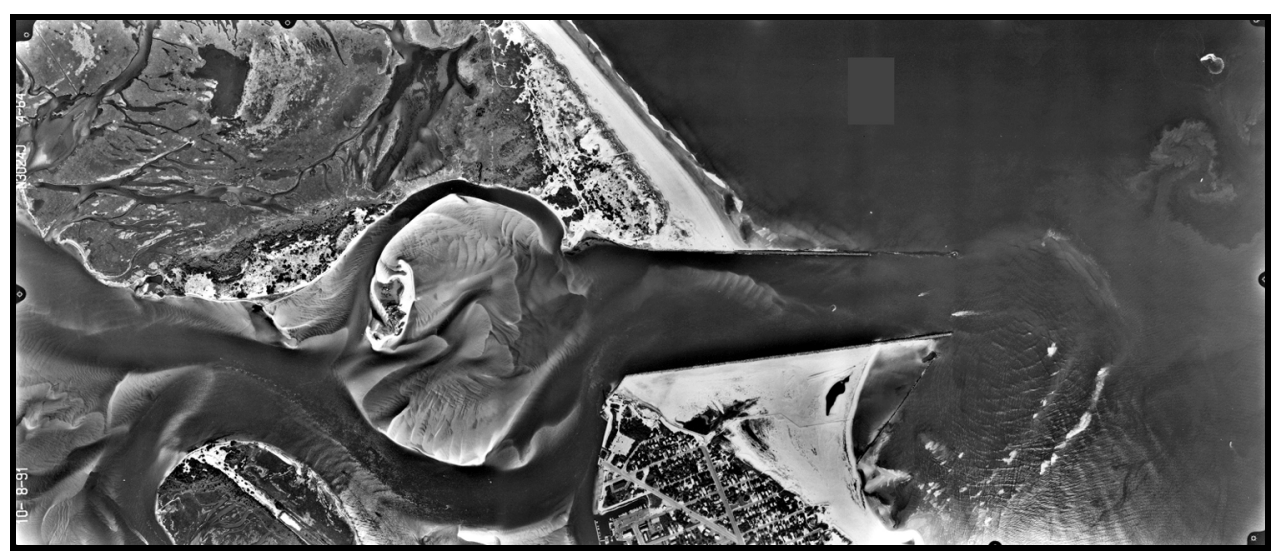

Figure 30. Flood shoal and entrance channel alignment after construction of new south jetty, photo October 1991 
shoal. This jetty paralleled the original north jetty and replaced the original low south jetty. Upon completion of the project, this MCNP monitoring study was initiated to understand the response of the navigation channel to the most recent inlet structures. However, in order to do so, an understanding of the historic interaction of the channel and structures was also necessary. Figure 31 (aerial photograph taken in June 1992 immediately prior to initiation of this MCNP monitoring study) shows the extensive flood shoal and waves being reformed by the ebb shoal in the ocean in front of the inlet.

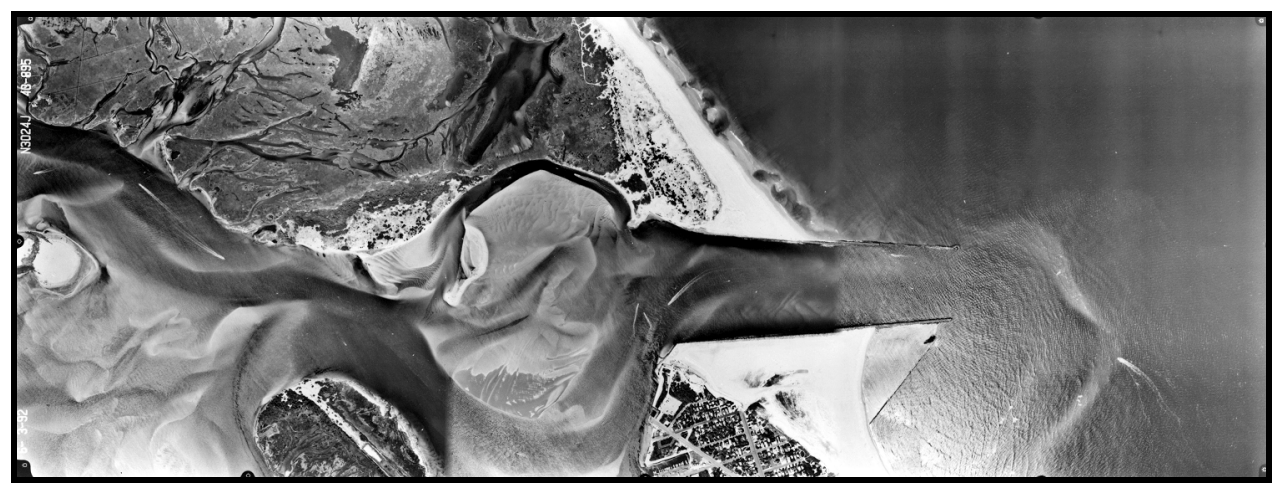

Figure 31. Extensive flood shoal and waves being reformed by the ebb shoal in the ocean in front of the inlet, photo June 1992

A more extensive set of historical photos of Barnegat Inlet, NJ, change chronology is presented in Appendix A.

\section{Physical factors}

The inlet separates Island Beach, a spit to the north, from Long Beach Island, a barrier island to the south. These barriers are characterized by medium-to-fine sand. Within the inlet region, medium-to-fine sands $(0.25-0.5 \mathrm{~mm})$ are on both the ebb and flood shoals, and coarser sands $(0.50-1.0 \mathrm{~mm})$ are in the deeper channel areas (Stauble and Cialone 1995). The inlet provides access for commercial fishermen, day fishing excursion boats, and small craft. The inlet design channel is $300 \mathrm{ft}(91.5 \mathrm{~m})$ wide by $10 \mathrm{ft}(3 \mathrm{~m})$ deep mlw, extending through the ebb shoal. The mean ocean tide range is $4.2 \mathrm{ft}(1.28 \mathrm{~m})$, and mean wave height is $3.9 \mathrm{ft}(1.20 \mathrm{~m})$. Littoral transport estimates at the inlet are $1,100,000 \mathrm{cu}$ yd $(840,000 \mathrm{cu} \mathrm{m})$ per year gross transport, with a net of $144,000 \mathrm{cu}$ yd $(110,000 \mathrm{cu} \mathrm{m})$ per year to the south. These estimates are based on wave heights hindcast at the $65-\mathrm{ft}(20-\mathrm{m})$ contour near the inlet.

\section{Effect of inlet hydraulics on channel dynamics}

Throughout the recent history of Barnegat Inlet there has been the interaction of structures, changing both the sedimentation patterns and inlet hydrodynamics. The inlet system now contains four consecutive, fully developed shoal features (compared to the typical one ebb shoal and one flood shoal), with an ebb shoal seaward of the jetties, a shoal in the intra-jetty region (particularly evident for the arrowhead configuration), a large flood shoal contained by the sand dike, and a bay-side flood tidal delta where flow exits into Barnegat Bay (Figure 31).

Development of these shoals initially created a higher friction environment that, 
with the initial structural configuration, created increased sedimentation and a gradual decrease in tidal prism. Raising the north jetty reduced sediment input from the north beach and, coupled with dredging and the construction of the new south jetty, some flow efficiency was regained as evidenced by increased tidal prism.

Important in relating the channel response to inlet structures is an understanding of the inlet hydrodynamics. This inlet has maximum flood currents near high water elevations with maximum ebb currents near low water, and is typical for an inlet lagoon that has a very large surface area relative to the channel cross-sectional area. Essentially, the lagoon level fluctuates very little and the ocean tide range oscillates about that level, resulting in maximum head differences across the inlet near high and low waters. This phasing of flow relative to structure crest elevation and flow over shallow shoal areas is important to channel location. Figure 32 shows flow patterns for maximum ebb and flood flows as determined for 1968 conditions from the physical model study (Sager and Hollyfield 1974). For the mean tide level elevation jetties, maximum flood currents (strongest near high water) had a great potential for introducing sediment to the inlet system and, thus, the development of a large flood shoal complex. Low-water ebb currents are more channelized. This permits shoals to be more effective ebb shields (i.e., ebb flow will tend to be deflected around the shoal area if the shoal elevation is higher than low water). Also, maximum ebb flows at low water elevation can lead to incising of channels.

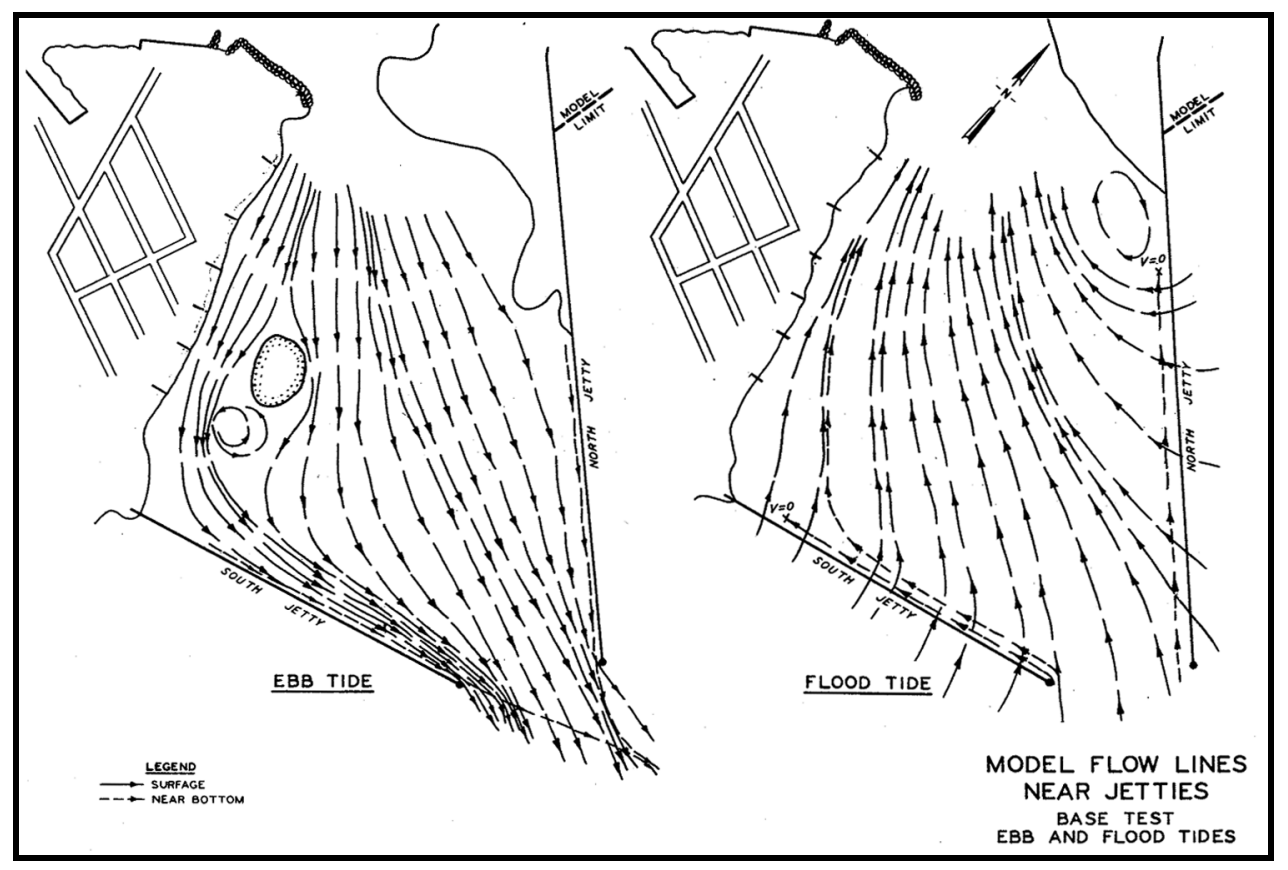

Figure 32. Physical model study flow lines for ebb and flood currents (after Sager and Hollyfield 1974) 


\section{Historic channel bathymetry analysis}

A review of historical bathymetry was performed to provide a basis for interpreting recent bathymetric changes at Barnegat Inlet and providing guidance to anticipate future changes. Historical information was derived from U.S. Army Engineer District, Philadelphia (1981), and Fields and Ashley (1987).

Pre-jetties. The 1937 (Figure 33a) prejetty inlet bathymetry shows that the interior channel swept south, then turned east-to-northeast to exit the inlet, then turned southeast on the ebb shoal in response to predominant waves from the northeast. The 1937 interior channel was more than 1,510 ft (460 m) southeast of its 1996 position. The channel probably owed its large curvature to the infilling of the natural inlet on its north side as the inlet and channel both migrated south. The predominant portion of the tidal prism exited the bay from the north, channelizing around the large flood shoals due to a strong ebb shield factor resulting from the hydraulic phasing of this inlet.

Arrowhead jetties. In 1939 arrowhead jetties were constructed and a channel about parallel to the north jetty was dredged into the bay in an attempt to provide a more direct route to the bay. Figure $33 \mathrm{~b}$ shows the new interior channel in 1941. Also note the deflection of the ocean channel resulting from having the south jetty placed directly in its path.

Sand dike. By 1943 (Figure 33c), the sand dike was constructed to cut off the strong ebb flow from the dominant interior channel that was causing excessive scour on the inside shoulder of the inlet behind Barnegat Lighthouse. It was anticipated that flow would be diverted to the straight interior channel, providing a deeper direct channel connecting ocean and bay. In addition, groins were constructed along the ocean shoreline inside the south jetty to mitigate shoreline erosion.

The 1946 bathymetry (Figure 34a) indicated a slight deflection of the navigation channel at the intersection of the inlet with the shoreline as sediment moved over the low jetties at this location. On the south side of this region there was a shoal extending seaward from the Barnegat Lighthouse area, probably derived from sediment moving toward the inlet gorge along the shoreline inside the south jetty, then deflecting seaward on ebb. A buildup of sand at the shoreline is noted just inside the south jetty indicating an influx from the south beaches.

By 1953 (Figure 34b), the main navigation channel had shifted slightly south and rotated somewhat to the southeast. Sediment was moving over the low north jetty into the inlet gorge region. The interior region between the inlet gorge and the north tip of the sand dike contained flood shoals and three smaller channels. On the ocean side of the inlet, the navigation channel was close to the north jetty, as it had been for the previous 10 years.

As of 1959 (Figure 34c) the navigation channel through the inlet gorge rotated away from the north jetty to the south, and a scour area reappeared adjacent to the outer portion of the south jetty. The influx of sediment over the north jetty contributed to this rotation. Interesting to note was the shifting of the deepest area at the bayward end of the sand dike, which moved to the southeast side (compared with earlier conditions). 


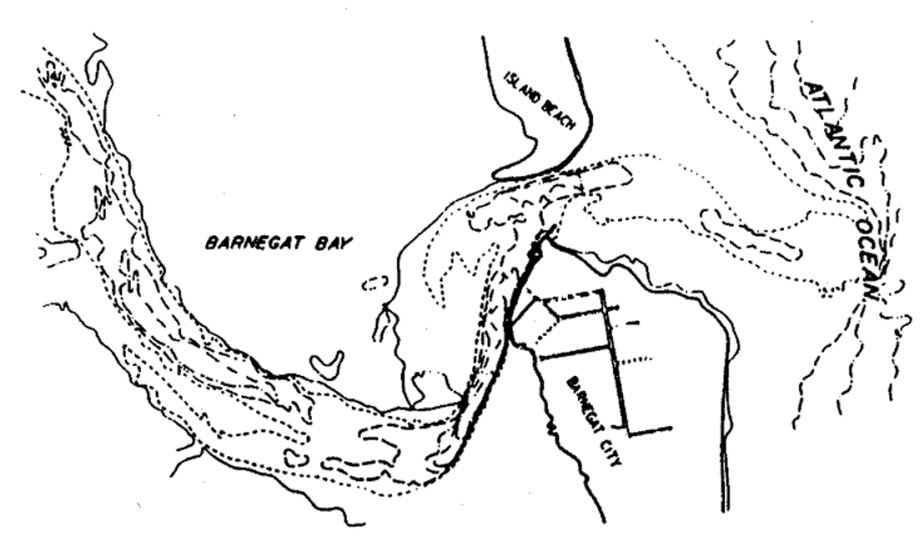

a. Jul-Aug 1937

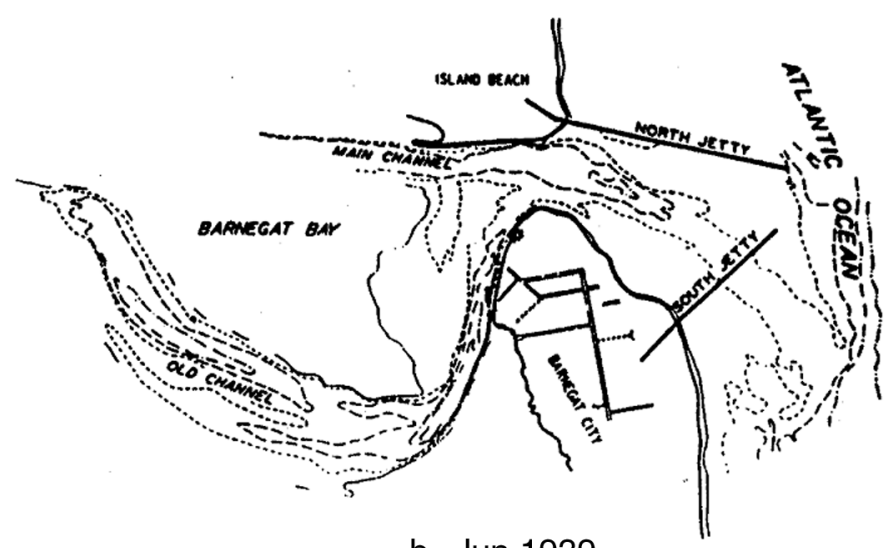

b. Jun 1939
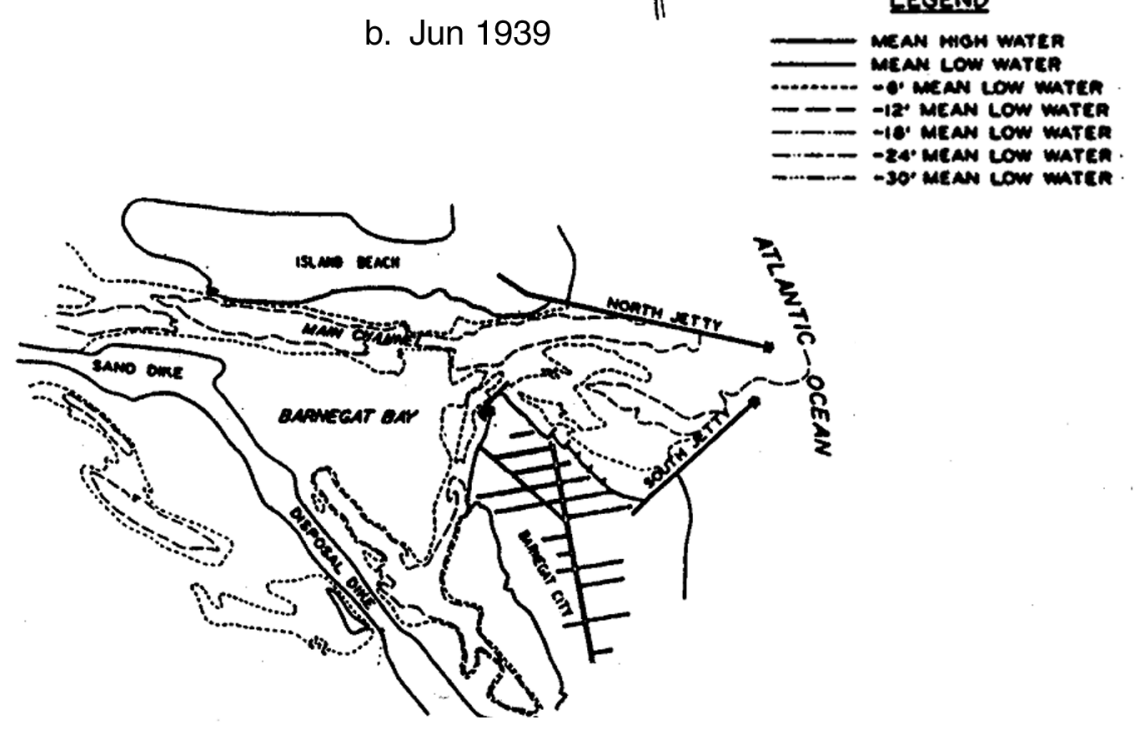

c. Sep-Oct 1943

Figure 33. Barnegat Inlet channel bathymetry, 1937-1943 (after Sager and Hollyfield 1974) 


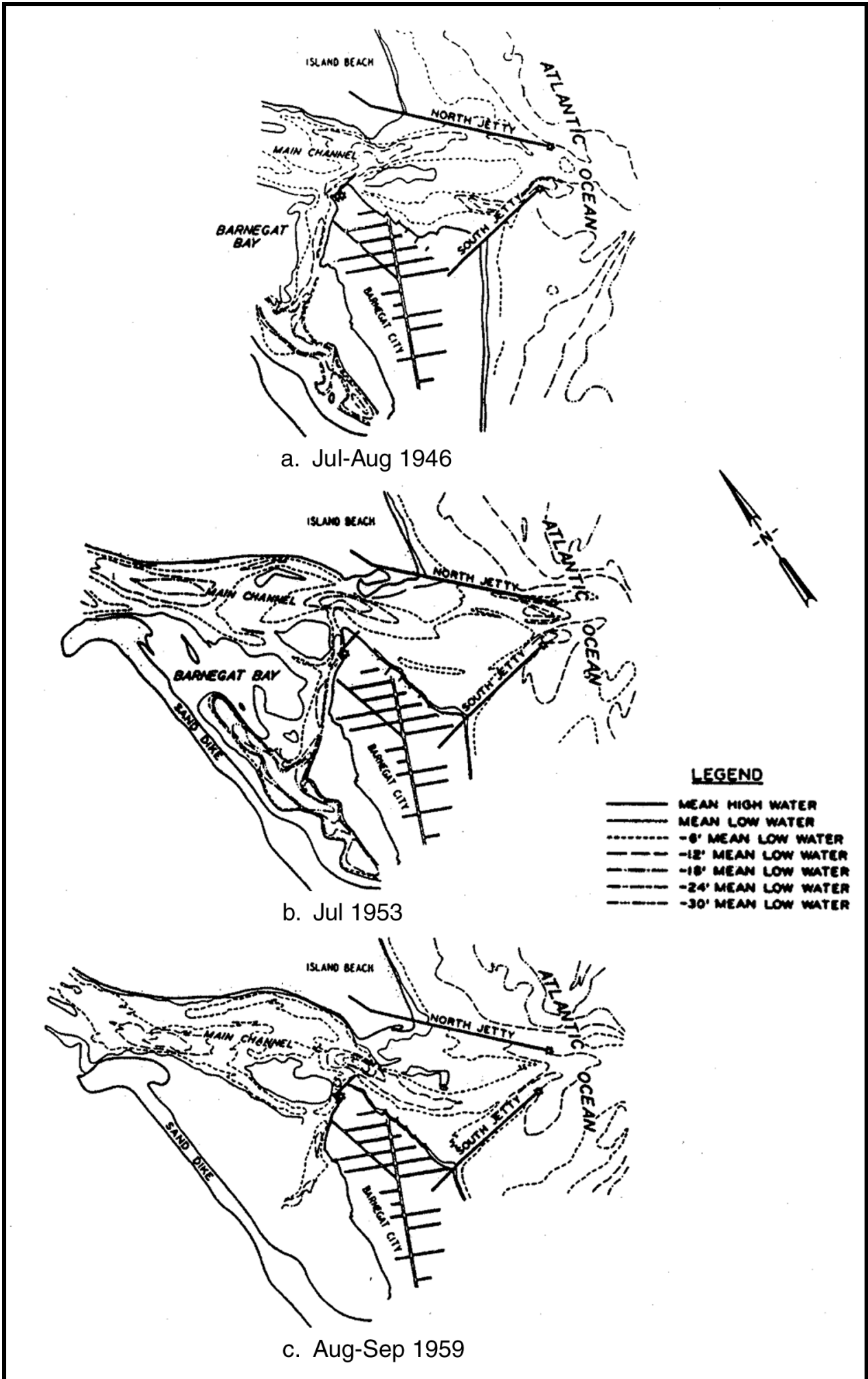

Figure 34. Barnegat Inlet channel bathymetry, 1946-1959 (after Sager and Hollyfield 1974) 
Year 1962 (Figure 35a) showed a new part of the flood shoal developing from sediment stripped from a spit that extended further from the north beachline into the inlet gorge. The minimum width of the inlet was reduced considerably due to sediment movement over the north jetty. The seaward portion of the channel migrated against the south jetty.

By 1968 (Figure 35b), the flood shoal occupied the location of the original dredged interior navigation channel. The interior channel was still bifurcated, but the region south of the flood shoal was widening and becoming the main interior ebb channel. It was forming in a similar configuration as was seen for the prejetties condition, except not as far southeast due to the presence of the sand dike. Sediment movement over the north jetty almost closed off the inlet gorge. The region between the arrowhead jetties was shoaling considerably, except for the channel that had migrated against the south jetty. This sinuous channel was eroding the ocean-facing shoreline inside the south jetty and creating toe erosion that endangered the integrity of the oceanward portion of the south jetty. The trend of flood shoal growth and interior channel shifting south continued until the north jetty was raised $5.9 \mathrm{ft}(1.8 \mathrm{~m})$ from its original mean tide level crest elevation in the 1972-74 period.

Raised north jetty. The 1975 bathymetry (Figure 35c) indicated a major reorientation of the navigation channel through the jetty region. Dredging at the inlet gorge, combined with cutting off sediment input by raising the north jetty, permitted a straighter channel that was more in alignment with, and closer to, the north jetty. This channel orientation is reinforced by a concept presented by Kieslich (1981) where a channel at a single-jettied inlet migrates toward the structure independent of whether or not the jetty structure is situated on the side of stronger longshore sediment drift. The Barnegat system probably can be considered a single jetty system in this respect due to the free flow of sediment and currents over the mean tide level south jetty, which helps move the channel toward the single north jetty.

Raising the north jetty caused a significant change in sediment pathways. The ebb shoal began to increase in magnitude (Figure 36a). This most likely can be attributed to the movement of sediment along the outside of the north jetty. This sediment previously had passed over the landward end of the low north jetty and contributed to flood shoal building and the movement of the inlet gorge toward the south. The same trend of channel alignment seen in the 1970s continued through the 1980s (Figure 36b). The interior navigation channel moved more toward its preproject (1930s) location, and the channel between the jetties was concentrated on the north side adjacent to the raised north jetty. This configuration was maintained until the construction of a new south jetty between late 1987 and 1991.

\section{Hydraulic response to new south jetty}

In order to build the new south jetty (Figure 3 ) from the revetted region on the south shoulder of the inlet beneath the Barnegat Lighthouse, shallow shoals were removed from this region. The inlet system became more efficient hydraulically due to an increase in minimum cross-sectional area that resulted from this shoal removal. This follows from O'Brien's (1969) relation between minimum inlet 


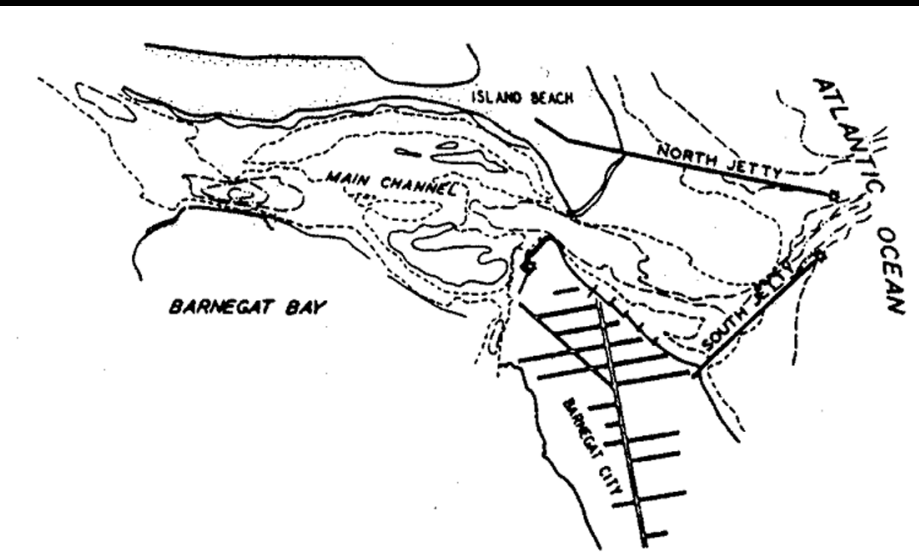

a. Jun-Jul 1962
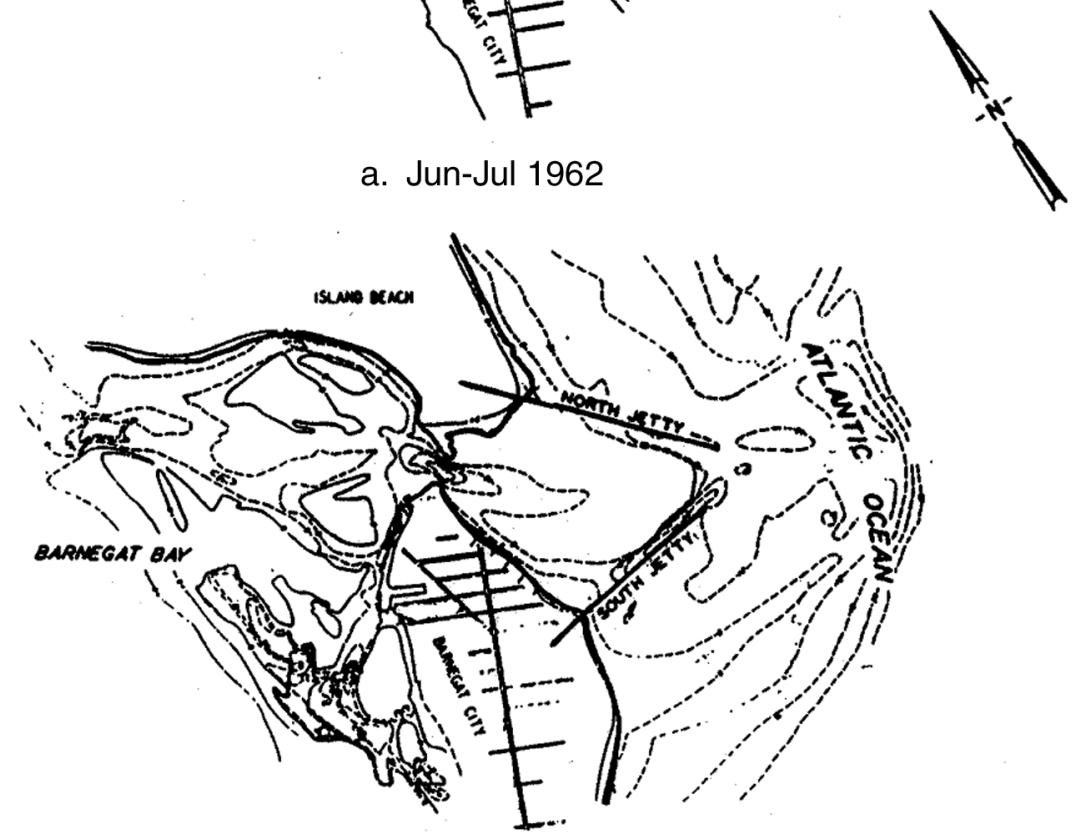

b. Apr-May 1968

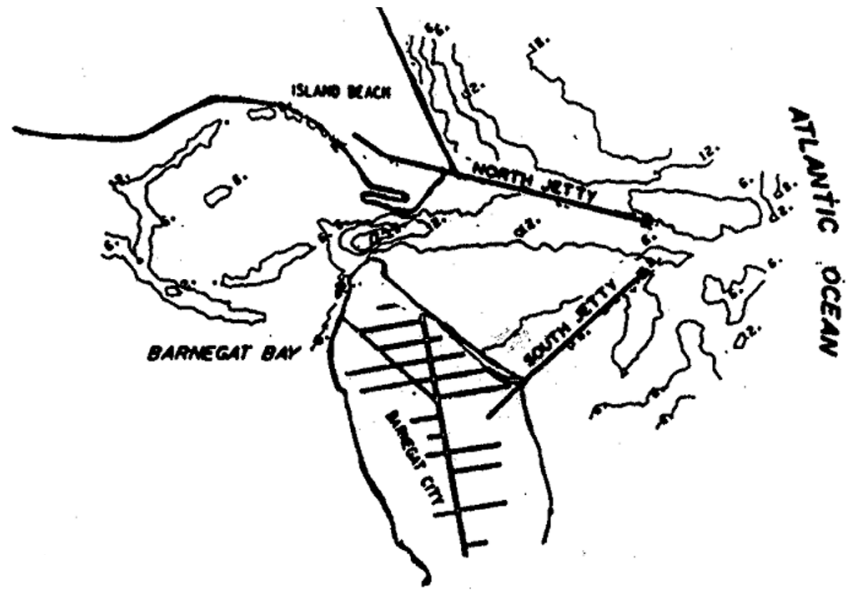

c. Dec 1975

Figure 35. Barnegat Inlet channel bathymetry, 1962-1975 (Figure 35a after Sager and Hollyfield 1974; Figures 35b and 35c are unpublished maps provided by U.S. Army Engineer District, Philadelphia) 


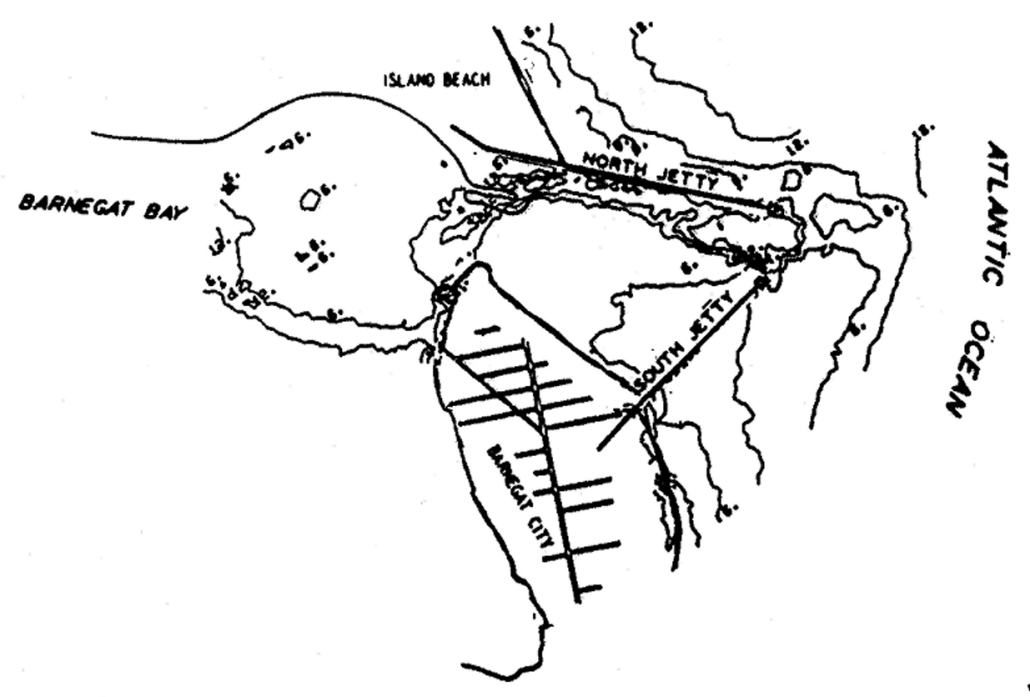

a. Jun 1979
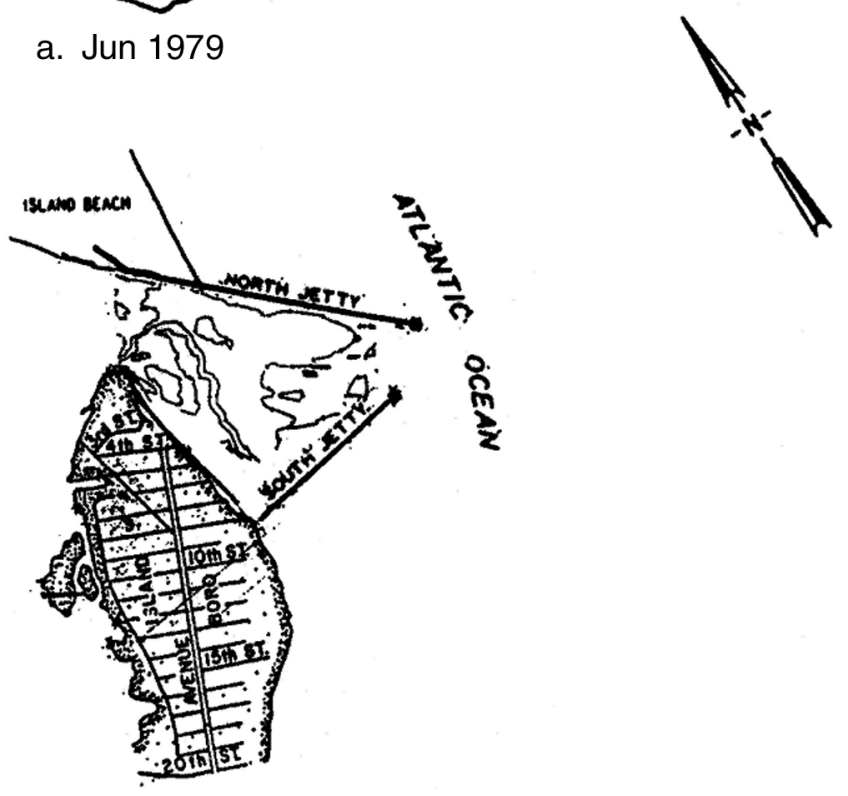

b. Dec 1986

Figure 36. Barnegat Inlet channel bathymetry, 1979-1986 (unpublished maps provided by U.S. Army Engineer District, Philadelphia)

area, $A_{C}(\mathrm{sq} \mathrm{m})$, and tidal prism, $P(\mathrm{cu} \mathrm{m})$, at dual jettied systems: $A_{C}=7.489 \times$ $10^{-4} P^{0.86}$. With minimal sediment entering the inlet system, the increase in prism has been maintained since completion of the new south jetty. Figure 24 shows the variation in prism for the duration of the project. After the construction of jetties (1941), the inlet initially had the same tidal prism as the natural inlet, but the addition of the inside sand dike (Figure 2) lengthened the inlet channel, and the newly dredged interior navigation channel had a reduced channel area compared to the old sinuous one. Sediment influx reduced areas and, thus, prism. The new south jetty prevented the influx of sediments that had 
previously occurred for the low south jetty and so the new, larger, minimum area has been maintained.

\section{Channel response to new south jetty}

Analysis of the channel response to the most recent addition of the new 4,270-ft-(1,300-m-) long south jetty reveals what appears to be an evolutionary change in channel depth in the region between the north jetty and new south jetty (Figures 37 and 38). The net sediment mass is translating bayward in the region of the parallel jetties. An important aspect of this is the flood dominance of currents on the south side of the intra-jetty region of the channel. Flood currents tend to enter the inlet region from the north jetty side (due to greater ebb shoal depth on the north and shallower ebb shoal depth on the south side), and sweep toward the south jetty. Also the outer $1,000 \mathrm{ft}(305 \mathrm{~m})$ of the north jetty remains at the mean tide level elevation, permitting maximum flood currents to flow over this low section into the channel perpendicular to flow coming through the oceanward jetty tips. This also helps guide flood currents to the south side of the intra-jetty region.

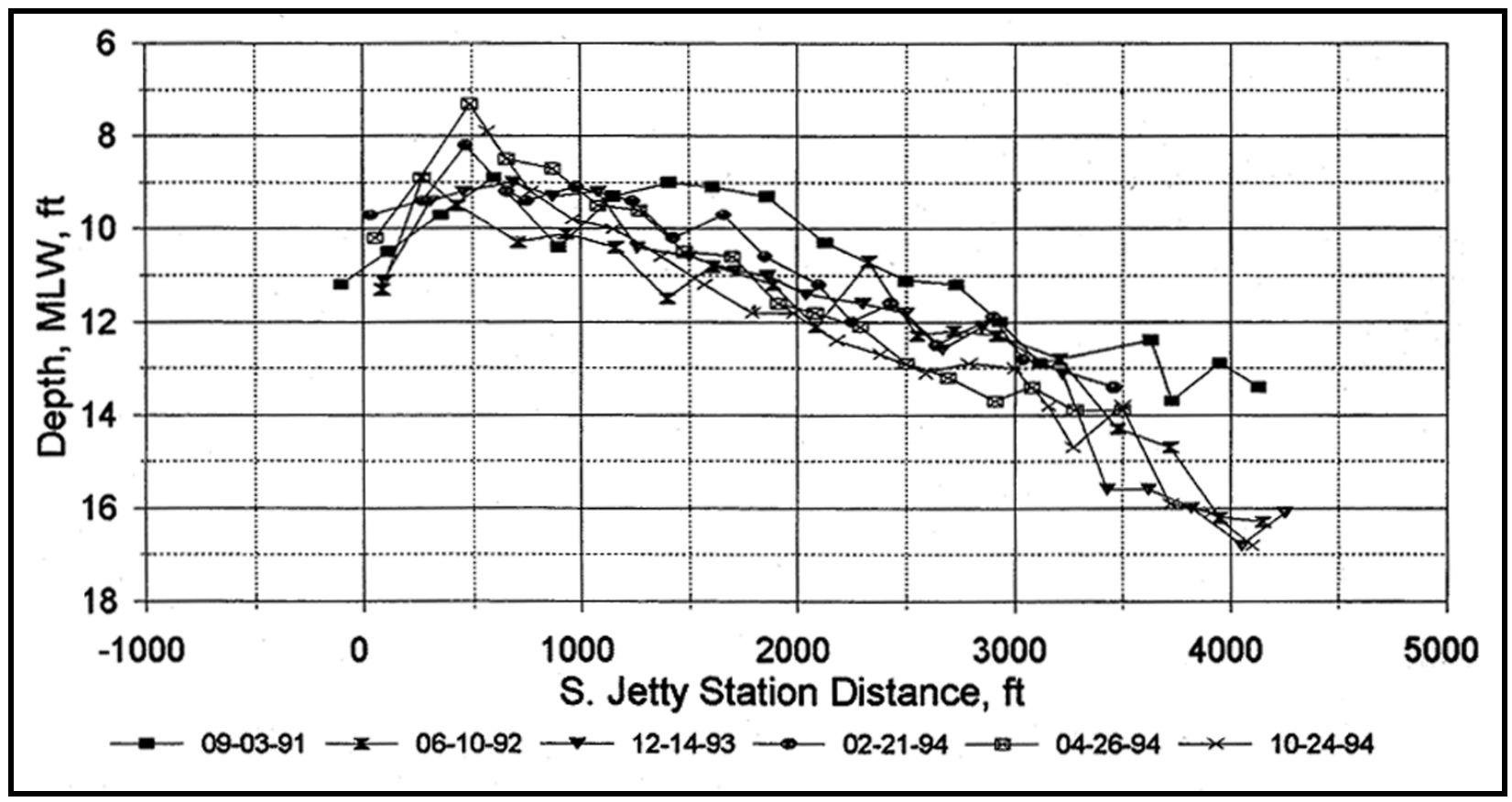

Figure 37. Average channel depths between jetties, 1991-1994 (to convert feet to meters, multiply by 0.3048)

The occurrence of a shoal region between stations 200 and 600 is essentially a nodal point between ebb and flood flow dominance. Flood flow pushes sediment through the channel mostly on the south side, as revealed by velocity distribution measurements obtained during the period 1994-96. Ebb currents from the curved interior channel shear this shoal, and sediment moves along the north side of the shoal (where ebb flows are concentrated) toward the ocean. Dredging of the channel shoal and, evidently, a net oceanward sediment circulation out of the intra-jetty region have caused a progressively deeper channel. 


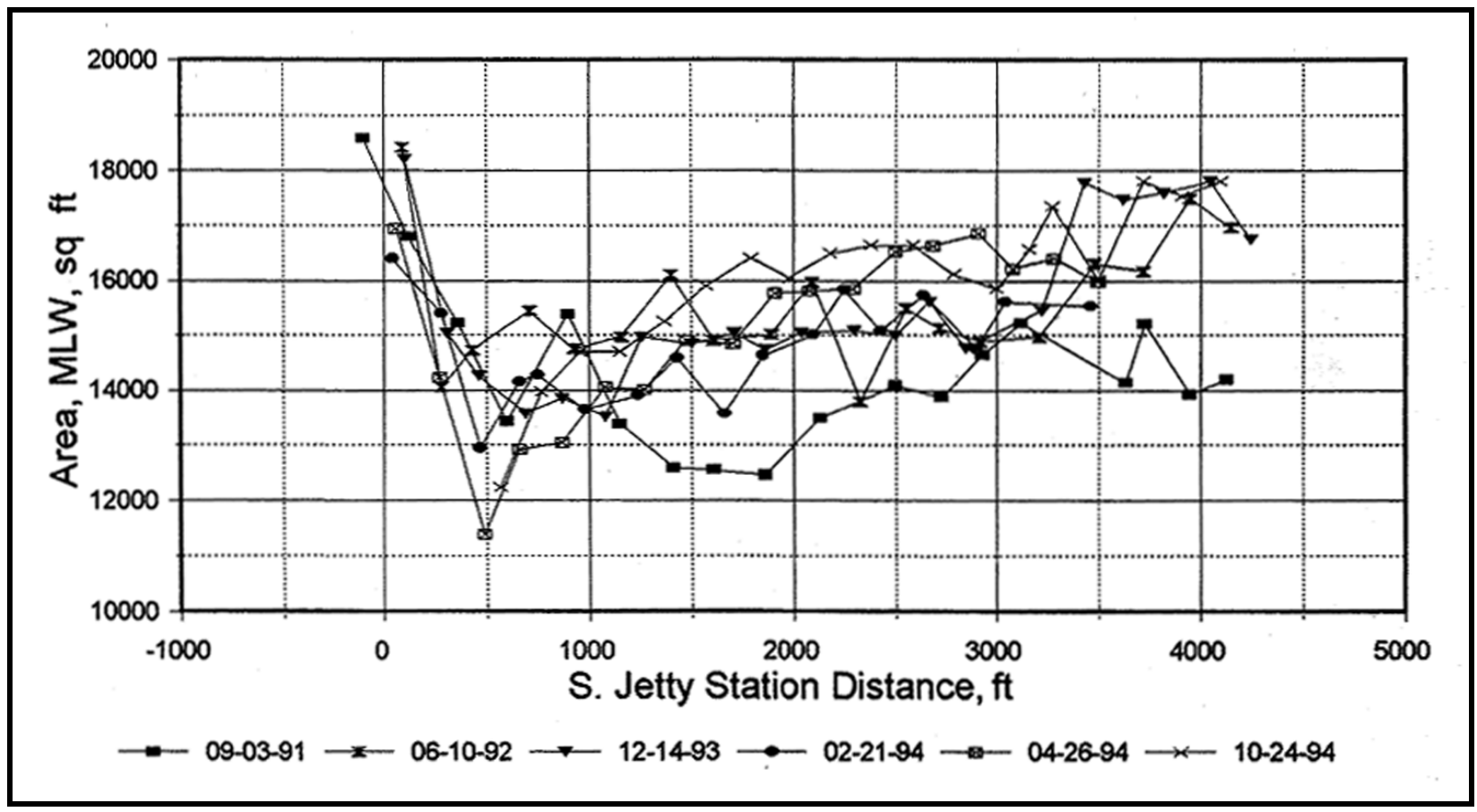

Figure 38. Average channel area between jetties, 1991-1994 (to convert feet to meters, multiply by 0.3048 ; to convert square feet to square meters, multiply by 0.0929 )

The interior navigation channel is moving southward as the flood shoal flattens out since sediment is not reaching it from the north or south adjacent shorelines or the ebb shoal. This channel migrated south about $295 \mathrm{ft}(90 \mathrm{~m})$ during the years 1994-96. Flood currents plus ocean waves traveling with the currents move sediment toward the bay side of the flood shoal. On ebb, the current shears sediment from the back edge of the flood shoal and transports it counterclockwise along the edge of the shoal. Sediment settles out on the south edge of the flood shoal as strong ebb currents move away from the shoal to the outside of the curved channel. This spreading out of sediment may decrease the effectiveness of the flood shoal as an ebb shield and gradually permit more ebb flow over the shoal. Figure 31 shows some incised cutting of the center of the flood shoal.

\section{Impact of Structures on Flood Shoal}

Yearly bathymetric surveys collected since 1992 show definitive change in the flood shoal configuration. Deflation of the two main lobes, an increase in the southwest marginal area, and a general broadening of the shoal feature have been observed. The main navigation channel has migrated to the southwest, and a small incised channel through the shoal has become more pronounced (Figure 39). The overall volume of the shoal has not changed significantly since project completion whereas, historically, the shoal feature had shown growth. Volume loss from the higher elevations is extensive. Sediment volume above the $-3.3-\mathrm{ft}$ (-1.0-m) North American Vertical Datum 1988 (NAVD 88) contour has been reduced by 70 percent, and sediment volume above the $-1.6-\mathrm{ft}(-0.5-\mathrm{m})$ 


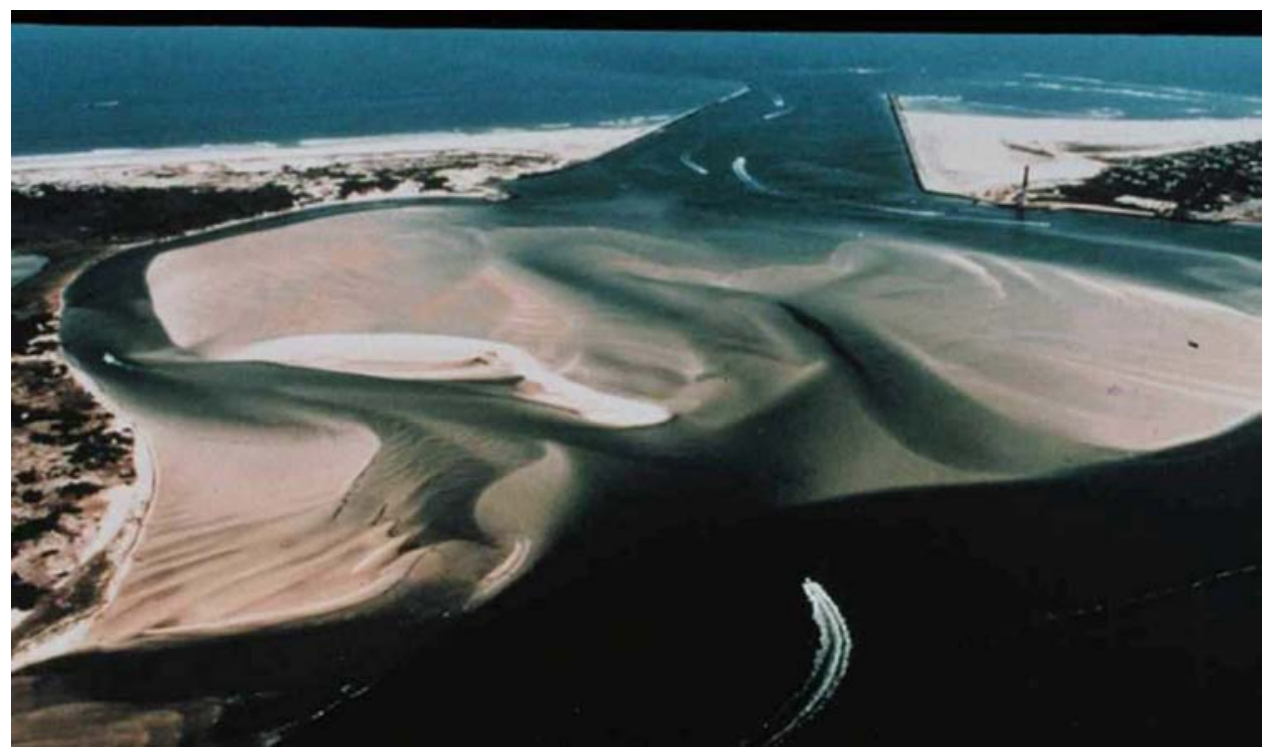

Figure 39. Barnegat Inlet flood shoal closest to the inlet throat looking seaward, photo December 1992

NAVD 88 contour has been reduced by 95 percent. The higher elevations have been planed off and sediment has shifted bayward. The tidal prism and inlet cross-sectional area have returned to values similar to those of the early history of the engineered project.

At Barnegat Inlet two successive flood shoals and a meandering navigation channel are present within a large relic flood tidal delta complex. Surrounding the flood shoal closest to the inlet throat are (a) the main navigation channel to the south, (b) a small channel to the north, and (c) a small, incised channel developing through the central portion of the shoal (Figure 3). Since completion of the new south jetty project in 1991, yearly bathymetric surveys of this flood shoal were collected between 1992 and 1997. All data were converted to the common datum NAVD 88 and are expressed in meters. (NAVD 88 is $1.6 \mathrm{ft}$ $(0.49 \mathrm{~m})$ above mean lower low water near the flood shoal.)

All bathymetric data used in this analysis by Cialone et al. (1999) were collected by the U.S. Army Engineer District, Philadelphia, using hydrographic survey techniques. The vessel used for data collection was positioned with a Trimble 4000 Differential Geodetic Positioning System. Bathymetry data were collected with a bottom-mounted Interspace 448 echo sounder set in continous mode. HYPAC 7.1 navigation system software was used to control and integrate the positioning and sounding information. Areas that were too shallow to navigate were surveyed using traditional land-based methods. A Real Time Kinematic Geodetic Positioning System was used for land areas for recent flood shoal surveys. All surveys were conducted during the same season of each year (fall) to eliminate potential seasonal effects. The nominal density of the data was $200 \mathrm{ft}(60 \mathrm{~m})$ between survey lines. Data spacing along a given survey line was approximately $25 \mathrm{ft}(7 \mathrm{~m})$ for the hydrographic portion, and $100 \mathrm{ft}(30 \mathrm{~m})$ for the traditional land-based portion. 


\section{Flood shoal cross sections and thalweg depth}

Bathymetric change analysis was performed between the recent yearly data sets. Cross-section data for 1995 could not be deciphered. Earlier (1992-1994) and later (1996-1997) data allowed the general trend of bathymetric change in this region to be determined. Comparison of 1992 to 1997 surveys at the three cross sections given in Figures 40 and 41 shows definitive change in the flood shoal configuration. In plan view, deflation of the two main lobes of the shoal, an increase in the southwest marginal area, and a general broadening of the shoal feature are observed. Examining three cross sections through the shoal gives further evidence of change in the flood shoal since project completion.

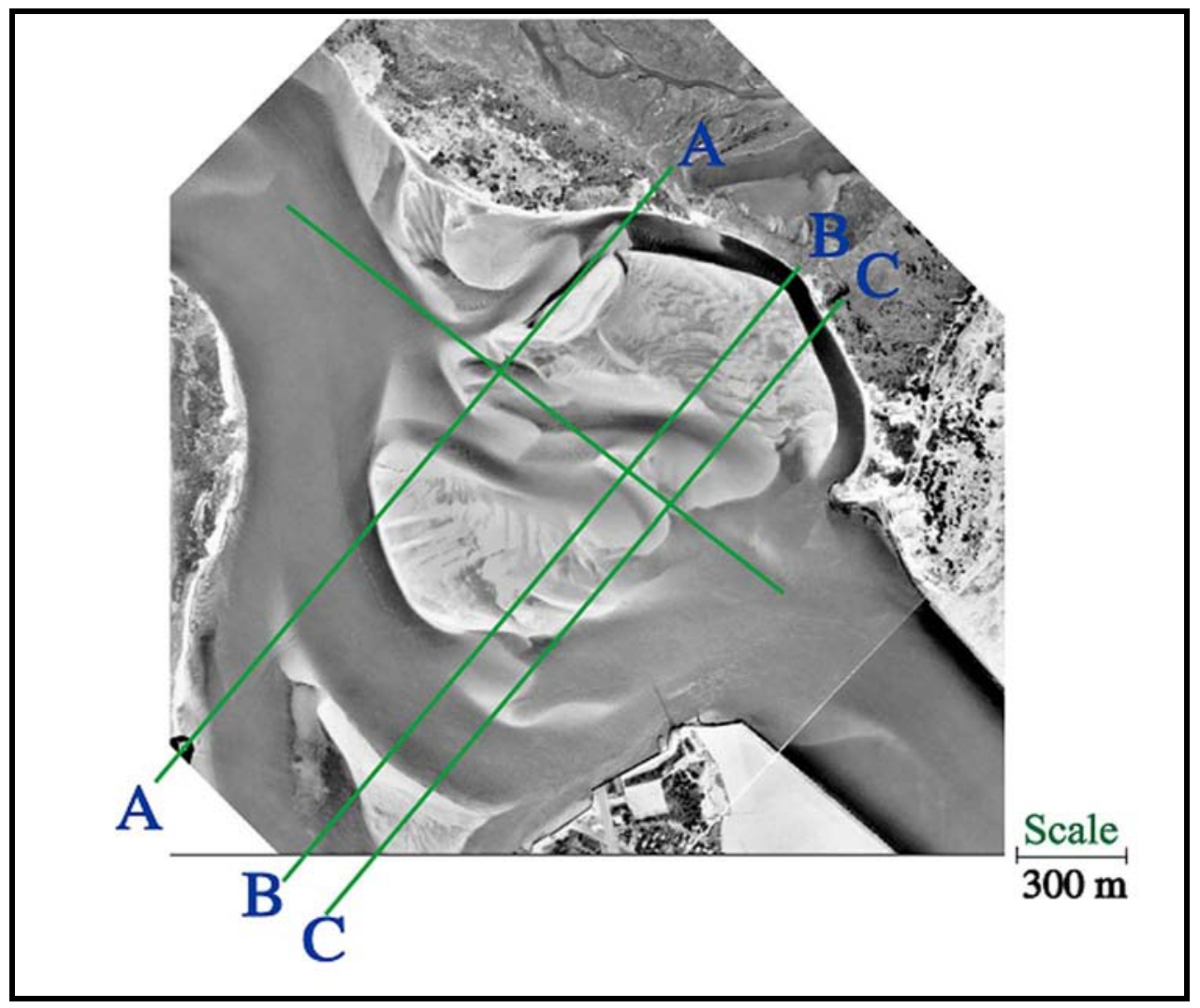

Figure 40. Cross sections taken through flood shoal, 1992 and 1997

Section A-A is at the bayward side of the flood shoal, looking seaward (Figure 42). Clearly it is observed that the main navigation channel thalweg shifted to the southwest approximately $490 \mathrm{ft}(150 \mathrm{~m})$, deepened by about $9.2 \mathrm{ft}(2.8 \mathrm{~m})$, and increased in cross-sectional area by about $9,700 \mathrm{sq} \mathrm{ft}(900 \mathrm{sq} \mathrm{m})$. The small, incised channel migrated in the opposite direction approximately $230 \mathrm{ft}(70 \mathrm{~m})$, increased in depth by about $4.9 \mathrm{ft}(1.5 \mathrm{~m})$, and increased in cross-sectional area by approximately $1,900 \mathrm{sq} \mathrm{ft}(175 \mathrm{sq} \mathrm{m})$. The two main lobes have not experienced significant change. Section B-B is through the center of the flood shoal looking seaward (Figure 43). At this location the main navigation channel 


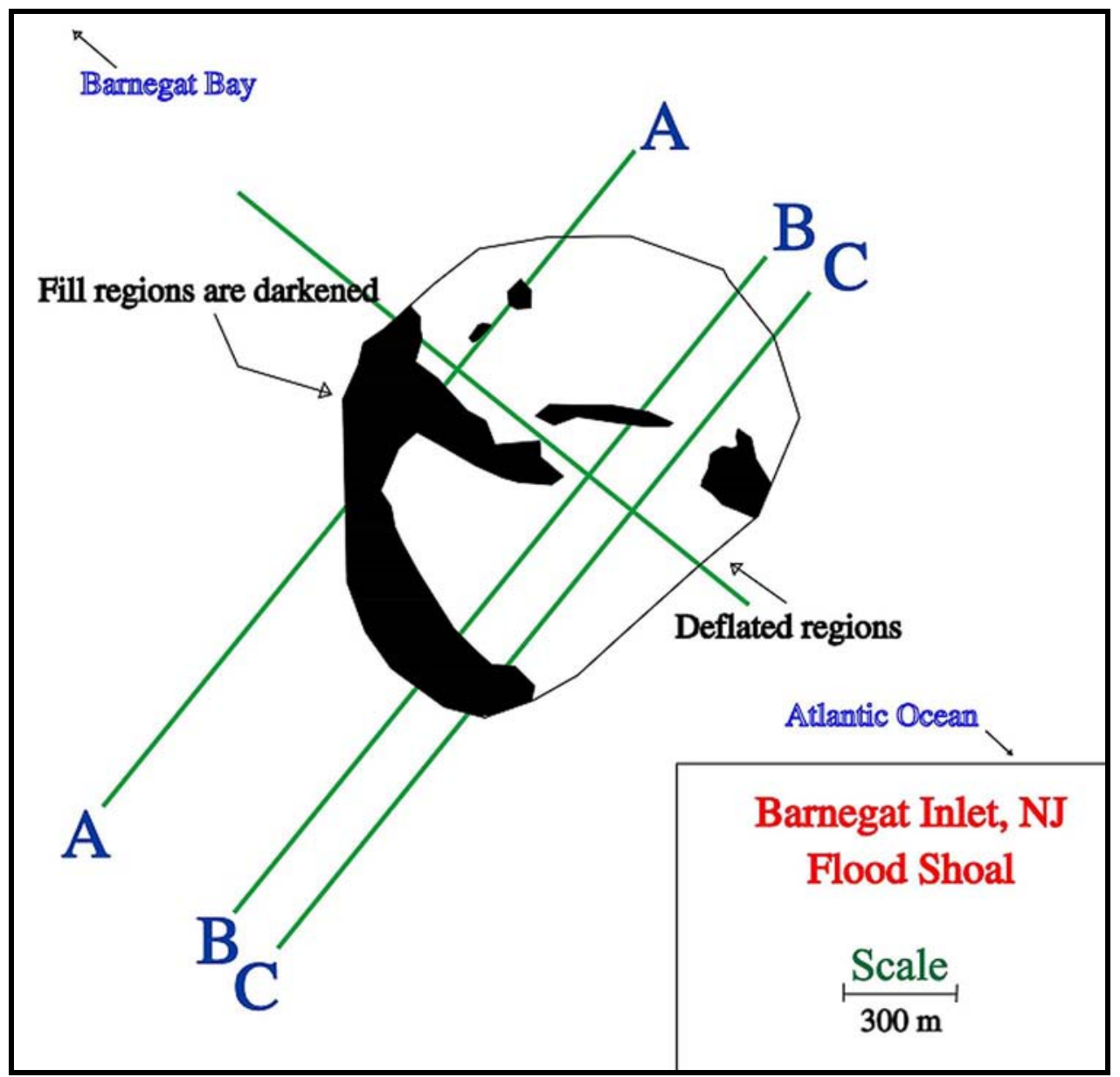

Figure 41. Fill and eroded areas where cross sections were taken through flood shoal, 1992 and 1997

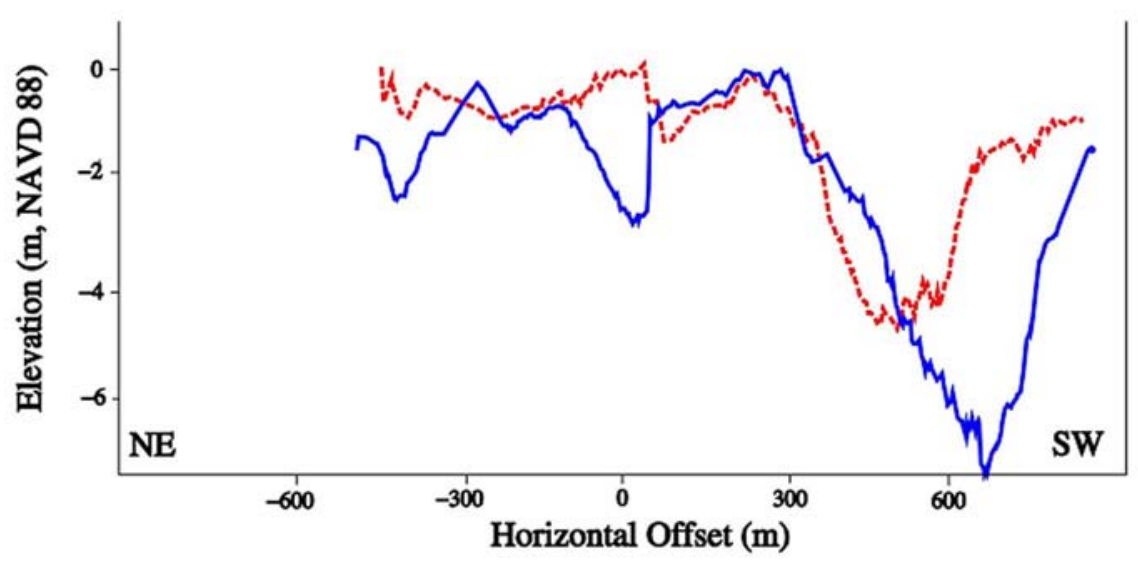

Figure 42. Cross-section A-A looking seaward (dashed line $=1992$, solid line $=$ 1997) 


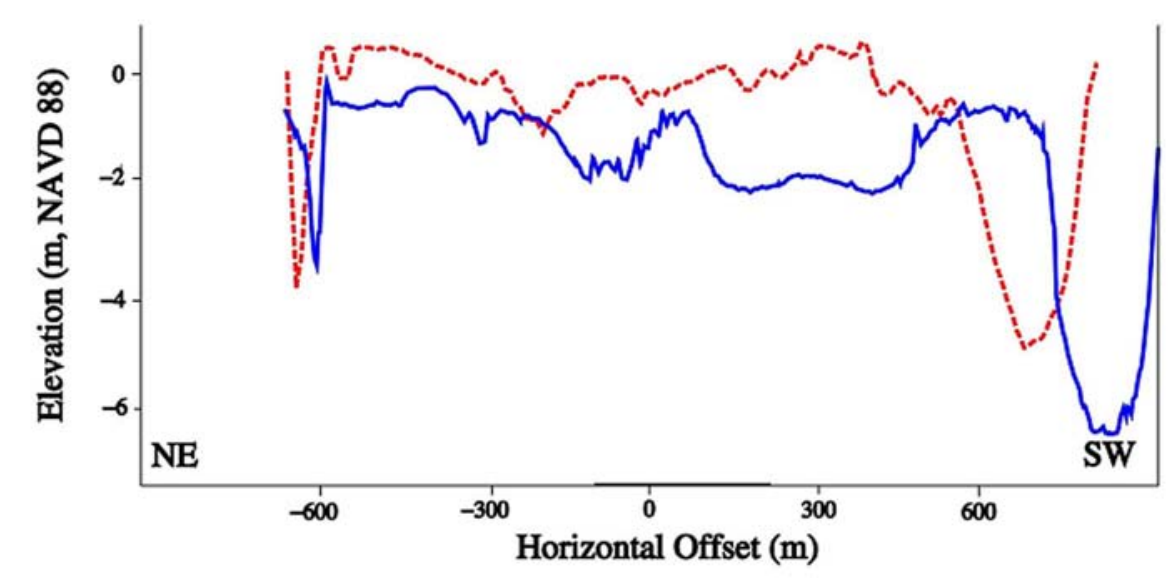

Figure 43. Cross-section B-B looking seaward (dashed line $=1992$, solid line $=$ 1997)

is narrower than at Sections A-A and C-C. The channel deepened from 16.4 to $21.3 \mathrm{ft}(5.0$ to $6.5 \mathrm{~m})$ and migrated to the southwest about $10 \mathrm{ft}(125 \mathrm{~m})$ since completion of the new south jetty. The cross-sectional area increased by $1,310 \mathrm{sq} \mathrm{ft}(400 \mathrm{sq} \mathrm{m})$. Deflation of the southern lobe is significant, at approximately $6.6 \mathrm{ft}(2.0 \mathrm{~m})$. The northern lobe has been reduced to a lesser extent of $3.3 \mathrm{ft}(1.0 \mathrm{~m})$. Section $\mathrm{C}-\mathrm{C}$ is the seawardmost cross section, looking seaward (Figure 44). Here the main navigation channel thalweg shifted to the southwest $375 \mathrm{ft}(115 \mathrm{~m})$ and deepened from 15.1 to $19.7 \mathrm{ft}(4.6$ to $6.0 \mathrm{~m})$. The cross-sectional area increased by $7,525 \mathrm{sq} \mathrm{ft}(700 \mathrm{sq} \mathrm{m})$. The entire flood shoal at this section has been significantly deflated, by as much as $8.2 \mathrm{ft}(2.5 \mathrm{~m})$, taking on a bowl-like, channelized shape. This could be the beginning of a new flood channel cutting through the flood shoal.

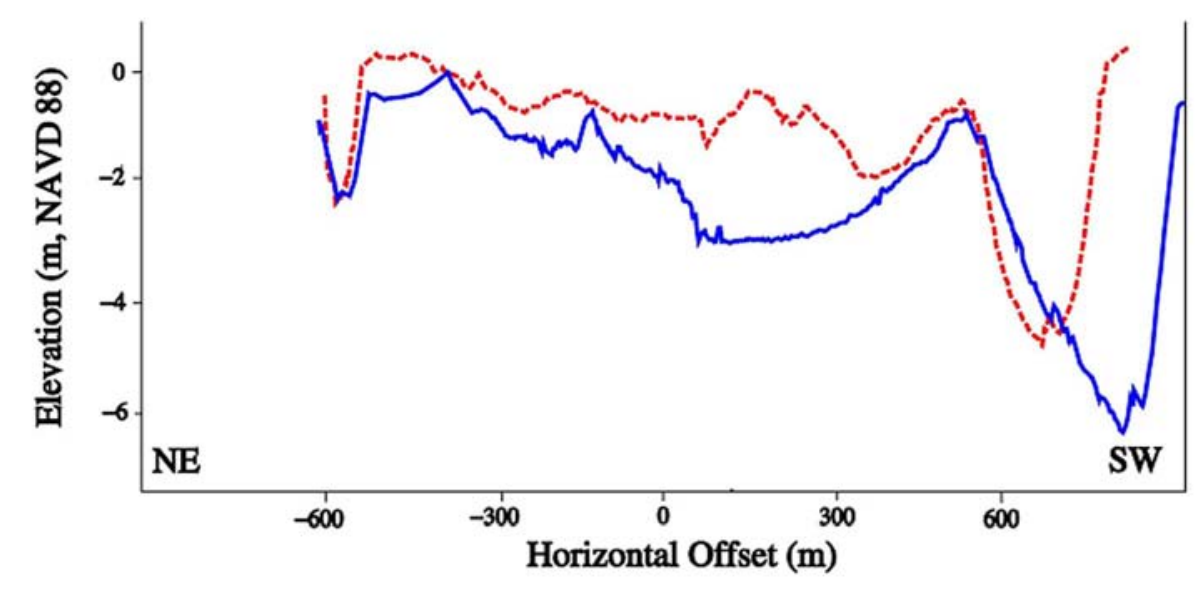

Figure 44. Cross-section C-C looking seaward $($ dashed line $=1992$, solid line $=$ 1997) 
The thalweg depth through the flood shoal is shown in Figure 45 for years 1992-1996. Deflation of the two main lobes and a general broadening of the shoal feature are reflected in a deepening of the channel thalweg through 1995, when the major response of the flood shoal to the effects of the new south jetty may have been reached.

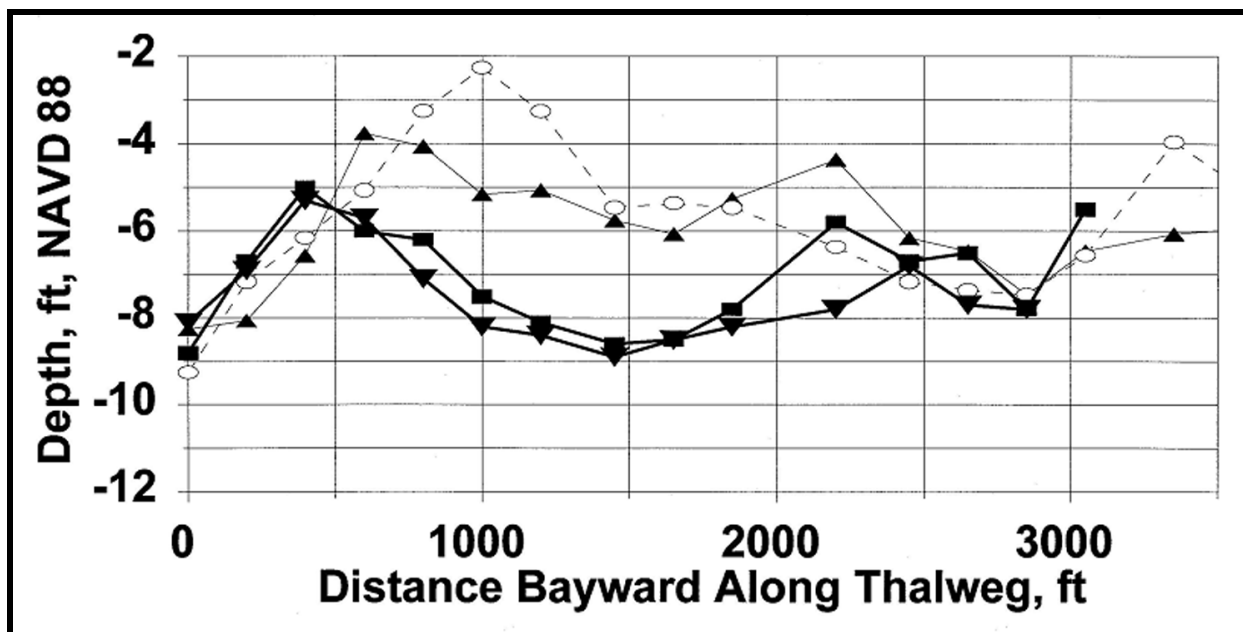

Figure 45. Thalweg depths through the Barnegat Inlet flood shoal

\section{Morphologic changes to the flood shoal}

Figures 46 and 47 show contour plots of the flood shoal for 1992 and 1997, respectively. Most noticeable is the elimination of the $+1-\mathrm{m}$ contour known by locals as Party Island, and the near elimination of the 0 -m contour over the 5-year period since completion of the south jetty and navigation channel. Comparing Figures 46 and 47 also shows the -9.8-, -6.6-, and -3.3-ft (-3-, -2-, and -1-m) contours cutting further into the southern lobe of the flood shoal in the 5 years since project completion. Figure 48 shows the dramatic change to the $0-\mathrm{ft}(0-\mathrm{m})$ contour area. The plan view area above the $0-\mathrm{ft}(0-\mathrm{m})$ contour has been reduced from $0.013 \mathrm{sq}$ mile $\left(0.34 \mathrm{~km}^{2}\right)$ in 1992 (dotted) to less than $0.004 \mathrm{sq}$ mile $\left(0.01 \mathrm{~km}^{2}\right)$ in 1997 (solid). The plan view area above the $-3.3-\mathrm{ft}(-1-\mathrm{m})$ contour shows the bayward and southward shifting of the shoal feature (Figure 49). The $3.3-\mathrm{ft}(-1-\mathrm{m})$ contour surface area has been reduced 24 percent from $0.30 \mathrm{sq}$ mile (0.77 sq km) in 1992 to $0.22 \mathrm{sq}$ mile $(0.58 \mathrm{sq} \mathrm{km})$ in 1997.

\section{Flood shoal volume changes}

Another method of examining change in the flood shoal is to compute the volume above a given contour for each year of data collection for the region bounded by the $1997-13.1-\mathrm{ft}(-4-\mathrm{m})$ NAVD 88 contour. This area encompasses approximately $0.46 \mathrm{sq}$ mile $(1.2 \mathrm{sq} \mathrm{km})$. Table 8 shows the volume above the $-1.6-,-3.3-,-6.6-,-9.8-$, and -13.1-ft (-0.5-, -1-, -2-, -3-, and -4-m) NAVD 88 contours for each year of data collection. Figure 50 shows the percent change in 


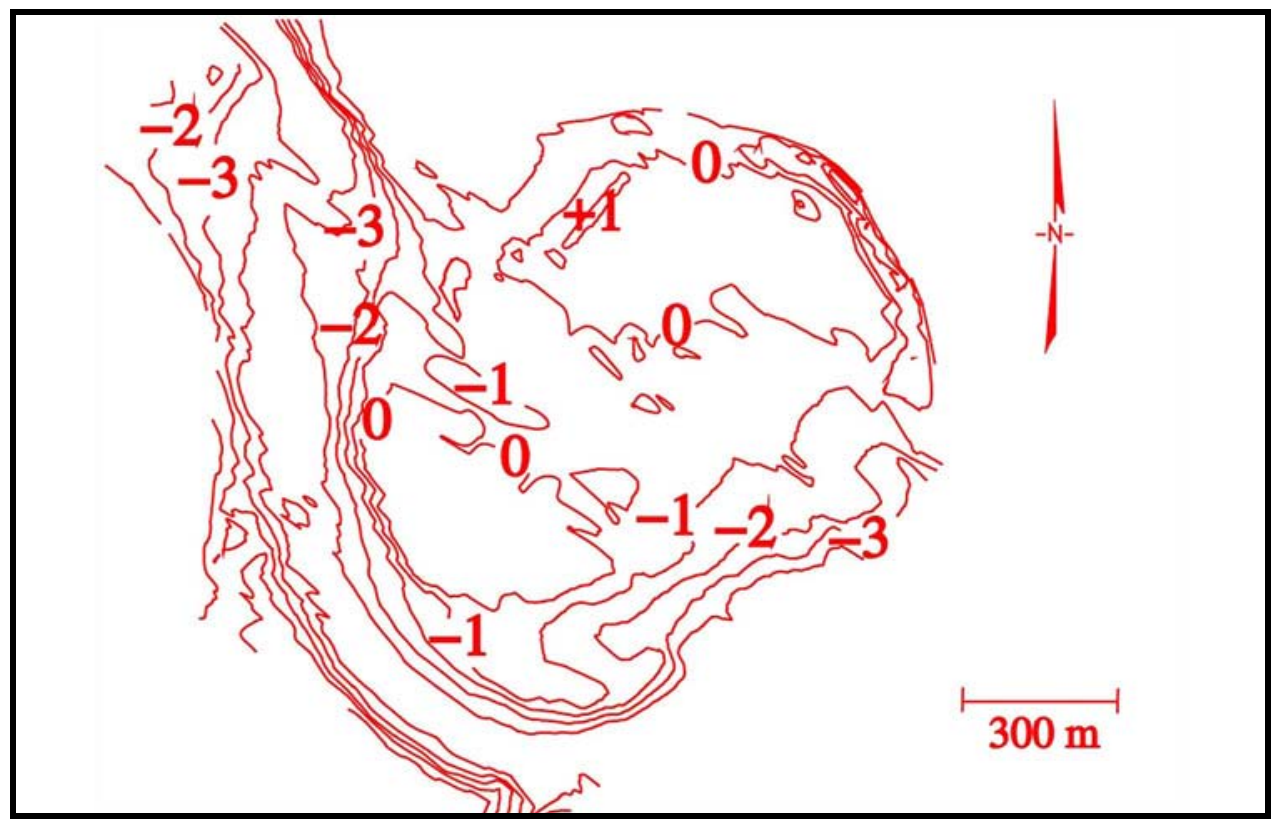

Figure 46. Flood shoal contour plot for 1992 NAVD 88 datum, $m$

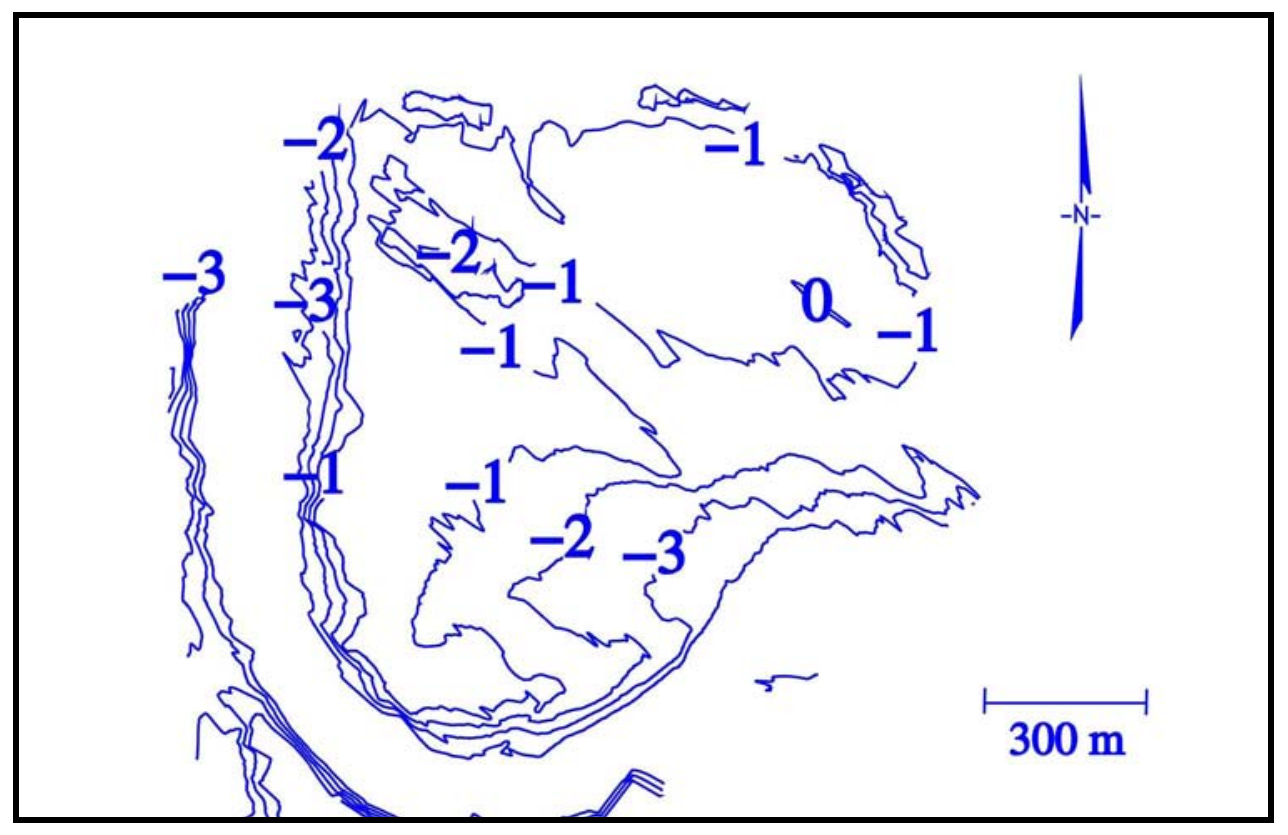

Figure 47. Flood shoal contour plot for 1997 NAVD 88 datum, m

volume above these contours since 1992. Most noticeable is the significant reduction in the volume above the $-1.6-\mathrm{ft}(-0.5-\mathrm{m})$ and $-3.3-\mathrm{ft}(-1.0-\mathrm{m})$ contours. However, the volume above the $-13.1-\mathrm{ft}(-4-\mathrm{m})$ contour shows little change since 1992. 


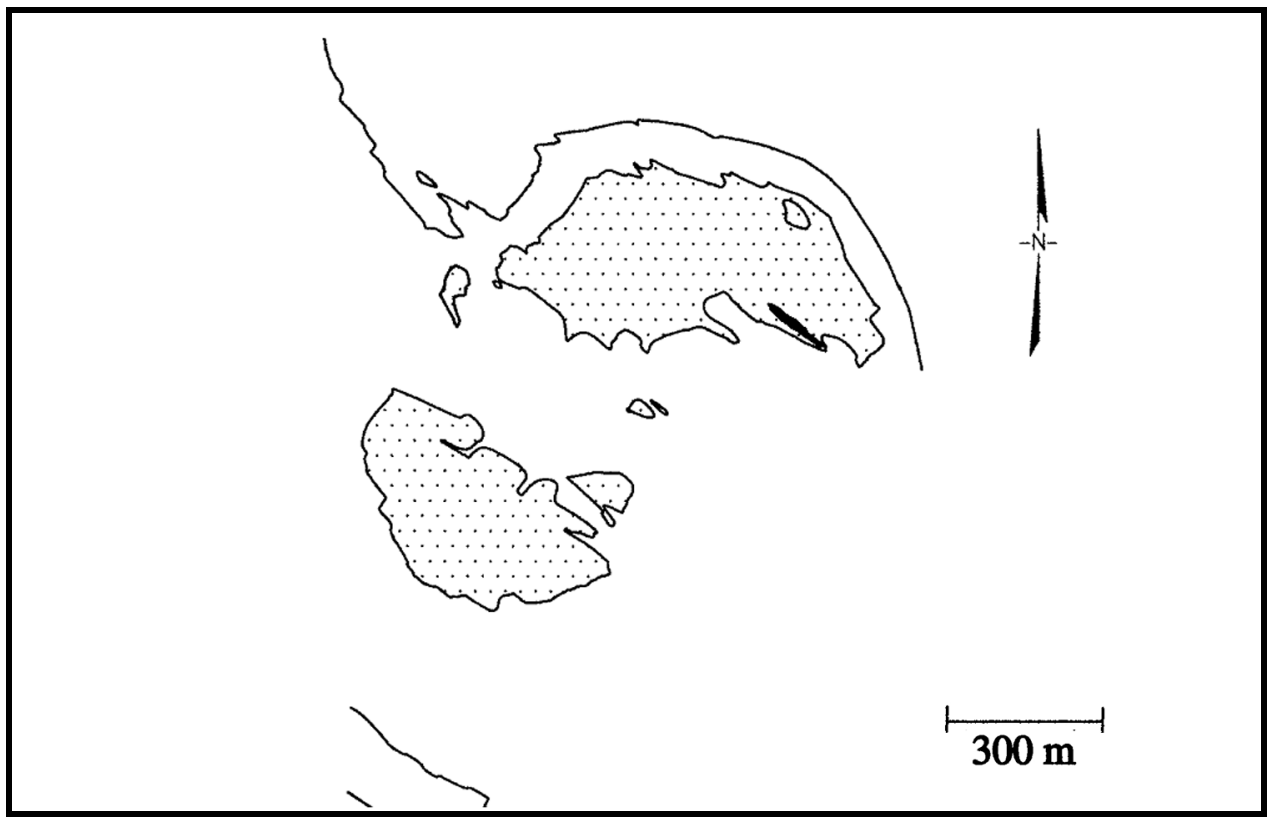

Figure 48. Plan view area above the $0-\mathrm{ft}(0-\mathrm{m})$ NAVD 88 contour (dotted $=1992$, solid $=1997$ )

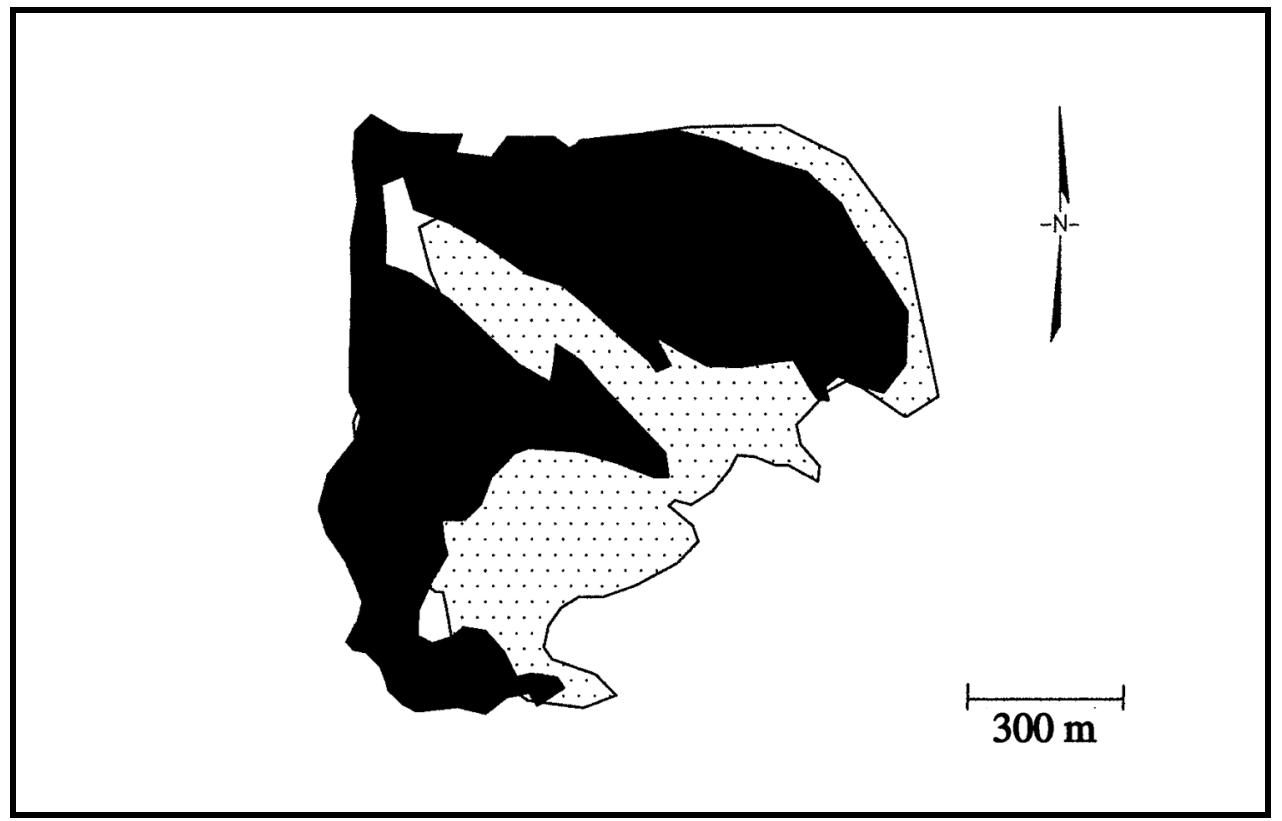

Figure 49. Plan view area above the $-3.3-\mathrm{ft}(-1-\mathrm{m})$ NAVD 88 contour (dotted $=$ 1992, solid $=1997$ ) 


\section{Table 8 \\ Volume, cu m, above $-0.5,-1.0,-2.0-,-3.0$, and -4.0 NAVD 88 Contours}

\begin{tabular}{||l|l|l|l|l|l||}
\hline \hline Year & $\mathbf{- 0 . 5} \mathbf{~ m}$ & $\mathbf{- 1 . 0} \mathbf{~ m}$ & $\mathbf{- 2 . 0} \mathbf{~ m}$ & $\mathbf{- 3 . 0} \mathbf{~ m}$ & $\mathbf{- 4 . 0} \mathbf{~}$ \\
\hline \hline 1992 & 370,500 & 720,100 & $1,595,000$ & $2,565,000$ & $3,630,000$ \\
\hline 1993 & 248,400 & 593,600 & $1,472,000$ & $2,437,000$ & $3,500,000$ \\
\hline 1994 & 273,100 & 604,500 & $1,488,000$ & $2,482,000$ & $3,577,000$ \\
\hline 1996 & 175,100 & 372,500 & $1,106,000$ & $2,047,100$ & $3,121,500$ \\
\hline 1997 & 29,900 & 225,400 & 986,400 & $1,962,700$ & $3,073,500$ \\
\hline
\end{tabular}

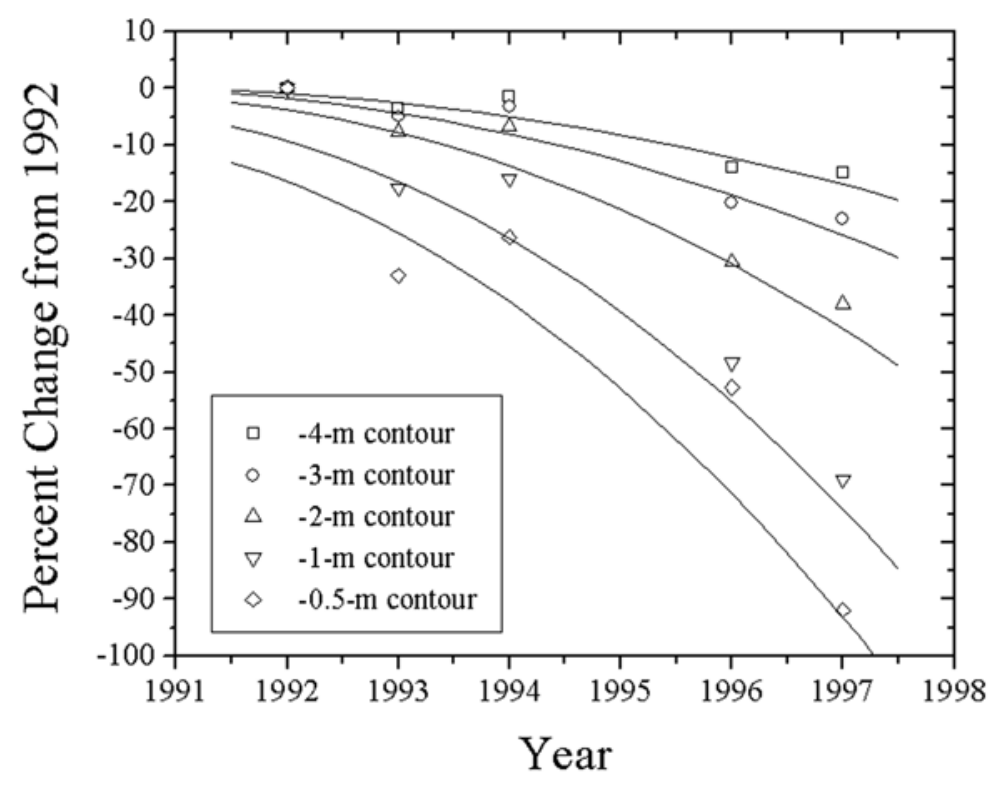

Figure 50. Percent reduction in flood shoal volume above -1.6-, -3.3-, -6.6-, -9.8-, and -13.1-ft (-0.5-, -1.0-, -2.0-, -3.0-, and -4.0-m) contours (reduction is relative to the 1992 volume above a given contour)

The overall shoal volume is nearly conserved, with sediment shifting to the southwest marginal areas as the main navigation channel south of the shoal has enlarged and migrated southward. These results suggest that further growth of the flood shoal is unlikely. Redistribution and possible losses of sediment from the higher elevations are expected. The lack of growth of the flood shoal is most probably due to the impermeable jetties preventing an appreciable influx of sediment. The reworking of the shoal is likely due to the ability of increased flow velocities to move sediment.

\section{Flow distribution}

Another factor investigated was the portion of the flood flow that traverses the navigation channel versus the portion that flows over the flood shoal since completion of the project. The distribution of flow for preproject conditions was 
not available for comparison, but the postproject distributions give some suggestion of how flood and ebb flows contribute to the flood shoal configuration at Barnegat Inlet. Again, it is important to note that peak flood velocities occur near high water and peak ebb velocities occur near low water at Barnegat Inlet.

The velocity distribution and discharges at three transect locations had been collected for several tidal cycles from 1993 through 1997. The tidal discharge time-series recorded by the ADCP were integrated to determine flow volume (tidal prism) at the three transect locations. From these data, the distribution of flow in the vicinity of the flood shoal was examined by comparing the total inlet tidal prism measured at Transect B with the portion of the tidal prism that reaches the main navigation channel at Transect A. Transect locations are shown in Figure 5.

For both spring and mean tide conditions, the distribution of ebb flow remained consistent. Approximately two-thirds (64 to 71 percent) of the ebb flow was through the navigation channel, and one-third (29 to 36 percent) was over the shoal. Flood flow for mean tide conditions indicated that about 56 percent of the flow was over the flood shoal region and 44 percent moved through the navigation channel. This compares with 64 to 73 percent over the flood shoal and 27 to 36 percent through the channel for spring tide flood flow conditions when water levels are higher.

This difference in flow distribution for mean and spring conditions is probably attributable to the lower water level of the mean tide not permitting as much flood flow over the flood shoal. Ebb flow velocity distribution is not affected by changes in tide range since ebb flow begins at about midtide on the falling tide curve when flow over the shoal is cut off as the water level drops and the shoal is exposed. This analysis indicates that from a flow volume standpoint, flow over the flood shoal is flood-dominant and flow through the navigation channel is ebbdominant.

Bathymetric data analysis indicating a reduction in elevation of the seaward portion of the flood shoal has been shown. Two factors contributing to these bathymetric changes are the asymmetric distribution of flow over the flood shoal and the increase in tidal prism since project completion. Both the cross-sectional area and the measured tidal velocities have increased, contributing to the larger volume of water traversing the shoal. Presently, the majority of the flood tidal prism is directed at and over the flood shoal with the potential for moving sediment bayward. The portion of the ebb tidal prism directed over the flood shoal is smaller, but can potentially move sediment seaward during the portion of the ebb cycle when the flood shoal is submerged. The predominance of flood flow over the flood shoal appears to have a greater ability to move sediment, as evidenced by the reworking of the shoal feature (i.e., the deflation, or cutting, at the seaward portion and bayward migration of the $-3.3-\mathrm{ft}(-1.0-\mathrm{m})$ contour).

\section{Impact of Structures on Navigation Safety and Dredging}

The MCNP study approach and monitoring plan addressed the hypothesis that the new south jetty realignment would improve navigation safety by stabilizing 
the navigation channel location and depth between the jetties and over the outer bar (ebb tidal shoal), and would eliminate dredging in these regions.

\section{Navigation safety}

The new south jetty construction was completed in June 1991. Since that time, the morphological regime of the ebb shoal, inlet channel, and flood shoal has responded to the hydraulic and hydrodynamic forcing functions induced by tidal currents, sediment influx, and wave conditions such that a state of quasiequilibrium has become established. The north side bulkhead has completely deteriorated, and the sand dunes have experienced considerable erosion over the past 10 years. It seems likely that at least a portion of the eroded dunes has ended up in the inlet. This source of sand, and sand migrating from other undetermined offshore and upstream sources, result in shoal formations in the inlet channel. Thus, annual dredging still remains a necessity at this dynamic inlet.

Following each annual dredging cycle, the balance of sand influx and hydrodynamic conditions consistently reestablishes the navigation channel location along the north side of the inlet, adjacent to the north jetty (Figure 51). Proceeding inland, the channel location then shifts to the south side of the flood shoal and extends on into the inland bay system. The locations of the shoals have stabilized. Even though annual dredging is still necessary, safety has significantly improved for mariners, especially for commercial fishermen, since the shoals are not shifting as previously happened. Deep water is consistently available on the north side of Barnegat Inlet.

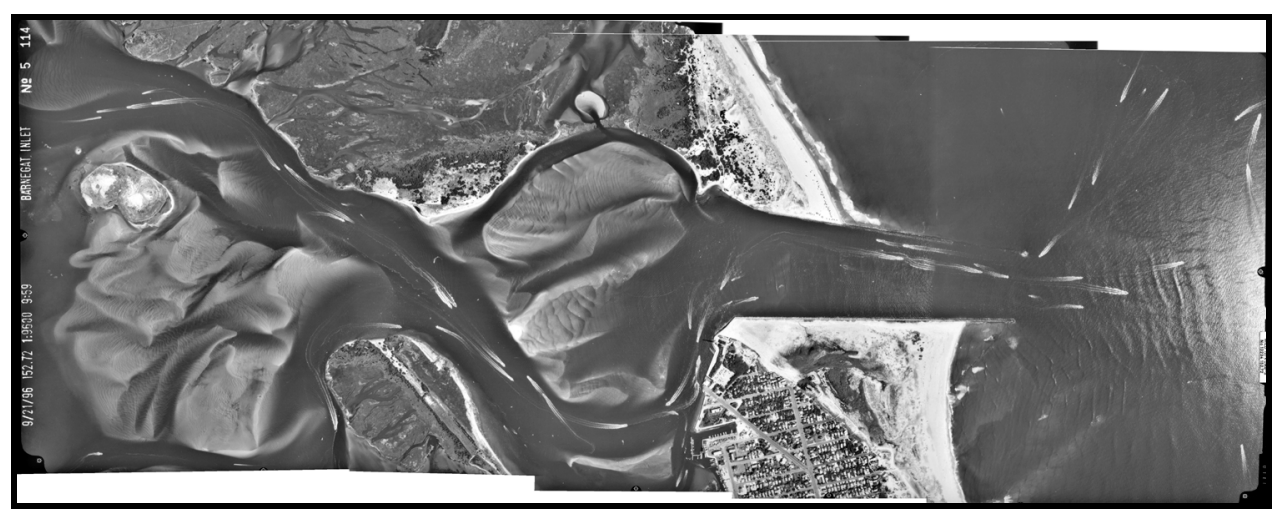

Figure 51. Boat wakes traversing Barnegat Inlet channel, showing location of stabilized shoals with navigation channel consistently adjacent to the north jetty and then passing along the south side of the flood shoal inside the inlet, photo June 1996

\section{Dredging volumes}

It was anticipated during planning for the new south jetty that by dredging a new initial navigation channel through the inlet, the north jetty and new south jetty layout would focus flood and ebb currents along the new channel and create a self-maintaining inlet system. The flood and ebb currents were expected to flush from the navigation channel any sediment that might possibly enter into the channel from whatever known or unknown sources. 
This has not proven to be the case. Dredging volume at Barnegat Inlet was a minimum in 1991 at about 170,000 cu yd $(130,000 \mathrm{cu} \mathrm{m})$ following completion of the new south jetty. Annual dredging quantities steadily increased over the next 6 years, reaching a maximum in 1997 at about 355,000 cu yd $(270,000 \mathrm{cu} \mathrm{m})$. Since that time, dredging volume has declined, being about 334,000 cu yd $(256,000 \mathrm{cu} \mathrm{m})$ in $1998,217,000 \mathrm{cu}$ yd $(166,000 \mathrm{cu} \mathrm{m})$ in 1999 , and 192,000 cu yd $(147,000 \mathrm{cu} \mathrm{m})$ in 2000 . However, the year 2000 dredging quantities were affected by dredge availability. The 192,000 cu yd (147,000 cu m) dredged in 2000 would have been higher except that the dredge had to undergo shipyard maintenance. Barnegat Inlet dredging quantities for years 1987 through 2000 are shown in Figure 52.

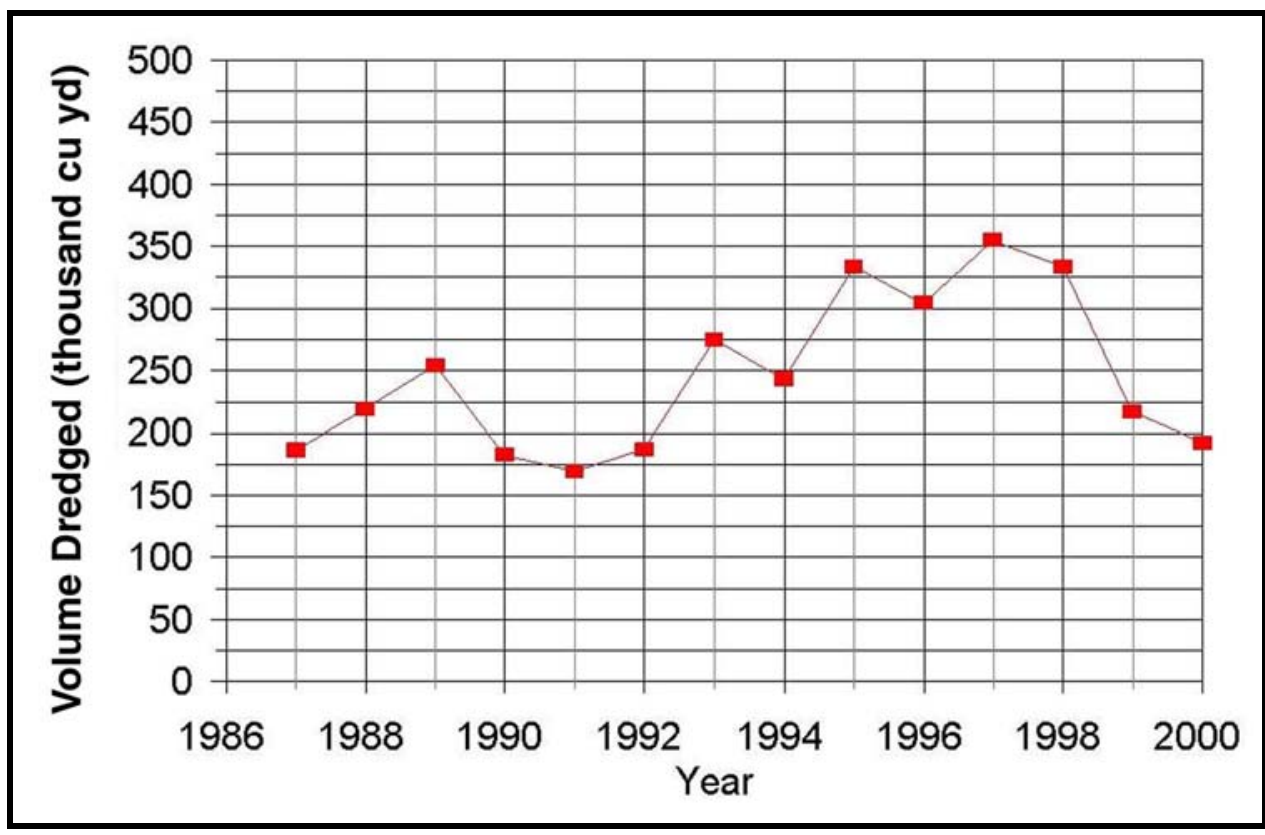

Figure 52. Dredging volumes at Barnegat Inlet, years 1986 through 2000

\section{Summary of New South Jetty Effects on Channel Stability and Dredging}

\section{Impact of structures on inlet channel location}

The concept of arrowhead jetties for concentration of ebb flows at the oceanward terminus (in order to cut through the ebb shoal) and for wave attenuation due to diffraction as waves propagated into the expansion area was believed to be a positive design attribute at the time of installation. The hydraulics of such a system with regard to the velocity phasing at Barnegat Inlet (maximum flood currents near high water and maximum ebb near low water), combined with mean tide level jetties, would permit broad, less concentrated flood currents to approach the inlet, with presumably less potential to carry sediments into the inlet. Strong ebb flow concentration in the navigation channel would flush sediments out of the channel as water surface elevation dropped. However, the sediment influx over these low jetties overshadowed the positive 
elements of the plan. Apparently most of the sediment movement was at the shoreline intersection with the jetties.

It was learned from the historical analysis of bathymetries that the interior navigation channel moved back to its prestructure alignment, probably due to the influx of sand coming over the low north jetty, which enlarged the flood shoal significantly and helped deflect ebb currents coming from the bay toward the southeast. There had been a similar situation for the natural inlet that had been migrating south, thus infilling on the north side and accumulating sediments to help deflect ebb currents to the south.

Raising the north jetty crest elevation cut off direct sediment influx from the north, but sediments from the south maintained the same minimum area at the inlet gorge. Channel migration to the now-dominant north jetty, plus dredging, cut off input to the flood shoal and redirected beach sediments to the ebb shoal.

The effect of sediment input into an inlet system in equilibrium usually is balanced by sediment moving out. At Barnegat Inlet, initially structural changes effectively lengthened the channel, led to increased friction, reduced currents, followed by sedimentation and reduction in tidal prism. The addition of a new higher south jetty paralleling the north jetty, along with an increase of minimum channel area due to dredging and the prevention of sediments entering from the south into the inlet gorge, permitted a larger tidal prism.

It took over 20 years (1941 to 1965) for the straight interior navigation channel to move to the south, and thus back to its historic curved configuration. However, recent incising of the flood shoal, and the apparent reduction in sediment supply to the flood shoal, indicate a potential for ebb currents to eventually shortcut across the flood shoal and deepen a channel there.

Inlet channel location is a complex function of inlet hydraulics, littoral influx to the channel system, and inlet structures. Historic analysis of structural effects has provided a clear picture of inlet response and impacts on channel location. Initially low arrowhead jetties followed by an interior sand dike, then sand tightening of one jetty with increased jetty elevation, and finally conversion to a parallel jetty system affected inlet hydraulics and sediment input, which in turn changed shoaling patterns and thus channel location. With the low arrowhead jetty system, sedimentation reduced channel cross-sectional area with a corresponding reduction in tidal prism. Today's inlet, which has effectively adjusted to the new parallel south jetty, allows a more stable channel to exist along the north jetty, due to the restriction of sediment input into the navigation channel. These factors, along with an increase in minimum channel area due to dredging, have changed the tidal prism back to prestructure conditions.

\section{Impact of structures on flood shoal}

Bathymetric changes to the flood shoal at Barnegat Inlet since completion of the new south jetty in 1991 and navigation channel in early 1992 were investigated. The most dramatic changes have been the decrease in mean elevation of the flood shoal and the changes on the seaward portion of the flood shoal, which has gone from convex to concave as a channel appears to be attempting to bisect the southern lobe. Deflation of the high lobes and increase of the marginal areas show that the flood shoal has flattened out and is broadening. From 1992 to 1997 the majority of the flood shoal was reduced 
from $0.0 \mathrm{ft}(0.0 \mathrm{~m})$ NAVD 88 to $-3.3 \mathrm{ft}(-1.0 \mathrm{~m})$ NAVD 88 . The plan view area above the $-3.3-\mathrm{ft}(-1.0-\mathrm{m})$ contour has shifted bayward and southward during the 5 years since project completion. Sediment volumes lost from the higher elevations are most significant. Only 15 percent of the overall volume has been displaced, which is predominantly the loss of sediment from the higher elevations, and thus an assumption of minimal volume loss is reasonable. The incised (smaller) channel has deepened and shifted to the northeast while the main navigation channel has deepened and shifted to the southwest. Therefore, the overall shoal volume is nearly intact, with sediment shifting to marginal areas as the main navigation channel has enlarged and migrated southward.

Historically, the flood shoal had shown growth. The impermeability of the south jetty and sand tightening of the north jetty in the early 1970s limited the sand supply to the flood shoal, thereby stopping further growth of this feature. The reduction in sediment supply caused by impermeable jetties also contributes to the fact that the flood shoal is being reworked rather than nourished with new sediment.

The changes observed for the flood shoal since project completion are due primarily to the increased tidal prism and flood flow velocities, as well as the limited sediment supply caused by both jetties being sand-tightened. Tidal prisms and inlet cross-sectional areas computed from this MCNP data collection were compared with historic mean and spring tidal prisms. There has been a large variation in tidal prism and inlet cross-sectional area for the engineered history of the inlet. These values of tidal prism were measurements for one day in the spring-neap cycle and, therefore, represent only the prism on that particular day. Historically, after construction of the jetties in 1939-40, there was a dramatic increase in the tidal prism, probably due to the increased cross-sectional area dredged for the project. Thereafter, the tidal prism continued to decrease until construction of the present project. The recent data collection and analysis indicate that the inlet cross-sectional area and tidal prism have returned to values similar to those reported for the early history of the engineered project. The increase in tidal prism is due to the 40-45 percent increase in cross-sectional area dredged for the project, and to increased velocities from channel straightening.

The increased channel cross-sectional area substantially increased the tidal prism. The sheer volume of flow through the inlet has increased dramatically; and the velocities have also increased, reshaping the flood shoal, planing off high areas, and giving the feature a broader, flatter footprint. Bathymetric data analysis indicating a reduction in elevation of the seaward portion of the flood shoal has been shown. Two factors contributing to these changes are the distribution of flow over the flood shoal and the increase in the volume of this flow since project completion. The majority of the flood tidal prism is directed at and over the flood shoal with the potential for moving sediment bayward. The portion of the ebb tidal prism directed over the flood shoal is smaller, but can potentially move sediment seaward during the portion of the ebb cycle when the flood shoal is submerged. The predominance of flood flow over the flood shoal appears to have a greater ability to move sediment as evidenced by the reworking of the shoal feature.

Two recent modifications to the inlet system (structural and dredging) have contributed to changes in the flood shoal configuration: 
a. The structural change (impermeable, parallel jetties) limited sediment supply to the flood shoal and altered the inlet hydraulics. With limited sediment influx, the flood shoal no longer increased in volume as it had historically. The change from low, arrowhead to impermeable, parallel jetties allowed more concentrated flood flows to be directed toward the flood shoal. These increased flood velocities through the straighter channel directly impacted the flood shoal, resulting in changes to the flood shoal configuration.

$b$. The major dredging during construction of the new south jetty increased the cross-sectional area 40-45 percent, which also contributed to greater tidal velocities. Both the increased cross-sectional area and increased velocities contributed to the dramatic increase in tidal prism. The increased velocities have greater sediment transport potential.

It appears the southern lobe of the flood shoal will continue to deflate as flood flows shortcut across to the main navigation channel. With limited sediment supply, the flood shoal will continue to be reworked, and the center portion of the flood shoal may become the more hydraulically efficient channel.

\section{Impact of structures on navigation safety and dredging}

The locations of the inlet and flood shoals have now stabilized. Even though annual dredging is still necessary, navigation safety has significantly improved for mariners, especially for commercial fishermen, since the shoals are not shifting as previously happened. Deep water is consistently available on the north side of Barnegat Inlet.

It was anticipated during planning for the new south jetty that by dredging a new initial navigation channel through the inlet and flood shoal, the new jetty layout would focus flood and ebb currents along the new channel and create a self-maintaining inlet system. The flood and ebb currents were expected to flush from the navigation channel any sediment that might possibly enter the channel from whatever known or unknown sources. This has not proven to be the case. Dredging quantities steadily increased from a minimum of about $170,000 \mathrm{cu}$ yd $(130,000 \mathrm{cu} \mathrm{m})$ in 1991 to a maximum of about $355,000 \mathrm{cu}$ yd $(270,000 \mathrm{cu} \mathrm{m})$ in 1997. Since that time, dredging volumes have decreased to about $192,000 \mathrm{cu}$ yd $(147,000 \mathrm{cu} \mathrm{m})$ in 2000 . However, the year 2000 dredging volume was impacted by dredge availability. The $192,000 \mathrm{cu}$ yd $(147,000 \mathrm{cu} \mathrm{m})$ dredged in 2000 would have been larger except that the dredge had to undergo shipyard maintenance. 


\section{Barnegat Inlet New South Jetty Structure Stability}

The interaction of tidal currents and waves, and bathymetric effects on these processes at an inlet entrance, lead to complex and often dangerous environmental conditions. The entrance at Barnegat Inlet, New Jersey, was considered to be a navigational challenge due to the complexity of these processes (Figure 53). Construction of the new south jetty at Barnegat Inlet completed in 1991 was aimed at improving navigation and minimizing channel meandering and shoaling. Understanding the effects of the ebb shoal and tidal currents on waves impacting this entrance channel and jetty structure will enhance the determination of jetty design wave heights for structure stability and for navigation safety.

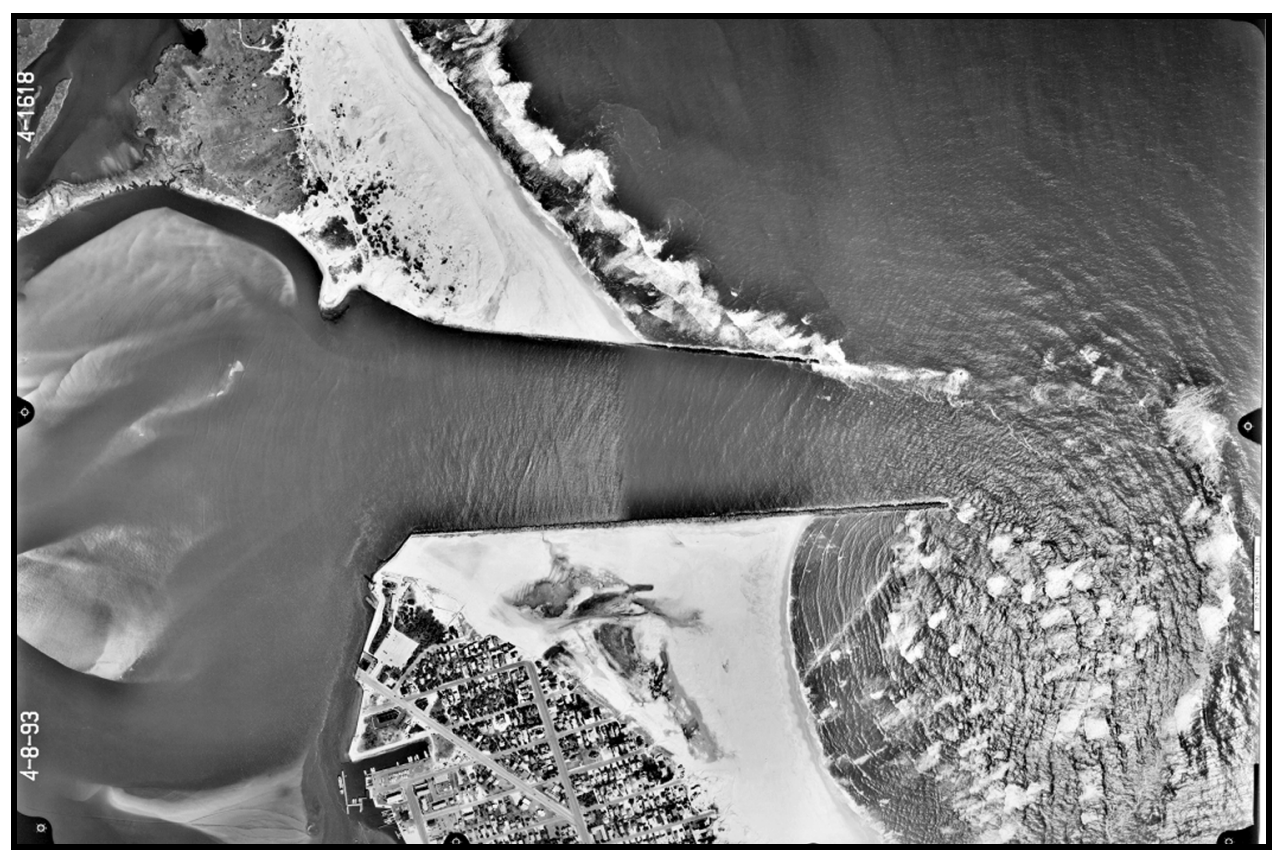

Figure 53. Waves being refracted by nearshore bathymetry and tidal currents in the vicinity of Barnegat Inlet jetties, photo April 1993

Project design Hypothesis 3 states that the new south jetty at Barnegat Inlet will be structurally stable. 
The determination of the design wave for the new south jetty was based on consideration of the wave record at Atlantic City Steel Pier (U.S. Army Engineer District, Philadelphia, 1981, 1984), and on application of the design wave criteria presented in Shore Protection Manual (1984). At that time, refraction techniques for deriving nearshore design waves from deepwater waves, often used where there is no wave record for the structure location, were not used in that analysis due to the questionable accuracy of refraction techniques in areas of highly complex and changing hydrography as occurs at Barnegat Inlet. At the present time techniques exist to look at the individual effects on the waves by bathymetry (Ebersole et al. 1986) and by currents (Smith 1997), and with a more recent integrated approach (Smith et al. 1997).

The methodology for determining if the new south jetty is structurally stable involved ascertaining actual prototype wave conditions in the vicinity of the structure to compare with wave height used in the original south jetty design. This, in turn, required determining the effects of the ebb shoal bathymetry and tidal currents on deepwater wave transformation as waves propagate from deep water offshore toward the nearshore zone. This was accomplished by examining field data from the offshore region, and then by performing a wave transformation analysis by application of the numerical simulation wave model Regional Coastal Processes Wave (RCPWAVE) model (Ebersole et al. 1986). Model simulations using the actual ebb shoal bathymetry were performed for a set of wave conditions derived from the field data and determined to be representative wave conditions. Simulation of an actual storm event was also performed with the ebb shoal bathymetry and compared to prototype data. Finally, the structure Condition Index (CI) was determined to ascertain (a) how well the structure was performing its intended function, and (b) its level of physical condition and structural integrity.

\section{South Jetty Design Waves}

The wave gauge on Steel Pier in Atlantic City dates back to September 1957. The available records used by U.S. Army Engineer District, Philadelphia, (1981, 1984), considered wave height observations for 7-min intervals every $4 \mathrm{hr}$ from that time until December 1965. From the 7-min intervals given in the records, a typical 1-min interval was selected for analysis. This typical period was then analyzed to determine the significant wave height (average of the highest onethird of the waves). The record was approximately 77 percent complete for that time period. On five occasions, the gauge failed as the wave intensity was increasing: March 1958, February 1960, September 1960, November 1960, and November 1961, when maximum wave heights immediately prior to record disruption were recorded as 13.2, 12.0, 11.0, 13.0, and $11.0 \mathrm{ft}(4.0,3.6,3.3,4.0$, and $3.3 \mathrm{~m}$ ), respectively. It is reasonable to assume that wave heights greater than those recorded had occurred during each of those nonrecord periods.

In addition to these periods of no record, the destruction of the gauge early on 6 March 1962 precluded obtaining any wave height observations during the intense portion of the 6-7 March 1962 storm. To include this period in the record, an estimate was made of the wave heights at 4-hr intervals during the most severe period of the storm. The tide gauge had continued to operate so that a record of tidal stage was available for the period. A comparison of this with the predicted tides made it possible to estimate the tidal surge caused by the storm. 
Since the major portion of tidal surge is the result of wind (which is also the primary wave-producing force), it is reasonable to assume that the surge and wave heights varied in a similar manner.

The unusual behavior of the 6-7 March 1962 storm lends additional weight to the validity of this assumption. Unlike a hurricane, when the center is usually moving and the wind fetch area is changing, the center of the March 1962 storm remained stationary for 2 or more days at a distance of 150 to 200 miles (240 to $320 \mathrm{~km}$ ) offshore. With the wind fetch and direction constant during that period, the wave and surge heights tended to be closely related. For this storm, maximum waves at sea ranging up to $40 \mathrm{ft}(12.2 \mathrm{~m})$ in height were reported, and have been accepted with reservations. However, since an 18-ft (5.5-m) wave was recorded in September 1961, and a 15-ft (4.6-m) wave was recorded in the early portion of the March 1962 storm, an estimated significant wave $20 \mathrm{ft}(6.1 \mathrm{~m})$ high off Steel Pier is not considered excessive. Using a 20-ft $(6.1-\mathrm{m})$ maximum significant wave, heights at 4-hr intervals were estimated for the storm period by assuming that they varied directly with the surge.

Due to the number of instances when the wave height record is missing for periods following increasing heights, it was believed that the frequency of high waves had been conservatively estimated. It was concluded that a 16-ft (4.9-m) significant wave may be expected to occur approximately once a year, and that a design significant wave height of $20 \mathrm{ft}(6.1 \mathrm{~m})$ with a frequency of about once in 10 years would be appropriate. The influence of including estimated values for the wave heights during the March 1962 storm becomes negligible as the height decreases and more frequent wave occurrences are considered.

Past design experience in the New Jersey coastal area had shown that the larger, nonbreaking waves coinciding with higher tide levels would pass over coastal structures, and are generally less destructive than breaking waves that occur at lower tide levels but break fully onto the structures. Thus, breaking waves were used for the design of the new south jetty at Barnegat Inlet. These design waves were determined using the method in Shore Protection Manual (1984). That design document shows the dependence of design breaking wave height on critical design depth at the structure toe, slope on which the structure is built, incident wave steepness, and distance traveled by the wave during breaking.

Because the water depth is critical for ascertaining the wave height that will begin to break in that water depth, and because the water depth increases with distance from the shoreline, the 4,270-ft- (1,300-m-) long south jetty was divided into four equal increments of length. A breaking design wave height was determined for each of these four increments. The net effects of the outer bar and the existing jetties would be to reduce the height of the waves from the north, northeast, and south that approach the new south jetty. Thus, it was determined by the U.S. Army Engineer District, Philadelphia (1981, 1984), that, due to the 1,000-ft (305-m) spacing between the jetties and the channel depths between the jetties and across the outer bar, design breaking waves with heights of 14.0, 14.0, 15.2 , and $15.9 \mathrm{ft}(4.3,4.3,4.6$, and $4.8 \mathrm{~m})$ (proceeding from the shoreline offshore) were appropriate for the four south jetty increments. Design water depths were determined by assuming that scour would occur along the jetty after completion of the project. The amount of this assumed scour was based on results of the previous physical model study (Sager and Hollyfield 1974). 


\section{Wave Heights at Barnegat Inlet}

Upon completion of the new south jetty project, this MCNP monitoring program was initiated to evaluate the performance of the project. Of primary interest was the collection of wave data both outside the influence of the ebb shoal and shoreward of the ebb shoal, near the jetty structure. The transformation of waves over the ebb shoal could thus be evaluated to ascertain the actual wave heights at increments along the jetty structure for comparison with the design wave heights used for construction of the jetty. The actual transformed wave heights impacting the structure determine whether or not the structure is stable. Also, the influence of currents on these waves could be evaluated with current data collected in the inlet.

\section{Data collection and analysis}

In May 1994, three instruments were deployed near Barnegat Inlet to monitor the south jetty project (Figure 54). A DWG was deployed 1,300 m off the south jetty tip in about $13 \mathrm{~m}$ of water for one year. A Seapac pressure sensor was placed $215 \mathrm{ft}(65 \mathrm{~m})$ off the south jetty tip in about $16.4 \mathrm{ft}(5 \mathrm{~m})$ of water for 6 months, and an ADCP was placed in the inlet for 35 days.

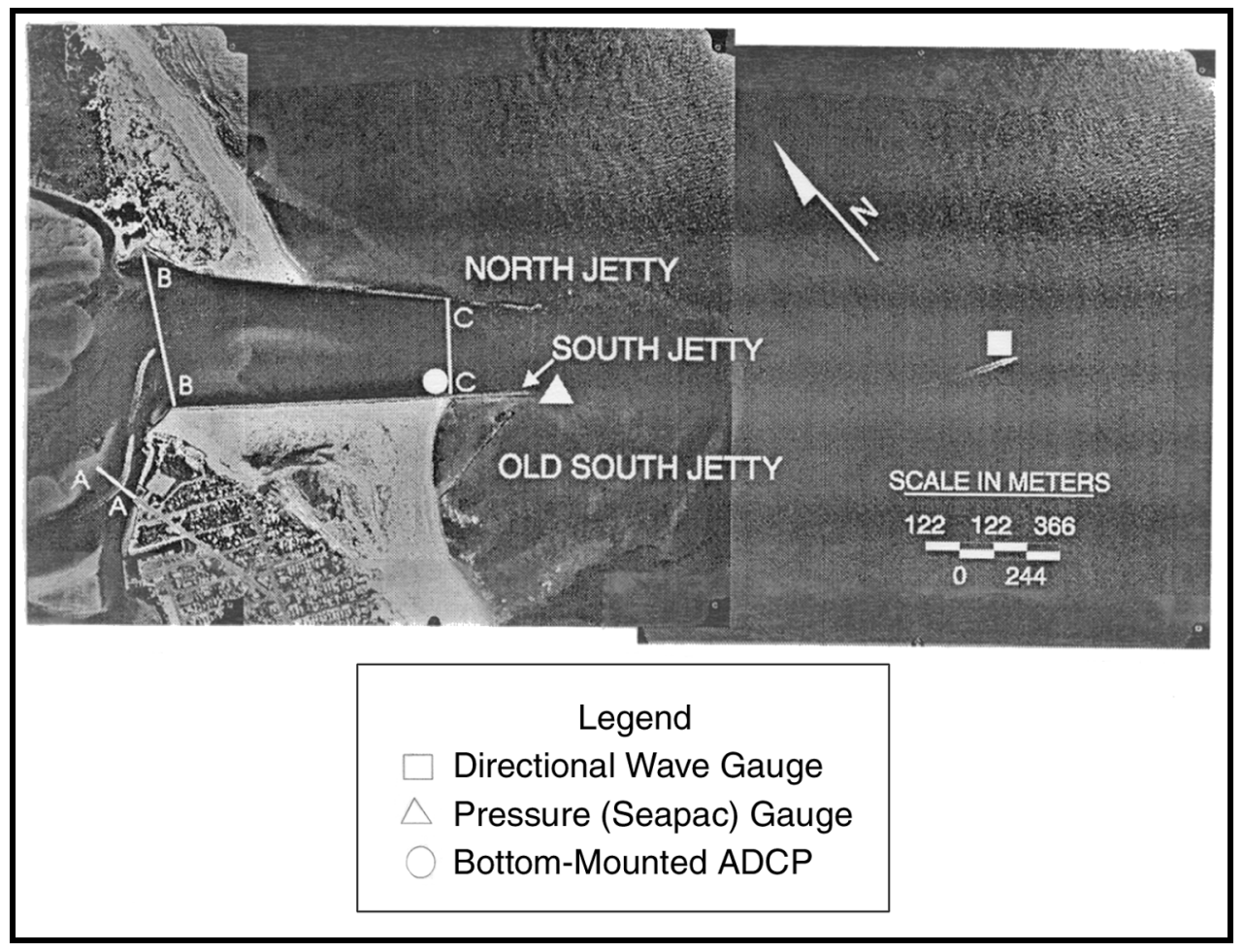

Figure 54. Instrumentation locations used in determining wave transformation at Barnegat Inlet jetties for ascertaining structural stability

The DWG was operational for a year. The average significant wave height $H s_{\text {avg }}$ for that period was $2.4 \mathrm{ft}(0.74 \mathrm{~m})$, the average peak period $T_{\text {avg }}$ was $8.9 \mathrm{sec}$, and the maximum significant wave height $H s_{\max }$ was $12.6 \mathrm{ft}(3.84 \mathrm{~m})$ (Table 9). For the 6-month period when data were available at both wave gauges, the statistics are similar. However, for the 35 days when ADCP data were available, 


\begin{tabular}{|c|c|c|c|c|c|c|}
\hline \multicolumn{7}{|c|}{$\begin{array}{l}\text { Table } 9 \\
\text { Wave Gauge Statistics }\end{array}$} \\
\hline \multirow{2}{*}{$\begin{array}{l}\text { Time } \\
\text { Period }\end{array}$} & \multicolumn{3}{|c|}{ DWG } & \multicolumn{3}{|c|}{ Seapac } \\
\hline & $H s_{\text {avg, }}, \mathrm{m}$ & $T_{\text {avg, }}$, sec & $H s_{\max }, \mathrm{m}$ & $H s_{\text {avg }}, \mathrm{m}$ & $T_{\text {avg, }}$ sec & $H s_{\max }, \mathrm{m}$ \\
\hline 1 year & 0.74 & 8.9 & 3.84 & --- & --- & --- \\
\hline 6 months & 0.72 & 8.7 & 3.84 & 0.75 & 9.0 & 2.59 \\
\hline 35 days & 0.63 & 8.0 & 1.74 & 0.70 & 8.1 & 1.76 \\
\hline
\end{tabular}

$H s_{\text {avg }}$ was smaller. During the 35-day period, the area experienced the highest spring tide water levels of the year. The Seapac, operational for 6 months, had $H s_{\text {avg }}=2.5 \mathrm{ft}(0.75 \mathrm{~m}), T_{\text {avg }}=9.0 \mathrm{sec}$, and $H s_{\max }=8.5 \mathrm{ft}(2.59 \mathrm{~m})$, again with a smaller average significant wave height for the shorter (35-day) period. Comparing the two gauges, the average significant wave height for the Seapac is slightly (4 percent) higher than the DWG for the 6-month period, but never achieves waves as high as the DWG gauge. The DWG occurrence data are shown in Figures 55 and 56.

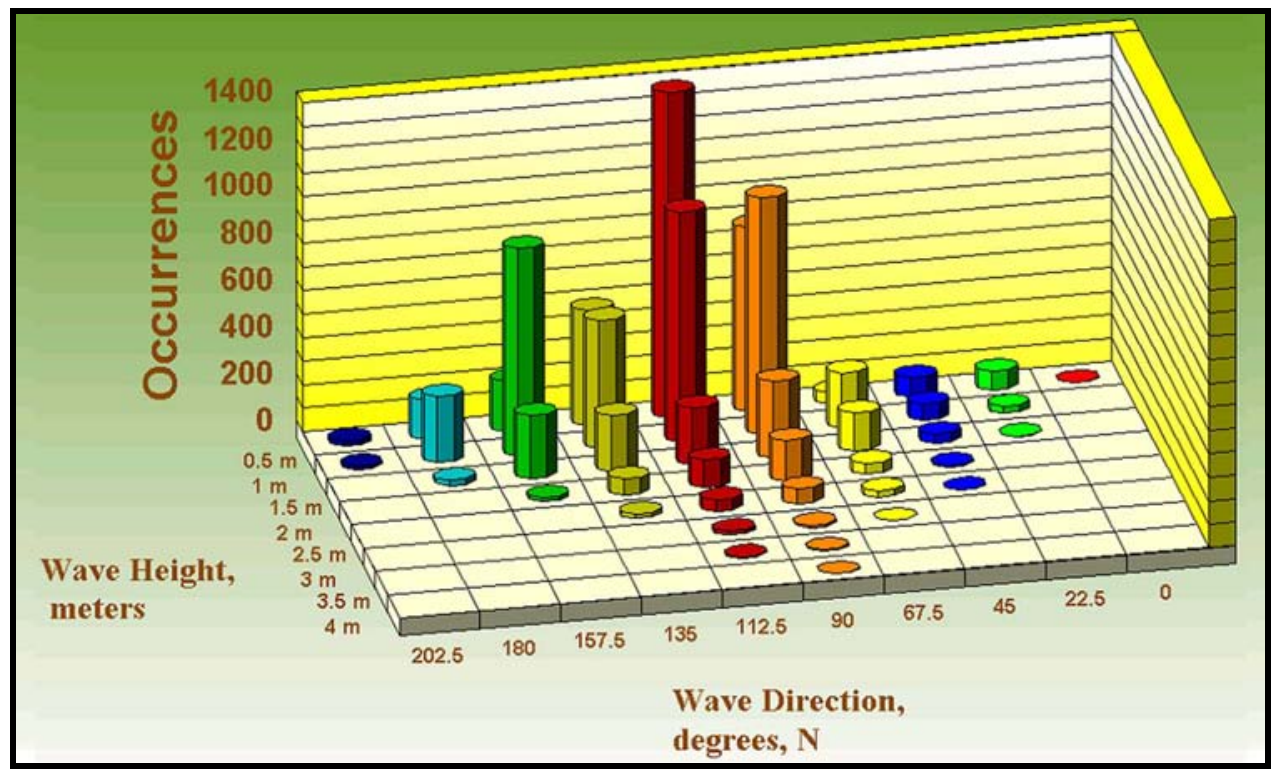

Figure 55. Occurrences of wave height by direction of approach, DWG, May 1994-June 1995

The ADCP was operational for 35 days from 18 May through 23 June 1994. Velocities through the water column at $1.6-\mathrm{ft}(0.5-\mathrm{m})$ intervals were recorded every $10 \mathrm{~min}$ with this instrument. During this period, depth-integrated flood velocities averaged $3.4 \mathrm{ft}$ per sec $(105 \mathrm{~cm}$ per sec), and depth-integrated ebb velocities averaged $2.5 \mathrm{ft}$ per sec $(75 \mathrm{~cm}$ per sec).

\section{Wave height transformation}

By simply comparing average wave heights from the two wave gauges, one might erroneously conclude that no change occurs from the DWG gauge to the 


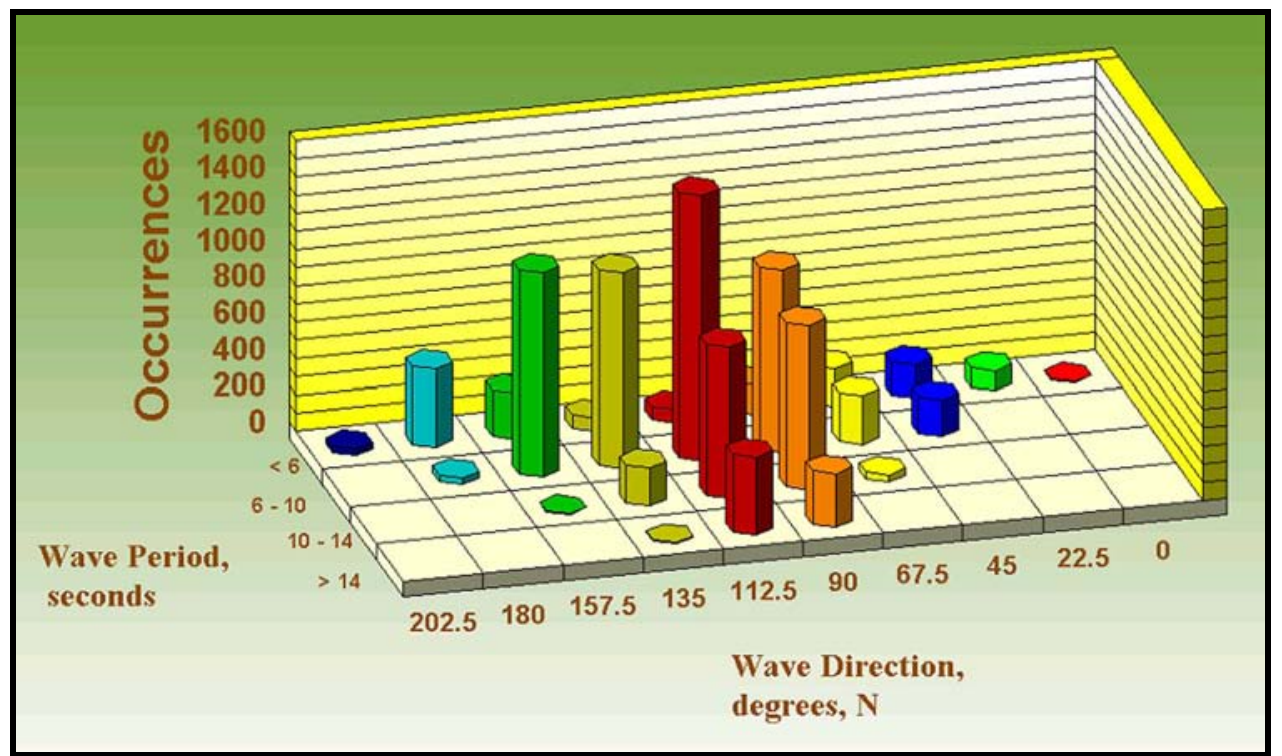

Figure 56. Occurrences of wave period by direction of approach, DWG, May 1994-June 1995

Seapac gauge since the average wave heights are only about 4 percent higher at the Seapac gauge. Rather than examining the overall average wave heights, the nondimensional wave height ratio $H_{\text {inner }}(\mathrm{Seapac}) / H_{\text {outer }}(\mathrm{DWG})$, for each hour of the 6-month period was evaluated. The overall ratio shows that waves shoal from the outer gauge to the inner gauge and increase in height by 10 percent (Table 10). Looking more specifically at flood and ebb tide conditions, the inner gauge experiences greater increases in wave height (12 percent) for ebb tide conditions than for flood tide conditions (9 percent). Ebb currents tend to shorten and peaken the opposing waves, whereas the flood currents tend to elongate and flatten the waves traveling in the same direction as the flood currents. For the 35-day period when water levels were elevated, the wave height ratios were higher due to less breaking on the ebb shoal. Since ebb currents occur near low water, the increased water levels during the 35-day period had the most dramatic effect during the ebb currents, allowing less breaking and thus increasing the wave height ratio by 4 percent to a value of 16 percent. The flood current ratio increased 1 percent to a value of 10 percent.

\section{Table 10}

\section{Wave Height Ratios}

\begin{tabular}{||l|l|l|l||}
\hline \hline Time Period & Ebb Ratio & Flood Ratio & Overall Ratio \\
\hline \hline 6 months & 1.12 & 1.09 & 1.10 \\
\hline 35 days & 1.16 & 1.10 & 1.13 \\
\hline
\end{tabular}

A more detailed examination of wave height ratios was accomplished by studying wave height ratios for different classes of DWG wave heights (Figure 57). Smaller waves less than 3.3 to $4.9 \mathrm{ft}$ ( 1.0 to $1.5 \mathrm{~m}$ ) increase in wave height by 5 to 30 percent. These smaller waves, when opposing an ebb current, tend to peak up more than the average condition, as shown by the higher-than-average curve. 


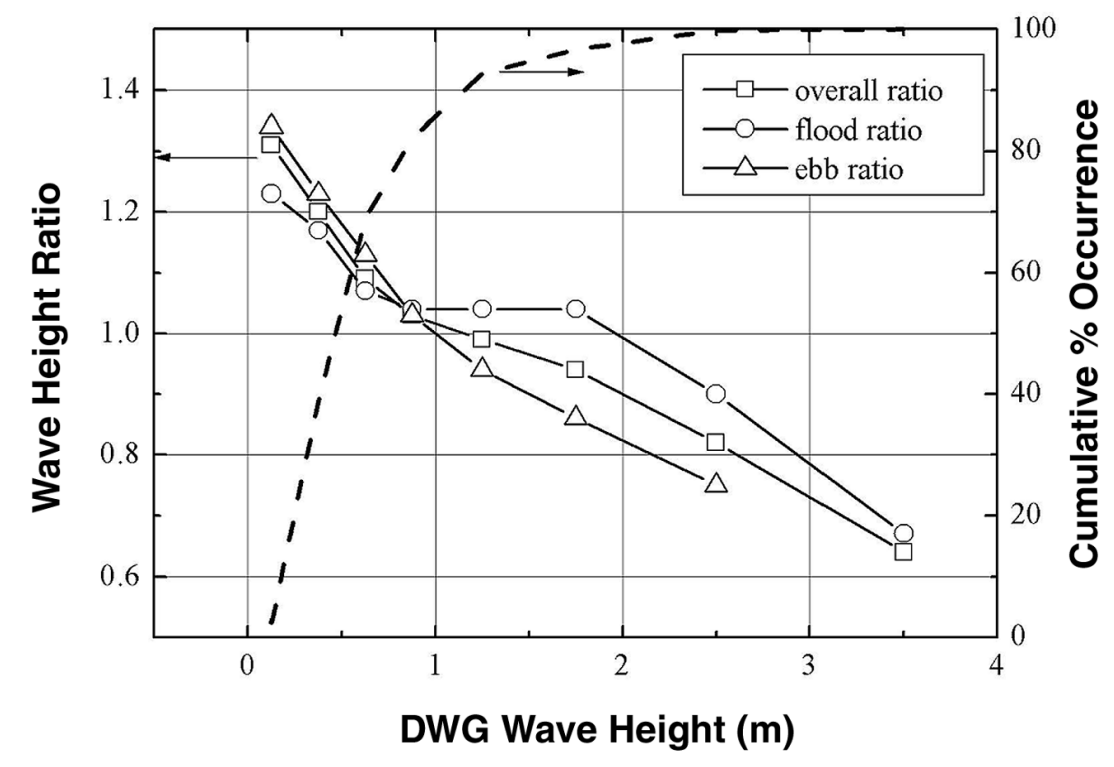

Figure 57. Wave height ratio versus DWG wave height (6-month average)

Small waves traveling with the flood current are elongated or flattened somewhat, as shown by the lower-than-average curve. Larger waves greater than $4.9 \mathrm{ft}(1.5 \mathrm{~m})$ tend to break (ratio less than 1.0) on the ebb shoal. Larger waves occurring at peak ebb, when the tide level is near its lowest, are more likely to break than large waves occurring at high water, which is when peak flood occurs. The overall ratios are greater than 1.0 because 80 percent of all waves for the data collection period are less than $3.3 \mathrm{ft}(1 \mathrm{~m})$ when shoaling is most prevalent.

Wave height ratios for the 35-day period when current data were collected were also compared (Figure 58). Instead of comparing peak flood and peak ebb periods based on water level as was done for the 6-month period, the entire ebb cycle and entire flood cycle could be analyzed. The general trend of the wave height ratio curve is the same. For ebb cycles, smaller waves increase in wave heights more than average, and larger waves break more than average. Slackwater ratios are similar to the overall ratios. Flood cycles show less than average increases in wave height for smaller waves and less breaking of large waves. The most interesting area is in the 3.3- to 4.9-ft (1.0- to 1.5-m) critical zone. There is less breaking during the 35-day period than for the 6-month period for waves of this size, indicating a strong dependence on water level. The highest spring tide water levels of the year occurred during the 35-day period.

Examining wave height ratios for various period bands shows that there is not a great deal of variation with period ( $<20$ percent) (Figure 59). The shortest period waves (circle and square symbols) tend to have somewhat lower wave height ratios for smaller waves and the large, long-period waves ( $\times$ symbol) experience the greatest energy loss. Looking at the wave height ratios for various angle bands, it can be seen that there is more variation with angle of approach (Figure 60). The more obliquely incident waves (square and $\times$ symbols) are most 


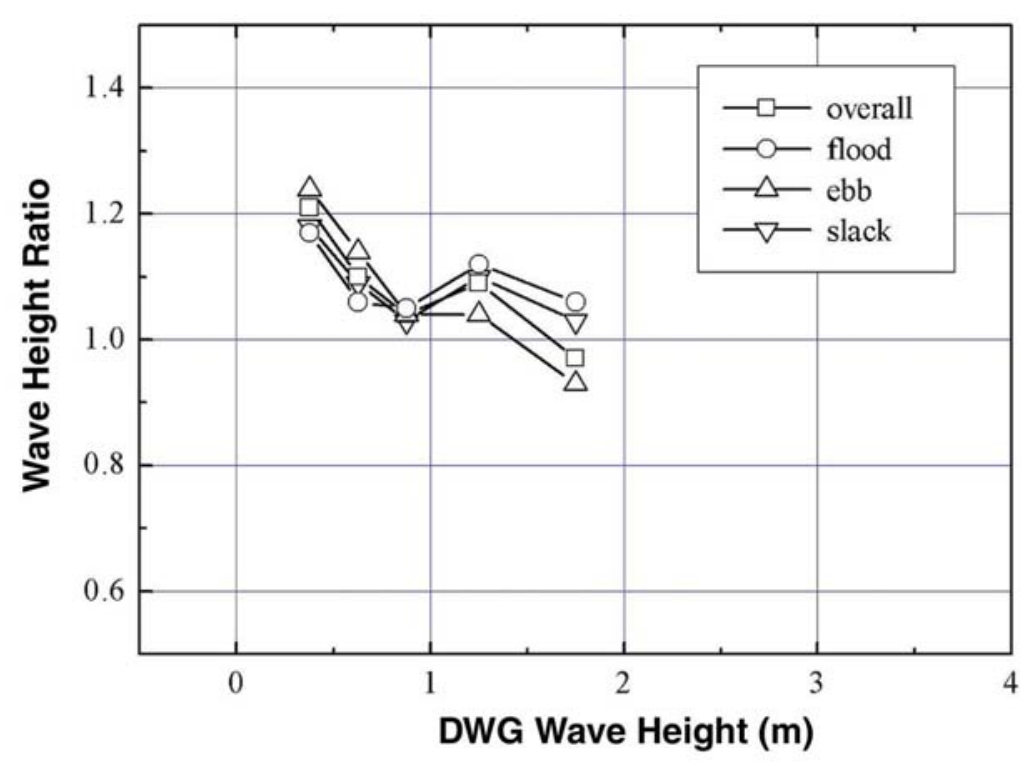

Figure 58. Wave height ratio versus DWG wave height (35-day average)

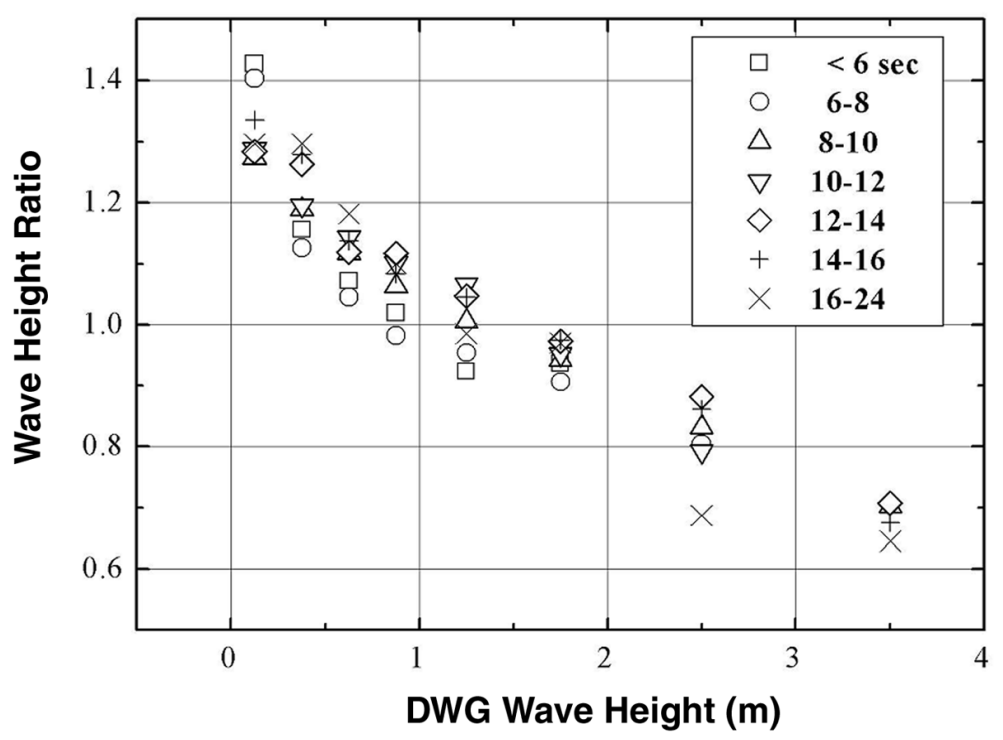

Figure 59. Wave height ratio versus DWG wave height (variation with period)

likely to have low wave height ratios. Waves from about 90-135 deg (inverted triangle and diamond symbols) relative to north have the highest wave height ratios.

In summary, small waves less than the critical 3.3- to 4.9-ft (1.0- to $1.5-\mathrm{m})$ range increase in height most likely due to shoaling. Ebb currents enhance the increased wave height near the jetty structure, whereas flood currents flatten the waves somewhat. Large waves greater than $4.9 \mathrm{ft}(1.5 \mathrm{~m})$ are likely to break, 


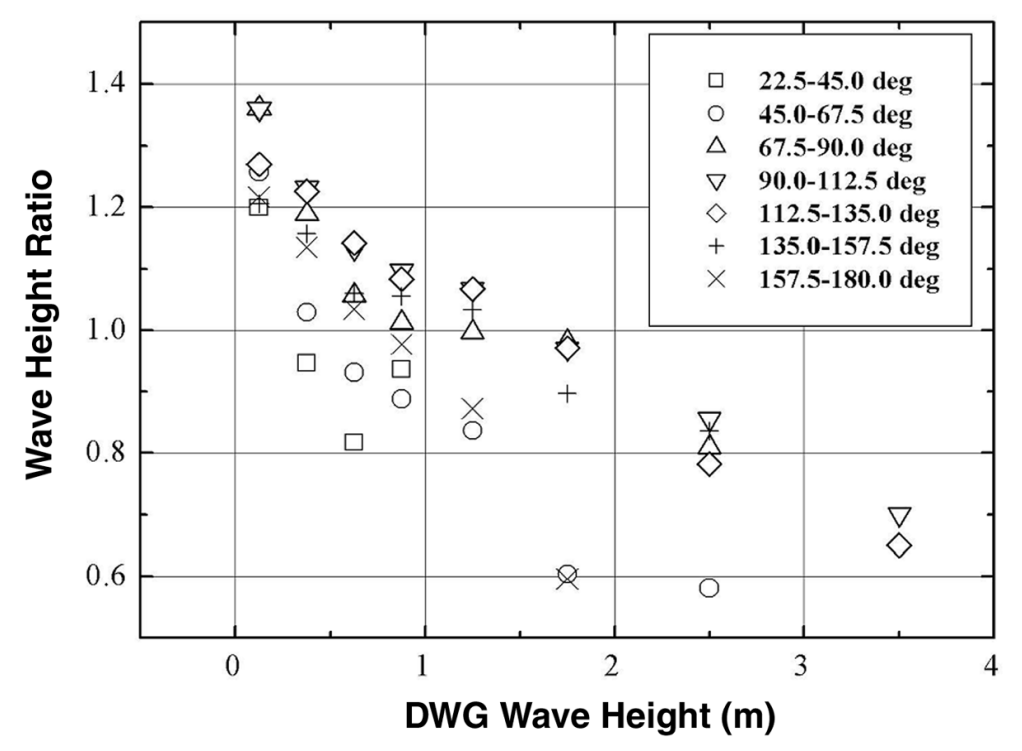

Figure 60. Wave height ratio versus DWG wave height (variation with direction)

with the greatest reduction in wave height for low water conditions. Maximum ebb currents at Barnegat Inlet occur near low water. During the 35-day period when water levels were superelevated, there was less breaking in the 3.3- to 4.9$\mathrm{ft}(1.0-$ to $1.5-\mathrm{m})$ critical zone, indicating a strong dependence on water level. There is more variation in wave height ratios for various angle bands than for various period bands.

\section{Numerical model simulations}

The initial motivation for the wave analysis for this MCNP project was to examine waves reaching the jetty structure. Determining the influence of tidal currents and the ebb shoal bathymetry on waves reaching the structure demanded further attention. Comparison of model simulations with and without the ebb shoal bathymetry for standard wave conditions would show the influence of the ebb shoal on wave heights reaching the structure. Model simulations of wave transformation over the ebb shoal and a plane beach bathymetry were done using model RCPWAVE (Ebersole et al. 1986). This linear, monochromatic wave model does not include the effects of currents. The purposes of the simulations were to look for trends and determine if either currents and/or bathymetry had a significant effect on wave transformation. Comparison of model simulations with the ebb shoal bathymetry to prototype conditions would give a good indication of the importance of tidal currents on waves reaching the structure.

For the standard (nonstorm wave) simulations, wave direction, wave height, and wave period bands were determined from the 6-month DWG data set; and representative wave conditions were determined. Five angle bands, three wave heights, three period bands, and three water levels were selected for simulating with the numerical simulation wave model, for a total of 135 model simulations (Table 11). A June-July 1994 bathymetric survey of the ebb shoal region using the Scanning Hydrographic Operational Airborne Lidar Survey (SHOALS) system was used in the model simulations (Figure 61). 


\section{Table 11}

Representative Wave Conditions for Numerical Model Simulations

\begin{tabular}{||l|l|l|l||}
\hline \hline Height, $\mathbf{m}$ & Period, sec & Direction, deg N & Water Level \\
\hline \hline 0.75 & 7 & 56 & Low tide \\
\hline 1.50 & 11 & 79 & Midtide \\
\hline 2.25 & 15 & 101 & High Tide \\
\hline & & 124 & \\
\hline & & 146 & \\
\hline
\end{tabular}

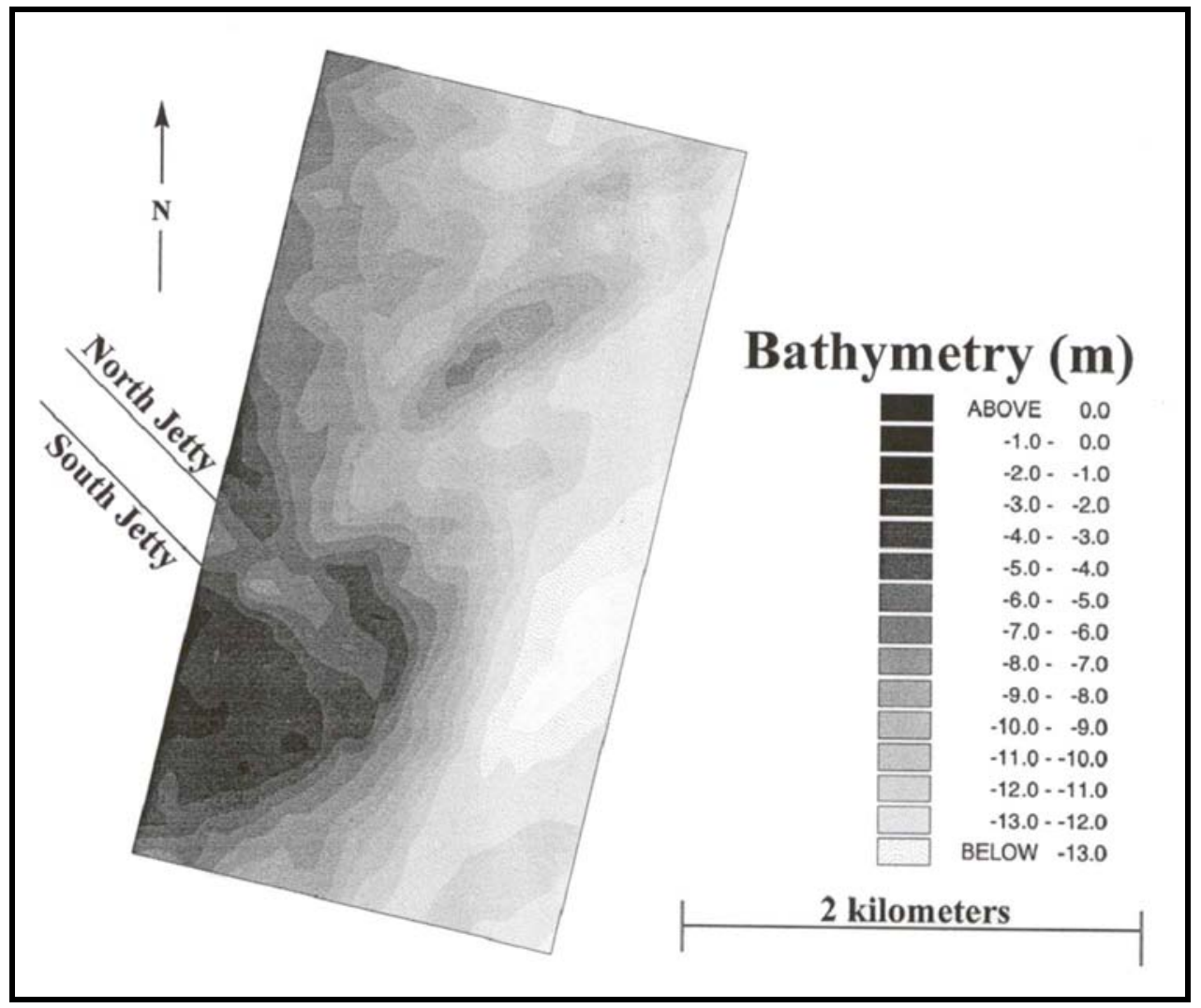

Figure 61. Barnegat Inlet ebb shoal bathymetry from SHOALS June-July 1994 survey

\section{Standard (nonstorm) simulation results}

Figure 62 is an example of numerical simulation model results from the largest (7.4-ft $(2.25-\mathrm{m}))$ height and longest period (15-sec) waves simulated. These results show breaking in the ebb shoal region for the lower water level indicated by lighter shading. At the higher water level there are higher wave heights on the ebb shoal indicated by darker shading and some decreased wave heights in the deeper channel areas indicated by lighter shading. 


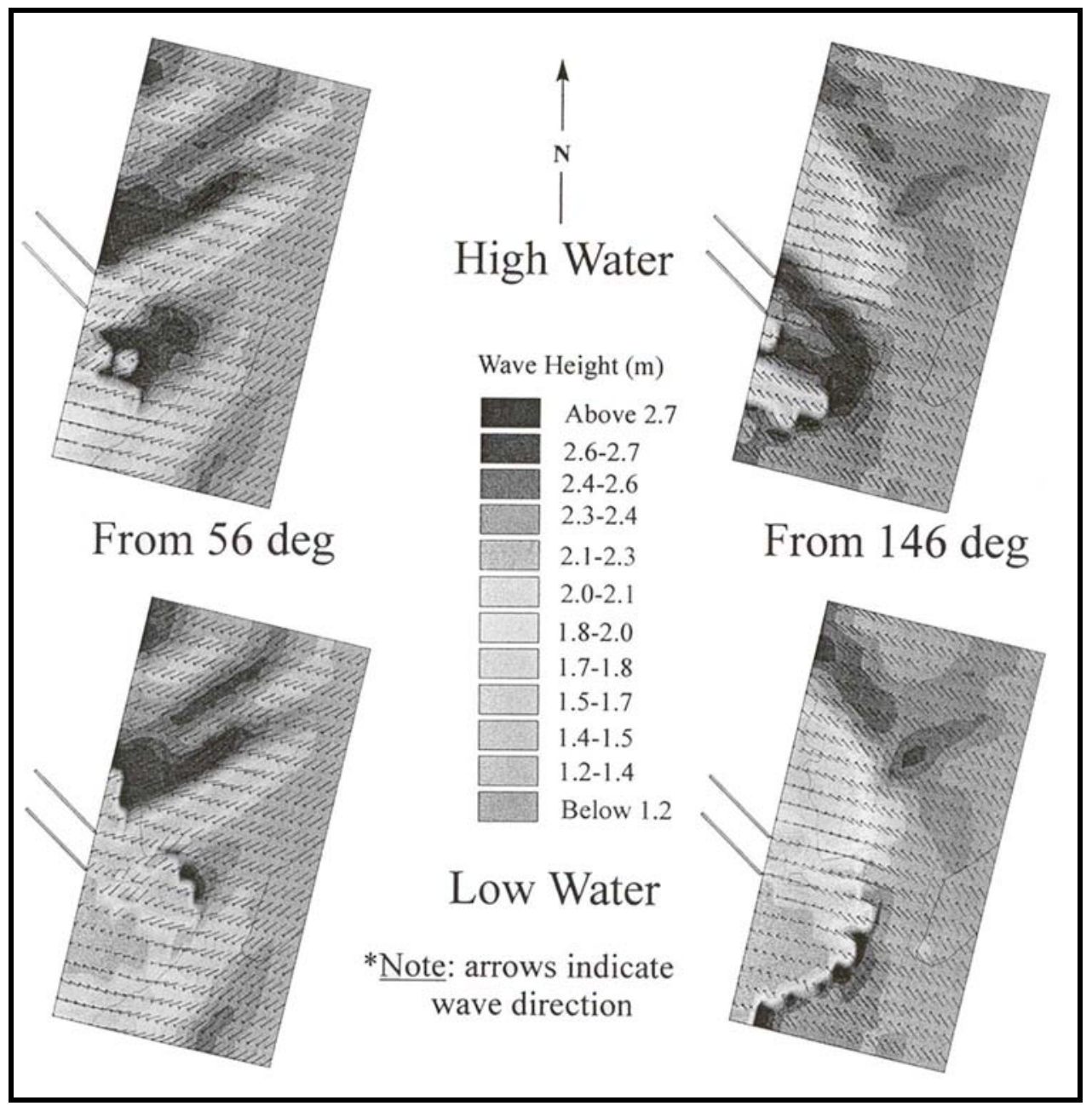

Figure 62. Standard (nonstorm) numerical simulation model results for $7.4-\mathrm{ft}$ $(2.25-\mathrm{m})$ wave height and $15-\mathrm{sec}$ wave period

Comparing overall wave height ratios produced by the model with the ebb shoal bathymetry to prototype ratios shows that the model simulates wave transformation at Barnegat Inlet well (Figure 63). Simulations with the plane beach bathymetry consistently overpredict wave height ratios. Both of these results indicate the significant influence of the ebb shoal bathymetry on wave transformation at an inlet entrance.

Examination of model versus prototype wave heights and wave height ratios by direction band, period band, and water level reveals more detailed information about wave transformation at Barnegat Inlet (Figure 64). By direction band, waves that are nearly shore-normal (79- and 101-deg direction bands) have the largest wave heights at the Seapac gauge. Note that the prototype average wave height at the Seapac gauge is much less than the model average wave height because the model simulations average only the selected 135 conditions, whereas the prototype averages the entire 6-month hourly data set (approximately 5,000 values). However, the general trend of the model and prototype wave height curves versus wave direction is similar. 


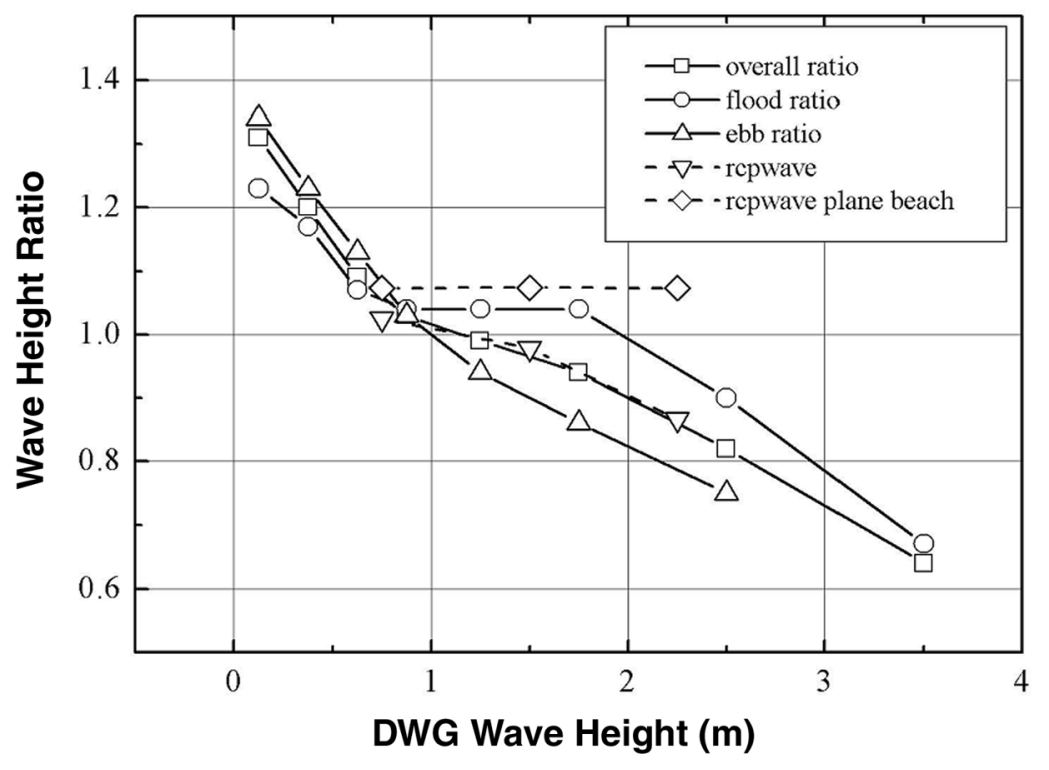

Figure 63. Wave height ratio versus DWG for both numerical simulation model and prototype

Wave height ratios are also largest for the nearly shore-normal (101- and 124-deg) direction bands. Wave height at the Seapac gauge varies less with wave period. Prototype wave heights are slightly smaller for longer periods, and model wave heights are slightly larger for longer periods. Wave height ratios increase with increasing wave period. Model results follow the same general trend as the prototype. Wave heights grouped by water level show that waves occurring at low water (peak ebb) are slightly smaller than high water (peak flood) waves, possibly due to large waves breaking at low water. Wave height ratios are slightly higher at low water, possibly due to ebb currents peakening smaller waves. Model results show that wave heights and wave height ratios at low water are significantly lower, possibly due to the limited number of conditions simulated and lack of currents in the model.

\section{Storm simulation results}

From the DWG wave data analysis it was shown that most waves at Barnegat Inlet (>80 percent) are small, generally less than $1 \mathrm{~m}$ in height. However, waves as large as $12.6 \mathrm{ft}(3.84 \mathrm{~m})$ high (Figure 65) were measured at the DWG location during the 1-year data collection period. Storm waves reaching the inlet entrance are more likely to cause damage to the jetty structure and are, therefore, of more concern from an engineering design standpoint. By simulating an actual storm event through several tidal cycles, the effect of water level, bathymetry, and currents on wave transformation can be further examined.

A storm event that occurred in November 1994 was selected because of its long duration (4 days) for comparison of the numerical simulation results with the Seapac gauge at the jetty (Figure 66). Note that peaks in the jetty (Seapac) wave height time-series occur at high water (peak flood), troughs occur at low water (peak ebb), and steep gradients between the peaks and troughs indicate 


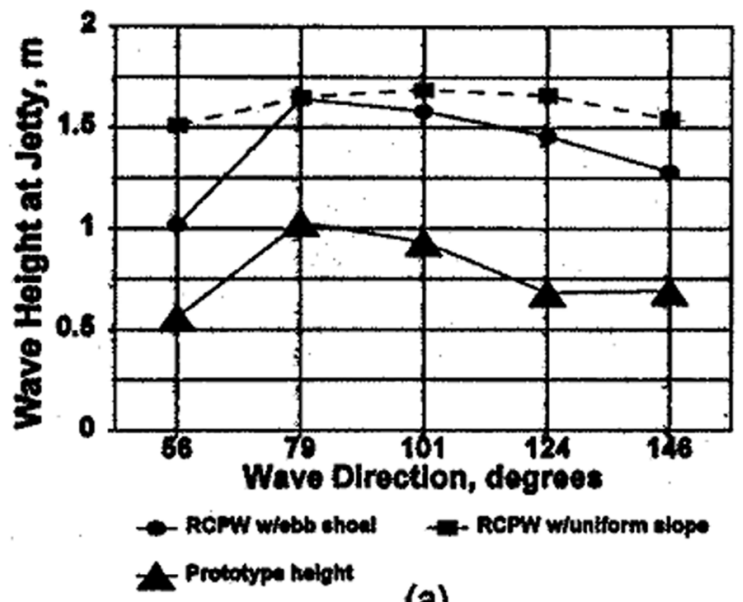

(a)

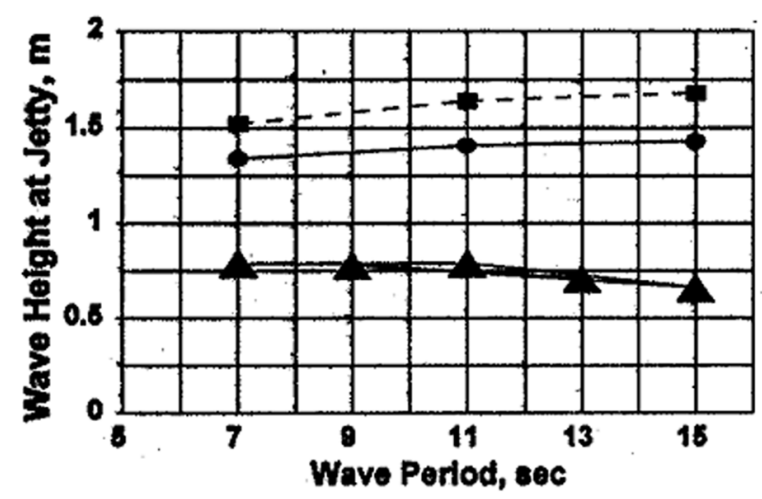

- RCPW w/ ebb shoal tan RCPW w/uniform olopo

A Pretotype Haight at Jetty

(c)

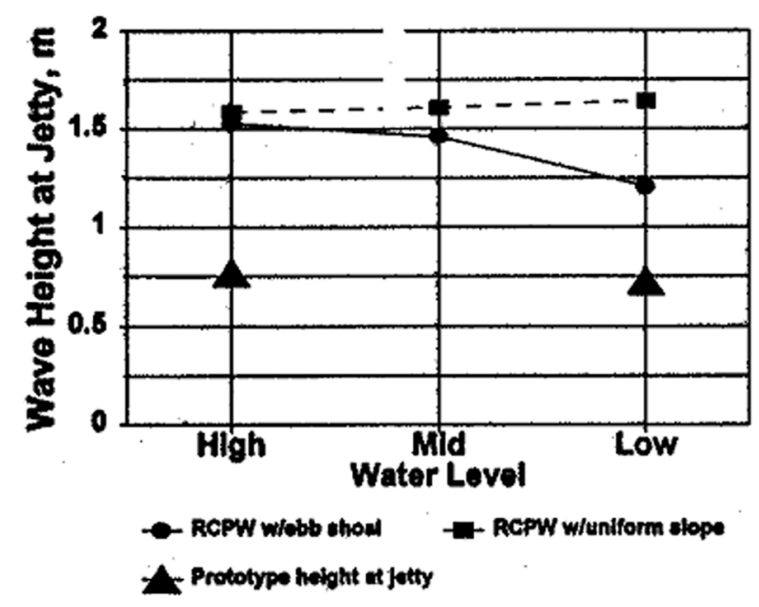

(e)

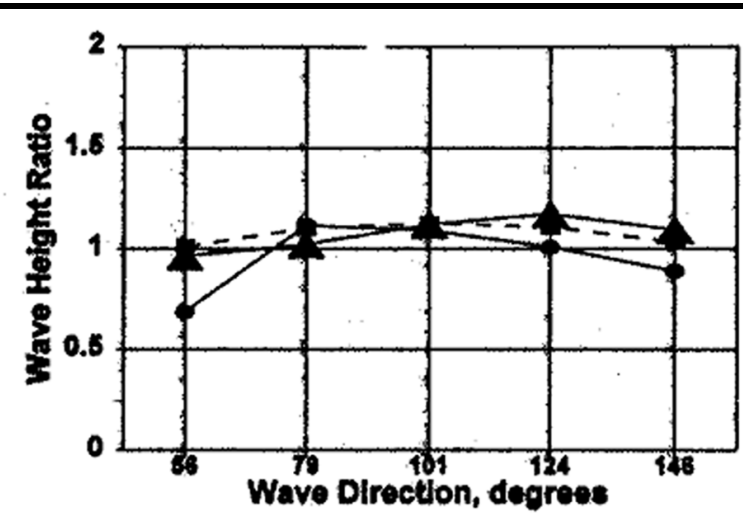

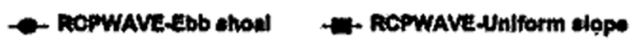

(b)

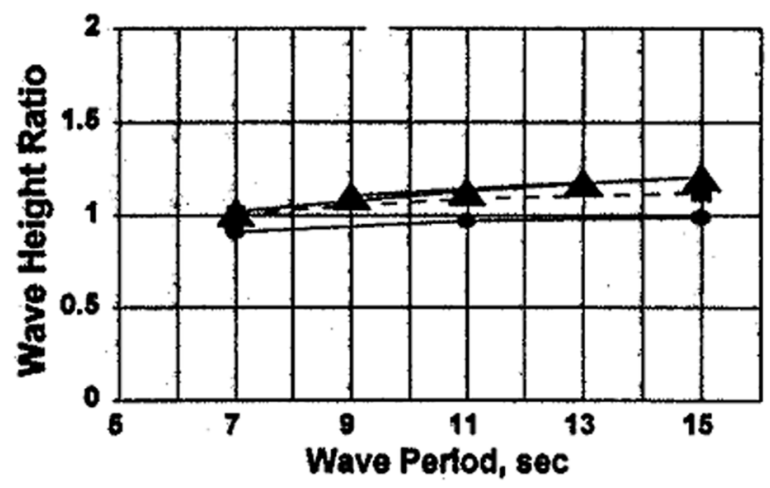

- RCPWAVEEbb shod RCPWAVE-Uniform slope

A Prototyp

(d)

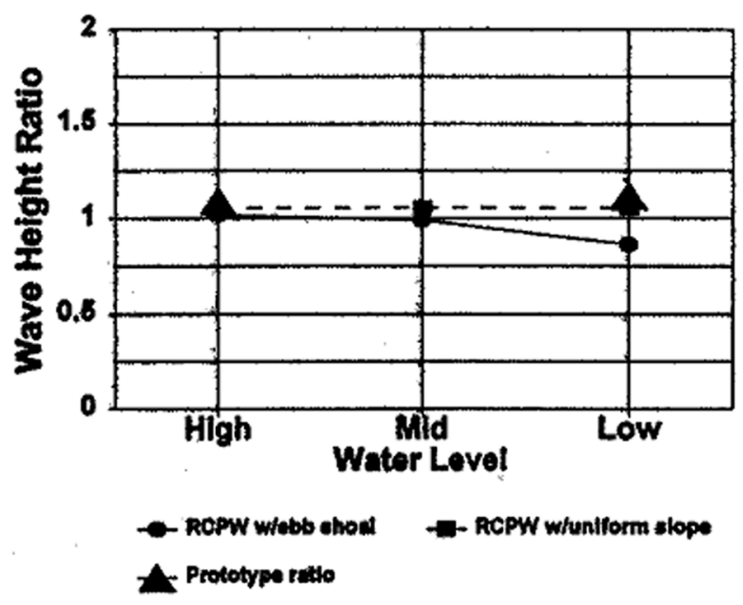

(†)

Figure 64. Wave height at the jetty and wave height ratio versus direction of approach, wave period, and water level 


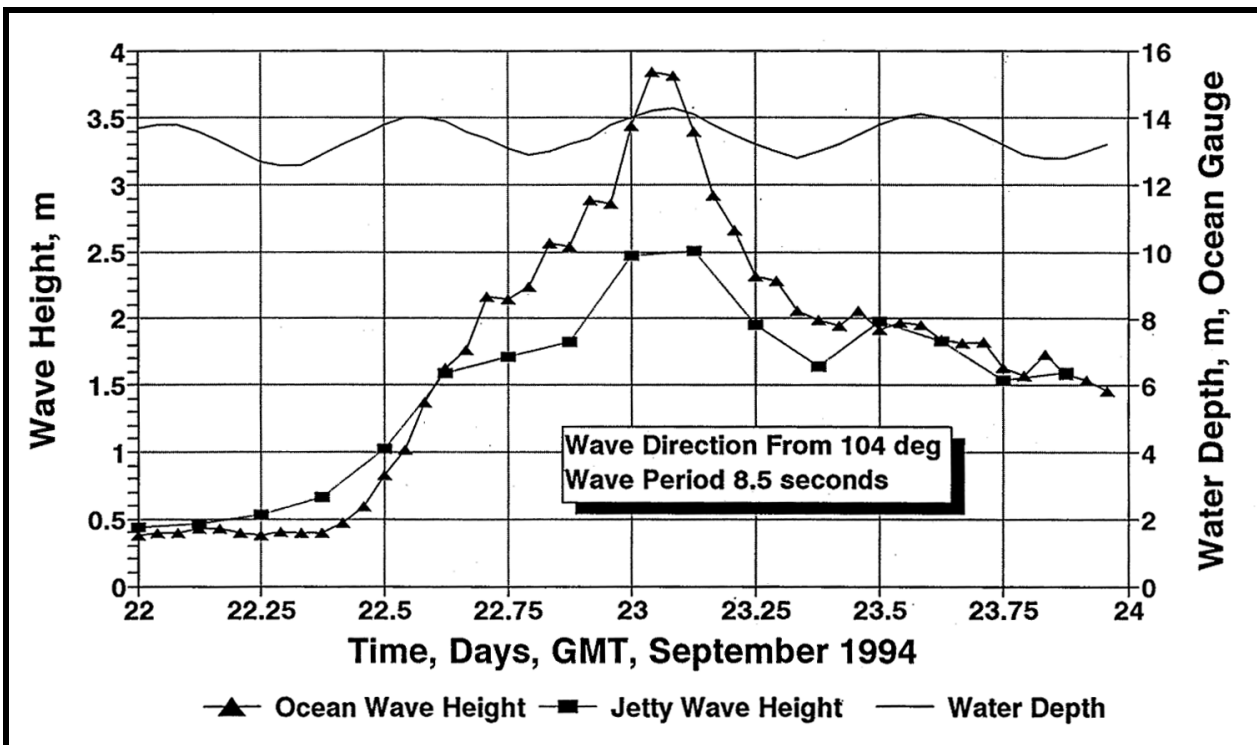

Figure 65. Wave height at DWG for storm of 22-23 September 1994, showing maximum deep-water wave height of $12.6 \mathrm{ft}(3.84 \mathrm{~m})$, and jetty maximum wave height reduced by refraction and shoaling to $8.2 \mathrm{ft}$ $(2.5 \mathrm{~m})$

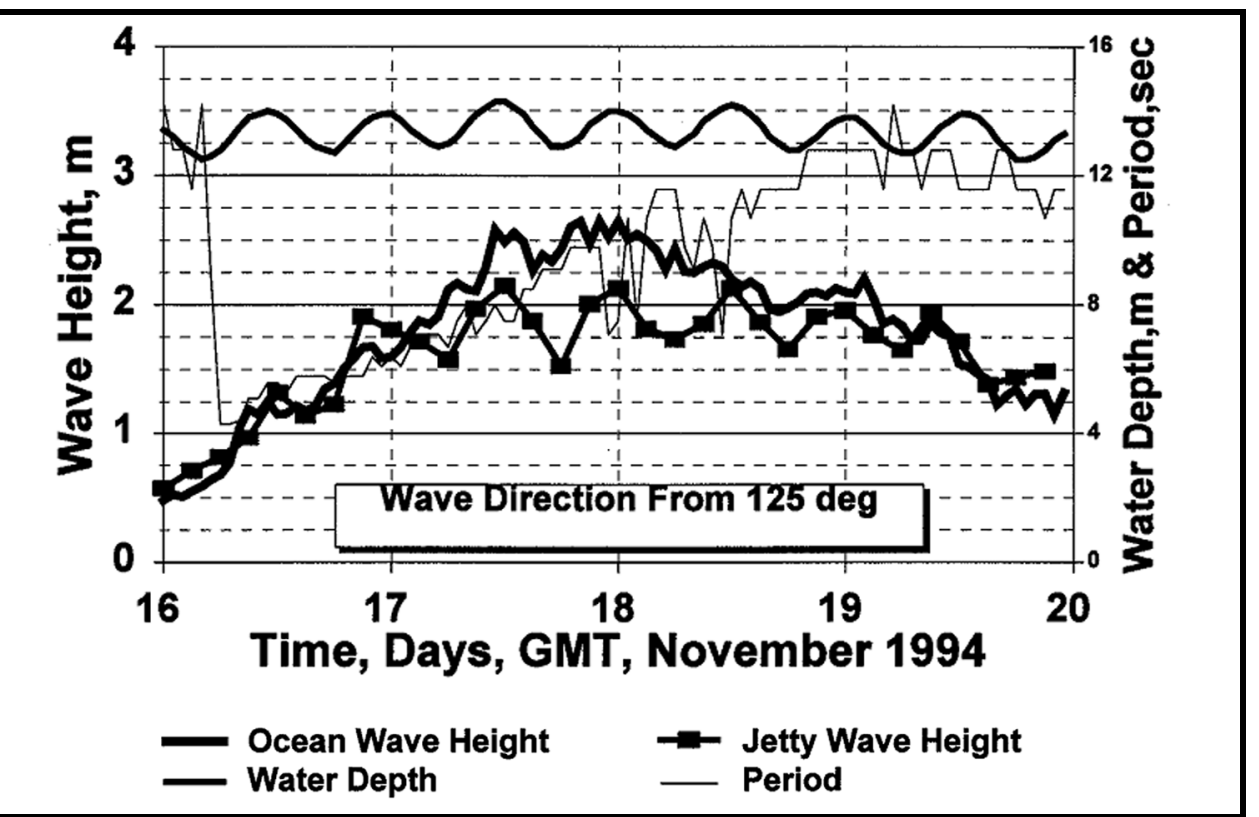

Figure 66. November 1994 storm time-series

slack-water conditions. To simulate this storm, hourly DWG wave conditions were used as input to the RCPWAVE model for a total of 96 simulations. Model results at the Seapac location were then compared to prototype Seapac conditions (Figure 67). The model performed well for slack water (no current) conditions, but overpredicted wave heights at peak flood and underpredicted wave heights at 


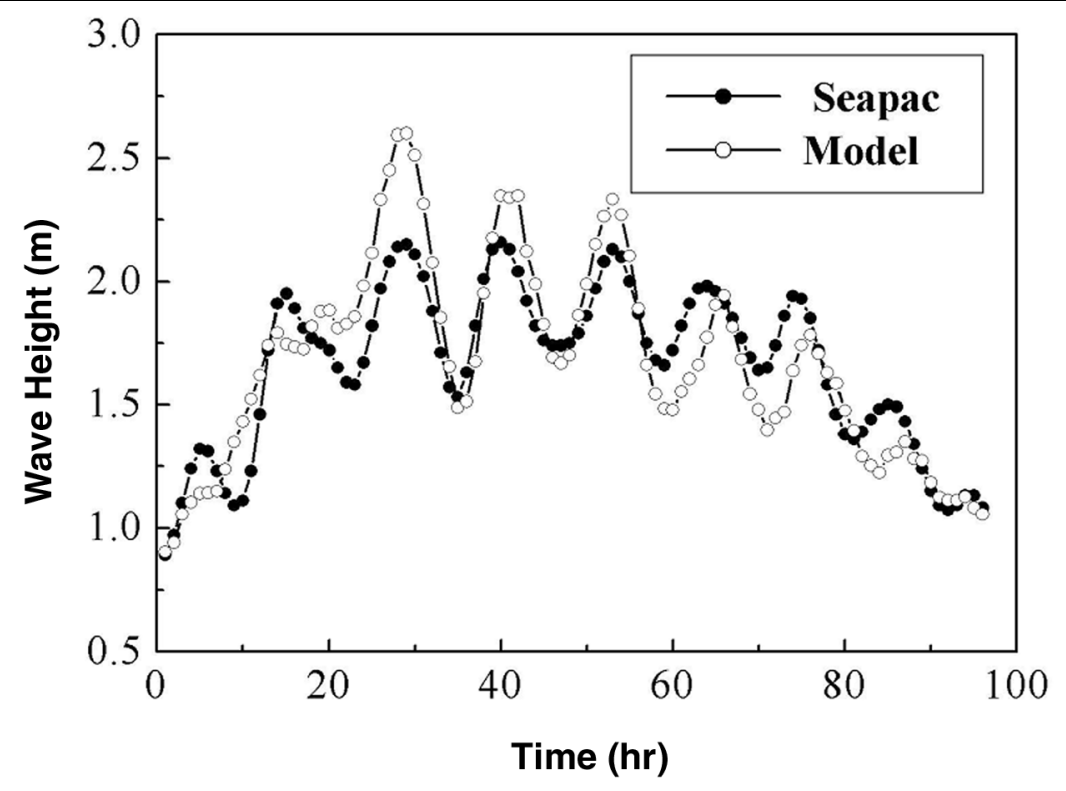

Figure 67. Wave height prototype and numerical simulation model comparisons at Seapac location

peak ebb. Since the model does not have the capability of simulating tidal currents, these results indicate that ebb currents may partly account for the increase in wave height at peak ebb, and flood currents may partly account for the decrease in wave height at peak flood.

\section{Examination of wave spectra}

Vincent and Jensen (1997) examined changes in the spectral distribution of wave energy for wind waves over a $3.1-$ mile $(5-\mathrm{km})$ reach just prior to the surf zone. Wave data used in their analysis consisted of frequency spectra collected near the U.S. Army Engineer Waterways Experiment Station, Coastal and Hydraulics Laboratory, Field Research Facility near Duck, North Carolina, during a storm on 26-27 October 1990. They found that midrange frequencies lose up to 40 percent of the energy content while the low- and high-frequency ranges gain energy. In the onshore wind cases, gain in the high-frequency range dominated; and for the offshore wind cases, gain in the low-frequency range dominated.

This technique was applied with data at Barnegat Inlet for the 16-20 November 1994 storm. That analysis shows that the greatest energy loss is usually at or near the peak frequency with some energy gains at the high and low frequencies as shown by Vincent and Jensen (1997) (Figures 68a through 68d). Note that the frequency normalized by the peak frequency is indicated on the abscissa and the energy difference between the DWG and Seapac gauges normalized by the DWG energy at the peak frequency is indicated on the ordinate.

For larger waves (Figures 68a and b), energy losses occur for a wider band of frequencies. For larger waves at low water (Figure 68b), breaking is indicated by significant energy loss for most energy bands; however, there is some energy 


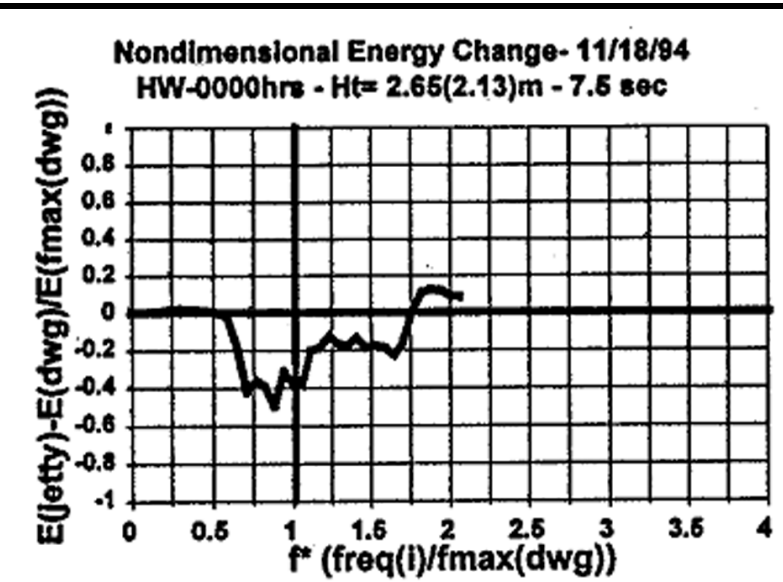

(a)

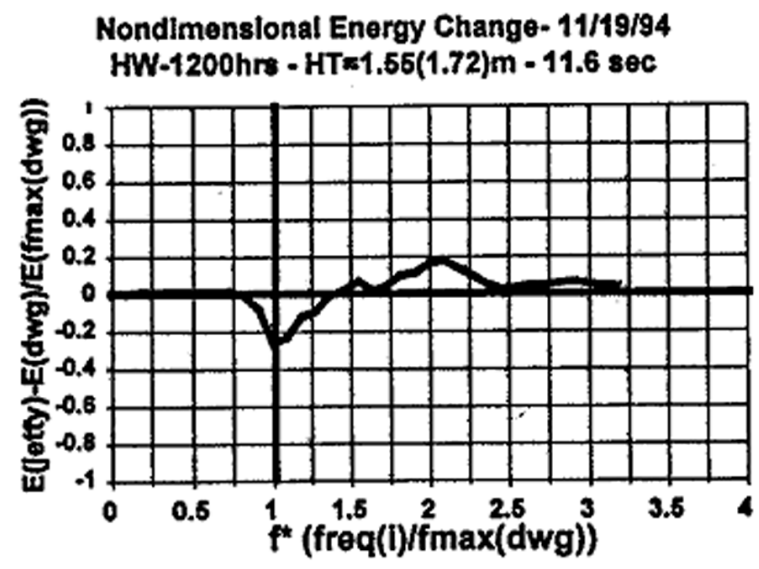

(c)

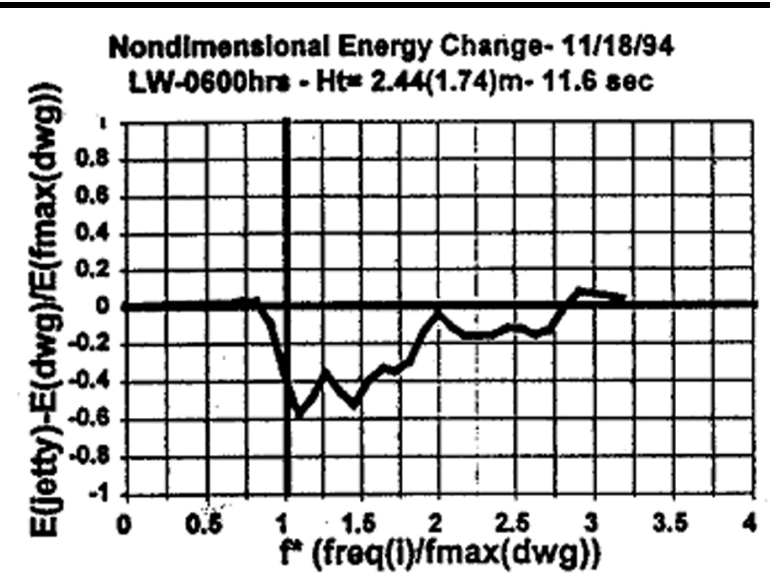

(b)

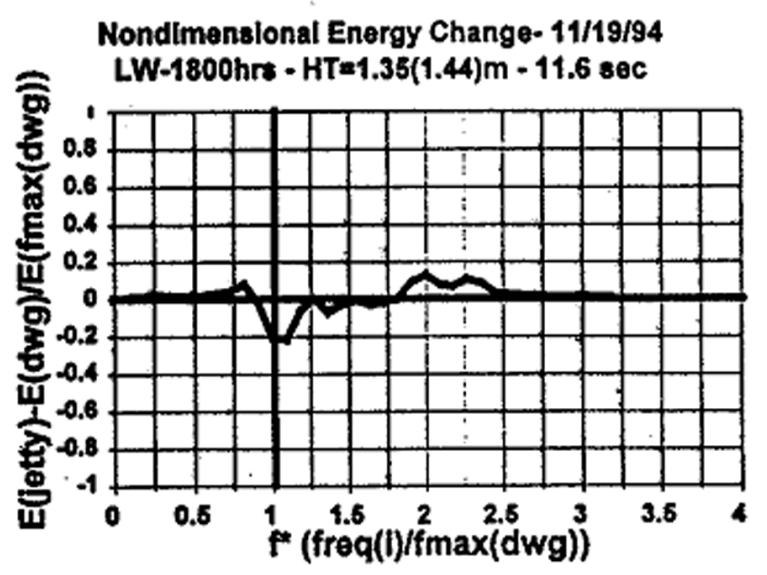

(d)

Figure 68. Nondimensional energy change between DWG and Seapac wave gauge (plot labels indicate water level, time, DWG significant wave height, Seapac significant wave height, and peak period)

gain at the second harmonic. For nonbreaking waves at low water (Figure 68d), energy loss is most significant at the peak frequency and energy gain is most significant at the first harmonic. For high water conditions, energy loss is most significant at the peak frequency for smaller waves (Figure 68c). For larger waves at high water (Figure 68a), the peak energy loss shifts below the peak frequency to a slightly lower frequency. Energy gains are, again, most significant at the first harmonic.

\section{South Jetty Condition Index}

\section{Condition Index for breakwaters and jetties}

The $\mathrm{CI}$ is a uniform procedure for assessing the condition of rubble-mound breakwaters and jetties. It creates assessment methods that allow the conditions of structures and their parts to be expressed numerically to take best advantage of computational techniques in maintenance management. The $\mathrm{CI}$ allows for a 
concise reporting system that indicates the deficiencies a structure may have, which parts of the structure are deficient, and the relative severity of the deficiencies.

For coastal structures, the CI is determined from a Functional Index (FI) and a Structural Index (SI). The FI indicates how well a structure (or reach) is performing its intended functions, while the SI for a structure or structural component indicates its level of physical condition and structural integrity. Before the first inspection and ratings are made, each structure must be divided along its length into permanent reaches based on functional and structural characteristics. These reach boundaries will apply to all future CI inspections and ratings. In addition, structure performance requirements must be defined, as well as the minimum structural integrity level that will permit proper

performance.

The $\mathrm{CI}$ is determined by a detailed walking visual inspection of the structure. The inspector (or inspection/engineering team) rates six structural categories for three different structural components, for each reach of the structure. The six structural categories are (a) breach: displaced cap/armor, or settling cap/armor; (b) core exposure or loss; (c) armor loss: displaced, settling, or bridging; (d) loss of armor contact/armor interlock; (e) armor quality defects: rounding, cracking, spalling, or fracturing; and (f) slope defects: steepening or sliding. The three structural components are (a) crest/cap, (b) seaside (head), and (c) channel/harbor side.

The CI ratings are determined primarily from visual inspections of the structure and by the rating guidance provided by U.S. Army Corps of Engineers (1993). The six structural categories are given a numerical rating from 0 to 100 (with 100 being ideal) for each structural component. Figure 69 illustrates the typical features of a rubble-mound breakwater or jetty. It is important to note that construction and cross-sectional composition of rubble structures may differ considerably from that shown in Figure 69. Where significant differences occur, the inspector may need to adjust the interpretation of some rating categories and determine ratings accordingly.

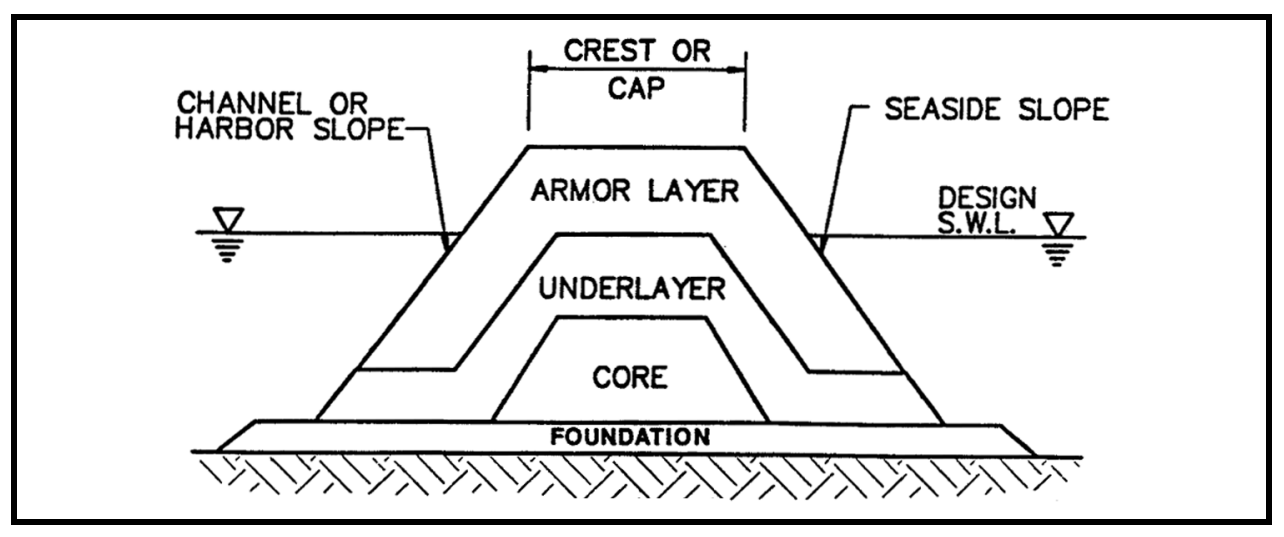

Figure 69. Typical rubble-mound breakwater or jetty cross-section features 


\section{New south jetty breakwater design}

The new south jetty has a unique design feature (Figure 70). It has a twolayer capstone design, with the bottom layer of capstones at the center replaced with corestone to prevent sand migration through the pervious capstone layer. No other Corps jetty design has the same cross section as that constructed at Barnegat Inlet south jetty. There are four layers of stone, with the two bottom layers (bedding stone layer and mat stone layer) being quite thin. The bedding stone layer is about $1 \mathrm{ft}(0.3 \mathrm{~m})$ thick, and the mat stone layer is about $2 \mathrm{ft}$ $(0.6 \mathrm{~m})$ thick. The use of two very thin bedding and mat stone layers is quite unusual. The top elevation of the core stone was increased in this design to make the design sandtight. This was done by reducing the armor layer thickness at the top center of the jetty from two stones to one stone. The core was thus raised one armor layer in thickness along the center line to form an impermeable barrier. A similar design had been used to make the north jetty sandtight when it was raised from $0 \mathrm{ft}(0 \mathrm{~m})$ mean sea level $(\mathrm{msl})$ to $+8 \mathrm{ft}(2.4 \mathrm{~m}) \mathrm{msl}$.

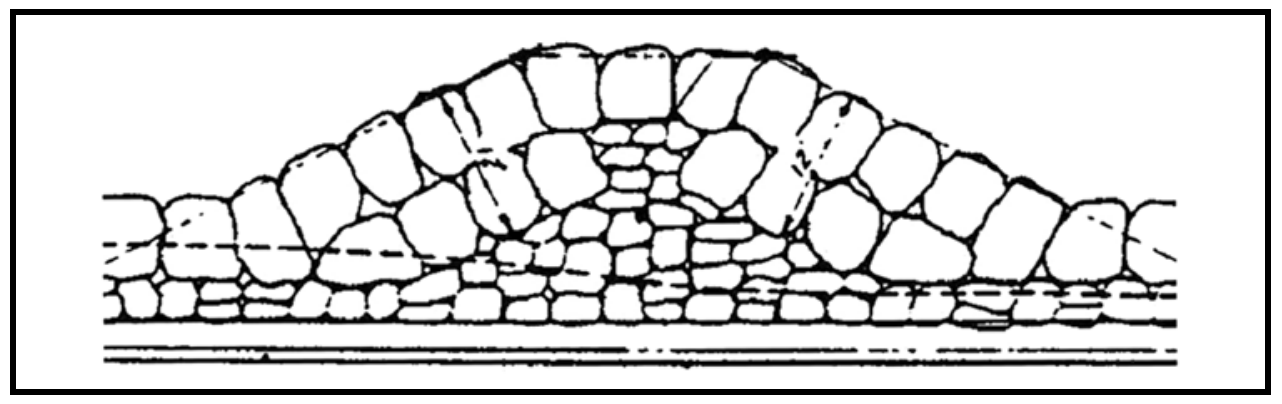

Figure 70. Barnegat Inlet new south jetty cross section showing unique design features

\section{Condition Index inspections}

South jetty structure CI inspections consisting of detailed visual walk-thestructure examinations were conducted in 1993, 1994, 1995, and 1996. Several significant and severe storms impacted this region of coastline during this period, and resulted in a slow but gradual movement of some of the armor and corestone. While the corestone design was intended to prevent sand movement through the capstone layer, some locations along the jetty indicated this was not the actual case. The water was able to move through the jetty onto the fill area immediately south of the structure, and a meandering channel on the landside indicated flow was occurring through the jetty as the tide rose. Conversely, pooling water flowed out on the falling tide. Dye studies were conducted to enhance understanding of movement through the jetty.

Figure 71, taken from Barnegat Lighthouse looking oceanward, shows the extensive fill region between the new south jetty and the old arrowhead jetty. Figure 72 was taken from the ocean end of the structure looking toward Barnegat Lighthouse, and shows the sand fill region adjacent to the jetty.

Two locations along the jetty were noted that appeared to permit flow through the jetty. At station 13+00 small corestone had been washed out to the south or landward side, and the jetty is highly permeable. At station $8+50$ there 


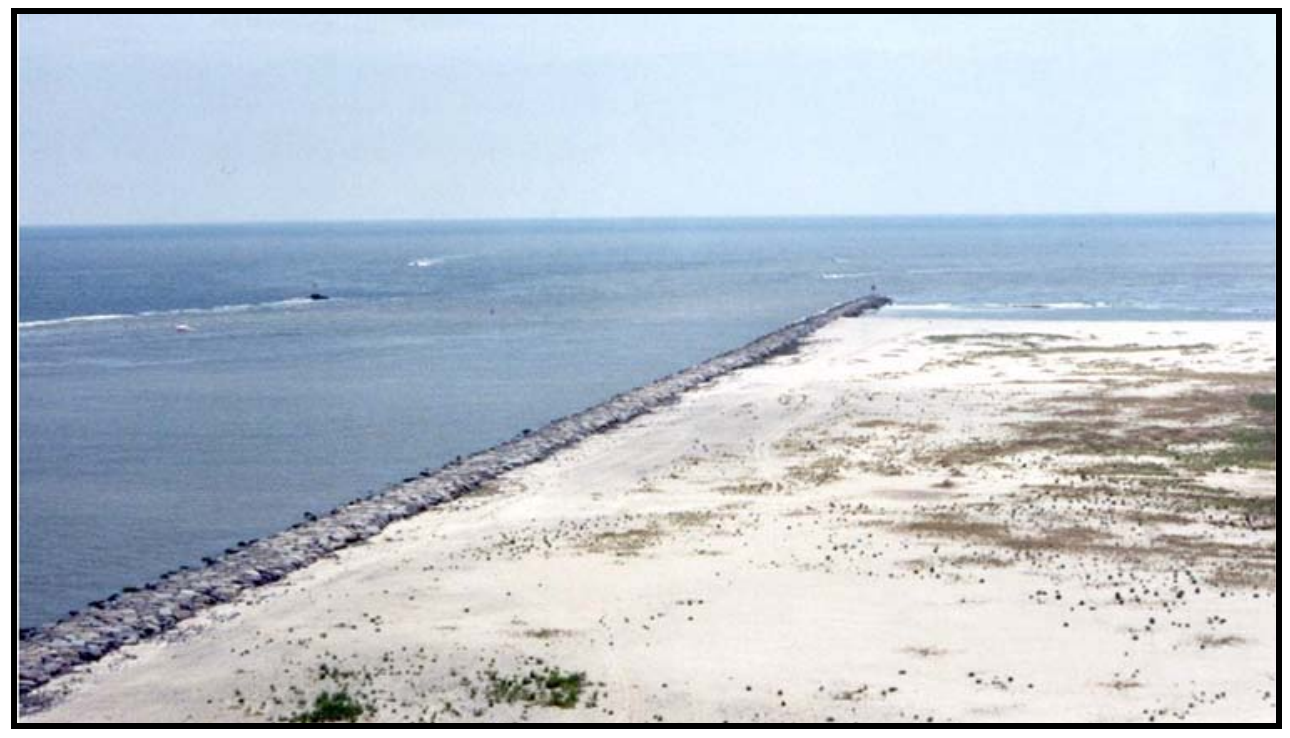

Figure 71. Barnegat Inlet new south jetty and fill region between new south jetty and old arrowhead jetty

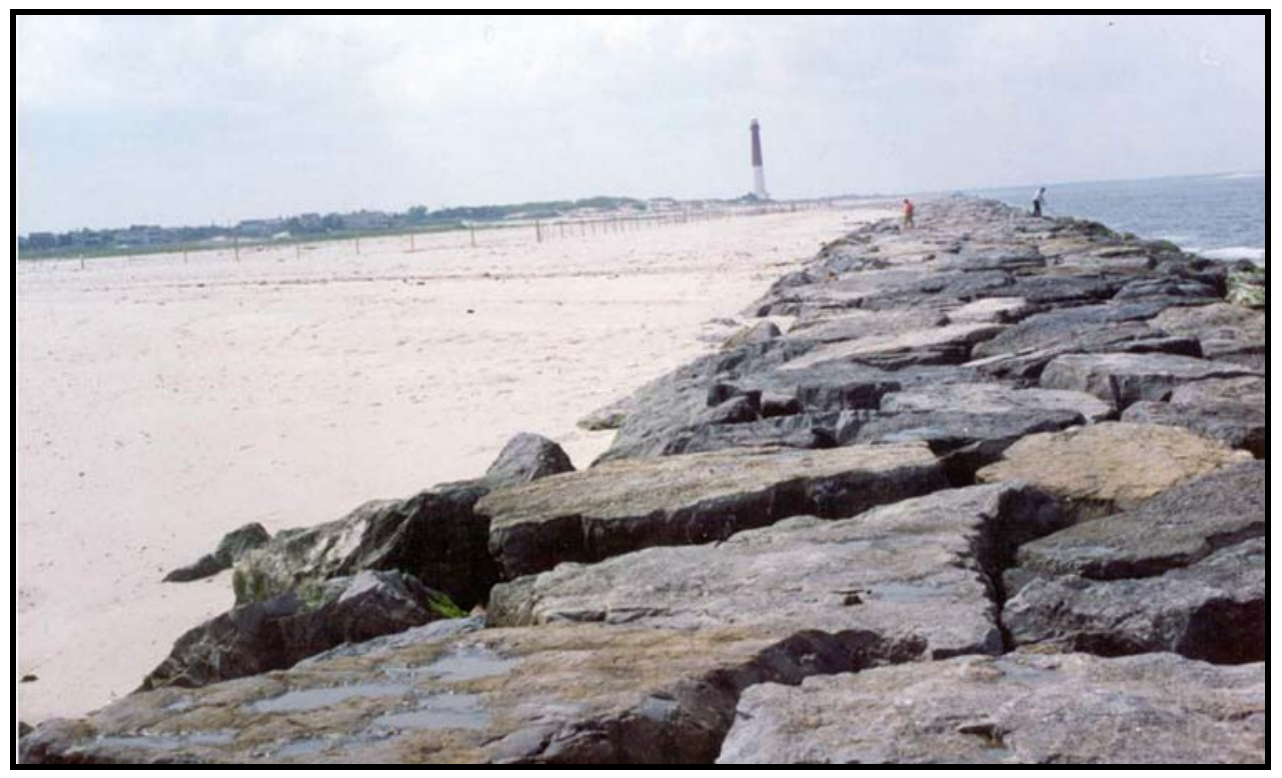

Figure 72. Barnegat Inlet new south jetty and fill region adjacent to new south jetty

is a meandering channel on the land side indicative of flow through the structure as the tide rises. This region fills with water as the tide rises and dries out on the falling tide, so it was never observed on aerial photos that are taken at low water elevation. Sediment moves out of this region through the area above the impermeable core and through the more permeable upper layer of armor stone. Also seaward at about station 34+00 during high tides and strong wave activity (Figure 73), sediment also moves out through the gaps where some corestone has washed out (Figure 74). This is near the intersection of the beachline on the south side of the new jetty. 


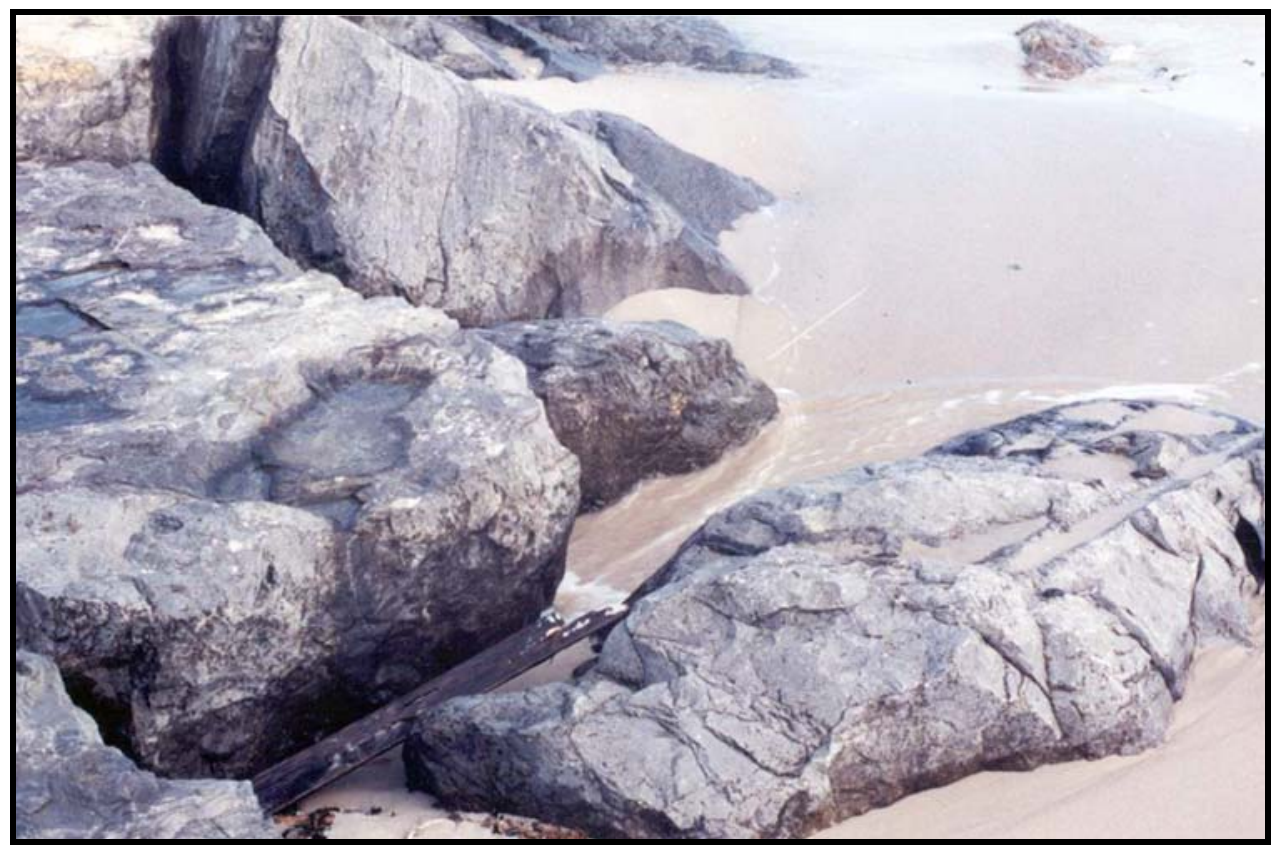

Figure 73. Sediment passing through the permeable upper layer of armor stone due to core loss above the impermeable core section

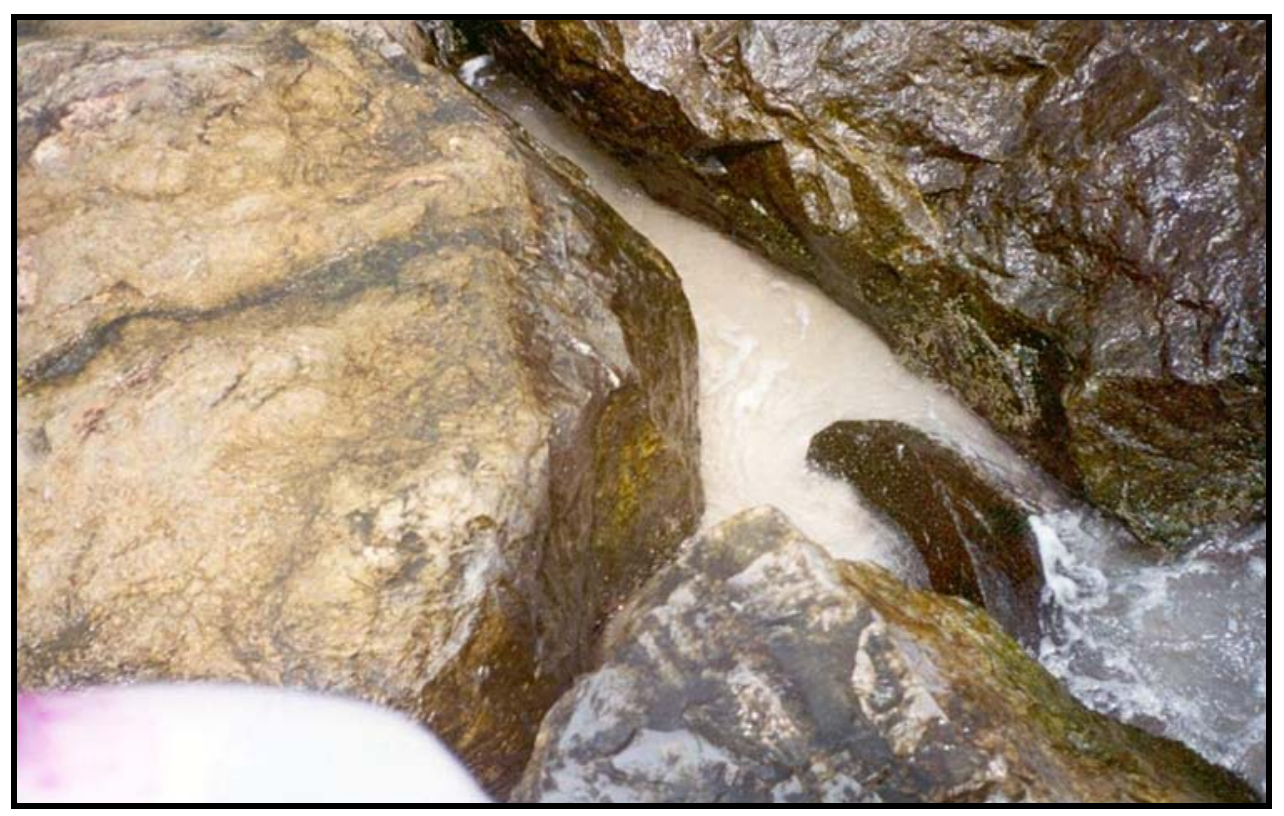

Figure 74. Sediment passing through the structure where corestone has washed out

At station $34+00$ dye studies were conducted by placing dye in the water on the ocean side of the structure and observing its passage through the structure voids created by loss of corestone (Figure 75) and dispersing into the water on the channel side (Figure 76). 


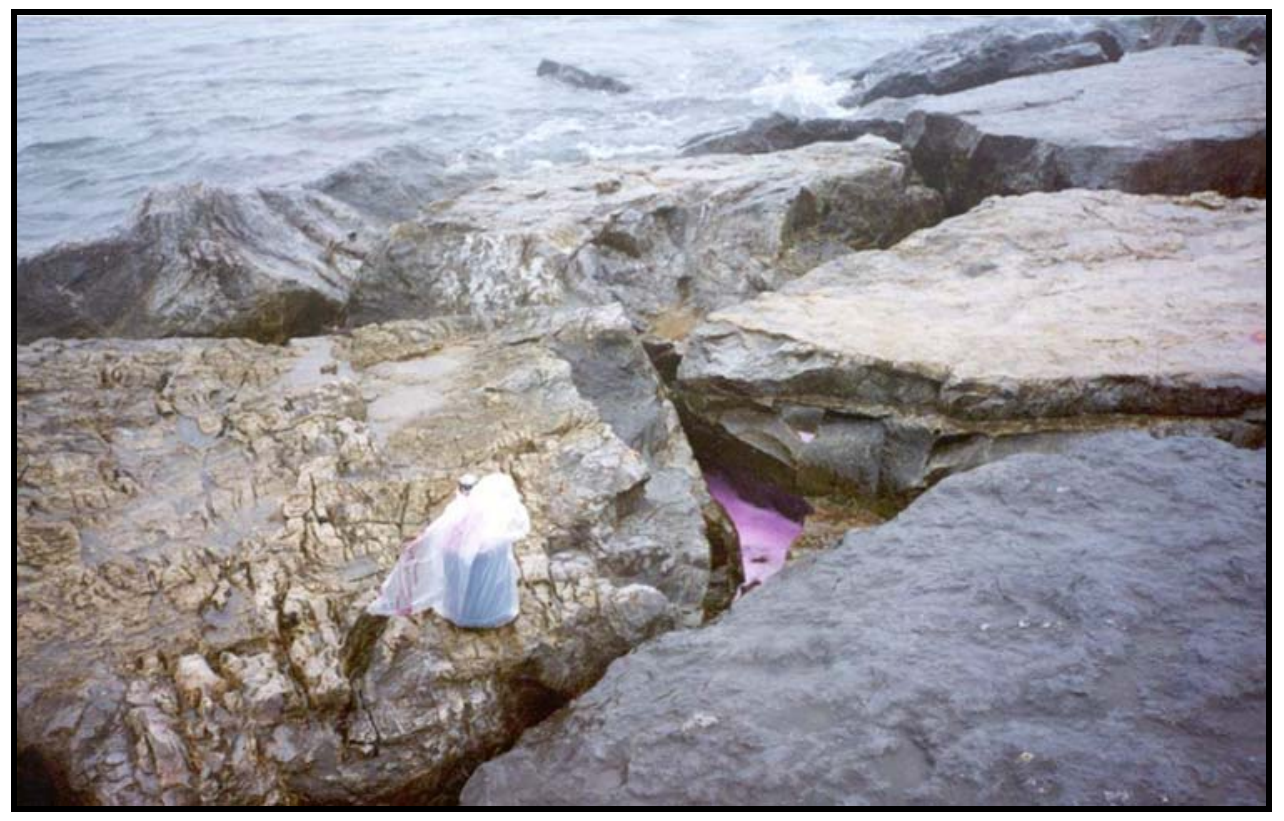

Figure 75. Dye passing through voids in the new south jetty resulting from loss of corestone

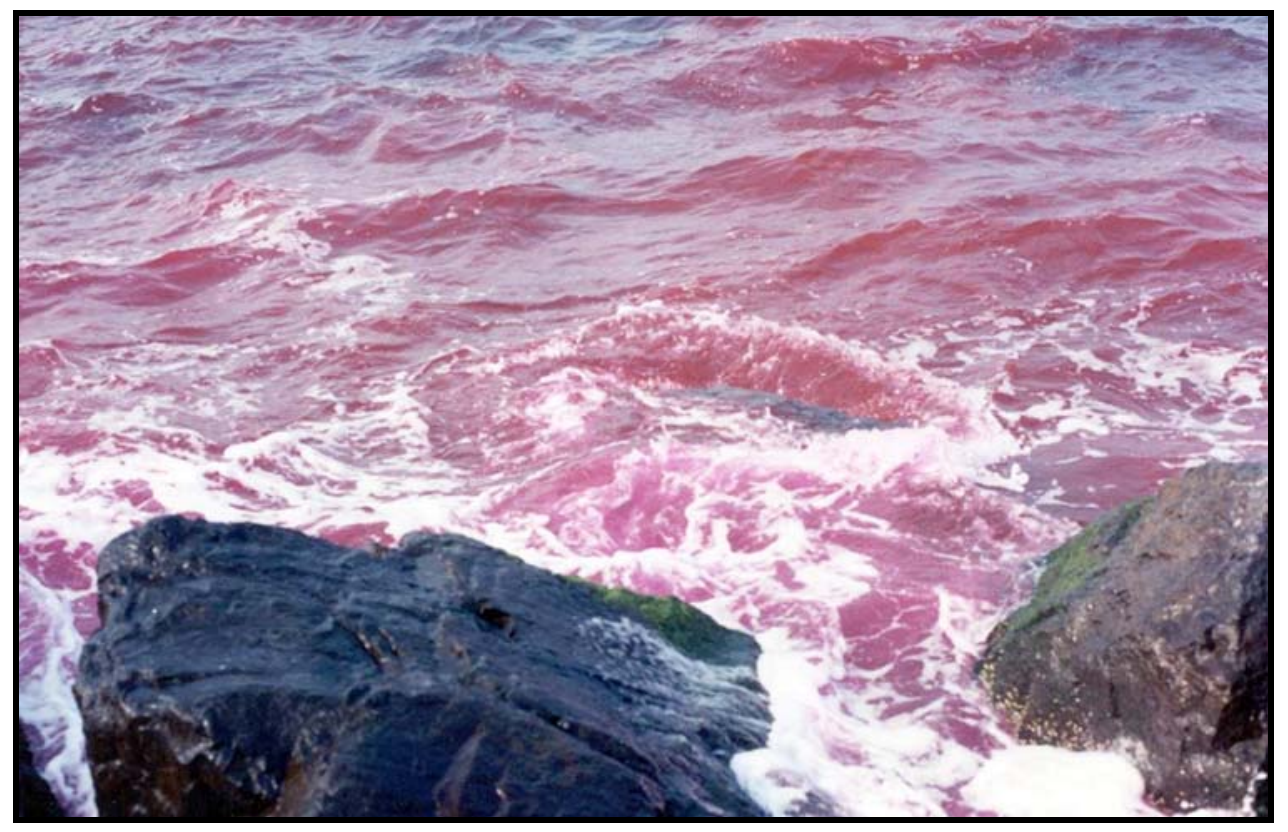

Figure 76. Dye dispersing into the channel after passing through voids in the new south jetty created by loss of corestone

Examination of side-scan data along the south jetty indicated a region where sand was atop the jetty corestone on the channel side where the beach intersects the jetty. It was believed that sand was moving through the south jetty. To investigate this belief, dye (liquid and blocks) was placed on the oceanward side of the jetty. This was done near high water when flood flow is strongest and wave action is able to penetrate the old south jetty arrowhead stone. The dye 
moved rapidly through the top layer of the jetty to the channel side of the structure. More important was the observation of sand pouring into the structure with each breaking wave. It was difficult to observe sediment movement through the entire structure, but it was easily moved inward from the location where it entered the structure, filling a pocket between stones that quickly emptied. It is hypothesized that sand may be moving along the inside of the south jetty to feed the shoal near the base of Barnegat Lighthouse. The location along the outside of the structure where this sediment movement occurs is between the average waterline and the location of maximum wave run-up.

The level of wave energy decreases with decreasing tide level since the old south arrowhead jetty at elevation $0 \mathrm{ft}(0 \mathrm{~m}) \mathrm{mlw}$ acts as a low breakwater. The transport of sediment through the structure occurs for only a few hours during higher water stages of the tide cycle. Also, as the tide level falls and reaches the level of the impermeable corestone at $+2 \mathrm{ft}(+0.6 \mathrm{~m}) \mathrm{mlw}$, sediment transport is cut off. It is difficult to estimate the amount of sediment passing into the channel from this location. A rough estimate for sediment transport can be made based on the fact that the location of the shoreline at the south jetty has remained constant since construction, and wave orientation is nearly always oblique to the shoreline, thus moving sediment toward the structure. This is due to refraction of wave energy over the ebb shoal for waves from the north. When waves are moving sediment northward, then sediment will be moving toward the south jetty also. Using simple longshore volume computations and limiting time and wave height duration, a longshore transport estimate in the range of 2,000 to $20,000 \mathrm{cu}$ yd $(1,530$ to $15,300 \mathrm{cu} \mathrm{m})$ per year might be expected to move through the structure.

The passage of water through the south jetty on rising tide is easily observed at many locations along the structure (Figures 77 and 78), and return flow on falling tide or rainfall carries sediment from the fill region through the structure into the channel (Figure 79). This implies corestone or underlayer exposure or loss by waves or currents attacking the structure over long periods of time. Core exposure occurs when the underlayer stones can be readily seen through gaps between the primary armor stones, possibly due to imprecise construction techniques. Core loss occurs when underlayer or core stone is removed from the structure by hydrodynamic forces of waves and currents. The U.S. Army Corps of Engineers (1993) developed the CI structural index scale of Table 12 to aid in a systematic and consistent although subjective indicator of coastal structure condition after exposure to severe waves and currents.

The CI visual inspections of the south jetty revealed various extents of core loss, as reflected by both water and sand movement through the structure (Figures 77 through 79). As an example, starting at the landward end of the structure and progressing seaward, at station 0+60 there were noticeable voids resulting from core loss on the channel side, and the $\mathrm{CI}$ inspector assigned a value of 80 . At station $9+50$ on both the channel and sea sides, there was visible loss of core stone, and a value of 70 was assigned. Further seaward at stations $10+00$ to $16+00$, core stone displacement and loss received a rating of 80 on both the sea side and under the crest. At station $23+50$, core loss and long voids under the crest received a rating of 50 from the $\mathrm{CI}$ inspector. 


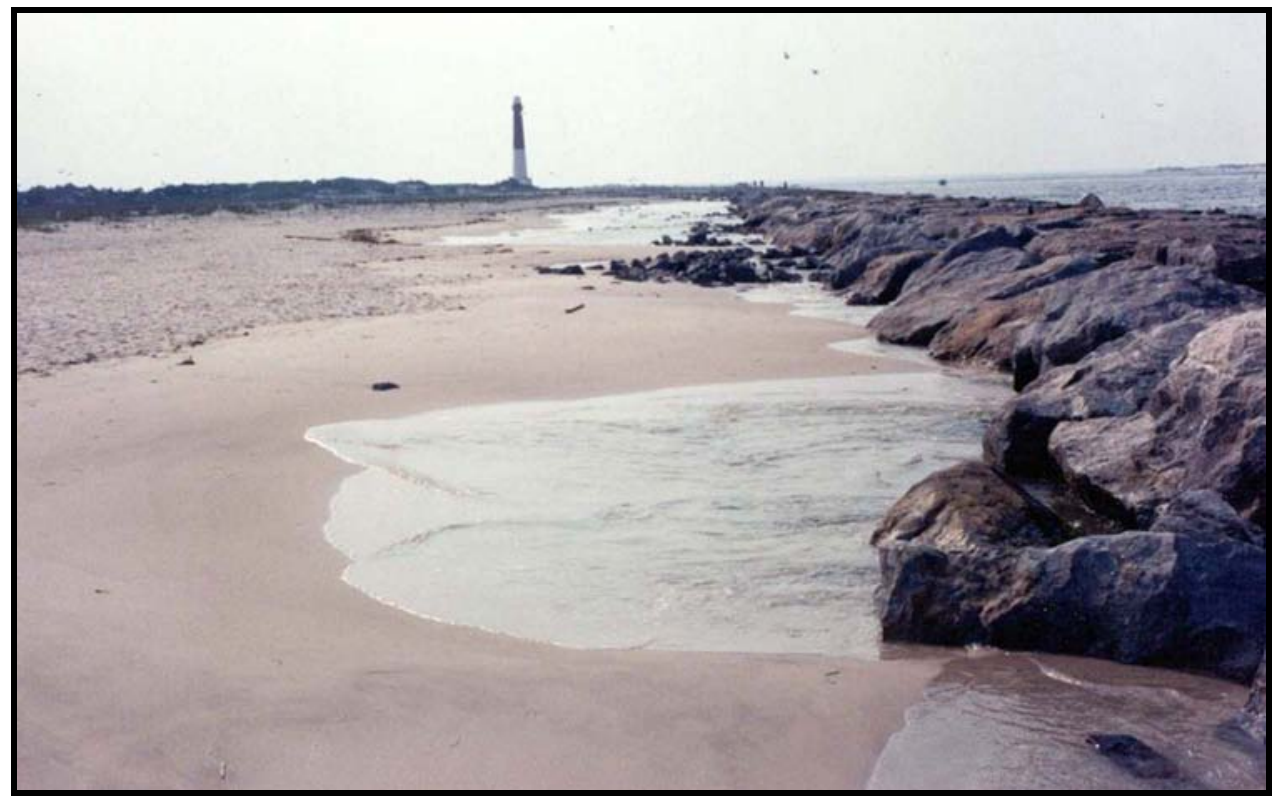

Figure 77. Water beginning to move through the new south jetty on rising tide

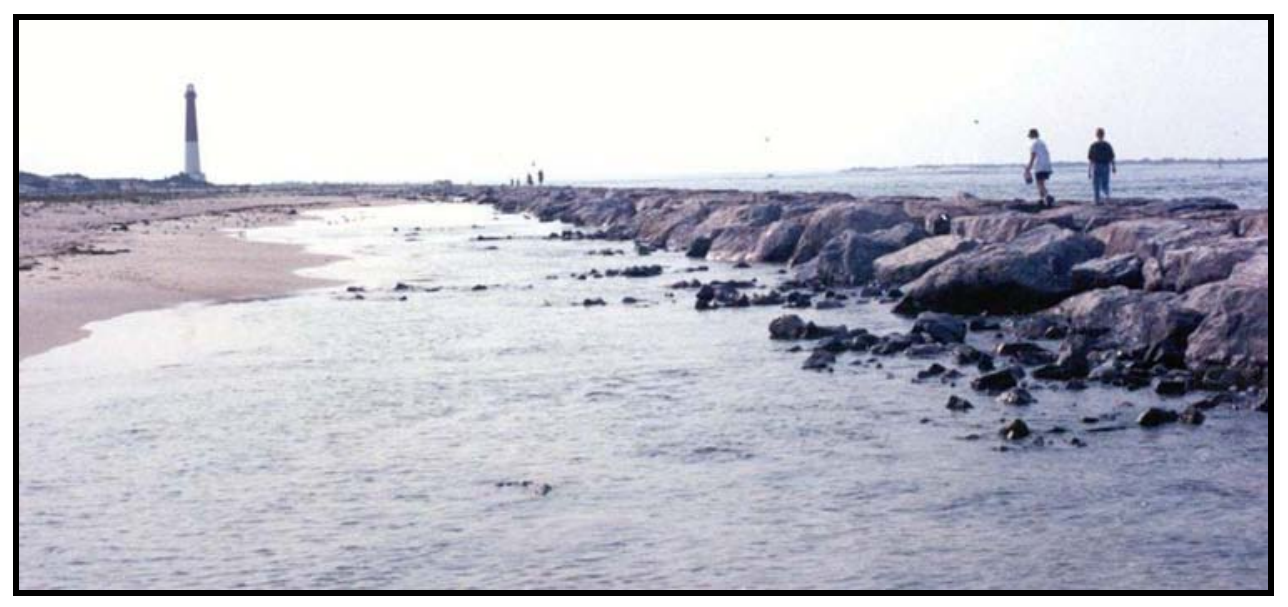

Figure 78. Water continuing to pass through the new south jetty on rising tide

\begin{tabular}{|c|c|c|c|}
\hline \multicolumn{4}{|c|}{$\begin{array}{l}\text { Table } 12 \\
\text { Structural Index Scale for Coastal Structures }\end{array}$} \\
\hline Zone & Structural Index & Condition Level & Description \\
\hline \multirow[t]{2}{*}{1} & 85 to 100 & Excellent & $\begin{array}{l}\text { No significant defects - only slight imperfections } \\
\text { may exist. }\end{array}$ \\
\hline & 70 to 84 & Very good & Only minor deterioration or defects are evident. \\
\hline \multirow[t]{2}{*}{2} & 55 to 69 & Good & $\begin{array}{l}\text { Deterioration is clearly evident, but the structure } \\
\text { still appears sound. }\end{array}$ \\
\hline & 40 to 54 & Fair & Moderate deterioration. \\
\hline \multirow[t]{3}{*}{3} & 25 to 39 & Poor & $\begin{array}{l}\text { Serious deterioration in some portions of the } \\
\text { structure. }\end{array}$ \\
\hline & 10 to 24 & Very poor & Extensive deterioration. \\
\hline & 0 to 9 & Failed & General failure. \\
\hline
\end{tabular}




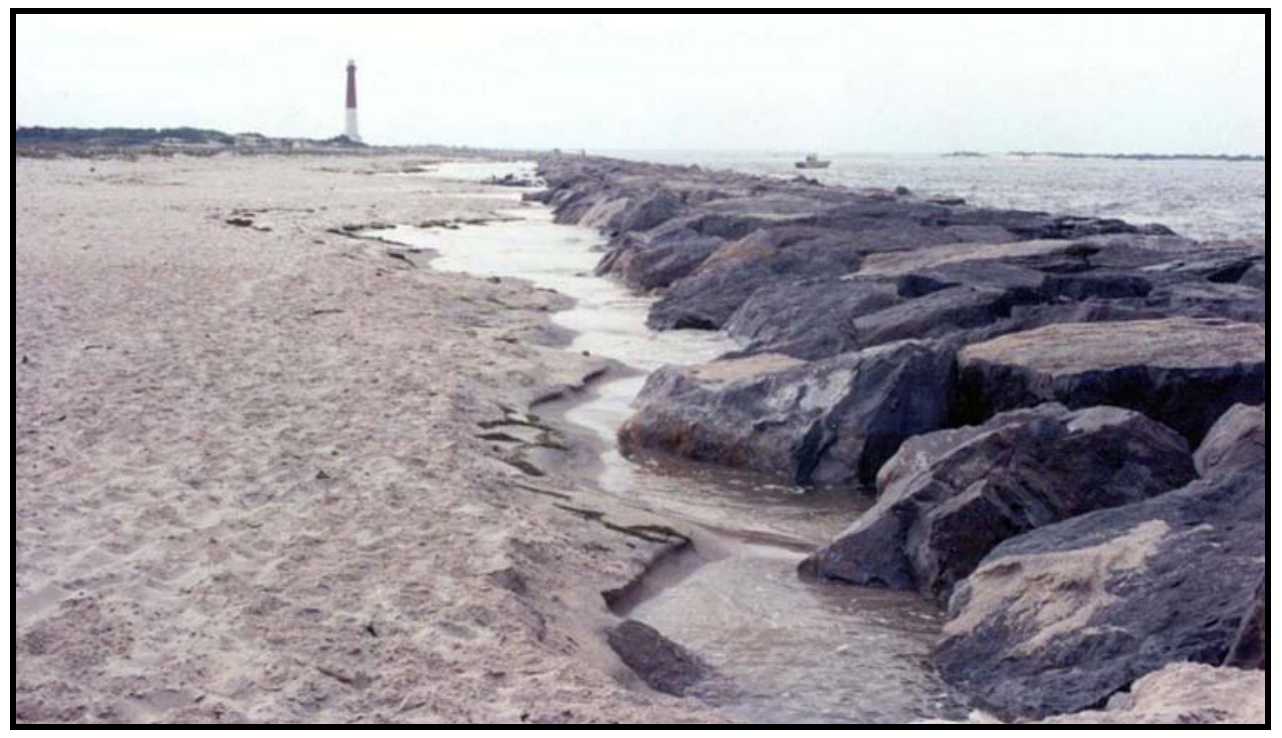

Figure 79. Meandering channels along landside of new south jetty, allowing sediment movement through the structure into the channel on falling tide as a result of loss of corestone

Typical examples of the loss of armor stone and steepening of the structure side slopes are presented in Figures 80 through 83 for essentially the entire length of the south jetty. From station $0+00$ to about station $16+00$, the CI inspector determined that a value of 80 was probably appropriate. From station $16+00$ toward the end of the structure, a value of 70 was believed to be more appropriate. Even a value of 70 indicates that the structure is still in very good condition, as determined from Table 12.

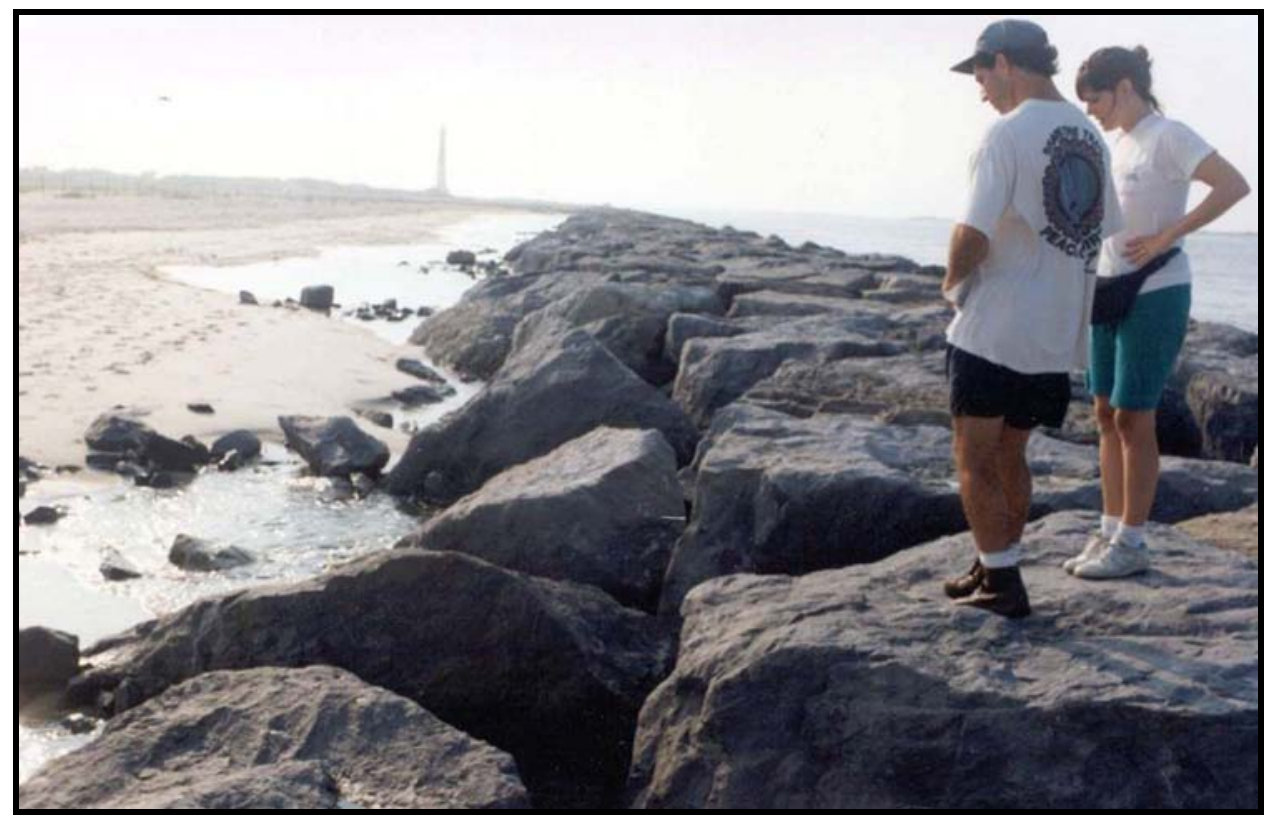

Figure 80. Armor stone settling and displacement on landside of new south jetty, exposing large voids between armor stone and loss of corestone 


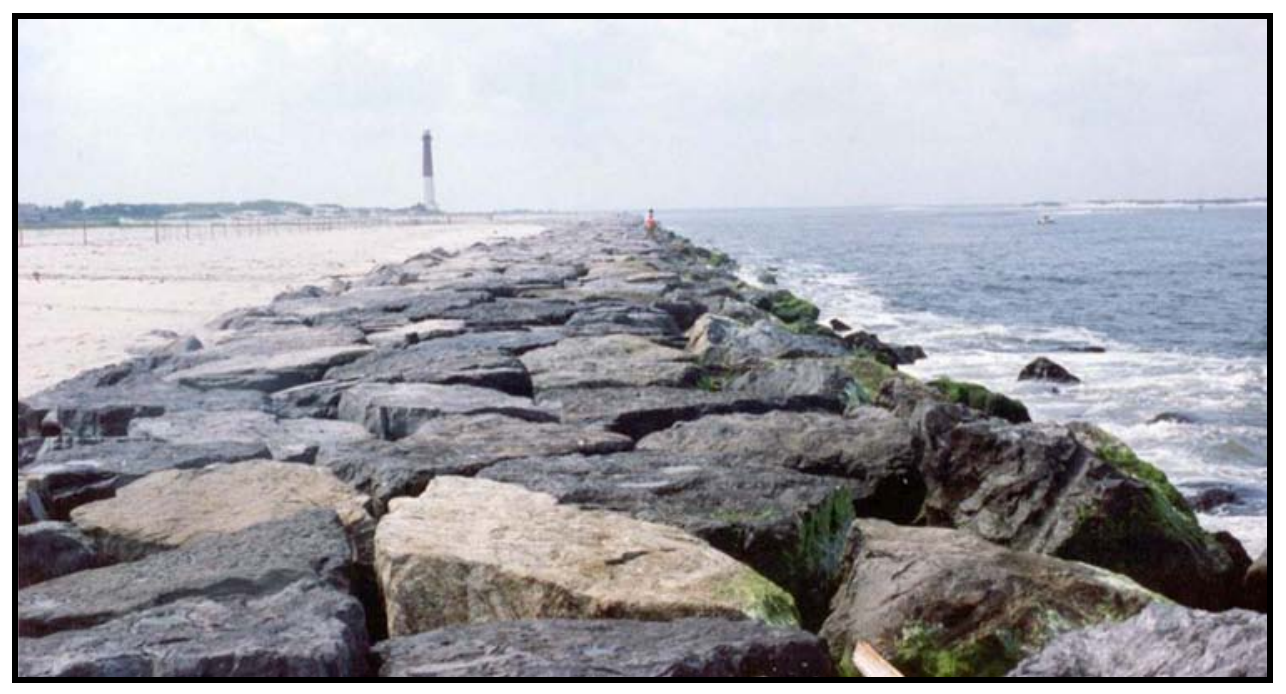

Figure 81. Armor stone displacement and slope steepening on channel side of new south jetty resulting from combined wave energy and tidal currents

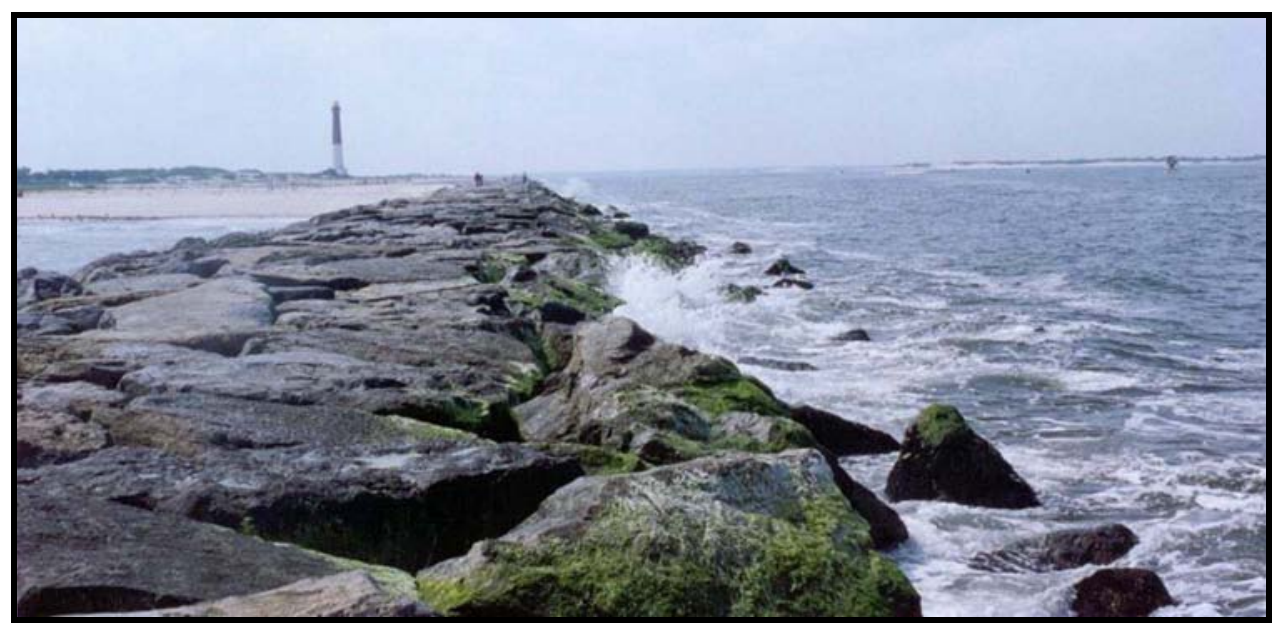

Figure 82. Indentations in structure channel side slope resulting from loss of armor stone and steepening of structure slope

Armor stone quality defects deal with structural or material flaws within the armor units. Four kind of armor quality defects are recognized by CI inspectors: (a) rounding, (b) spalling, (c) cracking, and (d) fracturing. At Barnegat Inlet new south jetty, only cracking of armor stone was detectable as a CI factor. Cracking involves visible fractures (Figure 84) in the surface of either rock or concrete armor units. The cracks may be either surficial or may penetrate deep into the body of the armor unit. Cracking is potentially most serious in slender concrete armor units such as dolosse (either with or without steel reinforcement). The armor stone cracking observed at Barnegat Inlet south jetty probably resulted from loss of underlying corestone and rocking of the armor unit under large wave action. 


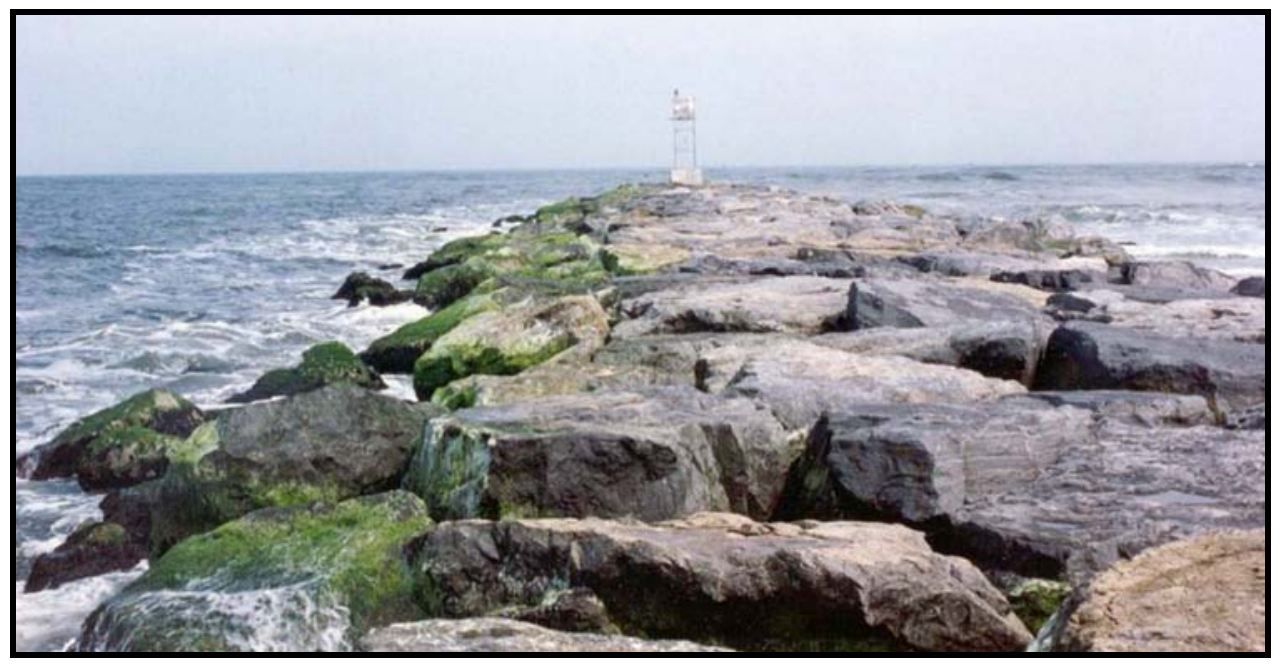

Figure 83. Large gaps and cracks between armor stone on crest of new south jetty near oceanward end resulting from high-energy wave activity

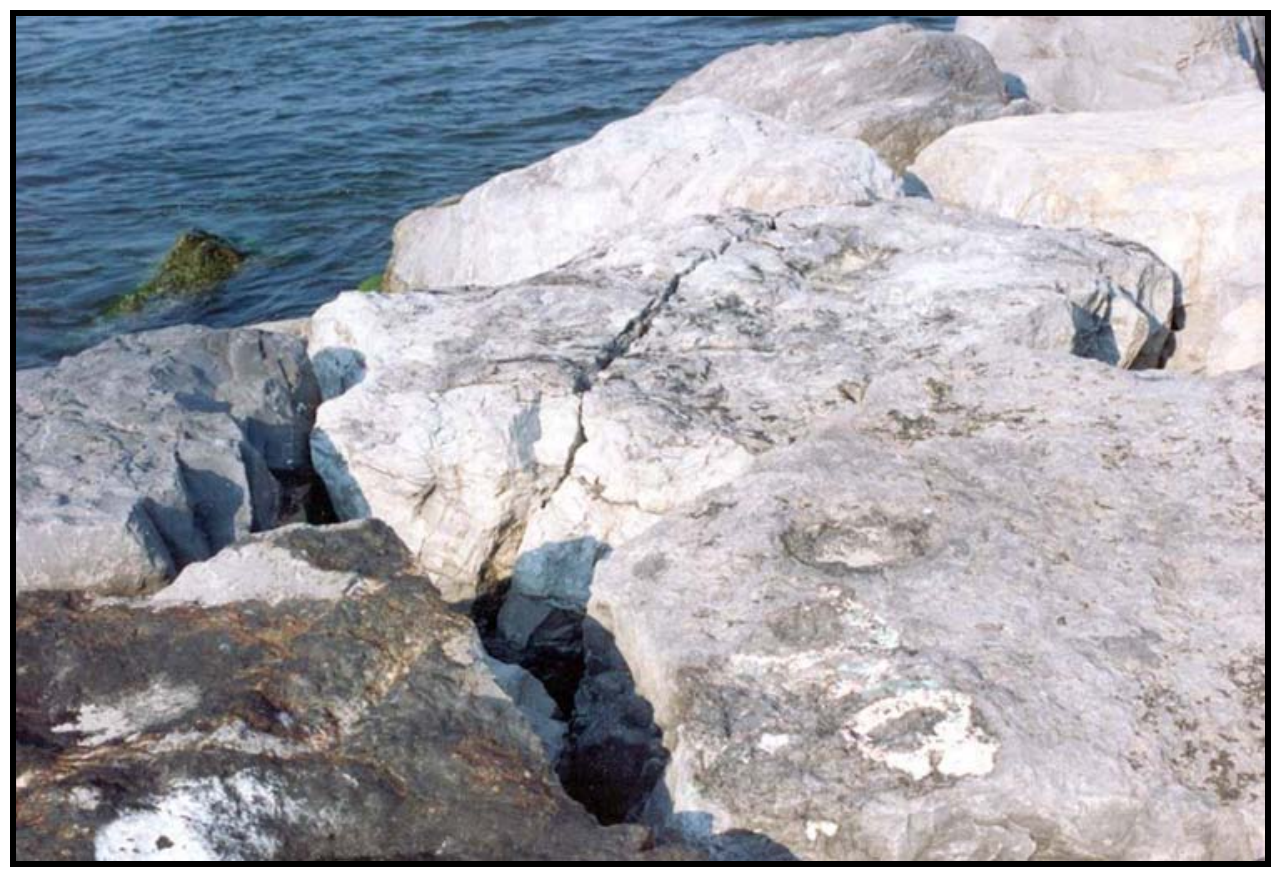

Figure 84. Cracking of armor stone from rocking and settling following loss of corestone

The new south jetty at Barnegat Inlet clearly exhibits some degree of imperfection. Part of the overall minor deterioration may be attributed to the unique design cross section of the structure. This may have permitted removal of a portion of the corestone under wave and current action, resulting in settling and slope steepening. On average, the structure has a CI index of at least 70, indicating that the condition level is very good, even though minor deterioration and defects are evident. Although slight imperfections may exist locally, no significant defects exist that would indicate imminent failure of the structure. All 
things considered, the new south jetty appears fundamentally sound, and is serving the functional purpose for which it was developed.

\section{Summary of New South Jetty Structure Stability}

\section{Structure design waves}

The 4,270-ft- (1,300-m-) long south jetty was divided into four equal increments of length. A breaking design wave height was determined for each of these four increments. The net effects of the outer bar and the existing jetties would be to reduce the height of the waves from the north, northeast, and south that approach the new south jetty. Thus, it was determined by the U.S. Army Engineer District, Philadelphia, $(1981,1984)$ that, due to the 1,000-ft $(305-\mathrm{m})$ spacing between the jetties and the channel depths between the jetties and across the outer bar, design breaking waves with heights of 14.0, 14.0,15.2, and $15.9 \mathrm{ft}$ $(4.3,4.3,4.6$, and $4.9 \mathrm{~m})$ (proceeding from the shoreline in an offshore direction, respectively) were appropriate for the four south jetty increments. Design water depths were determined by assuming that scour would occur along the jetty after completion of the project. The amount of this assumed scour was based on results of the previous physical model study (Sager and Hollyfield 1974).

\section{Wave heights at Barnegat Inlet}

At Barnegat Inlet, where maximum flood currents occur at high water and maximum ebb currents occur at low water, bathymetry and water levels have stronger effects than currents on wave transformation. Ebb shoal bathymetry and low water levels generally reduce the energy in waves greater than 3.3 to $4.9 \mathrm{ft}$ $(1.0$ to $1.5 \mathrm{~m})$. The average wave height at the jetty is slightly smaller for low water levels due to breaking of large waves at low water. The influence of tidal currents is most prevalent for smaller waves less than $3.3 \mathrm{ft}(1.0 \mathrm{~m})$. Smaller waves increase in wave height 10 percent more for ebb currents than flood currents. Flood currents tend to elongate and flatten the waves whereas ebb currents peaken waves.

Wave heights near the jetty structure vary most with approach angle. Normally incident (90- to 113-deg) waves have both large wave heights and large wave height ratios. Waves as large as $12.6 \mathrm{ft}(3.84 \mathrm{~m})$ high were measured at the DWG location during the 1-year data collection time of this MCNP study. Wave transformation analysis showed that waves could reach the jetty with a height amplification of 1.4 times the deepwater wave height. This would result in a wave height at the structure of $17.6 \mathrm{ft}(5.4 \mathrm{~m})$, for waves with periods up to $8 \mathrm{sec}$. The south jetty was designed for a no-damage criteria from waves up to $15.9 \mathrm{ft}$ $(4.9 \mathrm{~m})$ high. However, the structure has experienced a small degree of settling, armor shifting, and slope steepening. Thus, it appears the structure has indeed experienced waves slightly in excess of the design wave, but not to such an extent as to be exceedingly larger, and significant concerns about safety of the structure are not an issue. Frequency analysis shows that energy dissipation over the ebb shoal is usually greatest at the peak frequency, with some energy gains at the higher harmonics. 


\section{South jetty Condition Index}

The $\mathrm{CI}$ is a uniform procedure for assessing the condition of rubble-mound breakwaters and jetties. The CI allows for a concise reporting system that indicates the deficiencies a structure may have, which parts of the structure are deficient, and the relative severity of the deficiencies.

The new south jetty has a two-layer capstone design, with the bottom layer of capstones at the center replaced with core stone to prevent sand migration through the pervious capstone layer. No other Corps jetty design has the same cross section as that constructed at Barnegat Inlet south jetty. There are four layers of stone, with the two bottom layers (bedding stone layer and mat stone layer) being quite thin. The bedding stone layer is about $1 \mathrm{ft}(0.3 \mathrm{~m})$ thick, and the mat stone layer is about $2 \mathrm{ft}(0.6 \mathrm{~m})$ thick. The use of two very thin bedding and mat stone layers is quite unusual. The top elevation of the core stone was increased in this design to make the design sandtight. This was done by reducing the armor layer thickness at the top center of the jetty from two stones to one stone. The core was thus raised one armor layer in thickness along the center line to form an impermeable barrier. A similar design had been used to make the north jetty sandtight when it was raised from $0 \mathrm{ft}(0 \mathrm{~m}) \mathrm{msl}$ to $+8 \mathrm{ft}(2.4 \mathrm{~m}) \mathrm{msl}$.

South jetty structure CI inspections consisting of detailed visual walk-thestructure examinations were conducted in 1993, 1994, 1995, and 1996. Several significant and severe storms impacted this region of coastline during this period, and resulted in a slow but gradual movement of some of the armor and corestone. While the corestone design was intended to prevent sand movement through the capstone layer, some locations along the jetty indicated this was not the actual case. The water was able to move through the jetty onto the fill area immediately south of the structure, and a meandering channel on the landside indicated flow was occurring through the jetty as the tide rose. Conversely, pooling water flowed out on the falling tide. Dye studies were conducted to enhance understanding of movement through the jetty. There has also been minimal movement of armor stone with steepening of the side slopes in some locations. While there are gaps between armor stone on the crest of the structure that may be the result of imprecise construction techniques, the structure appears to be fundamentally stable for the most part.

The new south jetty at Barnegat Inlet clearly exhibits some degree of imperfection. Part of the overall minor deterioration may be attributed to the unique design cross section of the structure. This may have permitted removal of a portion of the corestone under wave and current action, resulting in settling and slope steepening. On average, the structure has a CI index of at least 70, indicating that the condition level is very good, even though minor deterioration and defects are evident. Although slight imperfections may exist locally, no significant defects exist that would indicate imminent failure of the structure. All things considered, the Barnegat Inlet new south jetty appears fundamentally sound, and is serving the functional purpose for which it was developed. 


\section{Effects of New South Jetty on Upcoast and Downcoast Beaches}

Profile surveys and aerial photographs were assimilated to evaluate Hypothesis 4 of the MCNP study approach and monitoring plan for Barnegat Inlet. This hypothesis states that the jetty system realignment would not adversely affect upcoast or downcoast beaches. Profile data were entered into the Corps Interactive Survey Reduction Program (ISRP) and analyzed using various profile analysis programs. Pre- and post-project surveys were compared to examine shoreline trends since the new south jetty construction in 1992.

\section{Beach Profile Surveys}

Beach profile surveys were performed annually for 5 years by contract during years 1993-1997 at both Island Beach State Park on the north side of Barnegat Inlet and Long Beach Island on the south side of Barnegat Inlet. A coastal survey sled beach profiling system that provided high-quality data from the dune line to beyond a depth of $-30 \mathrm{ft}(-9.1 \mathrm{~m})$ NGVD was used for 9 full beach profiles along Island Beach State Park and for 14 full beach profiles along Long Beach Island, for a total of 23 full beach profiles near Barnegat Inlet. The full beach profiles extended from the dune line seaward to a water depth of at least $-30 \mathrm{ft}$ (-9.1 m) NGVD, or to a maximum distance of 1 mile from the survey baseline on the beach. Additionally, 9 shorter wading beach profiles were taken during the measurement period along Island Beach State Park, and 12 shorter wading beach profiles were taken along Long Beach Island, for a total of 21 shorter wading beach profiles. The shorter wading beach profiles extended from the dune line seaward to an average water depth of about $-3 \mathrm{ft}(-0.9 \mathrm{~m})$ NGVD. The relative locations and the relative lengths of all 44 beach profiles are shown in Figure 85. The initial 1993 survey and the last survey (usually 1997) are presented in Appendix B. For Island Beach State Park, the full beach profiles are numbers IB $1,4,6,8,10,12,14,16$, and 18. The wading beach profiles are numbers IB 2, 3, $5,7,9,11,13,15$, and 17. For Long Beach Island, the full beach profiles are numbers LB 1, 2, 3, 4, 5, 8, 11, 14, 16, 18, 20, 22, 24, and 26. The wading beach profiles are numbers LB $6,7,9,10,12,13,15,17,19,21,23$, and 25. 


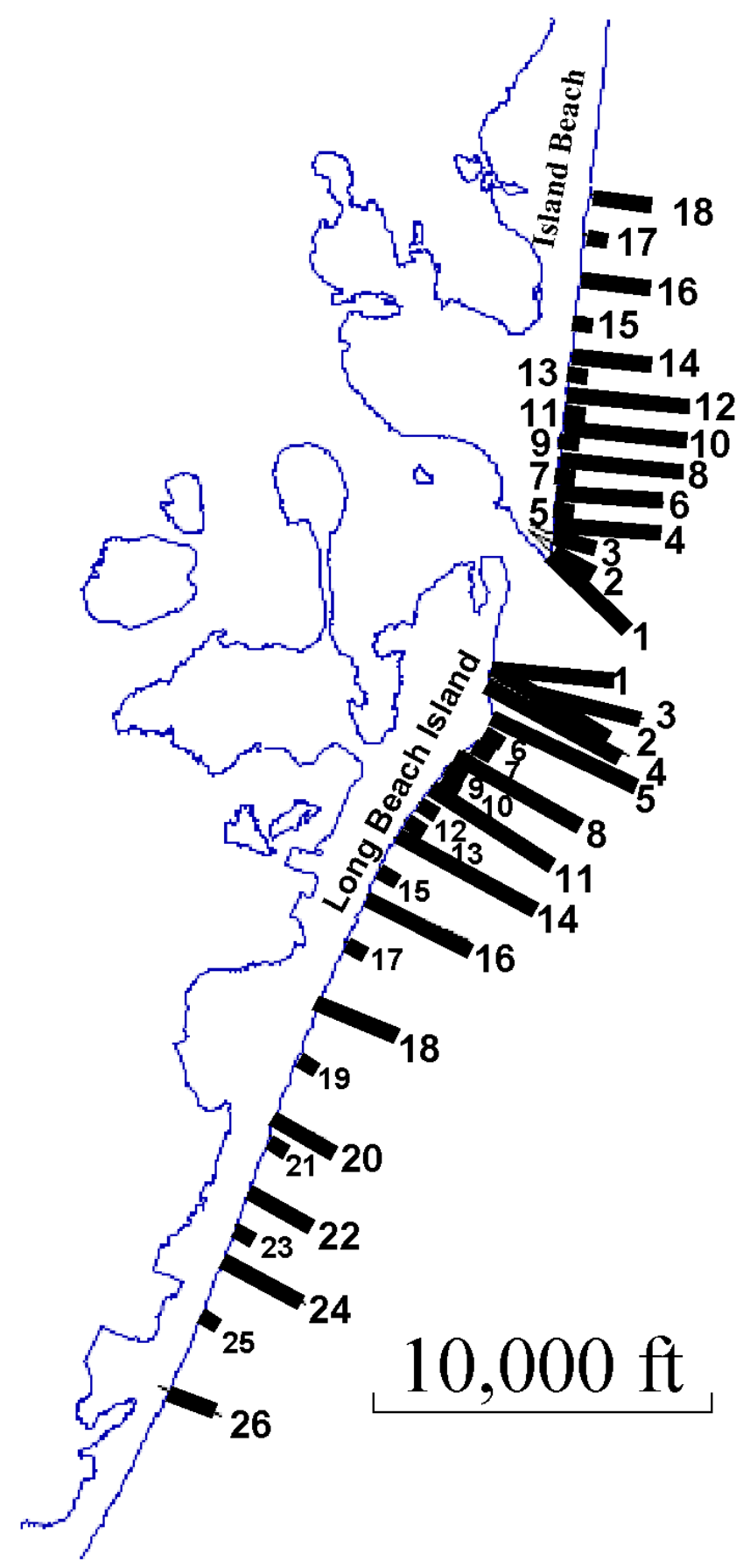

Figure 85. Location of beach profiles along Island Beach State Park and Long Island Beach, near Barnegat Inlet, NJ (to convert feet to meters, multiply by 0.3048 ) 


\section{Survey control}

Horizontal and vertical controls were maintained by using established Federal and State benchmarks located at both Island Beach State Park and Long Beach Island. A Philadelphia District control point from previous profile surveys was located on the southern end of Island Beach State Park (Norman Porter Reference Point 53) and close to the northern end of the survey reach called Forked River No. 2. On Long Beach Island, four Corps of Engineers horizontal and vertical control monuments were located along the survey reach north of the village of Harvey Cedars on 4th Street, 26th Street, Coast Avenue, and Essex Avenue.

During September 1992, monumentation was established on each profile line. Steel fence posts were installed along the profiles at Island Beach State Park, on and behind the dunes so that profile bearings and reference elevations could be recovered for future surveys. On Long Beach Island, a steel fence post was installed along each profile to mark the profile location on the dune or street end, and manhole covers were surveyed to allow recovery of profile bearing and reference elevations in the field.

Profile locations were established at the most uniform horizontal spacing possible along the shorelines, with the goal being 500-ft (152-m) spacings within 1 mile $(1.6 \mathrm{~km})$ of the jetties and wider spacing beyond. At Island Beach State Park, a 1,000-ft $(305-\mathrm{m})$ spacing beyond 1 mile $(1.6 \mathrm{~km})$ from the north jetty was desirable; however, it was also desired that profile locations be spaced so that overlap with previous Norman Porter profiles be achieved if possible. Therefore, a 1,182-ft (360-m) spacing at Island Beach State Park was selected to coincide with some of those profiles (within about $100 \mathrm{ft}(30.5 \mathrm{~m})$ ). On Long Beach Island, all profile spacing was governed by the locations of streets because access to private property was severely limited, especially in the village of Loveladies. The street spacing in the village of Barnegat Light immediately to the south of Barnegat Inlet was about $320 \mathrm{ft}(97 \mathrm{~m})$ per block, making the profile spacing approximately a multiple of that distance within 1 mile $(1.6 \mathrm{~km})$ of the south jetty. Beyond 1 mile from the jetty, it was desirable to have as many of the profiles as possible coincide with the previous Norman Porter profiles in addition to coinciding with street ends or public access areas while covering Harvey Cedars south to Essex Street. Therefore the profiles were spaced generally about $1,500 \mathrm{ft}(457 \mathrm{~m})$ apart, with some variation from profile to profile.

Profile bearings were chosen based upon a judgment of shoreline alignment (profiles were perpendicular to the general alignment of the shoreline).

Navigation charts were reviewed to make an initial estimate of profile bearing. This initial estimate of profile bearing was then modified based upon field inspection of the shoreline. The resulting bearings were very similar to previous Norman Porter bearings at Island Beach State Park; however, more variation resulted on Long Beach Island due to the degree of shoreline change since the Norman Porter profiles were established in 1963.

\section{Profile surveys}

The onshore-offshore survey distances are seaward of the front control point. Depths are relative to NGVD. All horizontal positions of data are presented in State Plane coordinates. 


\section{Survey system components}

The beach profile surveying system consisted of a towable sled and a total survey station. The sled was designed for surveys to water depths of $33 \mathrm{ft}(10 \mathrm{~m})$ (about -30 ft (-9.1 m) NGVD at high tide at this project site). The sled was towed by a boat that was outfitted with appropriate propellers and towing apparatus. The sled runners and structure were constructed of steel, and the mast was made of aluminum. Two triple arrays of glass surveying reflectors (prisms) were fixed atop the sled mast, with a lower single reflector located $3 \mathrm{ft}(0.9 \mathrm{~m})$ below the main reflector array. The upper arrays consisted of three reflectors and were the primary targets used in surveying beach profiles. The lower reflector provided additional data for correcting elevations surveyed on steeply sloping bottoms, where sled tilt could be important.

The shore-based portion of the survey system consisted of a Leitz Set2 total station and a Sokkisha SDR33 data collector. This laser-based system had a range of $7,700 \mathrm{ft}(2,347 \mathrm{~m})$ with an accuracy better than $0.01 \mathrm{ft}(0.3 \mathrm{~cm})$ in distance and in elevation at ranges surveyed. Elevation resolution in typical beach profile ranges was estimated to be about $0.04 \mathrm{ft}(1.2 \mathrm{~cm})$ at maximum range.

\section{Profile survey procedure}

The surveying procedure consisted of setting up the shore-based instruments on each beach profile at preset locations along a baseline. Elevations were referenced to a local benchmark set prior to the survey. Profile orientation was established by turning a predetermined angle relative to the baseline. Once the instrument was referenced to the local benchmark and baseline, a manual survey of the subaerial beach was performed using a standard survey rod. The rod had a 0.7 -sq-ft $(0.065-\mathrm{sq}-\mathrm{m})$ plate attached to its base to provide consistent penetration of the sand surface with the rod.

Measurements were made approximately every $20 \mathrm{ft}(6.1 \mathrm{~m})$ along the subaerial profile, or at a shorter interval to define major morphologic features, starting at the dune crest and proceeding seaward to about $-3 \mathrm{ft}(-0.9 \mathrm{~m})$ NGVD. The sled was then towed by boat out into the water from about $+5 \mathrm{ft}(+1.5 \mathrm{~m})$ to beyond $-30 \mathrm{ft}(-9.1 \mathrm{~m})$ NGVD. The boat was navigated along the profile. Measurements of the position of the sled reflectors were made along the profile line. The measurements were recorded by the data collector and copied to a computer for processing or editing at the end of each survey day.

\section{Survey accuracy}

Errors associated with beach profile surveys can arise from several possible sources including (a) instrument error, (b) operation error, (c) bias due to beach properties, and (d) monumentation error.

Instrument error. Inaccuracies of the electronic surveying instruments used by the contractor were considered to be small (less than $0.05 \mathrm{ft}(1.5 \mathrm{~cm})$ in horizontal and vertical distances). This is a random error as opposed to a bias or systematic error. The contractor used the highest quality total station equipment available.

Operation error. Measurement inaccuracies can arise through errors associated with instrument setup (leveling) and data collection technique (ability to aim the laser at a consistent location on the target). The same instrument 
operator was used throughout the project annual surveys and on subsequent annual surveys at this project site so that systematic errors would be consistent among surveys, thereby minimizing possible errors in volumetric change calculation. It was estimated that the operator systematic error on any survey was less than $0.05 \mathrm{ft}(1.5 \mathrm{~cm})$.

Bias due to beach properties. The height of the sled mast above the beach depends upon the depth to which the sled runners penetrate the sand surface. On firm, wet surfaces the sled runners normally penetrated about $0.5 \mathrm{ft}(15.2 \mathrm{~cm})$. This figure was determined by comparing survey data collected by both sled and rod on the overlapping section of each beach profile and by field-testing of the sled on various saturated beach-face conditions. Postsurvey analysis included inspection of these comparison measurements to assure that the sled was not penetrating abnormally into the beach. Abnormal penetration could be corrected in postprocessing by using the overlapping data. This correction procedure was required only in areas of very fine or very coarse material at recently nourished or recovered beach areas.

Monumentation error. Beach profile line azimuths at both Island Beach State Park and Long Beach Island were established by using the angles defined relative to the baseline that is carefully staked out in advance of the survey. Angles in profile orientation (monumentation) are considered to be negligible at this Barnegat Inlet project.

Total error. The maximum random error associated with the beach profile procedures was considered to be approximately $0.05 \mathrm{ft}(1.5 \mathrm{~cm})$ for conditions at this Barnegat Inlet project (good monumentation and relatively short beach profile lengths and distances to adjacent control points). Actual mean error or bias was considered negligible at this site. These data were adequate for calculation of total volumetric changes in the surveyed stretch of beach along both Island Beach State Park and Long Beach Island, adjacent to the north and south sides of Barnegat Inlet, respectively.

\section{Beach Volume Changes}

\section{Longshore sediment transport}

The transport of noncohesive sediments under the simultaneous action of waves and currents takes place along natural beaches and elsewhere when waves become superposed upon currents. The currents may be wave-induced, winddriven, tidal, stream or river, or may originate from some other mechanism.

Because of refraction, waves usually break at a fairly small angle to the beach. The mass of water piling up in the surf zone generates a wave-induced current that flows along the beach, and is known as the longshore or littoral current. This longshore current, though relatively mild, is capable of transporting vast quantities of sediments that are tossed into suspension by the turbulence associated with wave breaking. In addition, the water mass produced by the breaking process rushes up the beach face at a slight angle, and then down the beach face in such a manner that there is a zigzag path to the particles of water on the beach. Sand particles traverse the same sort of pattern along the beach face (Johnson and Eagleson 1966). Hence, the total longshore drift of sand consists of the general drift due to the longshore current in the breaker zone and the zigzag path on the foreshore due to wave uprush and backwash (or runup and rundown). 
Most investigators have attempted a correlation between wave characteristics and measured longshore transport rates to estimate potential longshore sediment transport. This potential longshore sediment transport is the amount of material that could possibly be moved in the presence of an unlimited source or supply of sand. Intuitively, the rate at which a transport process takes place should be related to the total power available for transporting material. Accordingly, the procedure that has evolved is to determine the alongshore component of wave power, or energy flux, in the surf zone, and then relate this energy flux to measured longshore transport quantities through a calibration coefficient.

Cialone and Thompson (2000) estimated the potential longshore sediment transport for the region of New Jersey coastline to the north of Barnegat Inlet (Island Beach State Park), across Barnegat Inlet, and to the south of Barnegat Inlet (Long Island Beach). It is interesting to note the nodal zone in the vicinity of Barnegat Inlet, where the general shoreline orientation of New Jersey changes. The potential net transport shows a notable change from net northerly transport (along Island Beach State Park) to net southerly transport in this region (along Long Island Beach). The predominant shoreline orientation changes dramatically at Barnegat Inlet. The position of Long Island, NY, limits waves from the north impinging on northern New Jersey. South of Barnegat Inlet, the sheltering effect is not as apparent, and net transport along Long Beach Island, $\mathrm{NJ}$, is generally to the south. There is a local reversal with transport to the north near Barnegat Inlet, probably due to the effects of the inlet and its shoal system on the downdrift beaches.

Using Offshore and Coastal Technologies, Inc. (OCTI), and Corps Wave Information Studies (WIS) hindcast wave climatology for this region, Cialone and Thompson (2000) determined net potential longshore sediment transport north of Barnegat Inlet to be about 520,000-650,000 cu yd $(400,000-500,00 \mathrm{cu}$ m) per year to the north.

Net potential longshore sediment transport across Barnegat Inlet was estimated by Cialone and Thompson (2000) to be approximately 650,000$785,000 \mathrm{cu}$ yd $(500,000-600,000 \mathrm{cu} \mathrm{m})$ per year to the south. Gravens et al. (1991) had previously estimated the net potential longshore transport near Barnegat Inlet to be $690,000 \mathrm{cu}$ yd $(530,000 \mathrm{cu} \mathrm{m})$ per year to the south, assuming a local shoreline orientation of $29 \mathrm{deg}$ east of north. In 1954, the Corps had estimated the net potential longshore transport in the Barnegat Inlet area to be 248,000 cu yd (190,000 cu m) per year to the south (U.S. Army Engineer District, New York, 1954). Other Corps estimates of net potential longshore transport at Barnegat Inlet range from 105,000 cu yd $(80,000 \mathrm{cu} \mathrm{m})$ per year to the north to $365,000 \mathrm{cu}$ yd $(280,000 \mathrm{cu} \mathrm{m})$ per year to the south (U.S. Army Engineer District, Philadelphia, 1995).

Using OCTI hindcast wave climatology, the net potential longshore transport along Long Beach Island was found by Cialone and Thompson (2000) to be approximately $99,000 \mathrm{cu}$ yd $(76,000 \mathrm{cu} \mathrm{m})$ per year to the south, and using the WIS hindcast wave climatology, they found the net potential longshore sediment transport to be approximately $149,000 \mathrm{cu}$ yd $(114,000 \mathrm{cu} \mathrm{m})$ per year to the south. The U.S. Army Engineer District, Philadelphia (1981), had previously estimated the net potential longshore sediment transport to be approximately $91,000-183,000 \mathrm{cu}$ yd $(70,000-140,000 \mathrm{cu} \mathrm{m})$ per year to the south. U.S. Army Engineer, Philadelphia (1995), estimates of net potential longshore sediment transport for Long Beach Island indicate a much lower value of approximately 
$52,000 \mathrm{cu} \mathrm{yd}(40,000 \mathrm{cu} \mathrm{m})$ per year to the south. It is evident that there is great variability in potential longshore sediment transport estimates due to the quality of the input data as well as the level of sophistication used in the study. A reasonable value of net potential longshore sediment transport for Long Beach Island is on the order of 98,000-196,000 cu yd (75,000-150,000 cu m) per year (Cialone and Thompson 2000).

The net actual longshore sediment transport will always be equal to or less than the net potential longshore sediment transport. Sheltering effects of structures such as inlet jetties will reduce the potential transport to the actual transport. Regardless of the absolute magnitudes of the estimated net potential longshore sediment transport, there exists a normal wave climate along the New Jersey shoreline sufficiently adequate to move large quantities of sand along the coastline on an annual basis. In the absence of a source of sediment supply to the beach, it would not be surprising to observe fluctuations in surveyed beach profiles over long periods of time.

\section{Beach profile changes}

The full beach profiles both for Island Beach State Park and Long Island Beach were evaluated for five annual surveys during 1993-1997. Using 1993 as the baseline year, subsequent annual surveys were compared with the 1993 survey, and the volume of material between the two surveys was computed in increments from the berm toward the ocean of (a) berm to mean waterline (mwl), (b) berm to $-6 \mathrm{ft}(-1.8 \mathrm{~m}) \mathrm{mwl}$, (c) berm to $-12 \mathrm{ft}(-3.6 \mathrm{~m}) \mathrm{mwl}$, (d) berm to $-18 \mathrm{ft}$ $(-5.5 \mathrm{~m}) \mathrm{mwl}$, (e) berm to $-24 \mathrm{ft}(-7.3 \mathrm{~m}) \mathrm{mwl}$, and (f) berm to $-30 \mathrm{ft}$

$(-9.1 \mathrm{~m})$ mwl. These beach volume computations are displayed in Appendix C. Here it is apparent that only minimal changes took place from year to year anywhere along a profile. A typically representative example of a profile for Island Beach State Park north of Barnegat Inlet is shown in Figure 86. The beach volume computations for this profile are shown in Figure 87.

A typically representative example of a profile for Long Island Beach south of Barnegat Inlet is shown in Figure 88. The beach volume computations for this section are shown in Figure 89.

\section{Summary of Effects of New South Jetty on Upcoast and Downcoast Beaches}

The new south jetty was constructed entirely within the confines of the previous arrowhead jetties (Figure 90). The new south jetty extends from Barnegat Lighthouse to the ocean end tip of the old existing arrowhead jetty. The new south jetty terminates in the ocean at exactly the same location where the old arrowhead jetty still terminates. Hence, any otherwise potential impacts of the new south jetty on the system are negated by the continued existence of the arrowhead jetty that prevents the new south jetty from exerting an influence on the coastlines. 


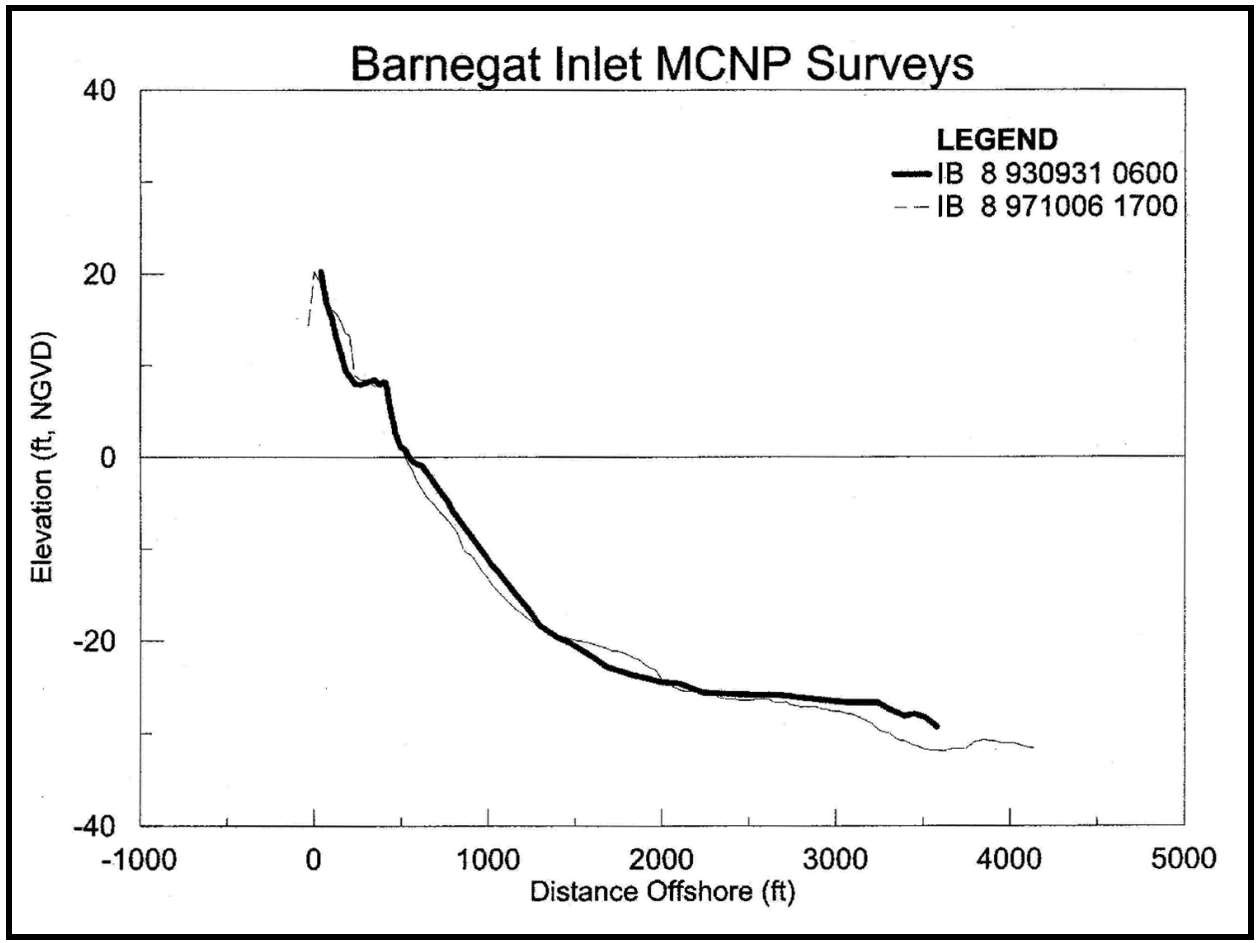

Figure 86. Typical beach profile change for Island Beach State Park, Profile IB 8

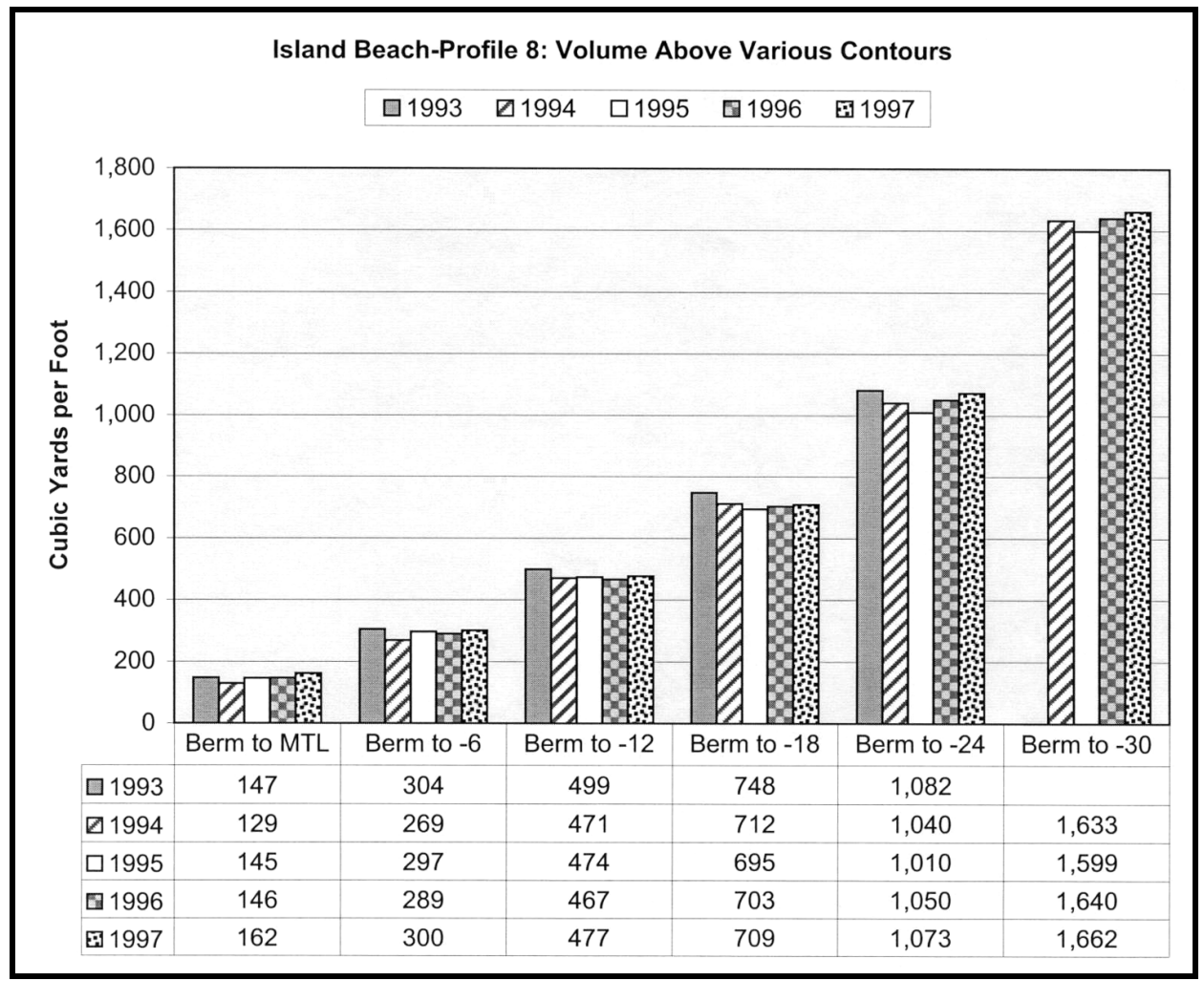

Figure 87. Beach volume changes along Island Beach State Park, Profile IB 8 (to convert cu yd per $\mathrm{ft}$ to cu $\mathrm{m}$ per $\mathrm{m}$, multiply by 2.50 ) 


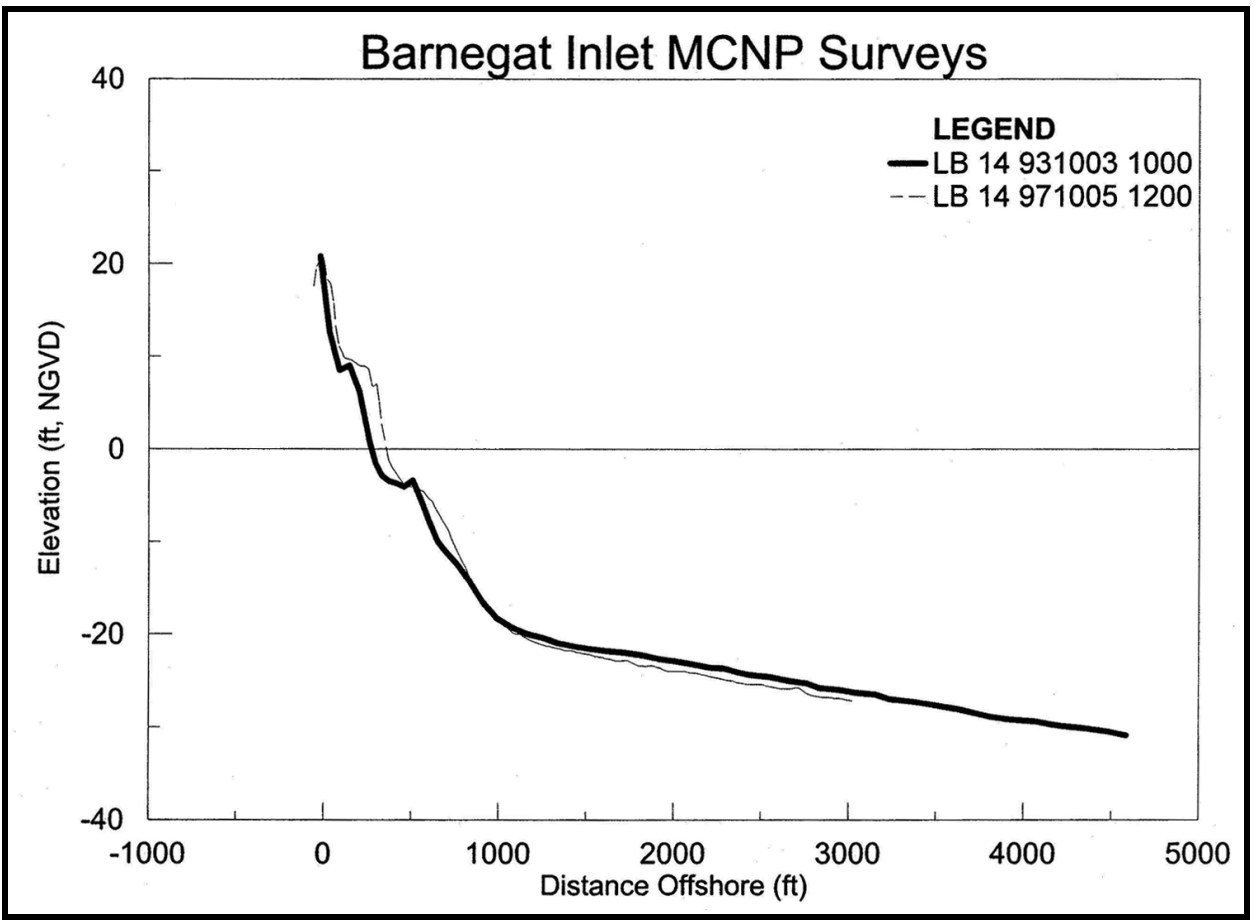

Figure 88. Typical beach profile change for Long Island Beach, Profile LB 14

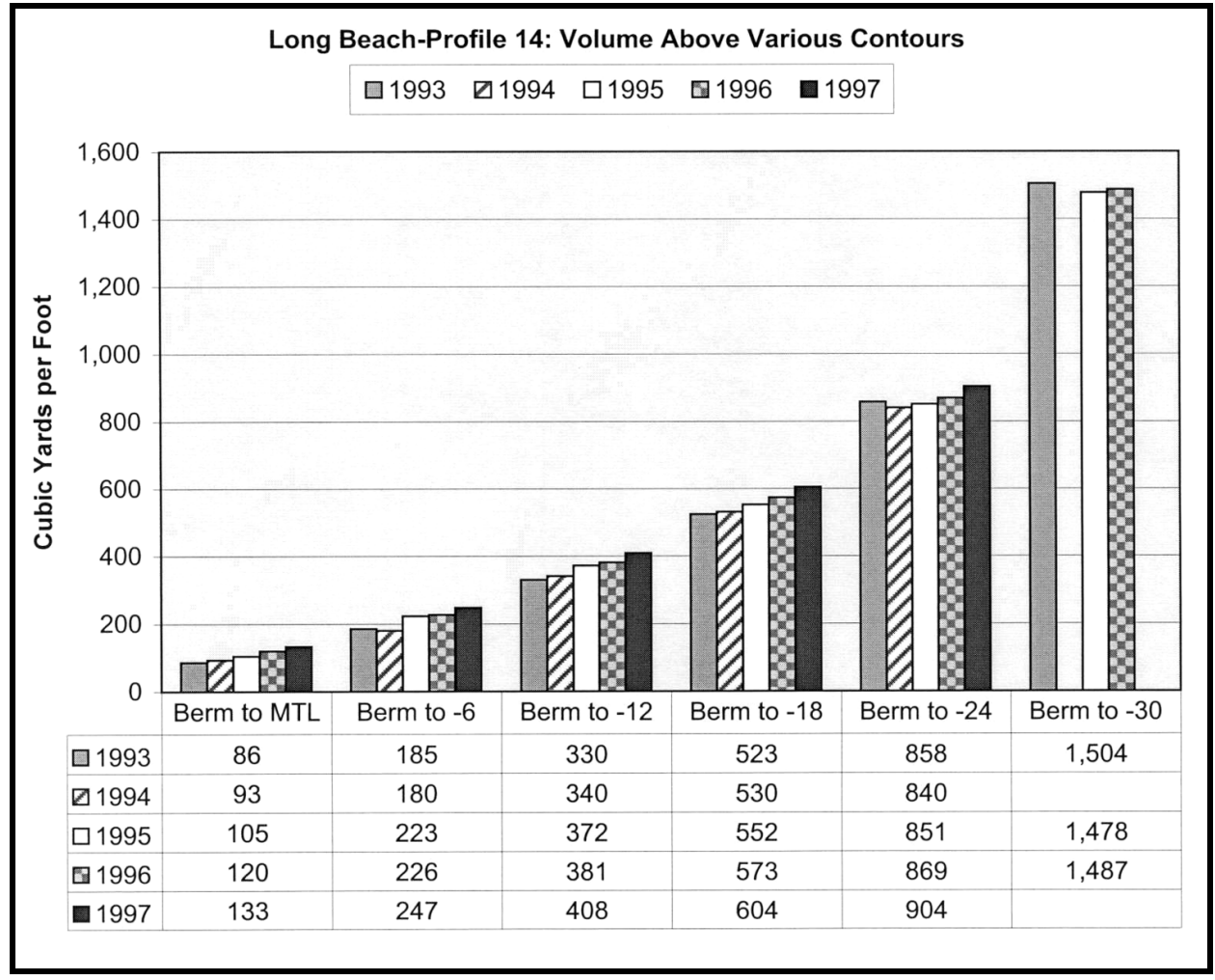

Figure 89. Beach volume changes along Long Island Beach, Profile LB 14 (to convert cu yd per $\mathrm{ft}$ to cu $\mathrm{m}$ per $\mathrm{m}$, multiply by 2.50 ) 


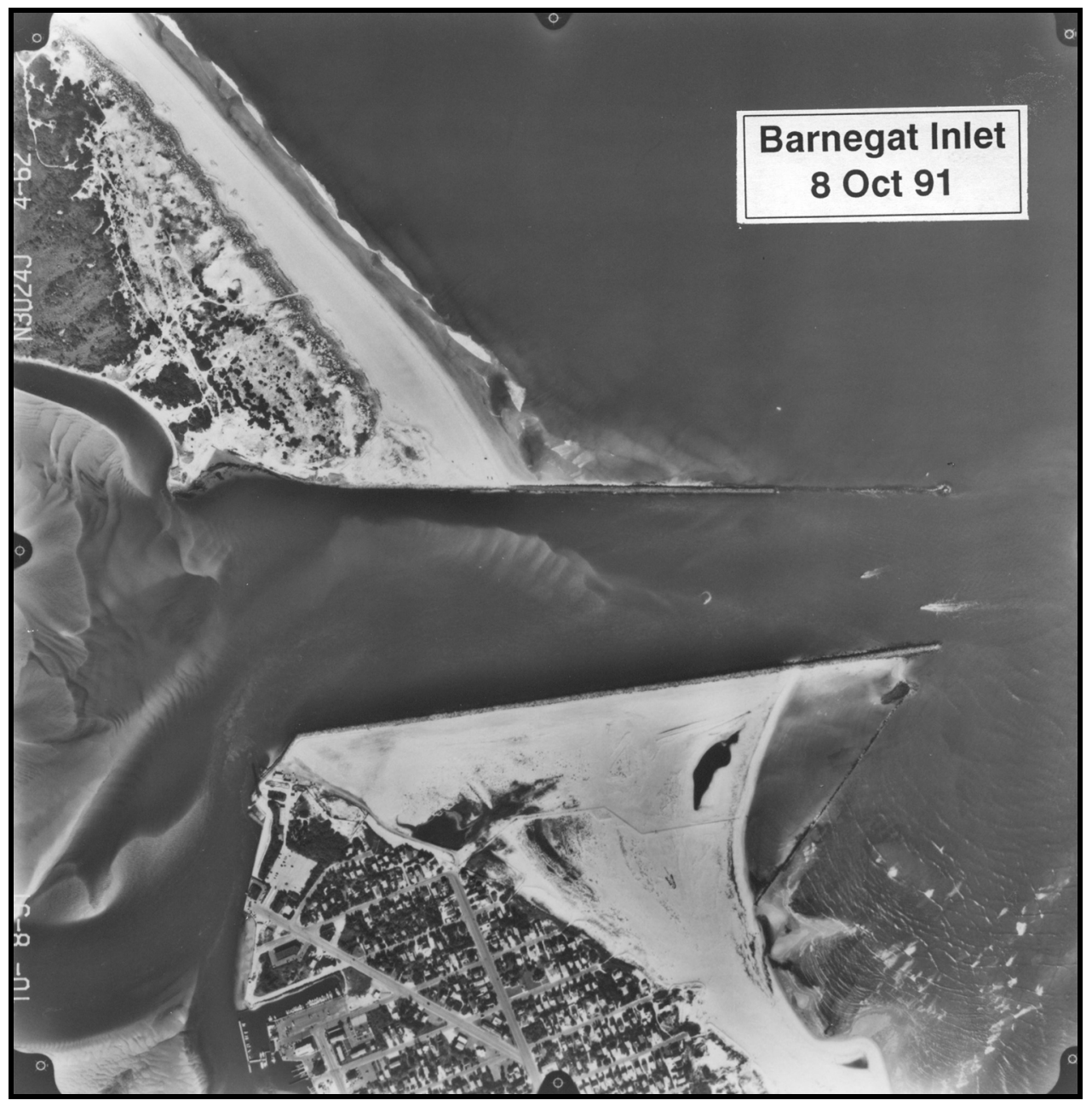

Figure 90. New south jetty constructed entirely within the confines of the old arrowhead jetty system

Hypothesis 4 of this MCNP study states that the new south jetty realignment would not adversely affect upcoast or downcoast beaches. It is concluded that this hypothesis is correct for two fundamental reasons:

a. The amount of beach profile change as determined by full profile surveys from the berm out to $-30 \mathrm{ft}(-9.1 \mathrm{~m}) \mathrm{mwl}$ for both Island Beach State Park (to the north of Barnegat Inlet) and Long Island Beach (to the south of Barnegat Inlet) are well within the realm of natural variation of beach processes as approximated from net potential longshore sediment transport computations.

$b$. The construction of the new south jetty entirely within the confines of the existing jetty system minimizes the new south jetty from having any significant effect on the upcoast or downcoast beaches. 


\section{Summary and Conclusions}

\section{Introduction}

\section{Background}

Barnegat Inlet, $\mathrm{NJ}$, is a stabilized inlet centrally located on the Atlantic coast approximately 50 miles $(80 \mathrm{~km})$ south of Sandy Hook and 70 miles $(112 \mathrm{~km})$ northeast of Cape May. The inlet separates Island Beach State Park to the north from Long Beach Island to the south, and serves as the primary link between the Atlantic Ocean and Barnegat Bay. Barnegat Inlet is used by a large number of commercial and recreational vessels. Boaters contend that it is one of the most hazardous inlets on the East Coast (U.S. Army Engineer District, Philadelphia, 1984).

In 1939-1940, two mean tide elevation rubble-mound jetties were constructed in an arrowhead configuration as part of a Federal navigation project. The arrowhead configuration was selected to provide flow convergence promoting scour and maintaining the desired channel depth in the inlet throat. However, the low elevation arrowhead jetty configuration did not confine the ebb and flood tidal flows, resulting in several channels developing between the jetties. There was not a single stable navigation channel through the inlet, and the depths of the navigation channels were inadequate due to sediment entering the intra-jetty area over the low mean tide elevation jetties.

Several modifications were made to the jetties following their initial construction (Smith 1988). Numerous dredging projects were performed throughout the history of the project in an attempt to straighten or stabilize the channel, but all were unsuccessful. In 1943, a sand dike was constructed on the bay side of the inlet to eliminate one of the two major channels and stabilize the flow through the inlet, but this was also unsuccessful. A new south jetty was constructed during the period December 1987 through June 1991 parallel to the existing north jetty, extending from the base of the Barnegat Lighthouse to the end of the existing south jetty. Initial dredging of the 300-ft- (91-m-) wide $\times 10$-ft- (3-m-) deep channel and other minor project features were completed in early 1992.

\section{Problem statement}

An unstable navigation channel and navigation safety issues at Barnegat Inlet led to the construction of a new interior south jetty rubble-mound structure completed in 1991. The response of the inlet system to this new jetty construction was determined by MCNP data collection and monitoring, and compared with design predictions. 


\section{Objectives of MCNP monitoring at Barnegat Inlet}

The effectiveness of the new south jetty at Barnegat Inlet, NJ, on the inlet system needed to be evaluated to provide improved inlet and jetty system design guidance, to enhance construction of rubble-mound jetties, and to develop better maintenance techniques for tidal inlets. The project performance was assessed with regard to providing a stable navigation channel and a stable rubble-mound jetty structure, and was then compared with project design, physical model predictions, and other design criteria.

\section{Study approach and monitoring plan}

The monitoring plan evaluated four fundamental hypotheses of the project design objectives (U.S. Army Engineer District, Philadelphia, 1984).

a. Hypothesis 1: The new south jetty and new channel alignment will not adversely affect tidal hydraulic response or high tide level in the inlet bay system (i.e., no flooding problem).

b. Hypothesis 2: The new south jetty realignment will improve navigation safety by stabilizing the navigation channel location and depth between the jetties and over the outer bar (ebb tidal shoal), and will eliminate dredging in these regions. The new south jetty will help maintain interior channel location. Sediment placement in the area between the old and new south jetties during construction of the new south jetty does not affect channel shoaling.

c. Hypothesis 3: The new south jetty will be structurally stable.

d. Hypothesis 4: The jetty system realignment will not adversely affect upcoast or downcoast beaches.

\section{Effects of New South Jetty on Hydraulics}

Nearly continuous tidal records at five locations in Barnegat Bay were analyzed to determine changes in tidal constituents and bay tide range since completion of the project. Short-term (13- and 25-hr duration) measurements of tidal current in the inlet throat and near the flood shoal were used to determine flow patterns. A longer-term (34-day) tidal current data collection effort at a single point in the inlet throat was conducted and correlated with short-term measurements to understand variations in discharge and tidal prism over a lunar month.

\section{Tidal prisms}

Tidal prisms based on velocity measurements in the 1990s indicate that the inlet has returned to prism magnitudes measured in the preproject 1930s and early project years of the 1940s. Detailed, short-term ADCP measurements indicate that spring tide prisms range up to $42.4 \times 10^{6} \mathrm{cu}$ yd $\left(32.4 \times 10^{6} \mathrm{cu} \mathrm{m}\right)$. Early 1940s measurements were as high as $45 \times 10^{6} \mathrm{cu}$ yd $\left(34.5 \times 10^{6} \mathrm{cu} \mathrm{m}\right)$. This agreement follows naturally from the similarity between the 1930 s and 1990 s bay tide range measurements. In contrast, late 1960s to 1980s prisms measured 14 to $18 \times 10^{6} \mathrm{cu}$ yd ( 11 to $14 \times 10^{6} \mathrm{cu} \mathrm{m}$ ) when the inlet was more choked. This change in prism from the 1980s to the 1990s is accounted for by a 40 percent increase in minimum channel cross-sectional area due to dredging for 
the present project, and to the raised jetties limiting longshore sediment from entering the channel. The oceanward side of the inlet gorge between the jetties is much deeper for the high parallel jetty system (keeping sediment out and promoting channel efficiency through higher velocities) than for the lowelevation arrowhead jetty system of the 1960-80s. In contrast, late 1960s to 1980s prisms were much smaller due to sediment influx over the low arrowhead jetties that reduced the minimum cross-sectional area.

\section{Tidal constituents}

Tidal constituents at the USCG station on the bay side of the jetty system indicate an increase in flood dominance and greater admittance into Barnegat Bay since completion of the new south jetty, compared with the arrowhead jetty configuration. This is due to an increase in minimum cross-sectional area in the jetty region and to channel straightening and deepening. However, when the most recent jetty configuration is compared to the prestabilized inlet tides (1932), bay tide ranges for the present conditions are very similar, being in the range of 0.4 to $0.6 \mathrm{ft}(0.13$ to $0.17 \mathrm{~m})$. Bay tide range decreased when the arrowhead (mean tide level crest elevation) jetties and sand dike were constructed, then increased after jetty elevations were raised and the minimum cross-sectional area increased by dredging.

\section{Inlet dynamics}

The hydraulic condition at Barnegat Inlet indicates a small bay tide range of 0.3 to $0.7 \mathrm{ft}$ ( 0.1 to $0.2 \mathrm{~m}$ ) relative to the ocean tide, due to the large bay size in relation to the inlet cross-sectional area at the throat. Maximum flood flow in the entrance channel occurs near ocean high water elevations, and maximum ebb flow occurs near ocean low water elevations. This leads to ebb flow that is longer in duration than flood flow due to the increase in friction for ebb flow moving through a smaller, shallower cross-sectional area. In contrast, the predominant flood currents have greater variability. Maximum flood flows are as much as 60 percent greater than maximum ebb flow discharges. As neap tide ranges are approached, ebb predominance occurs as flood flow falls below the ebb threshold. Water stored in the bay during spring tide is gradually released to the ocean during the transition from spring to neap tide. The flood flow predominance of spring tides and accompanying inability to fully drain during ebb flow due to the maximum discharge capacity of the channel creates a net storage in the bay until the transition from spring to neap tide. At that time there is a net outflow. The duration of ebb flow typically reaches its maximum during spring tide, as the increased superelevation of the bay creates a greater bay-toocean elevation gradient for a greater portion of the tidal cycle than exists during neap tides.

\section{Wind effects}

The effect of wind can change the typical trends for ebb and flood flow duration, net bay inflow and outflow, and tidal prism magnitude. Winds along the channel axis can enhance bay inflows and outflows. The effects of winds on the bay tide elevations can also be significant, especially considering that the average bay tide range is only $0.4 \mathrm{ft}(0.12 \mathrm{~m})$. When winds are from the south and southwest, the northern portion of Barnegat Bay was superelevated by as much as $1.3 \mathrm{ft}(0.40 \mathrm{~m})$. Winds from the north, northeast, and northwest reverse the head difference, elevating the southern portion of Barnegat Bay up to $0.8 \mathrm{ft}$ $(0.24 \mathrm{~m})$. 


\section{Flow distribution}

Flow distribution through the navigation channel and over the flood shoal are similar for mean and spring conditions. Approximately two-thirds of the ebb flow exited through the interior navigation channel and one-third exited over the flood shoal. Flood flow entering into the bay for mean tide conditions indicated about 56 percent of the flow entered over the flood shoal, and 44 percent moved through the interior navigation channel adjacent to Barnegat Lighthouse. This compares with 65 percent entering over the flood shoal and 35 percent entering through the channel for spring tide flood flow conditions. Flood flows at the seaward end of the inlet are strongest near the south jetty. Near the inner part of the intra-jetty area, flood flows are strongest on the north side of the inlet. On ebb the trends are reversed. For spring tide, flow in the intra-jetty region showed higher average peak flood velocities, indicating local flood dominance. Overall mean conditions were nearly balanced, with a slight flood dominance.

\section{Flood and ebb currents}

Analysis of the 34-day bottom-mounted ADCP data showed that the lower magnitude ebb velocities are more uniform over depth (linear distribution), whereas the higher flood velocities have a logarithmic distribution over the same depth range. Flood tide conditions resulted in significantly larger average velocities of $1.0 \mathrm{ft}(0.3 \mathrm{~m})$ per sec greater. Flood and ebb velocities are directed somewhat toward the south jetty due to structural and bathymetric controls. The weir section at the oceanward end of the north jetty and greater adjacent seaward depths relative to the south approach to the inlet help direct flood flow toward the south side of the intra-jetty region. Ebb currents exiting through the intra-jetty region from the bay, once past this region, expand seaward of the intra-jetty shoal and are somewhat directed toward the south jetty.

\section{Sediment transport}

During spring tide, where flood velocities greatly exceed ebb velocities, flood dominance of potential sediment transport is implied. During neap conditions, where flows are more nearly in balance, sediment transport magnitude estimates are more evenly distributed, and net transport is slightly ebb-dominated due to longer ebb durations. Analysis of the entire 34-day record indicates that the cumulative sediment transport potential is flood-dominated.

\section{Effects of New South Jetty on Channel Stability and Dredging}

\section{Impact of structures on inlet channel location}

The concept of arrowhead jetties for concentration of ebb flows at the oceanward terminus (in order to cut through the ebb shoal) and for wave attenuation due to diffraction as waves propagated into the expansion area was believed to be a positive design attribute at the time of installation. Strong ebb flow concentration in the navigation channel would flush sediments out of the channel as water surface elevation dropped. However, the sediment influx over these low jetties overshadowed the positive elements of the plan. Apparently most of the sediment movement was at the shoreline intersection with the jetties. The interior navigation channel moved back to its pre-structure alignment, 
probably due to the influx of sand coming over the low north jetty, which enlarged the flood shoal significantly and helped deflect ebb currents coming from the bay toward the southeast.

Raising the north jetty crest elevation cut off direct sediment influx from the north, but sediments from the south maintained the same minimum area at the inlet gorge. Channel migration to the now-dominant north jetty, plus dredging, cut off input to the flood shoal and redirected beach sediments to the ebb shoal. The addition of a new higher south jetty paralleling the north jetty, along with an increase of minimum channel area due to dredging and the prevention of sediments entering from the south into the inlet gorge, permitted a larger tidal prism. Recent incising of the flood shoal, and the apparent reduction in sediment supply to the flood shoal, indicate a potential for ebb currents to eventually shortcut across the flood shoal and deepen a channel there. The deeper water for the navigation channel through the inlet between the jetties has stabilized in location, and is now consistently on the north side of the inlet, adjacent to the north jetty.

\section{Impact of structures on flood shoal}

The most dramatic changes have been the decrease in mean elevation of the flood shoal and the changes on the seaward portion of the flood shoal, which has gone from convex to concave as a channel appears to be attempting to bisect the southern lobe. Deflation of the high lobes and increase of the marginal areas show that the flood shoal has flattened out and is broadening. From 1992 to 1997 the majority of the flood shoal was reduced from $0.0 \mathrm{ft}(0.0 \mathrm{~m})$ NAVD 88 to -3.3 $\mathrm{ft}(-1.0 \mathrm{~m})$ NAVD 88 . The plan view area above the $-3.3-\mathrm{ft}(-1.0-\mathrm{m})$ contour has shifted bayward and southward during the 5 years since project completion. Sediment volumes lost from the higher elevations are most significant. Only 15 percent of the overall volume has been displaced, which is predominantly the loss of sediment from the higher elevations, and thus an assumption of minimal volume loss is reasonable. The incised (smaller) channel has deepened and shifted to the northeast while the main navigation channel has deepened and shifted to the southwest. Therefore, the overall shoal volume is nearly intact, with sediment shifting to marginal areas as the main navigation channel has enlarged and migrated southward. The changes observed for the flood shoal since project completion are due primarily to the increased tidal prism and flood flow velocities, as well as the limited sediment supply caused by both jetties being sand-tightened.

\section{Impact of structures on navigation safety and dredging}

Navigation safety. The locations of the inlet and flood shoals have now stabilized. Even though annual dredging is still necessary, navigation safety has significantly improved for mariners, especially for commercial fishermen, since the shoals are not shifting as previously happened. The navigation channel through the inlet between the jetties has stabilized on the north side of the inlet adjacent to the north jetty. Deep water is consistently available on the north side of Barnegat Inlet.

Dredging. It was anticipated during planning for the new south jetty that by dredging a new initial navigation channel through the inlet and flood shoal, the new jetty layout would focus flood and ebb currents along the new channel and create a self-maintaining inlet system. The flood and ebb currents were expected to flush from the navigation channel any sediment that might possibly enter the 
channel from whatever known or unknown sources. This has not proven to be the case. Dredging quantities steadily increased from a minimum of about $170,000 \mathrm{cu}$ yd $(130,000 \mathrm{cu} \mathrm{m})$ in 1991 to a maximum of about $355,000 \mathrm{cu} \mathrm{yd}$ $(270,000 \mathrm{cu} \mathrm{m})$ in 1997 . Since that time, dredging volumes have decreased to about $192,000 \mathrm{cu}$ yd $(147,000 \mathrm{cu} \mathrm{m})$ in 2000. However, the year 2000 dredging volume was impacted by dredge availability. The $192,000 \mathrm{cu}$ yd $(147,000 \mathrm{cu} \mathrm{m})$ dredged in 2000 would have been larger except that the dredge had to undergo shipyard maintenance.

\section{Barnegat Inlet New South Jetty Structure Stability}

The methodology for determining if the new south jetty is structurally stable involved ascertaining actual prototype wave conditions in the vicinity of the structure to compare with wave height used in the original south jetty design. This, in turn, required determining the effects of the ebb shoal bathymetry and tidal currents on deepwater wave transformation as waves propagate from deep water offshore toward the nearshore zone. Simulation of an actual storm event was performed with the ebb shoal bathymetry and compared to prototype data. Finally, the structure CI was determined to ascertain (a) how well the structure was performing its intended function, and (b) its level of physical condition and structural integrity.

\section{Structure design waves}

The structure design waves had been determined by the U.S. Army Engineer District, Philadelphia. The 4,270-ft- (1,300-m-) long south jetty was divided into four equal increments of length. A breaking design wave height was determined for each of these four increments. It was determined that, due to the 1,000-ft (305-m) spacing between the jetties and the channel depths between the jetties and across the outer bar, design breaking waves with heights of 14.0, 14.0, 15.2, and $15.9 \mathrm{ft}(4.3,4.3,4.6$, and $4.9 \mathrm{~m})$ (proceeding from the shoreline in an offshore direction, respectively) were appropriate for the four south jetty increments.

\section{Wave heights at Barnegat Inlet}

At Barnegat Inlet, where maximum flood currents occur at high water and maximum ebb currents occur at low water, bathymetry and water levels have stronger effects than currents on wave transformation. Ebb shoal bathymetry and low water levels generally reduce the energy in waves greater than 3.3 to $4.9 \mathrm{ft}$ $(1.0$ to $1.5 \mathrm{~m})$. The average wave height at the jetty is slightly smaller for low water levels due to breaking of large waves at low water. The influence of tidal currents is most prevalent for smaller waves less than $3.3 \mathrm{ft}(1.0 \mathrm{~m})$. Smaller waves increase in wave height 10 percent more for ebb currents than flood currents. Flood currents tend to elongate and flatten the waves whereas ebb currents peaken waves.

Wave heights near the jetty structure vary most with approach angle. Normally incident (90- to 113-deg) waves have both large wave heights and large wave height ratios. Waves as large as $12.6 \mathrm{ft}(3.84 \mathrm{~m})$ high were measured at the DWG location during the 1-year data collection time. Wave transformation analysis showed that waves could reach the jetty with a height amplification of 1.4 times the deep-water wave height. This would result in a wave height at the structure of $17.6 \mathrm{ft}(5.4 \mathrm{~m})$, for waves with periods up to $8 \mathrm{sec}$. The south jetty 
was designed for a no-damage criterion from waves up to $15.9 \mathrm{ft}$ (4.9 m) high. However, the structure has experienced a small degree of settling, armor shifting, and slope steepening. Thus, it appears the structure has indeed experienced waves slightly in excess of the design wave, but not to such an extent as to be exceedingly larger, and significant concerns about safety of the structure are not an issue.

\section{South jetty Condition Index}

The $\mathrm{CI}$ is a uniform procedure for assessing the condition of rubble-mound breakwaters and jetties. The $\mathrm{CI}$ allows for a concise reporting system that indicates the deficiencies a structure may have, which parts of the structure are deficient, and the relative severity of the deficiencies.

The new south jetty has a two-layer capstone design, with the bottom layer of capstones at the center replaced with corestone to prevent sand migration through the pervious capstone layer. The bedding stone layer is about $1 \mathrm{ft}(0.3 \mathrm{~m})$ thick, and the mat stone layer is about $2 \mathrm{ft}(0.6 \mathrm{~m})$ thick. The use of two very thin bedding and mat stone layers is quite unusual. The top elevation of the core stone was increased in this design to make the design sandtight by reducing the armor layer thickness at the top center of the jetty from two stones to one stone.

South jetty structure CI inspections consisting of detailed visual walk-thestructure examinations were conducted in 1993, 1994, 1995, and 1996. Several significant and severe storms impacted this region of coastline during this period, and resulted in a slow but gradual movement of some of the armor and corestone. While the corestone design was intended to prevent sand movement through the capstone layer, some locations along the jetty indicated this was not the actual case. The water was able to move through the jetty onto the fill area immediately south of the structure, and a meandering channel on the landside indicated flow was occurring through the jetty as the tide rose. Conversely, rainwater pooling in these channels provided a means for sediment to pass through the structure and into the channel at low tide. There has also been minimal movement of armor stone with steepening of the side slopes in some locations. While there are gaps between armor stone on the crest of the structure that may be the result of imprecise construction techniques, the structure appears to be fundamentally stable.

The new south jetty at Barnegat Inlet clearly exhibits some degree of imperfection. On average, the structure has a CI index of at least 70, indicating that the condition level is very good, even though minor deterioration and defects are evident. Although slight imperfections may exist locally, no significant defects exist that would indicate imminent failure of the structure. All things considered, the Barnegat Inlet new south jetty appears fundamentally sound, and is serving the functional purpose for which it was developed.

\section{Effects of New South Jetty on Upcoast and Downcoast Beaches}

Profile surveys and aerial photographs were assimilated to evaluate whether the south jetty realignment would adversely affect upcoast or downcoast beaches. Pre- and post-project surveys were compared to examine shoreline trends since the new south jetty construction in 1992. 


\section{Beach profile surveys}

Beach profile surveys were performed annually for 5 years by contract during 1993-1997 at both Island Beach State Park on the north side of Barnegat Inlet and Long Beach Island on the south side of Barnegat Inlet. A coastal survey sled beach profiling system that provided high-quality data from the dune line to beyond a depth of $-30 \mathrm{ft}(-9.1 \mathrm{~m})$ NGVD was utilized for 9 full beach profiles along Island Beach State Park and for 14 full beach profiles along Long Beach Island, for a total of 23 full beach profiles near Barnegat Inlet. The full beach profiles extended from the dune line seaward to a water depth of at least $-30 \mathrm{ft}$ ($9.1 \mathrm{~m}) \mathrm{NGVD}$, or to a maximum distance of 1 mile $(1.6 \mathrm{~km})$ from the survey baseline on the beach. Additionally, 9 shorter wading beach profiles were taken during the measurement period along Island Beach State Park, and 12 shorter wading beach profiles were taken along Long Beach Island, for a total of 21 shorter wading beach profiles. The shorter wading beach profiles extended from the dune line seaward to an average water depth of about $-3 \mathrm{ft}(0.9 \mathrm{~m})$ NGVD.

\section{Beach volume changes}

Full beach profiles both for Island Beach State Park and Long Island Beach were evaluated for five annual surveys during 1993-1997. Using 1993 as the baseline year, subsequent annual surveys were compared with the 1993 survey, and the volume of material between the two surveys was computed in increments from the berm toward the ocean. It was apparent that only minimal changes took place from year to year anywhere along a profile.

\section{Conclusions}

The new south jetty was constructed entirely within the confines of the previous arrowhead jetties. The new south jetty extends from Barnegat Lighthouse to the ocean end tip of the old existing arrowhead jetty. The new south jetty terminates in the ocean at exactly the same location where the old arrowhead jetty still terminates. Hence, any otherwise potential impacts of the new south jetty on the system are negated by the continued existence of the arrowhead jetty that prevents the new south jetty from exerting a significant influence on the coastlines.

It is concluded that the new south jetty realignment has no adverse effect on either upcoast or downcoast beaches for two fundamental reasons:

a. The amount of beach profile change as determined by full profile surveys from the berm out to $-30 \mathrm{ft}(-9.1 \mathrm{~m}) \mathrm{mwl}$ for both Island Beach State Park (to the north of Barnegat Inlet) and Long Island Beach (to the south of Barnegat Inlet) are well within the realm of natural variations of beach processes as approximated from net potential longshore sediment transport computations.

$b$. The construction of the new south jetty entirely within the confines of the existing jetty system minimizes the new south jetty from having any significant effects on the upcoast or downcoast beaches. 


\section{References}

Ashley, G. M. (1987). “Tidal prism study, Barnegat Inlet, New Jersey,” State University of New Jersey, Rutgers, NJ.

Ashley, G. M., and Halsey, S. D. (1982). "Beach nourishment on Long Beach Island; An evaluation three years later," New Jersey Sea Grant Annual Report 1981-1982, Rutgers University, New Brunswick, NJ, 29-31.

Aubrey, D. G., and Speer, P. E. (1985). "A study of non-linear tidal propagation in shallow inlet/estuarine systems: Part I; Observations," Estuarine, Coastal, and Shelf Science 21, 185-205.

Boothroyd, J. C., and Hubbard, D. L. (1975). "Genesis of bedforms in mesotidal estuaries." Estuarine Research, Myrtle Beach, SC, L. E. Cronin, ed., Academic Press, NY, 2, 217-234.

Caldwell, J. M. (1966). "Coastal processes and beach erosion," Journal of the Society of Civil Engineers 53, 142-157.

Caccese, L. A., and Spies, H. R. (1977). "Barnegat Inlet; Nature prevails." Proceedings, Coastal Sediments '77, Charleston, SC, November 2-4, 1977. American Society of Civil Engineers, 305-310.

Cialone, M. A., and Seabergh, W. C. (1997). "Effects of wave transformation at a tidal inlet." Ocean wave measurement and analysis, Proceedings, Waves 97, Virginia Beach, VA, November 3-7, 1997. American Society of Civil Engineers, Reston, VA, 1, 585-599.

Cialone, M. A., Seabergh, W. C., and Watson, K. D. (1999). "Flood shoal response to inlet modifications at Barnegat Inlet, New Jersey," Coastal sediments '99, Proceedings of the $4^{\text {th }}$ International Symposium on Coastal Engineering and Science of Coastal Sediment, Hauppauge, Long Island, New York, June 21-23, 1999. Nicholas C. Kraus, William G. McDougal, ed., American Society of Civil Engineers, Reston, VA, 1,434-1,449.

Cialone, M. A., and Thompson, E. F. (2000). "Wave climate and littoral sediment transport potential, Long Beach Island, New Jersey," Technical Report ERDC/CHL TR-00-21, U.S. Army Engineer Research and Development Center, Vicksburg, MS.

Ebersole, B. A., Cialone, M. A., and Prater, M. D. (1986). "Regional coastal processes numerical modeling system; Report 1, RCPWAVE, a linear propagation wave model for engineering use," Technical Report CERC-86-4, U.S. Army Engineer Waterways Experiment Station, Vicksburg, MS. 
Fields, M. L. (1984). "Physical processes and sedimentation in the intra-jetty area, Barnegat Inlet, New Jersey," M. S. thesis, State University of New Jersey, Rutgers, NJ.

Fields, M. L., and Ashley, G. M. (1987). "Barnegat Inlet, New Jersey - a stabilized inlet," Coastal sediments '87; Proceedings of a Specialty Conference on Advances in Understanding of Coastal Sediment Processes, New Orleans, LA, May 12-14, 1987. Nicholas C. Kraus, ed., American Society of Civil Engineers, New York, II, 2006-2021.

Gravens, M. B., Kraus, N. C., and Hanson, H. (1991). "GENESIS: Generalized model for simulating shoreline change; Report 2, workbook and system user's manual," Technical Report CERC-89-19, U.S. Army Engineer Waterways Experiment Station, Vicksburg, MS.

Harris, D. L. (1981). "Tides and tidal datums in the United States," Special Report No. 7, U.S. Army Engineer Coastal Engineering Research Center, Fort Belvoir, VA.

Headquarters, U.S. Army Corps of Engineers. (1977). "Monitoring completed navigation projects," ER 1110-2-8151, Washington, DC.

Hill, A. E. (1994). "Fortnightly tides in a lagoon with variable choking,"

Estuarine, Coastal, and Shelf Science 38, 423-434.

Jarrett, J. T. (1976). "Tidal prism - inlet area relationships," General Investigation of Tidal Inlets (GITI), Report No. 3, U.S. Army Engineer Coastal Engineering Research Center, Fort Belvoir, VA.

Johnson, J. A. (1969). "Barnegat Inlet: A problem and a solution," Shore and Beach 37(2), 17-20.

Johnson, J. A., and Eagleson, P. S. (1966). "Coastal processes," Chapter 9, Estuary and Coastline Hydrodynamics. A. T. Ippen, ed., McGraw-Hill, New York.

Kieslich, J. M. (1981). “Tidal inlet response to jetty construction,” General Investigation of Tidal Inlets (GITI), Report No. 19, U.S. Army Engineer Coastal Engineering Research Center, Fort Belvoir, VA.

Lucke, J. B. (1934). “A study of Barnegat Inlet, New Jersey," Shore and Beach 2(2), 40-94.

O'Brien, M. P. (1931). "Estuary tidal prisms related to entrance areas," Civil Engineering 1(8), 738-739.

O'Brien, M. P. (1969). "Equilibrium flow areas of tidal inlets on sandy coasts," Journal of the Waterways and Harbors Division, American Society of Civil Engineers 95(WW1), 43-52.

O’Brien, M. P. (1976). "Notes on tidal inlets on sandy shores," General Investigation of Tidal Inlets (GITI), Report No. 5, U.S. Army Engineer Coastal Engineering Research Center, Fort Belvoir, VA.

PRC Harris, Inc. (1980). "Barnegat Inlet, New Jersey, tidal prism study," Contract Report for U.S. Army Engineer District, Philadelphia, Woodbridge, NJ.

Robinson, I. S., Warren, L., and Longbottom, J. F. (1983). "Sea-level fluctuations in the Fleet, an English tidal lagoon," Estuarine, Coastal, and Shelf Science 16, 651-668. 
Sager, R. A., and Hollyfield, N. W. (1974). "Navigation channel improvements, Barnegat Inlet, New Jersey," Technical Report H-74-1, U.S. Army Engineer Waterways Experiment Station, Vicksburg, MS.

Seabergh, W. C., Cialone, M. A., and McCormick, J. W. "Inlet modifications and the dynamics of Barnegat Inlet, New Jersey," (in publication), Journal of Coastal Research, 19(3).

Seabergh, W. C., Cialone, M. A., and Stauble, D. K. (1996). "Impacts of inlet structures on channel location." Proceedings, $25^{\text {th }}$ International Conference on Coastal Engineering. 4, 4,531-4,544.

Shore Protection Manual. (1984). $4^{\text {th }}$ ed., 2 Vol., U.S. Army Engineer Waterways Experiment Station, U.S. Government Printing Office, Washington, DC.

Smith, E. R. (1988). "Case histories of Corps breakwater and jetty structures, North Atlantic Division,” Technical Report REMR-CO-3, Report 5, U.S. Army Engineer Waterways Experiment Station, Vicksburg, MS.

Smith, J. M. (1997). "One-dimensional wave-current interaction," Coastal Engineering Technical Note CETN IV-9, U.S. Army Engineer Waterways Experiment Station, Vicksburg, MS.

Smith, J. M., Militello, A., and Smith, S. J. (1997). "Modeling waves at Ponce de Leon Inlet, Florida." Proceedings, $5^{\text {th }}$ International Workshop on Wave Hindcasting and Forecasting. 201-214.

Stauble, D. K., and Cialone, M. A. (1995). "Analysis of sediment grain size trends for defining inlet sediment processes." Proceedings, 1995 National Conference on Beach Preservation Technology. Florida Shore and Beach Preservation Association, 211-226.

U.S. Army Corps of Engineers. (1993). "Condition rating procedures for rubble breakwaters and jetties," Washington, DC.

U.S. Army Engineer District, New York. (1954). "Atlantic coast of New Jersey, Sandy Hook to Barnegat Inlet," Beach Erosion Control Report on Cooperative Study, New York.

U.S. Army Engineer District, Philadelphia. (1936). "Barnegat Inlet, New Jersey," House Document No. 85, Seventy-fourth Congress, Second Session.

U.S. Army Engineer District, Philadelphia. (1974). "Barnegat Inlet, New Jersey; Survey Report, Philadelphia, PA.

U.S. Army Engineer District, Philadelphia. (1976). "Barnegat Inlet, New Jersey; Phase I, General Design Memorandum," Philadelphia, PA.

U.S. Army Engineer District, Philadelphia. (1981). "Barnegat Inlet, New Jersey; Phase I, General Design Memorandum,” Philadelphia, PA.

U.S. Army Engineer District, Philadelphia. (1984). "Barnegat Inlet, New Jersey; Phase II, General Design Memorandum," Philadelphia, PA.

U.S. Army Engineer District, Philadelphia. (1995). "New Jersey shore protection study, Barnegat Inlet to Little Egg Inlet reconnaissance study," Philadelphia, PA.

U.S. Army Shore Protection Board. (1933). “Barnegat Inlet, New Jersey,” House Document No. 19, Seventy-third Congress, Second Session. 
Vincent, C. L., and Jensen, R. E. (1997). "Observations of wave transformation near breaking," Journal of Waterway, Port, Coastal, and Ocean Engineering, American Society of Civil Engineers, 249-251.

Zetler, B. D. (1959). "Tidal characteristics from harmonic constants," Journal of the Hydraulics Division, American Society of Civil Engineers, 12, 77-87. 


\section{Appendix A Historical Photos of Barnegat Inlet, NJ, Change Chronology}

The following series of aerial photographs documents the chronology of the historical changes that have occurred in the vicinity of Barnegat Inlet, NJ, since shortly after construction of the north jetty in 1939 through December 1996.

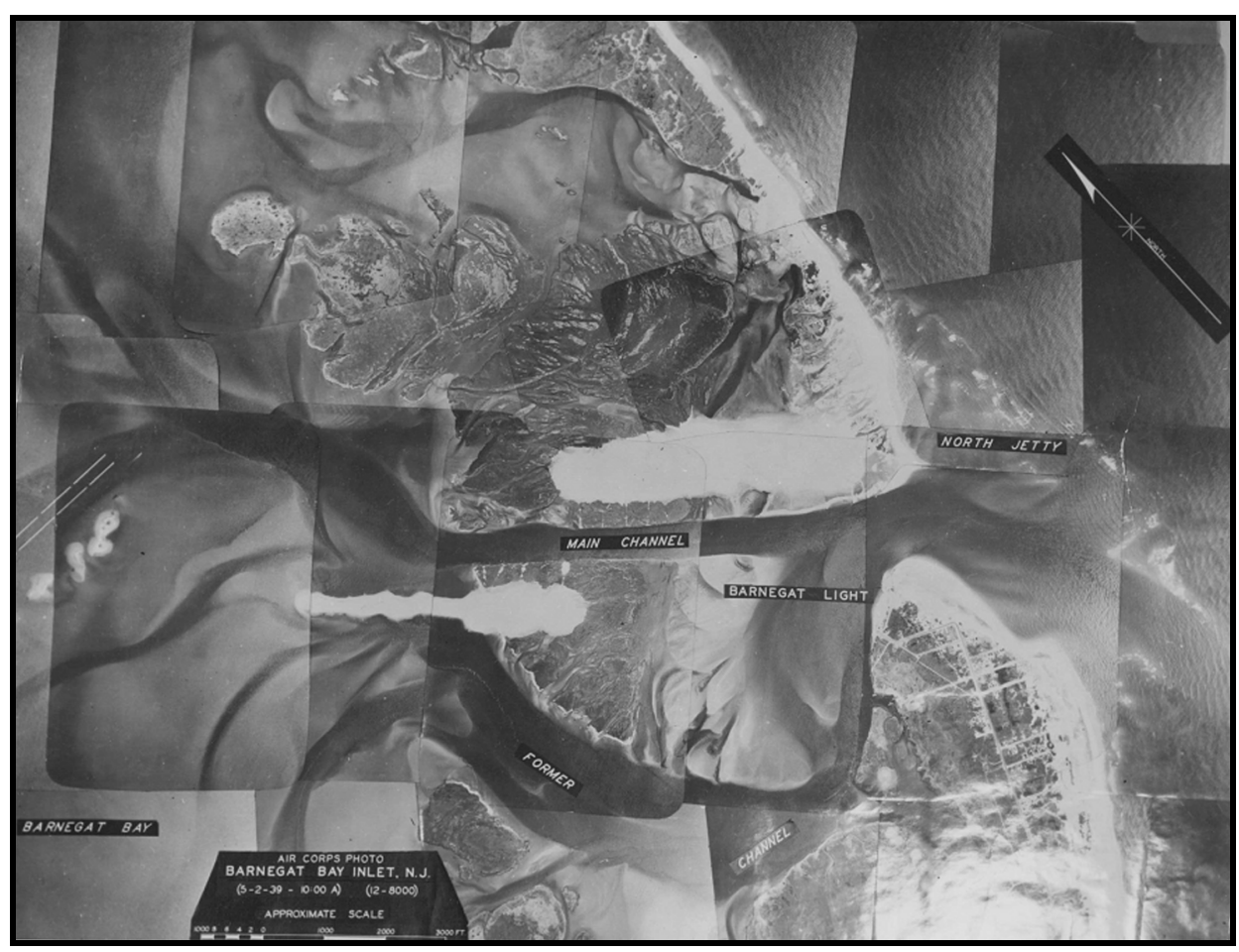

Figure A1. May 1939, immediately following construction of north jetty, but prior to construction of south arrowhead jetty. Main channel dredged through flood shoal 


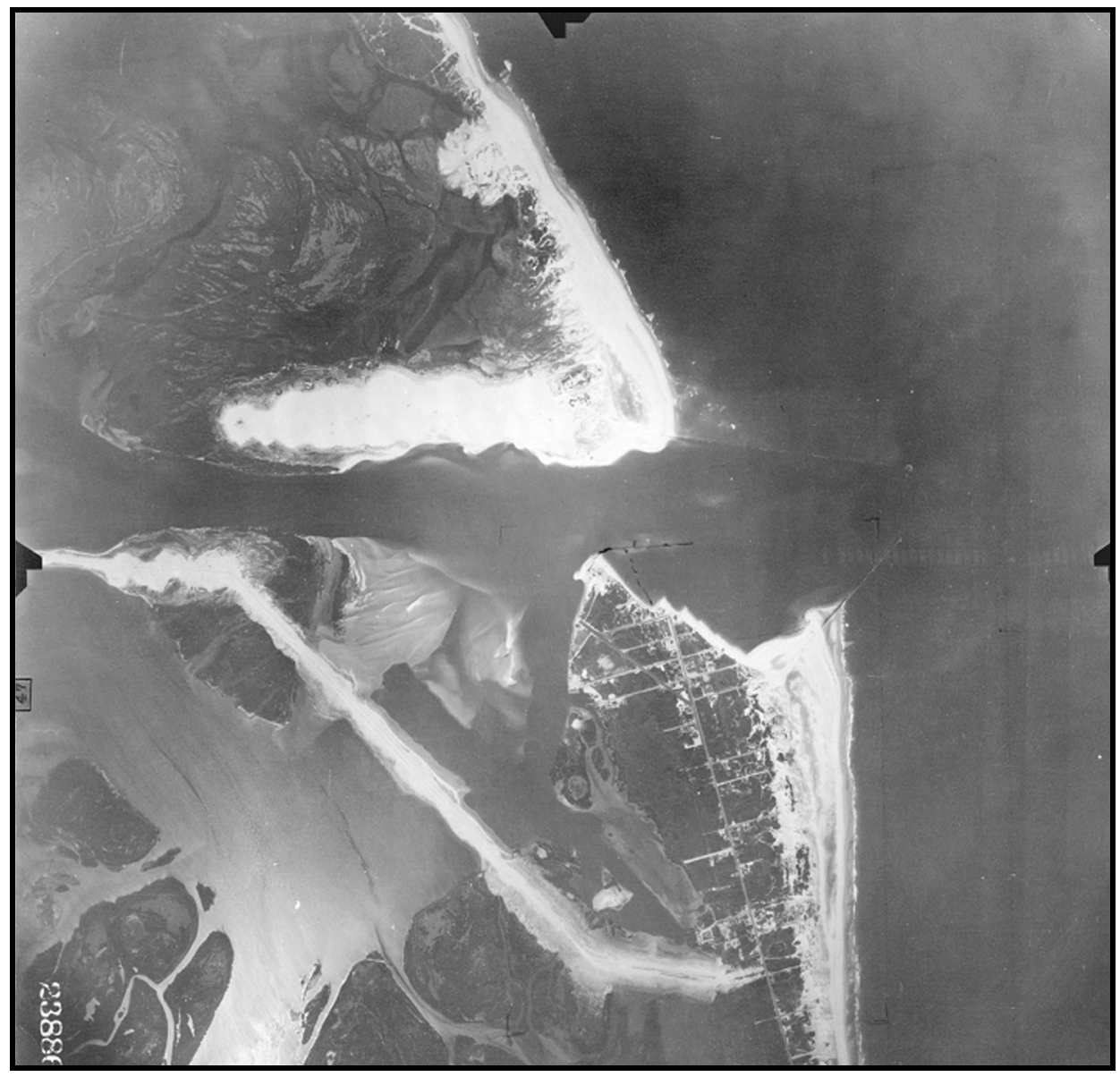

Figure A2. August 1944, after construction of south arrowhead jetty and sand dike

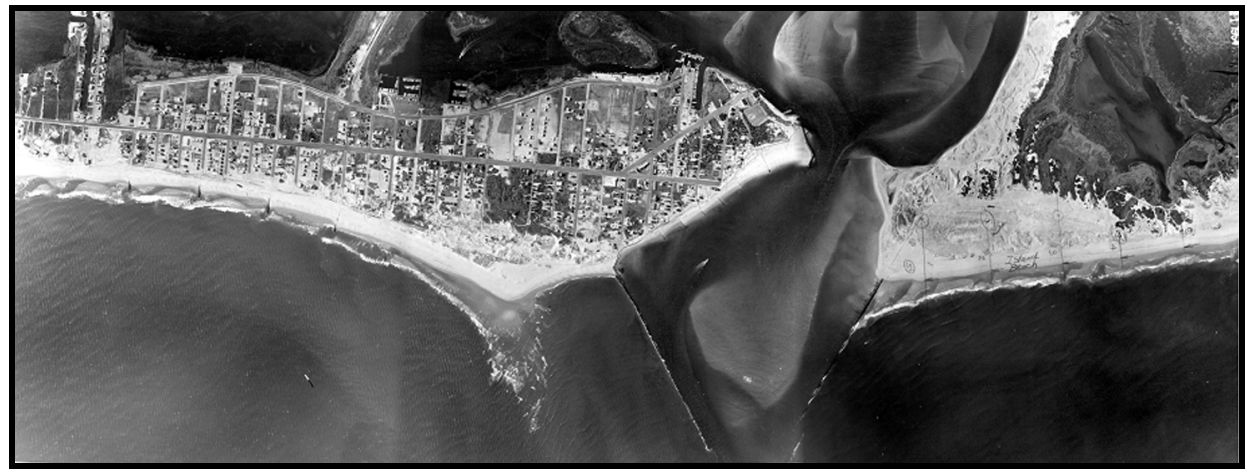

Figure A3. October 1964, shoal formation in the inlet between the jetties 


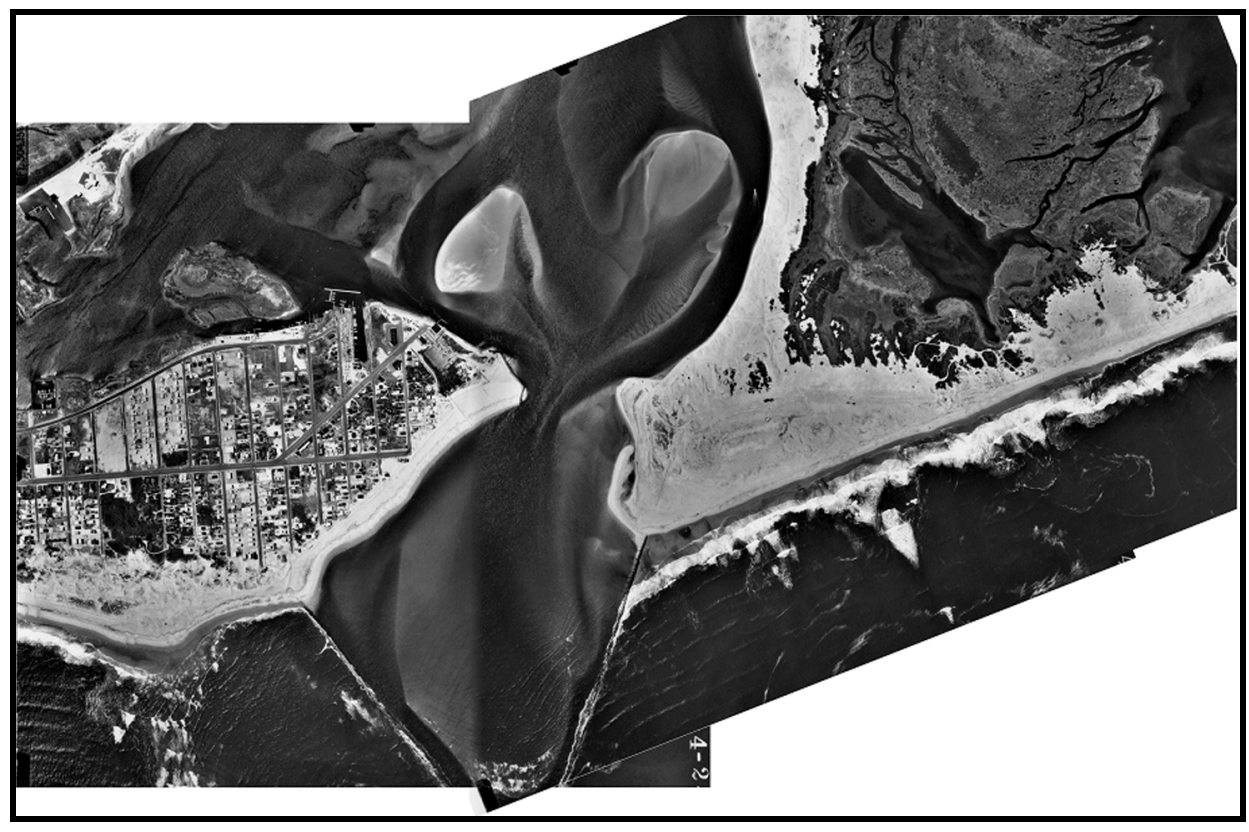

Figure A4. April 1968, entrance channel dredged through inlet shoal between jetties, and through flood shoal

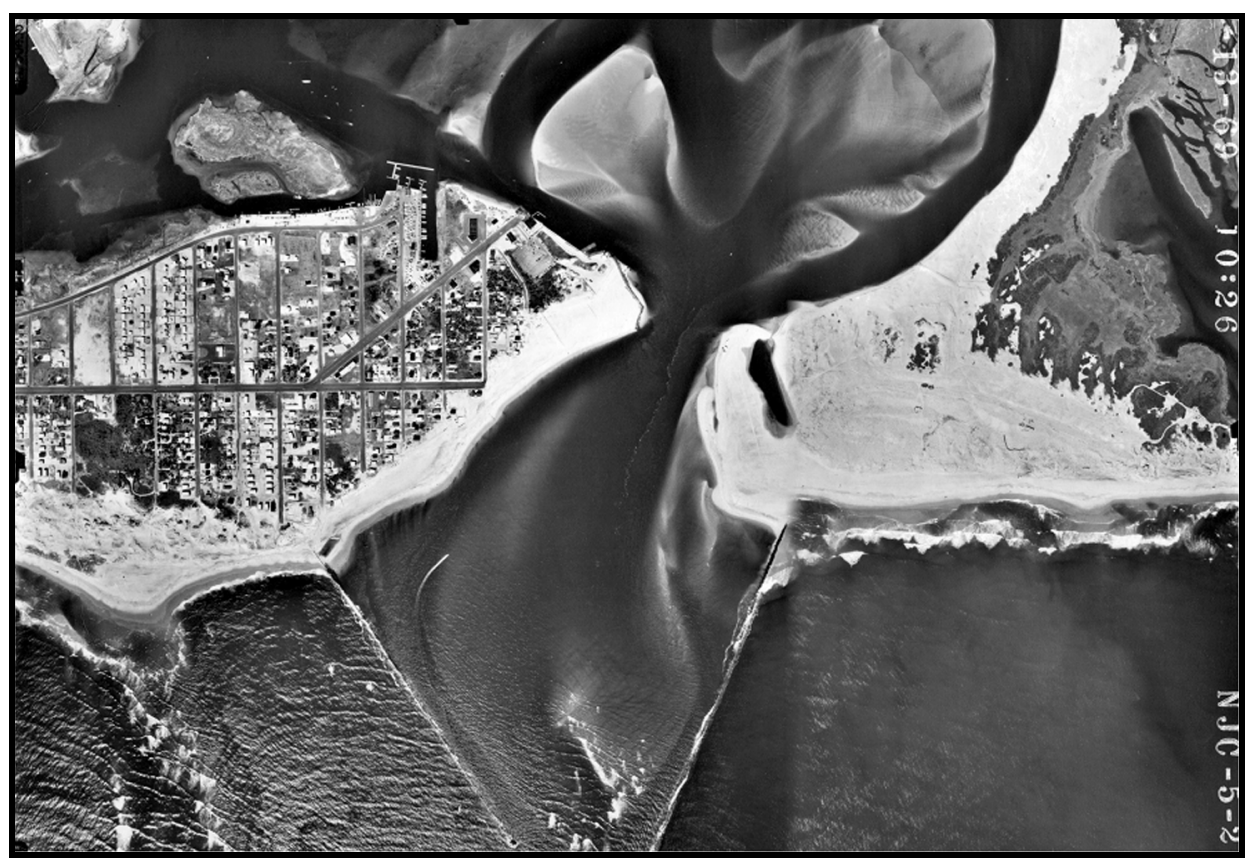

Figure A5. April 1969, inlet channel filling and navigation channel realignment due to sand movement throughout inlet and flood shoal region 


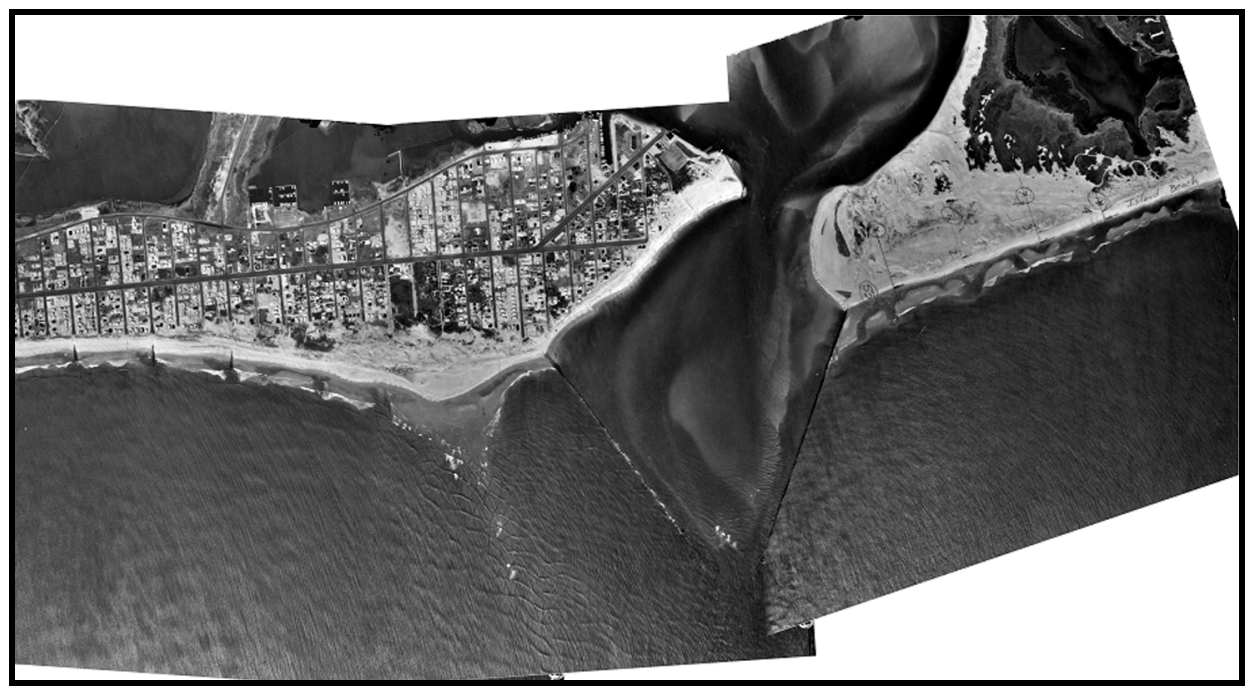

Figure A6. April 1971, continued filling of entrance between arrowhead jetties, and severe erosion of beach at south jetty

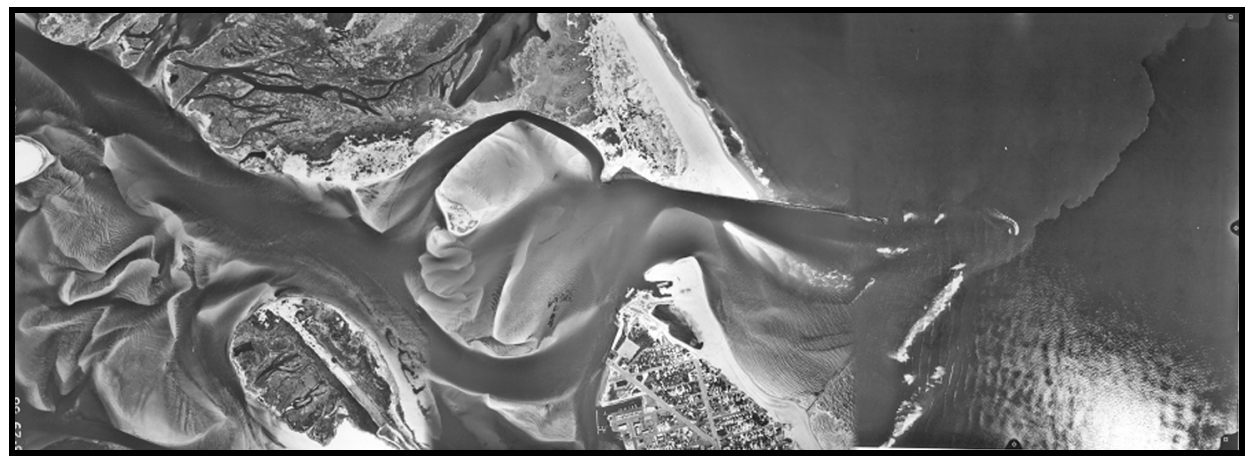

Figure A7. March 1988, navigation channel migration between arrowhead jetties and through flood shoal

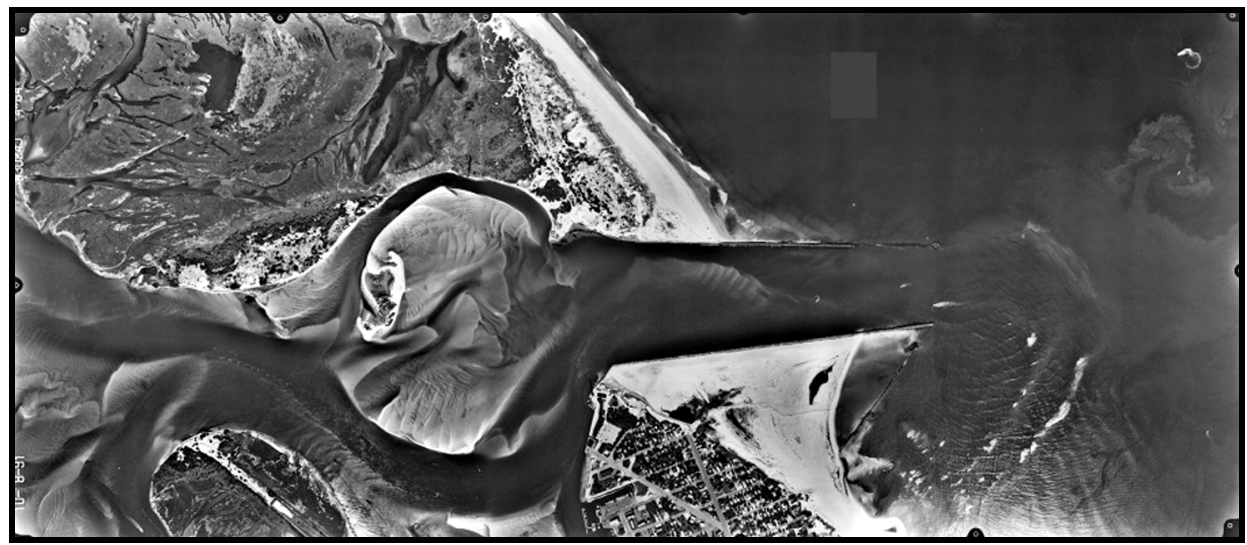

Figure A8. October 1991, immediately after construction of new south jetty 


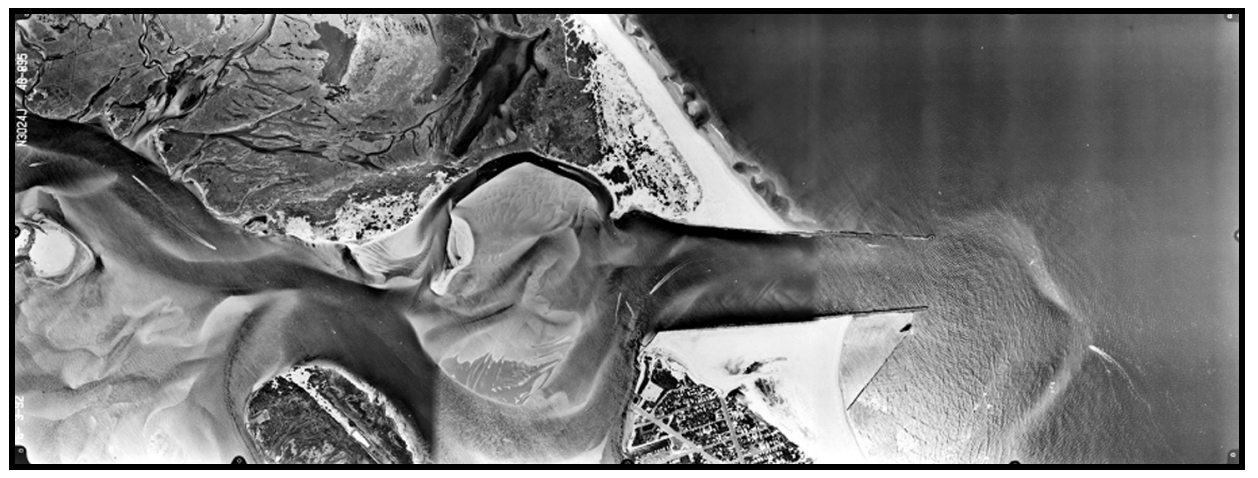

Figure A9. June 1992, flood channel shoal and navigation channel adjustment between parallel jetties. Material removed during construction of new south jetty was placed between new south jetty and old arrowhead south jetty

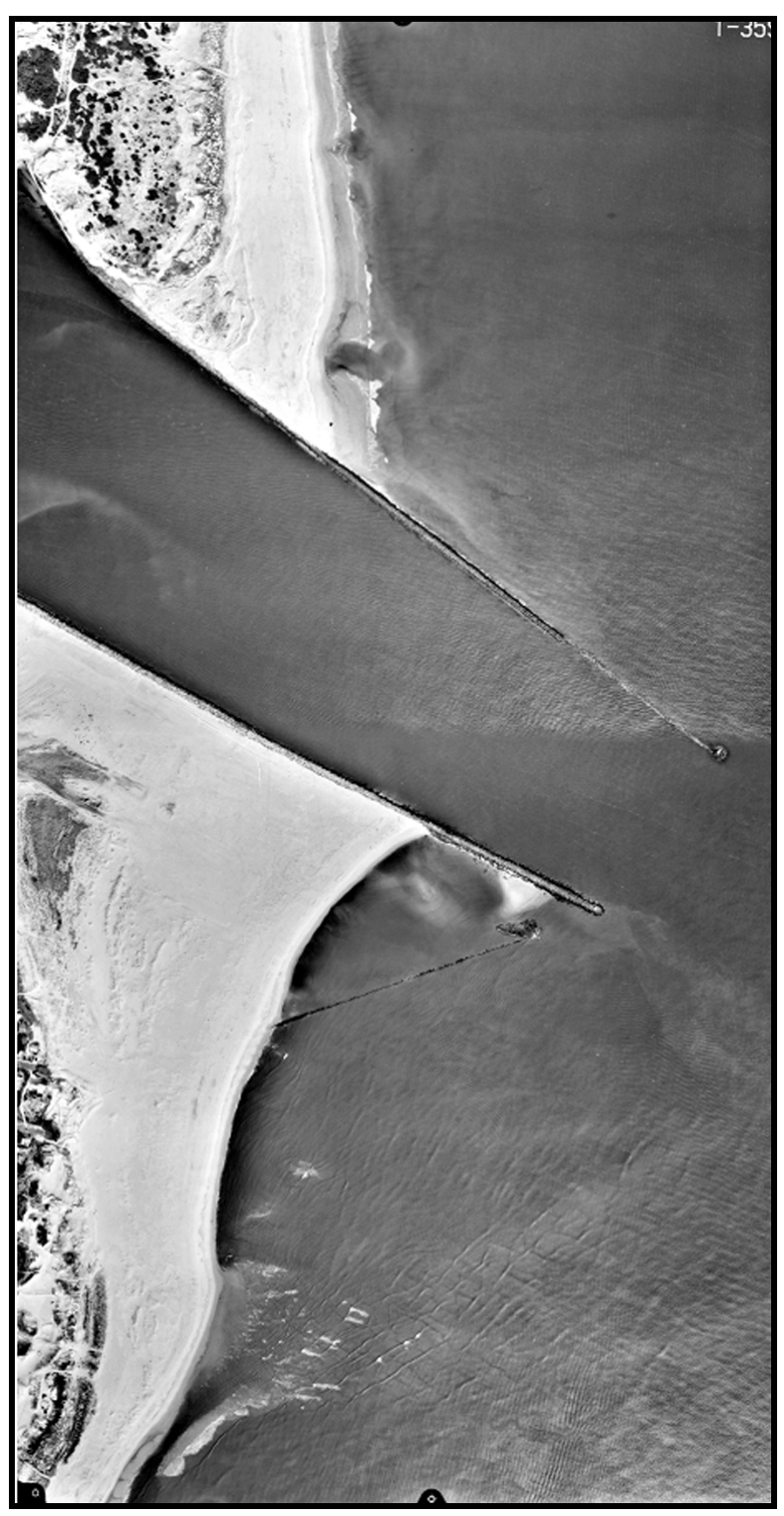

Figure A10. December 1992 , navigation channel adjustment between parallel jetties, and sand fill placed south of new south jetty 


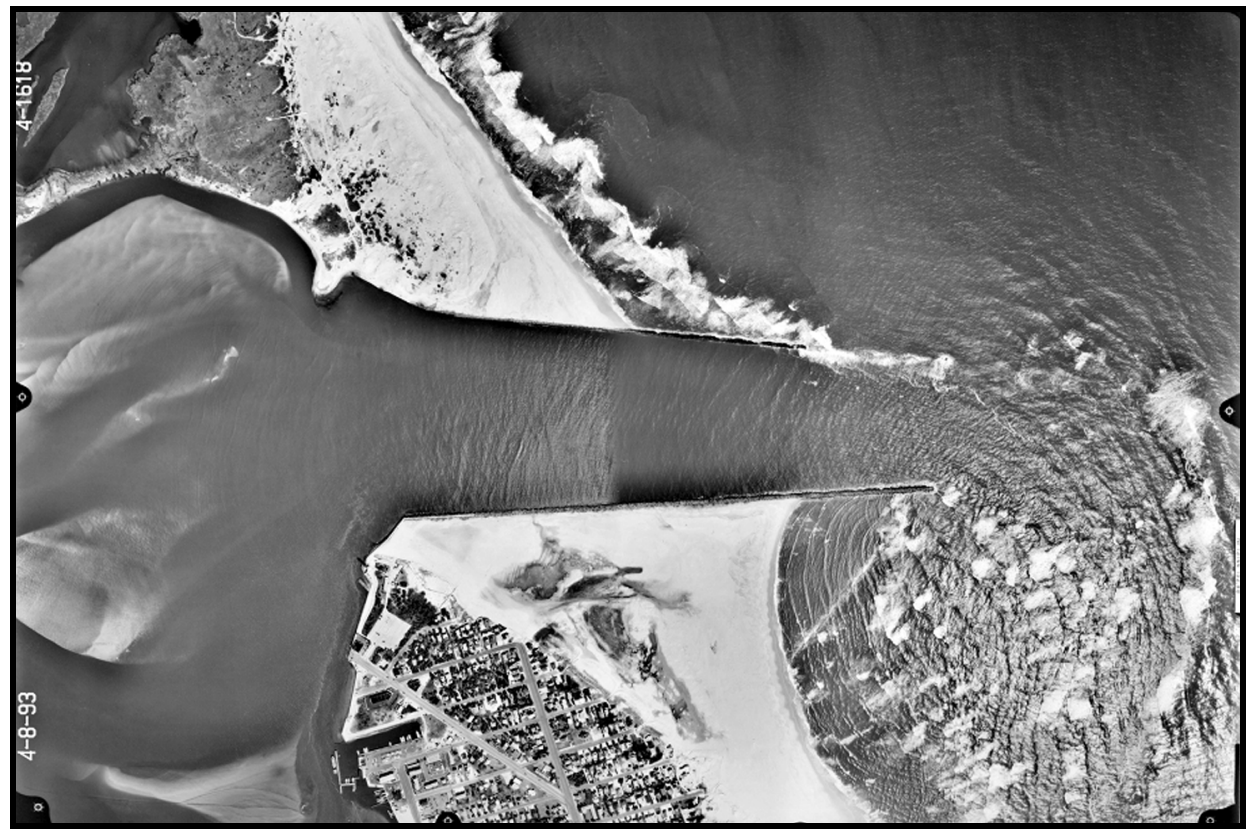

Figure A11. April 1993, high waves breaking on offshore ebb flood shoal and along beachline upcoast of north jetty

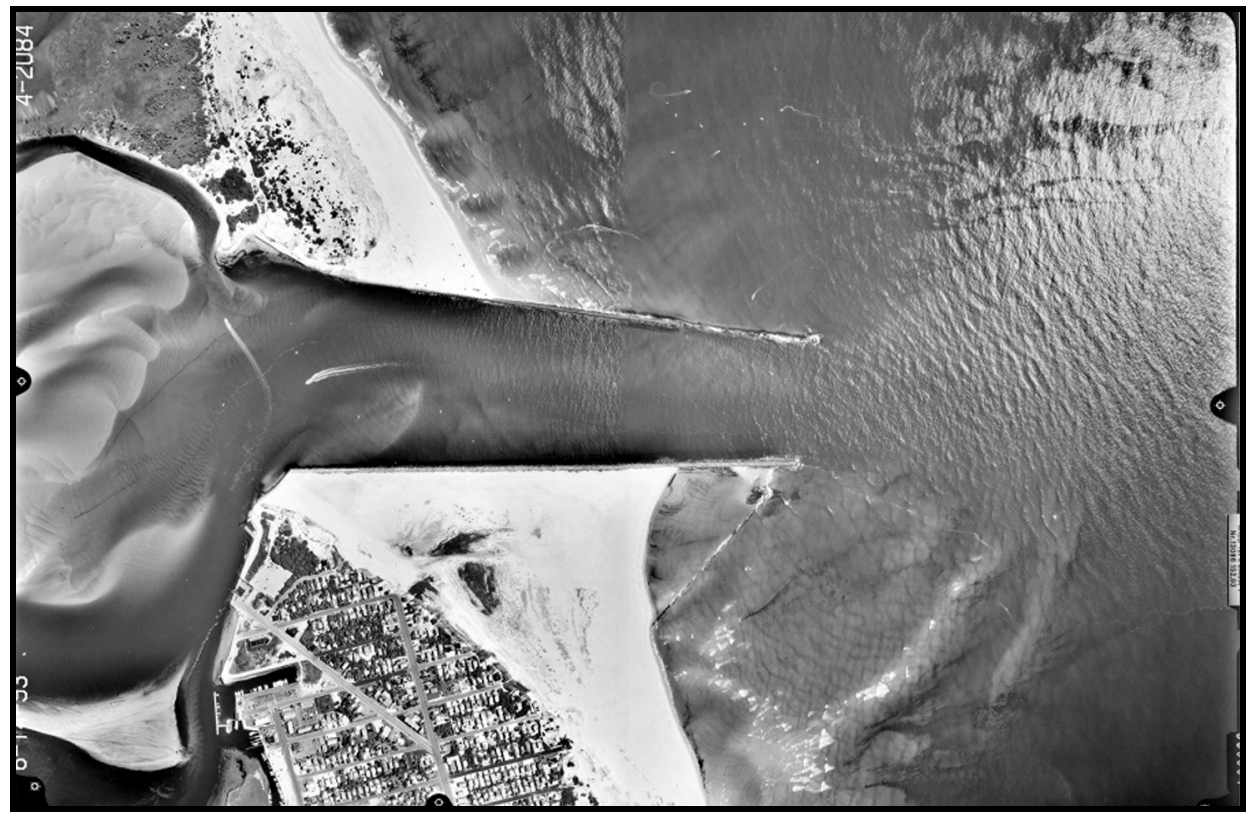

Figure A12. June 1993, navigation channel realigning along the south side of flood shoal 


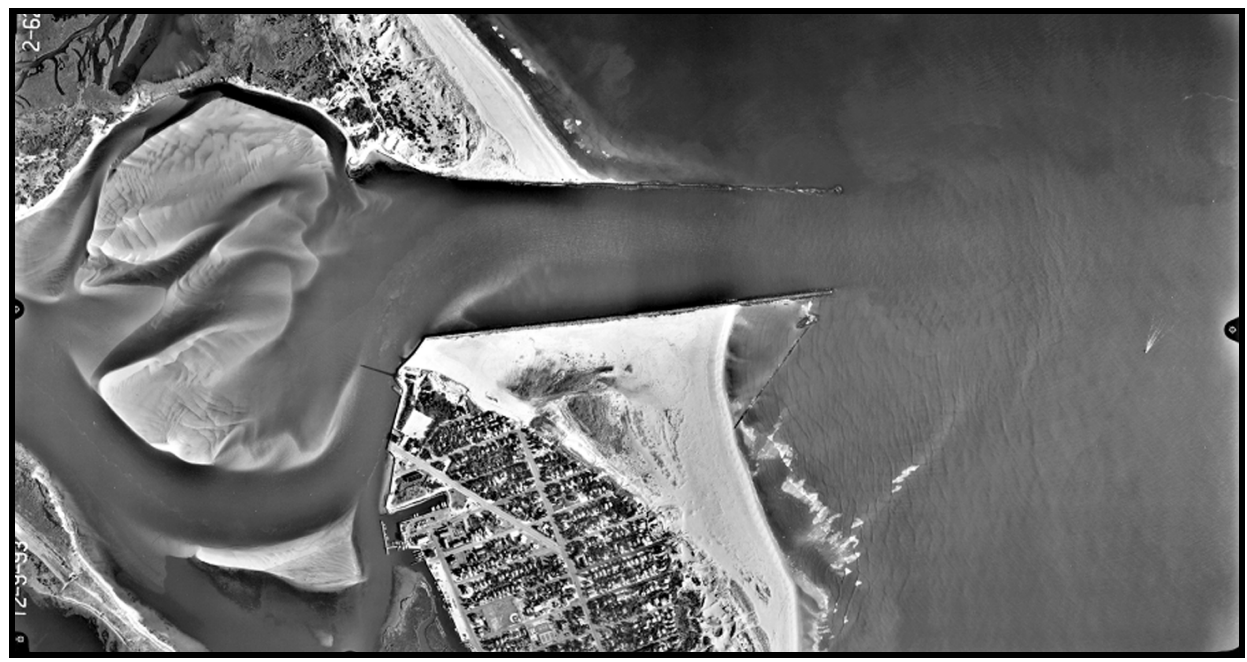

Figure A13. December 1993, continued channel formation along south side of flood shoal

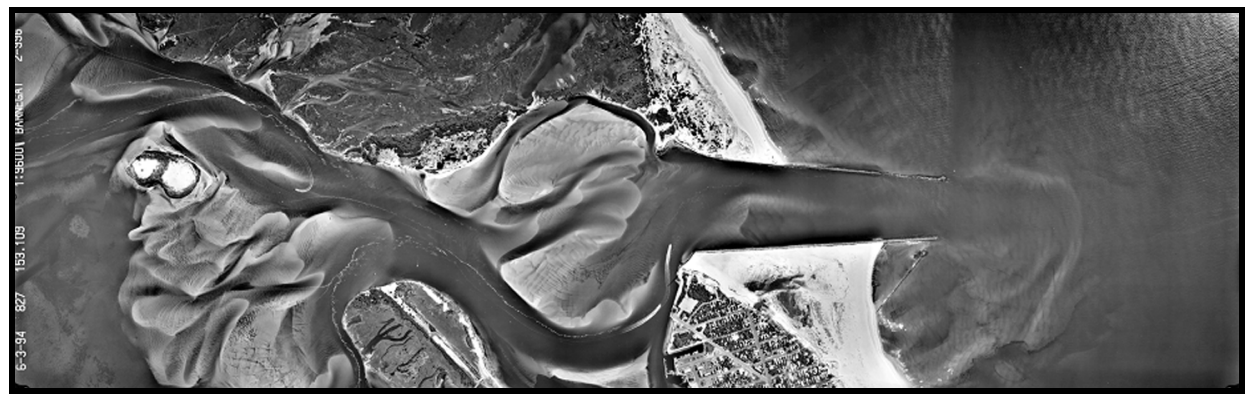

Figure A14. June 1994, entrance channel between jetties migrating toward north jetty

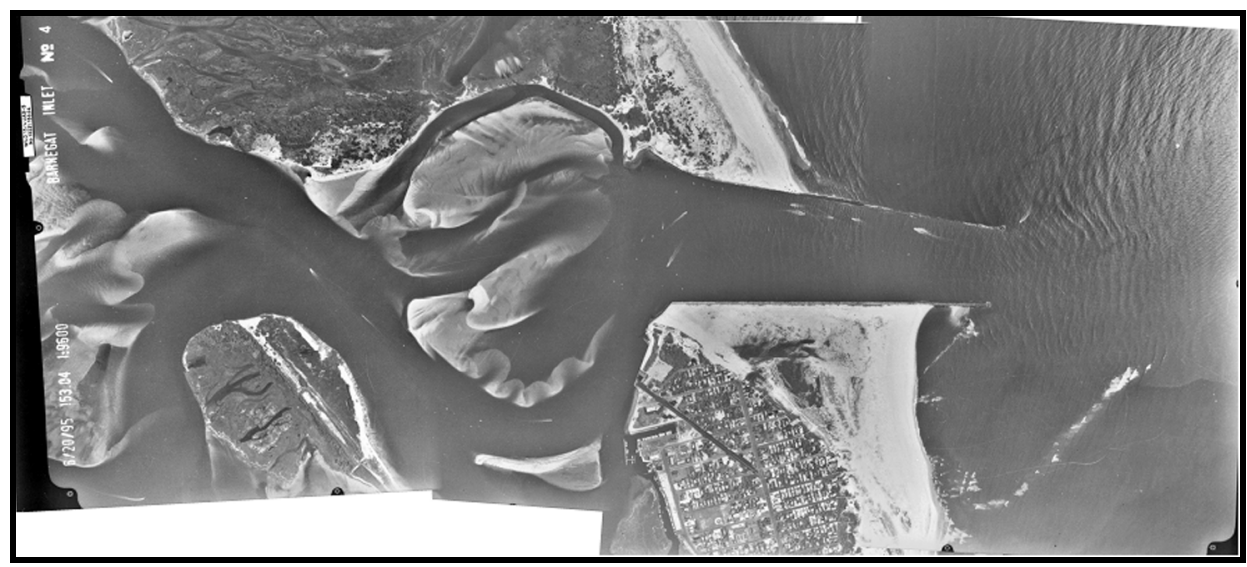

Figure A15. June 1995, boat wakes in navigation channel along north jetty 


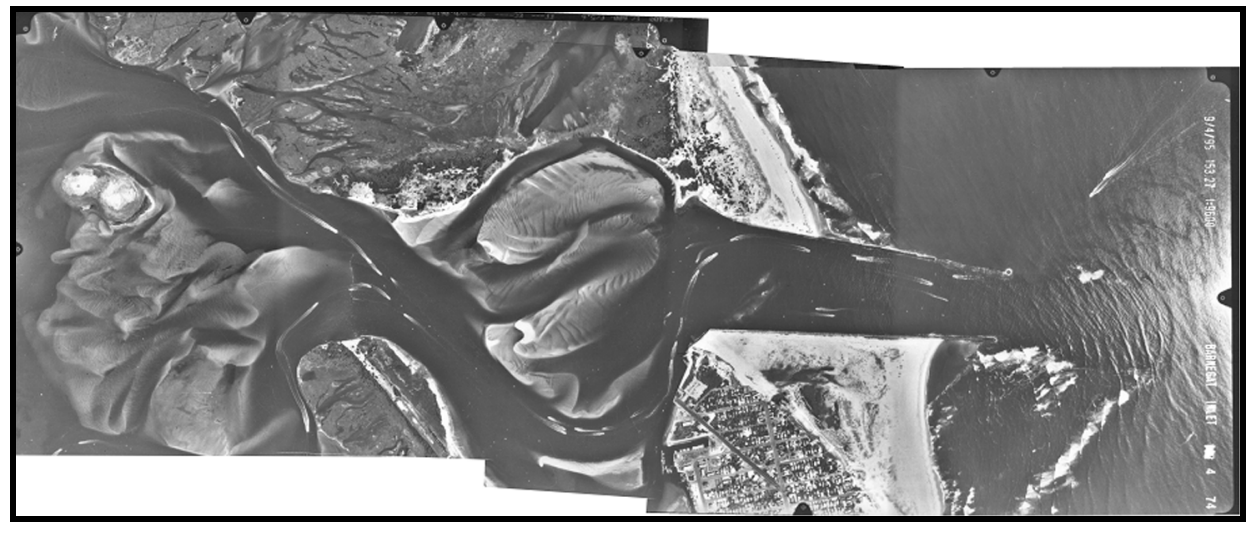

Figure A16. September 1995, boat wakes in navigation channel along north jetty and south of flood shoal

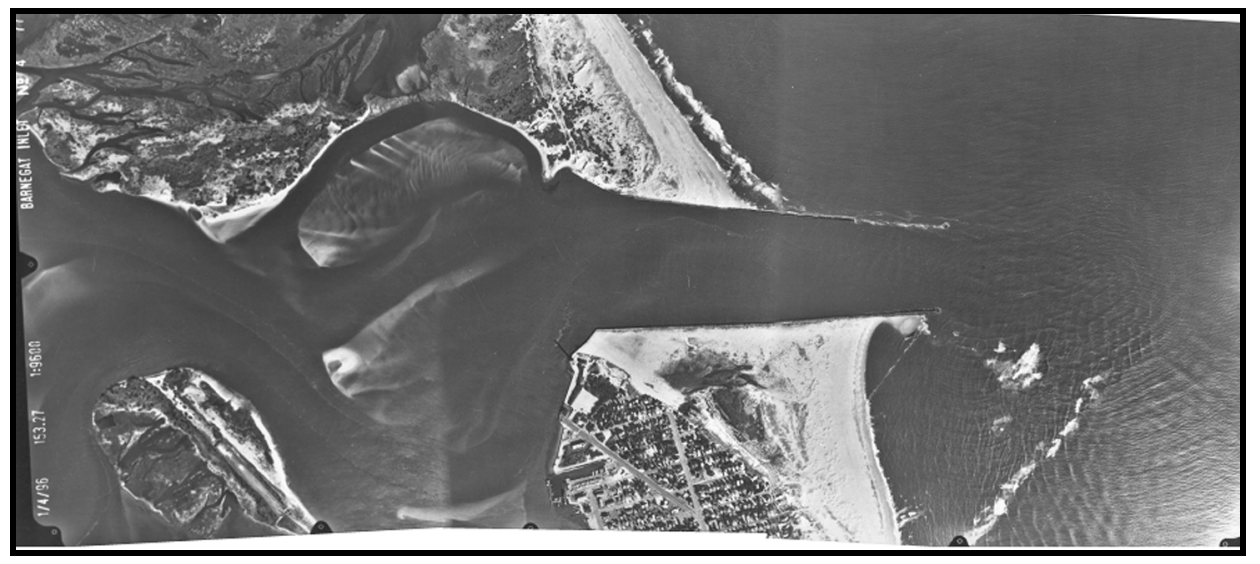

Figure A17. January 1996, flood shoal partially submerged during high tide

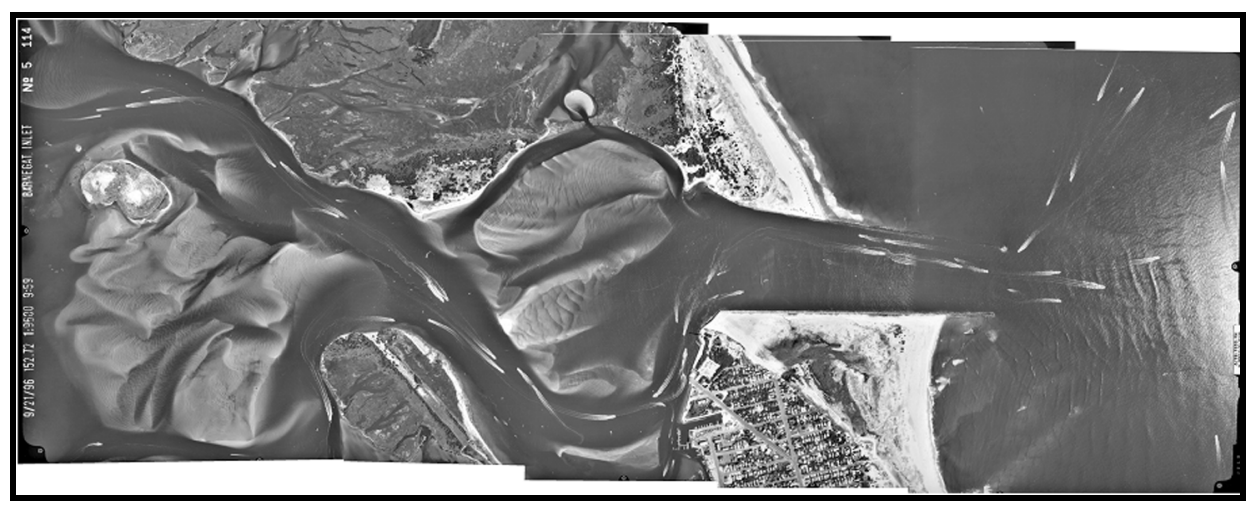

Figure A18. September 1996, boat wakes in navigation channel south of flood shoal, along north jetty, and exiting into Atlantic Ocean 


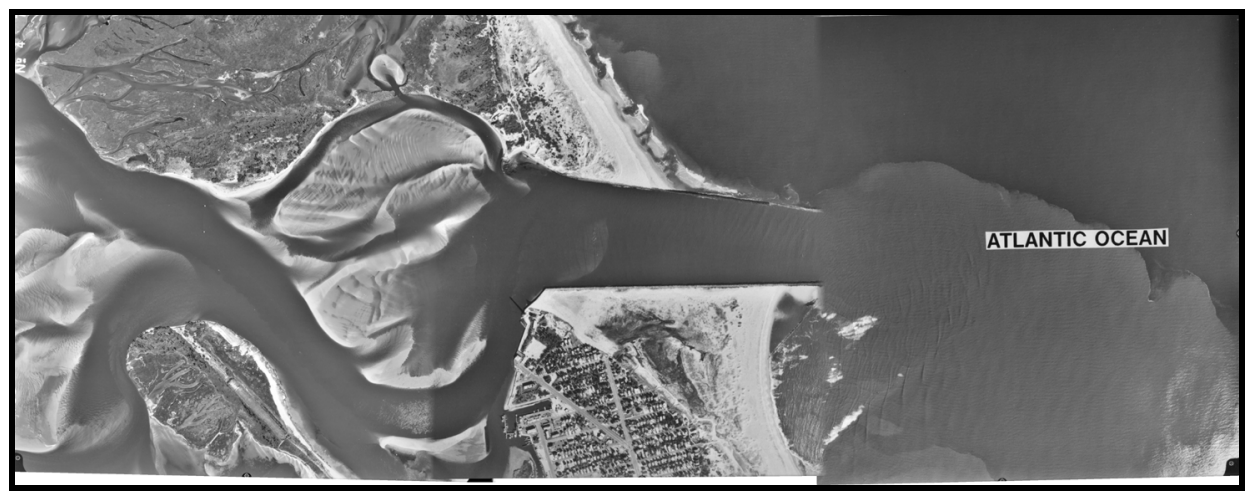

Figure A19. December 1996, sediment-loaded ebb discharge plume diffusing onto ebb tidal shoal 


\section{Appendix B Beach Profiles at Island Beach State Park and Long Island Beach, Adjacent to Barnegat Inlet, NJ}

Beach survey profiles were obtained annually during the 5-year period 19931997 to determine whether the new south jetty at Barnegat Inlet had adversely impacted the coastlines adjacent to Barnegat Inlet. The following beach profile plots show the initial surveys taken in 1993 and the last surveys taken in either 1996 or 1997 (not all profiles were surveyed in 1997). Locations of these profiles are shown in Figure 85. These initial and final surveys were used for computing the amount of beach accretion or erosion that has taken place subsequent to the construction of the new south jetty. Note: to convert feet to meters, multiply by 0.3048 . 


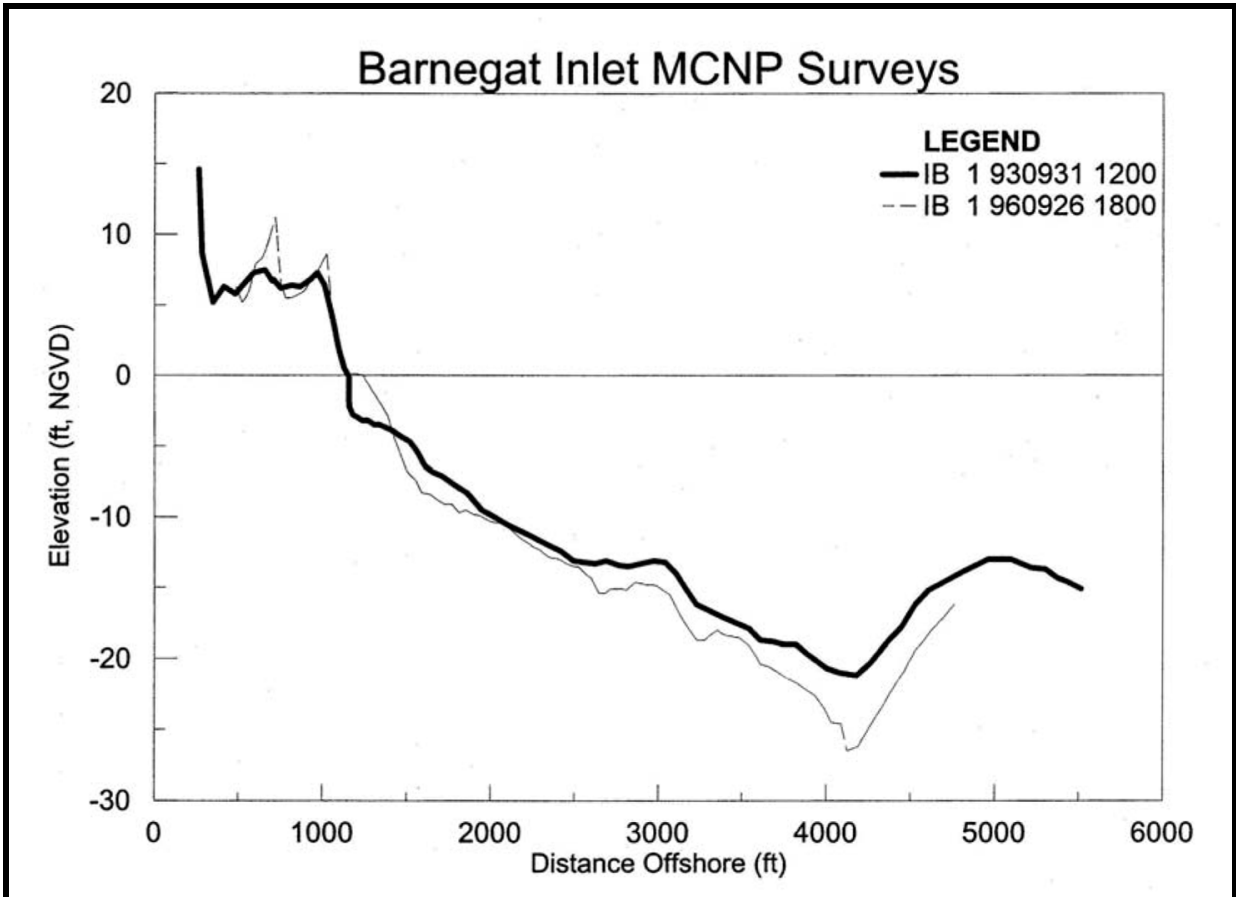

Figure B1. Island Beach State Park Profile No. 1

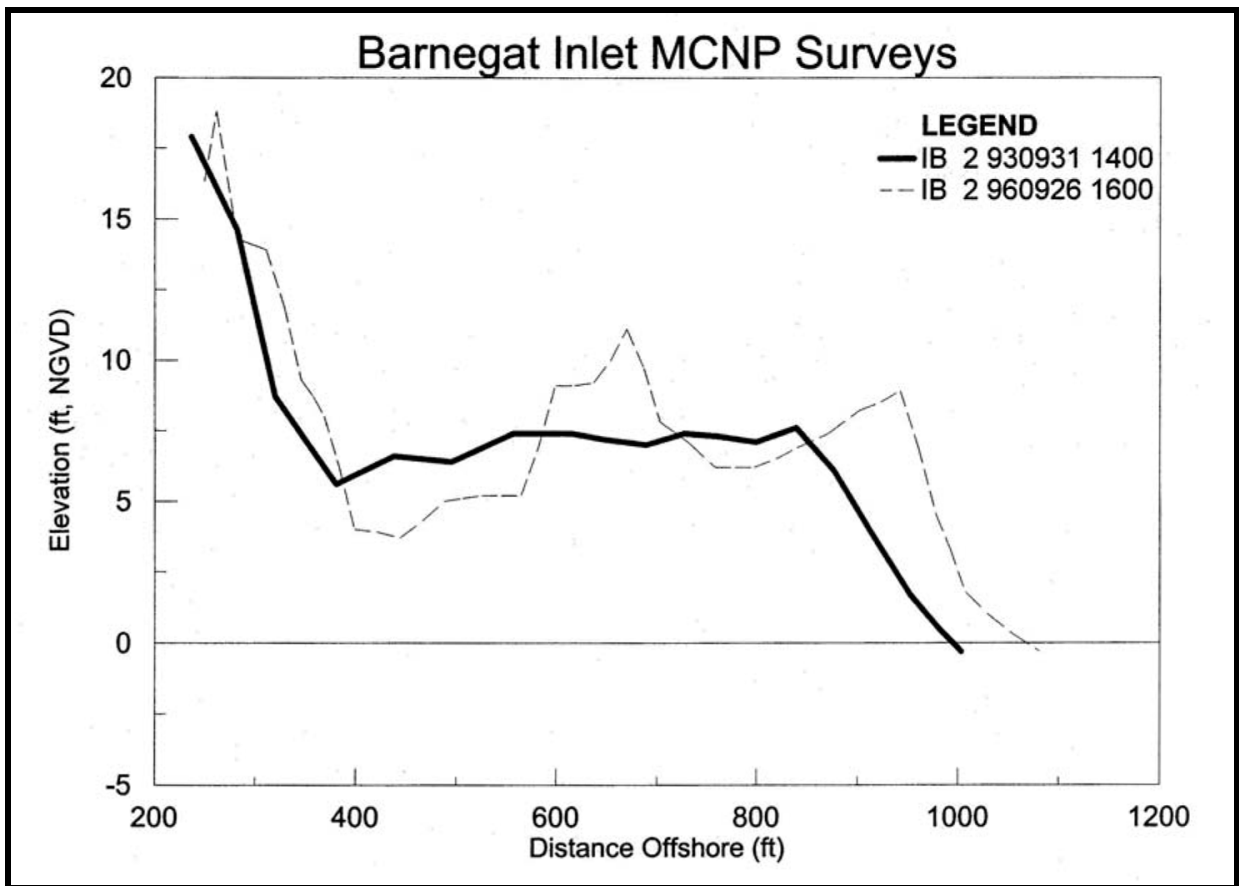

Figure B2. Island Beach State Park Profile No. 2 


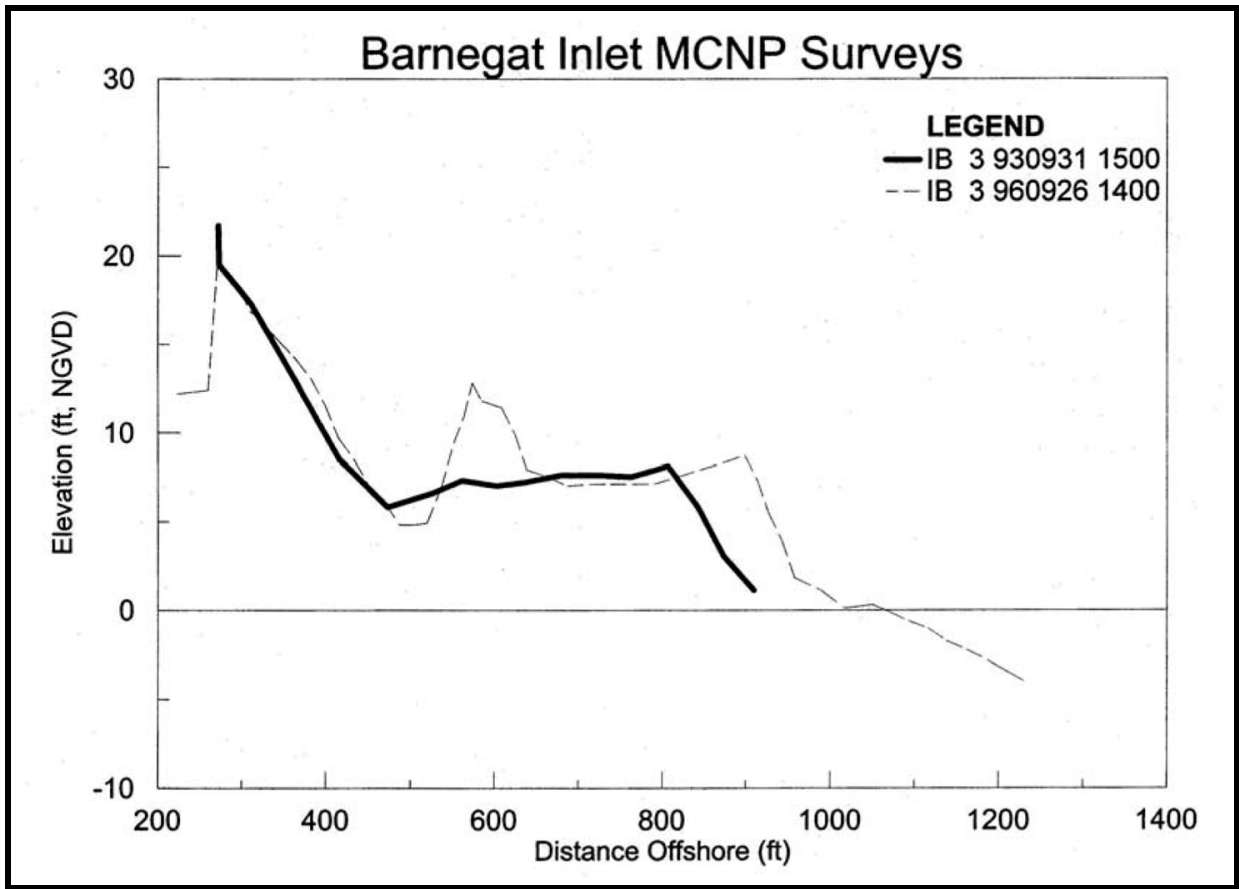

Figure B3. Island Beach State Park Profile No. 3

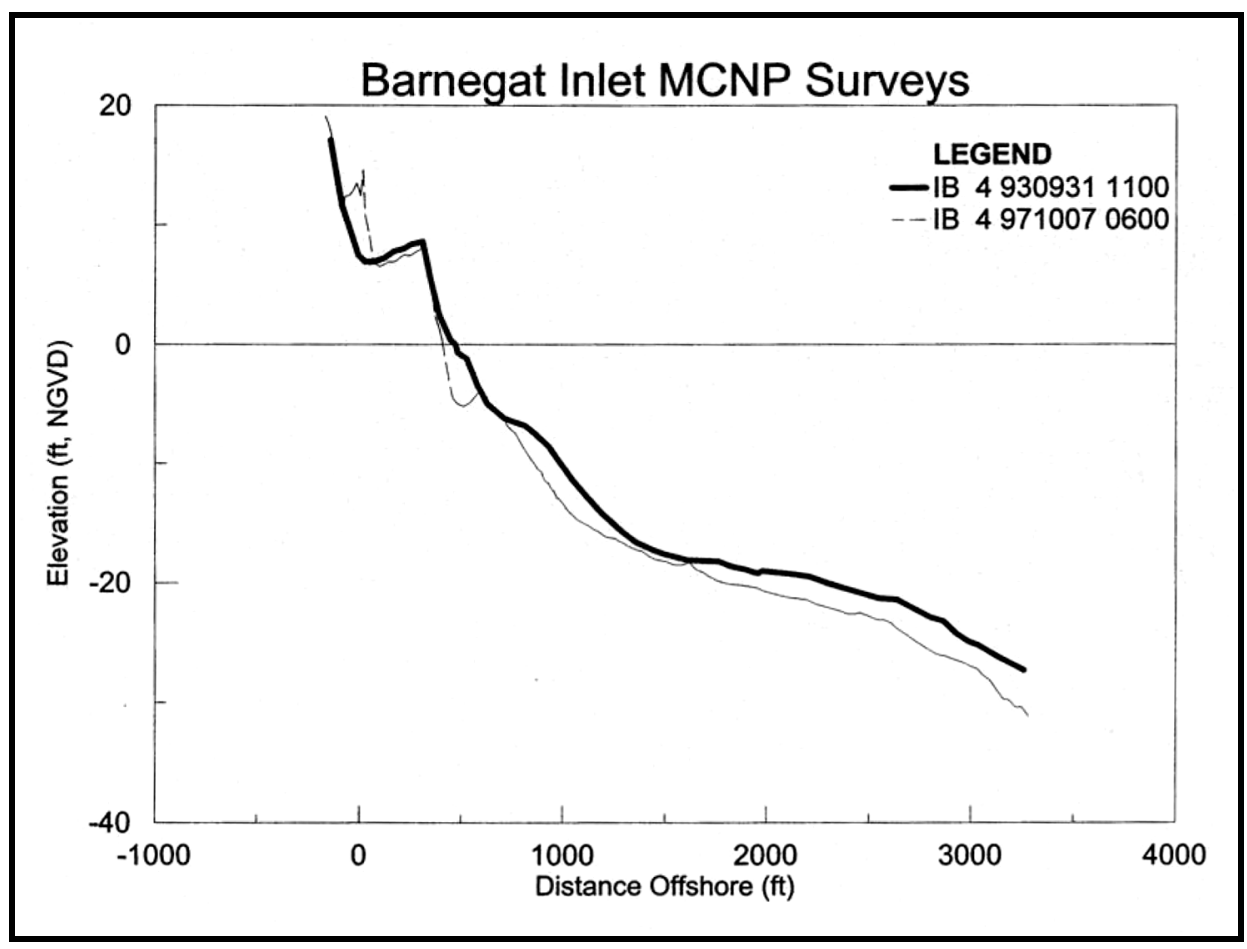

Figure B4. Island Beach State Park Profile No. 4 


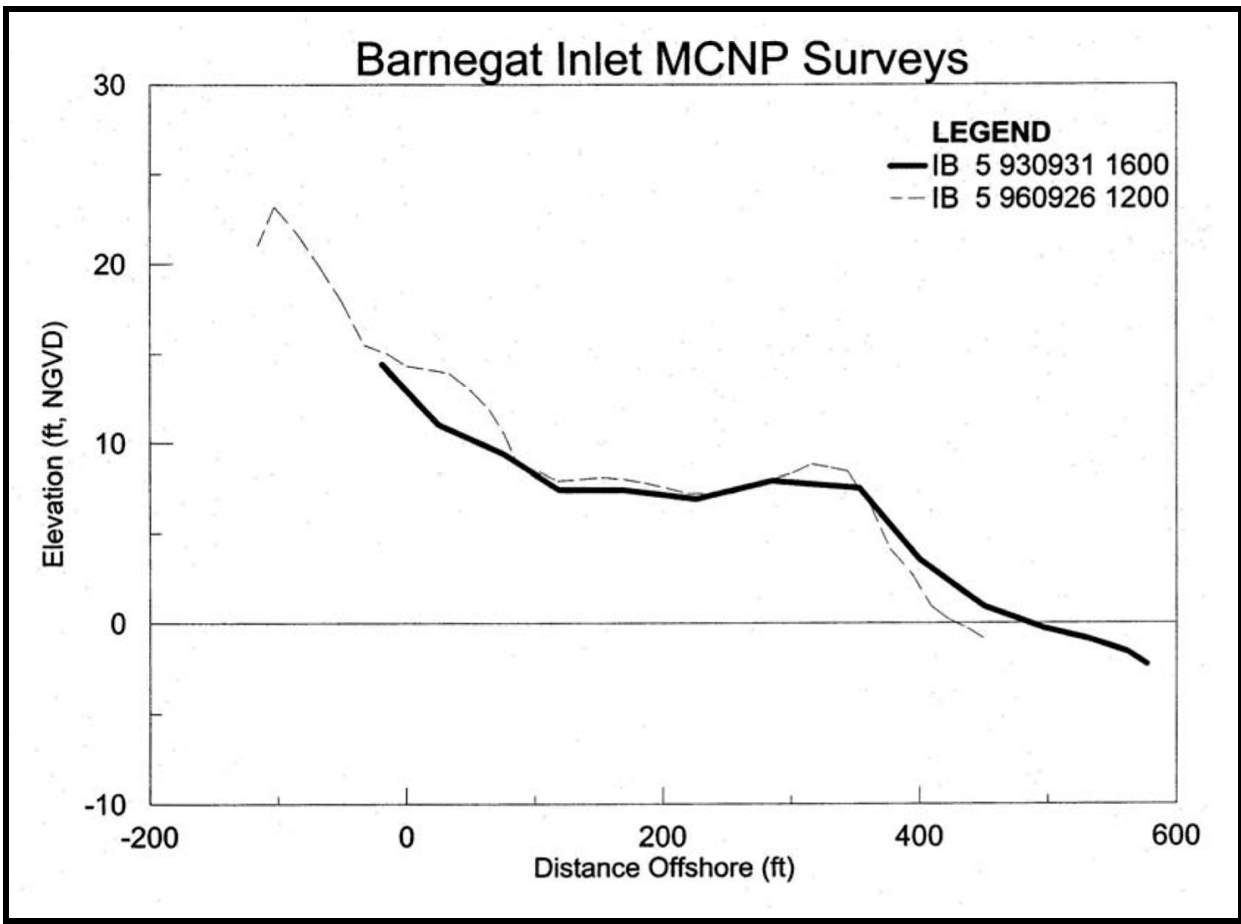

Figure B5. Island Beach State Park Profile No. 5

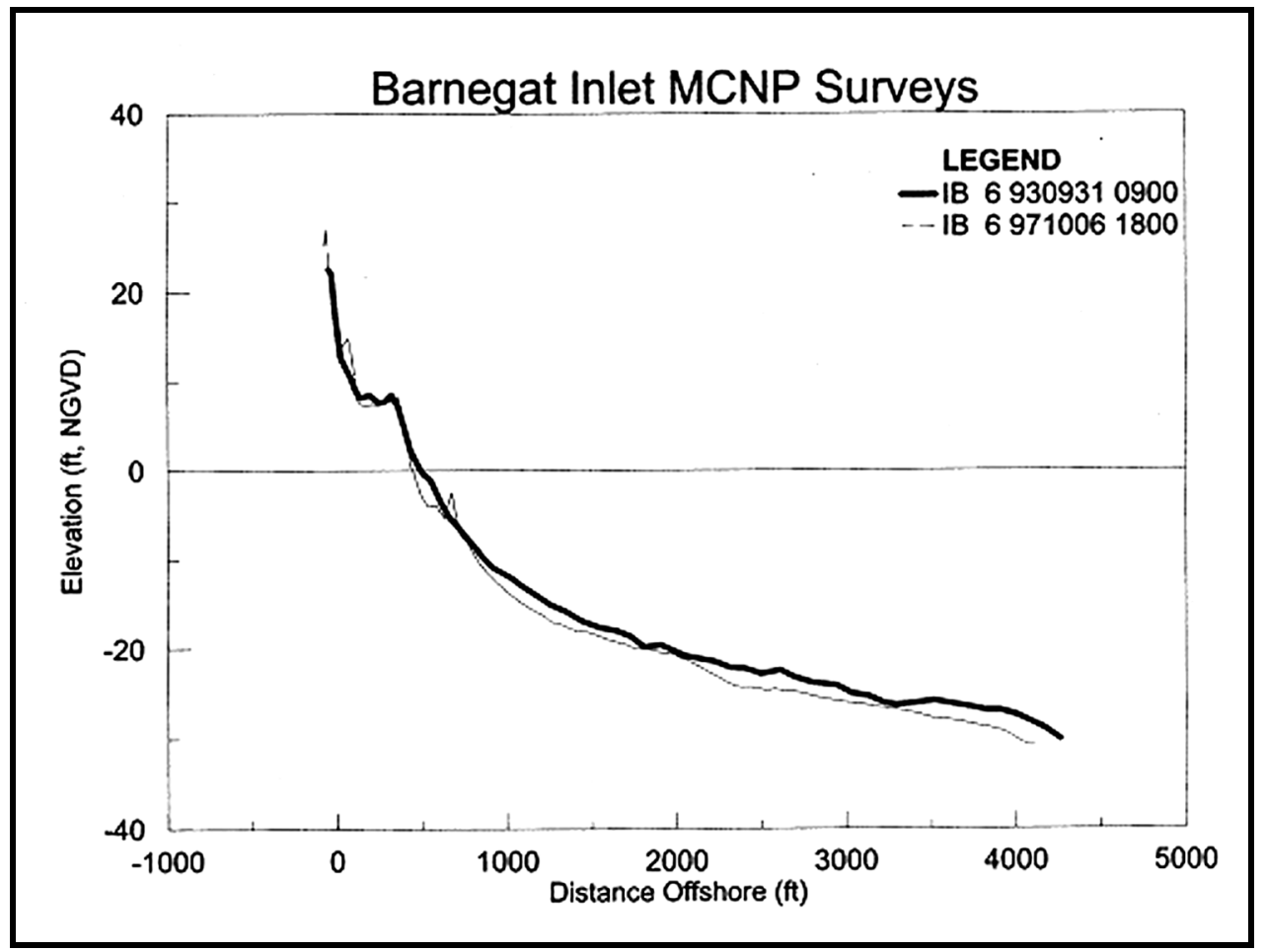

Figure B6. Island Beach State Park Profile No. 6 


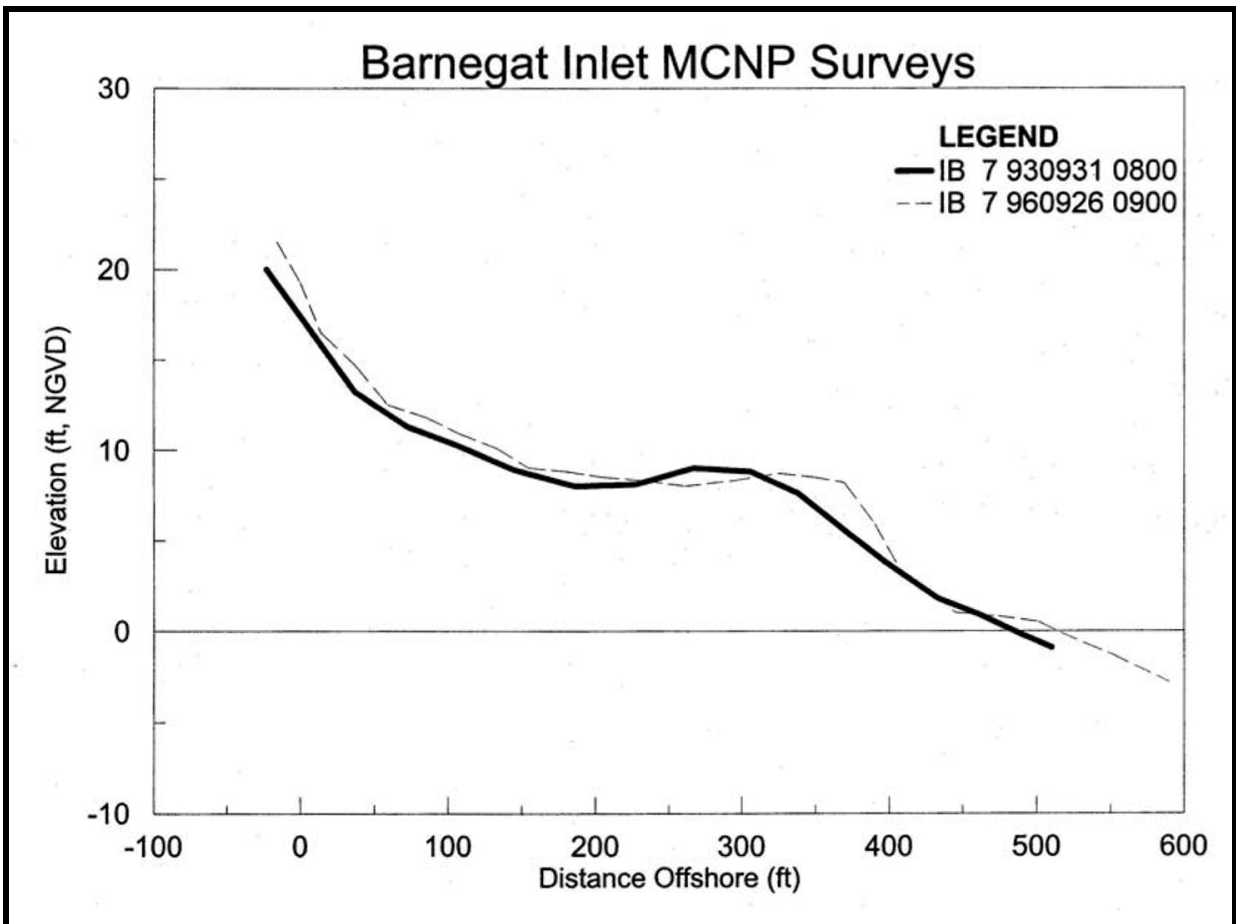

Figure B7. Island Beach State Park Profile No. 7

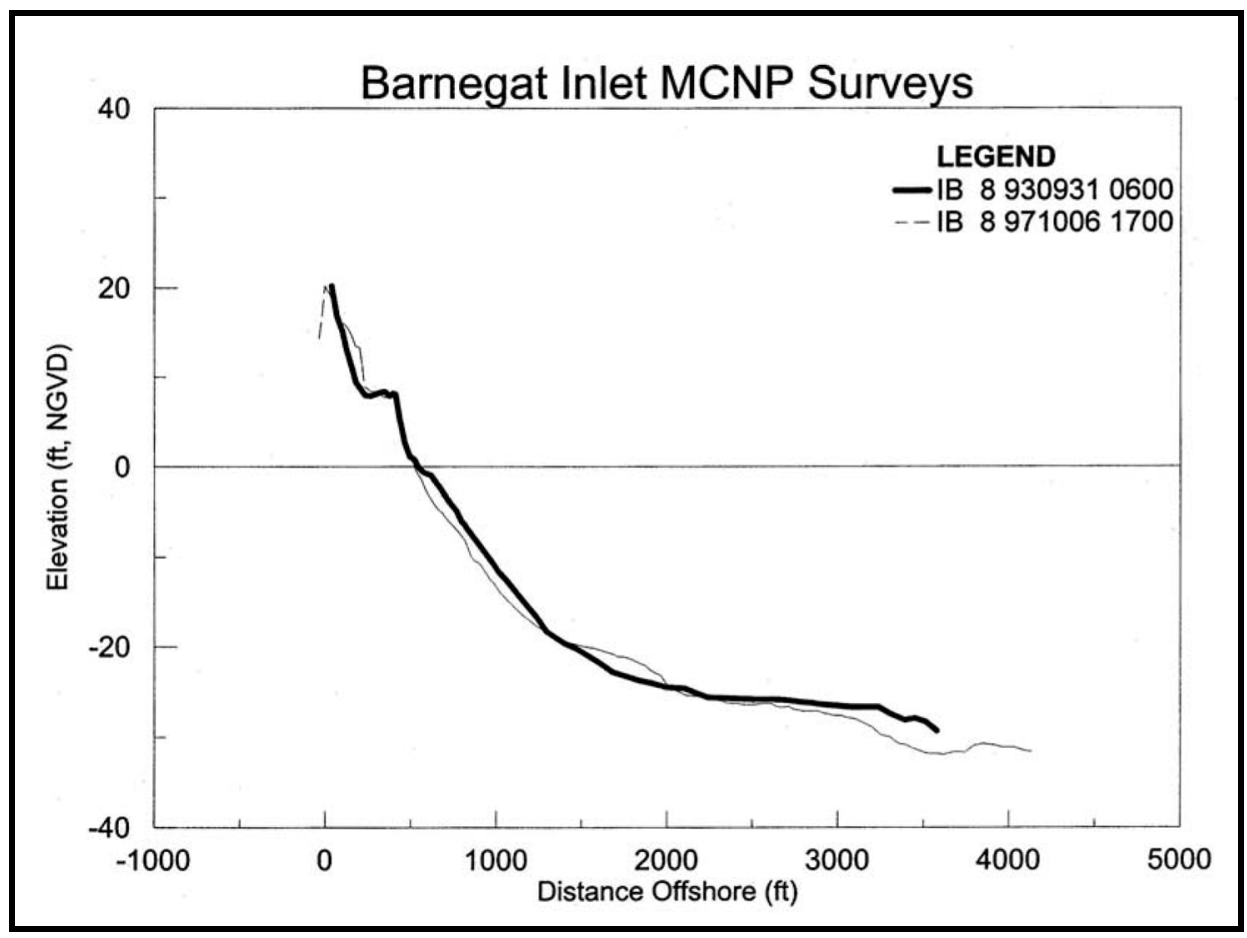

Figure B8. Island Beach State Park Profile No. 8 


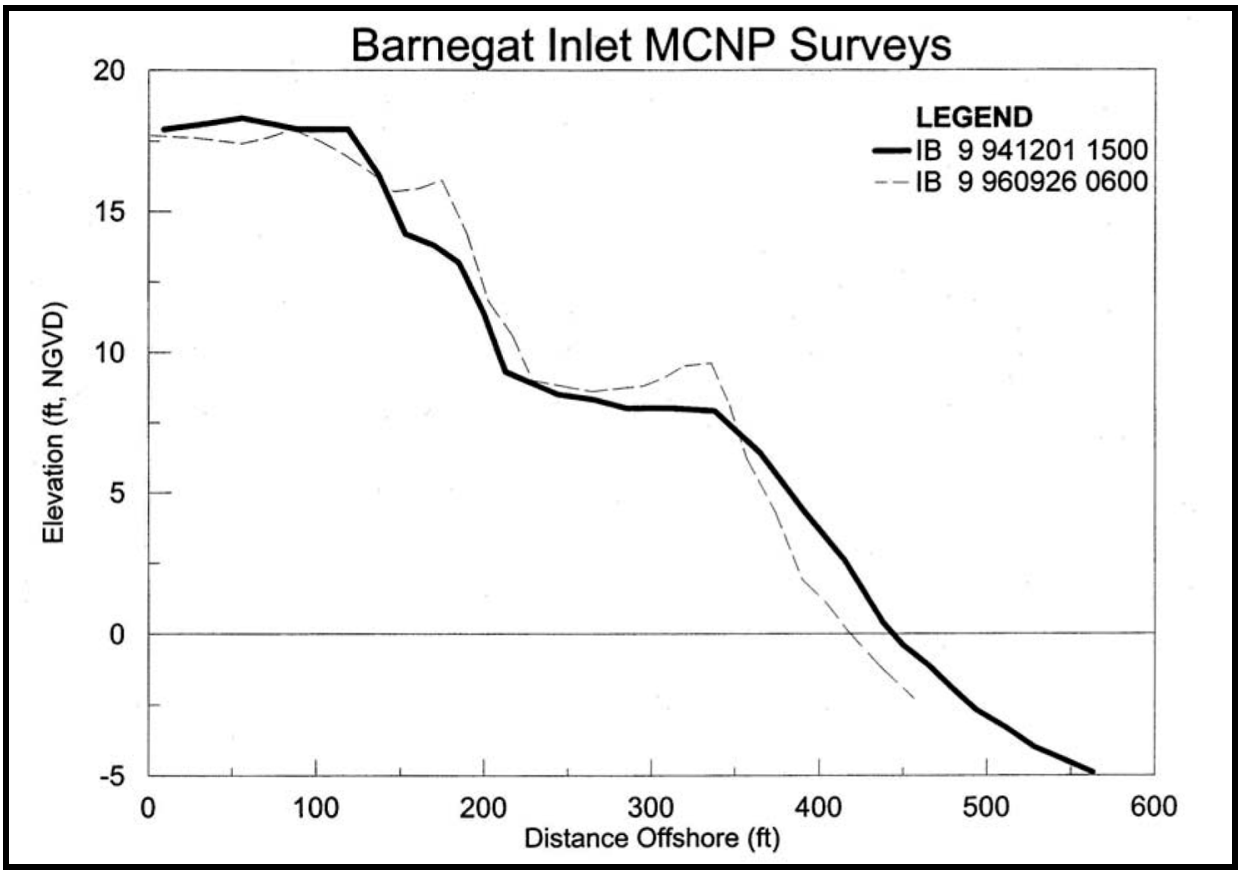

Figure B9. Island Beach State Park Profile No. 9

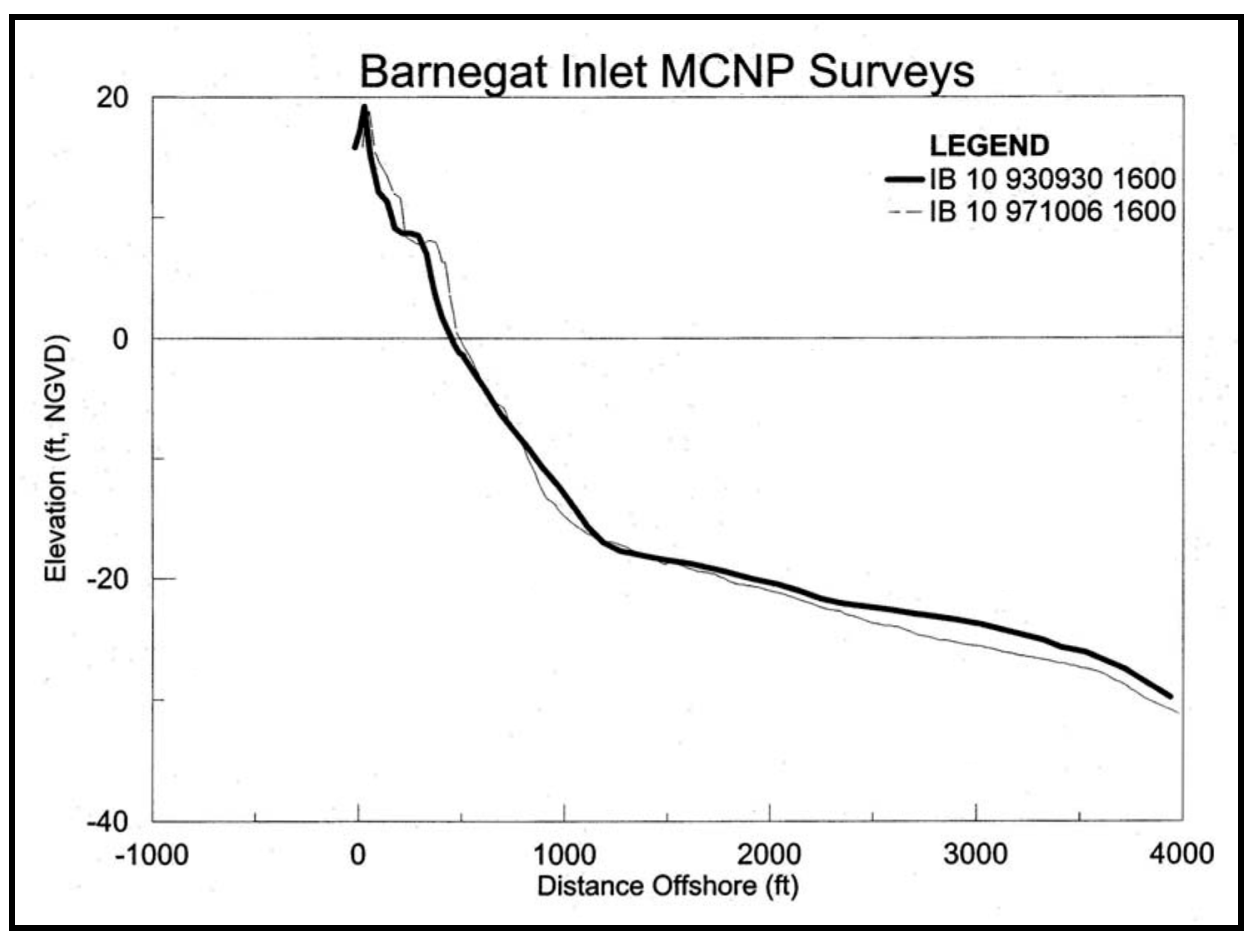

Figure B10. Island Beach State Park Profile No. 10 


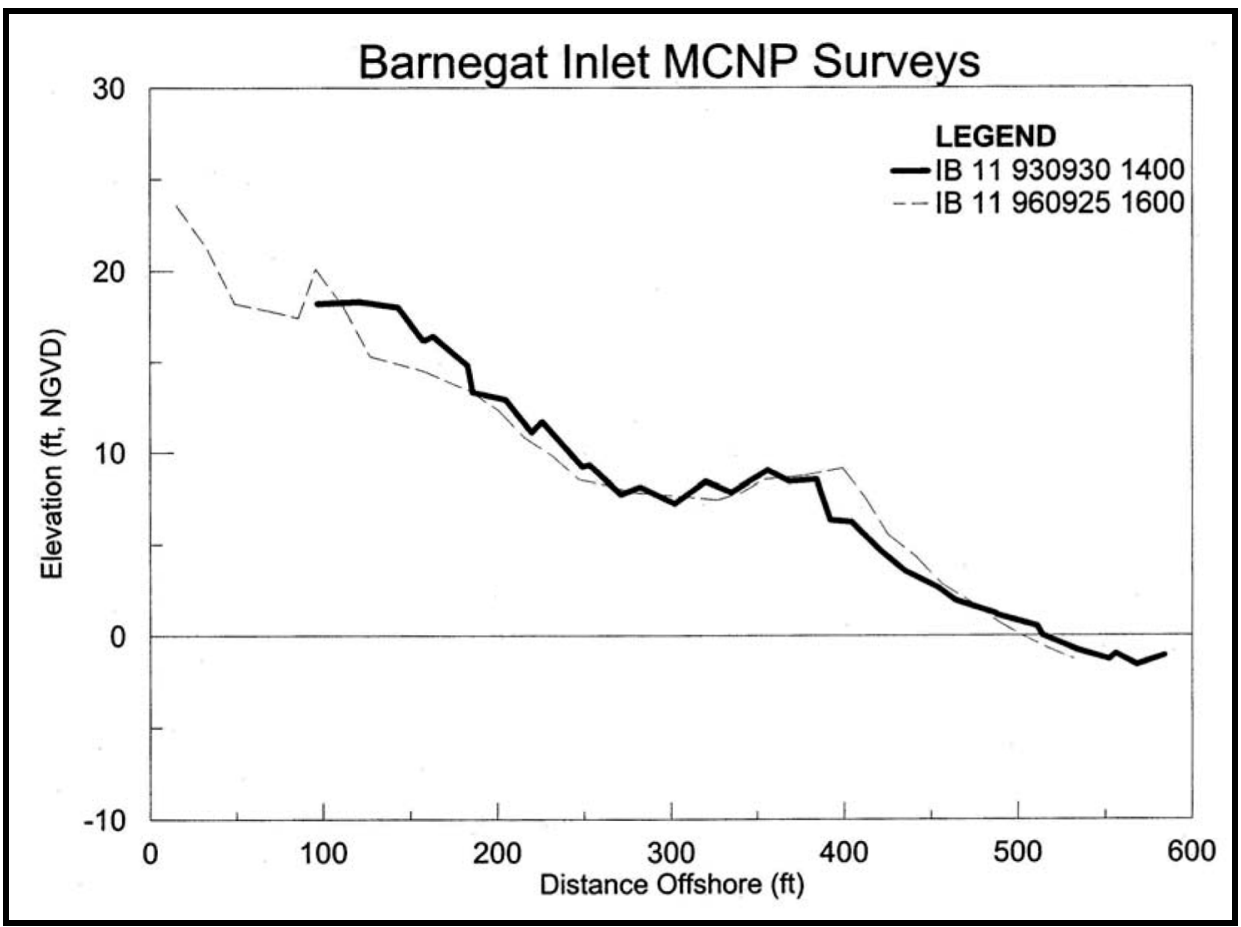

Figure B11. Island Beach State Park Profile No. 11

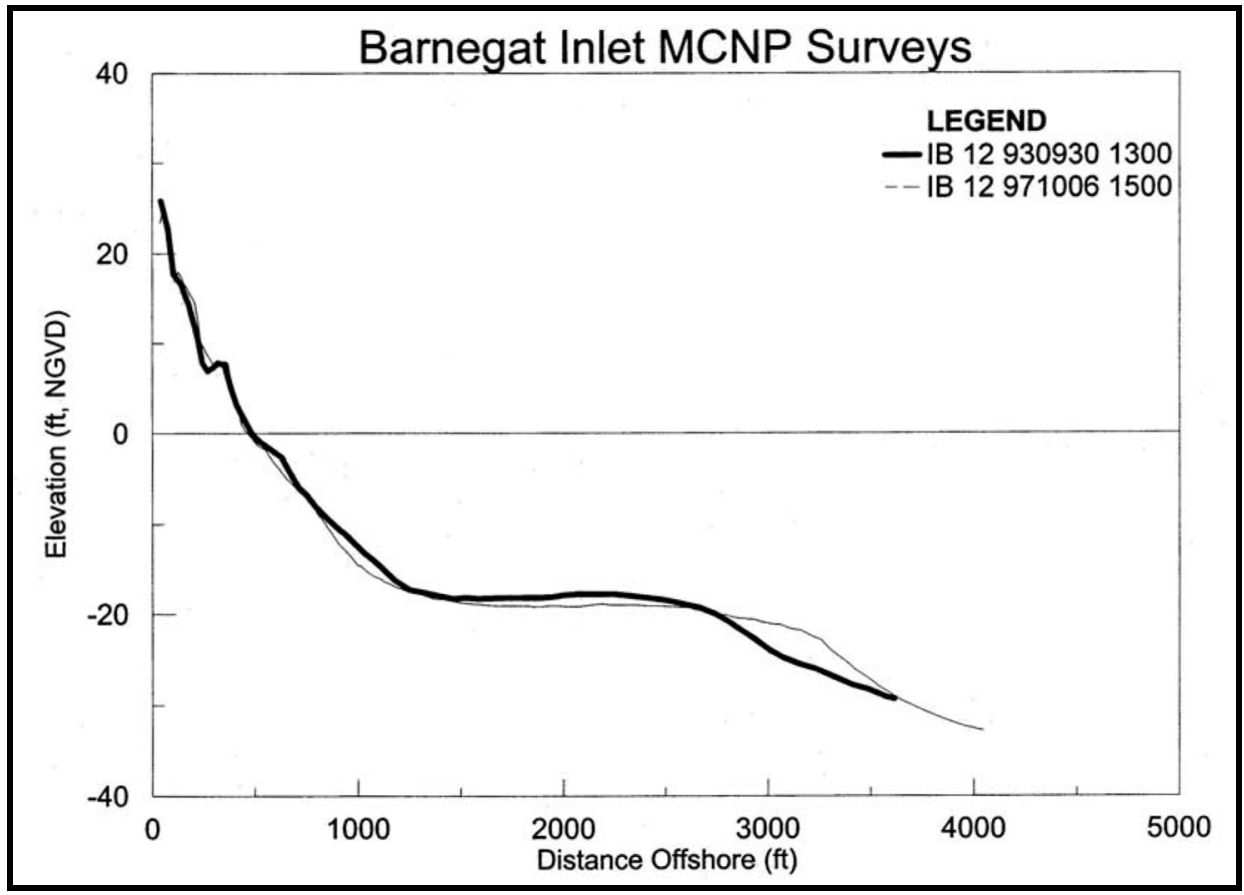

Figure B12. Island Beach State Park Profile No. 12 


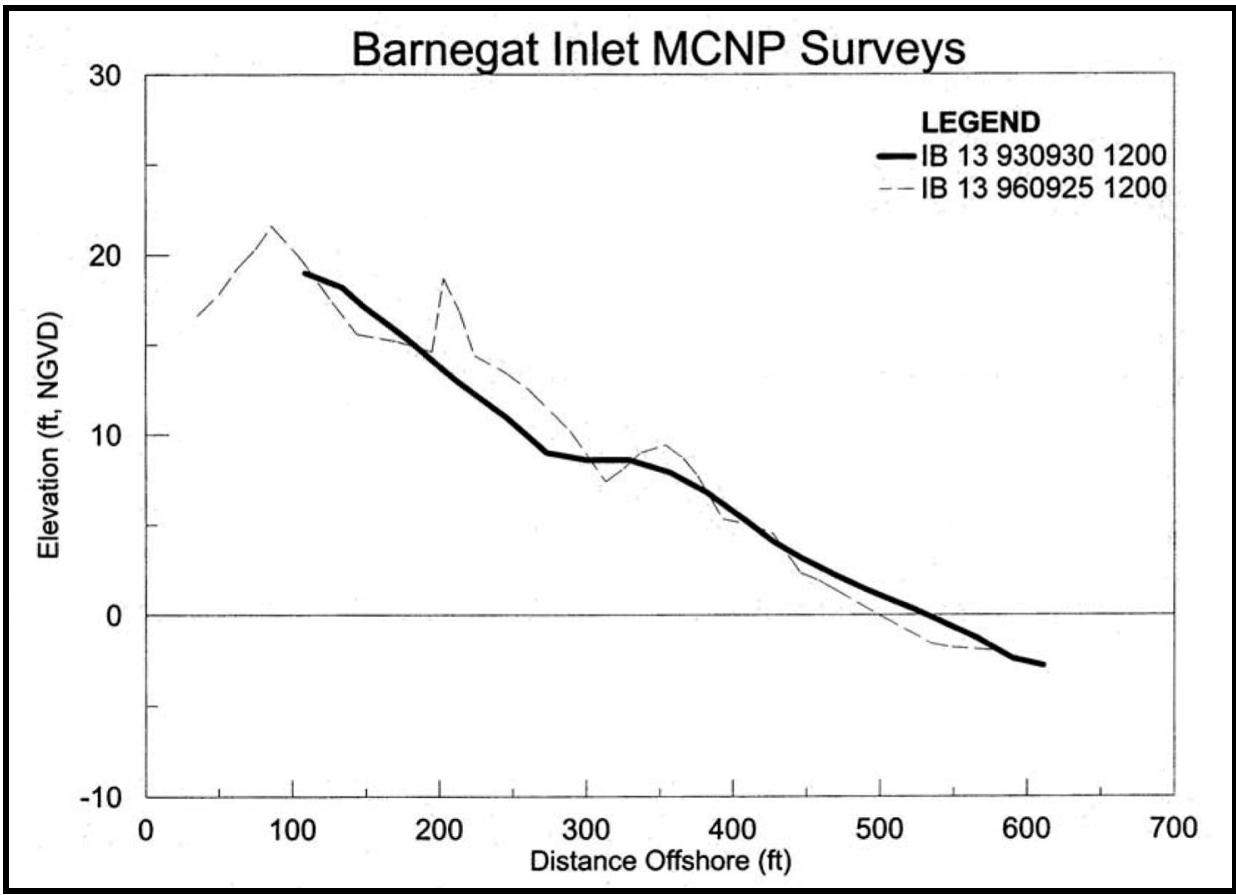

Figure B13. Island Beach State Park Profile No. 13

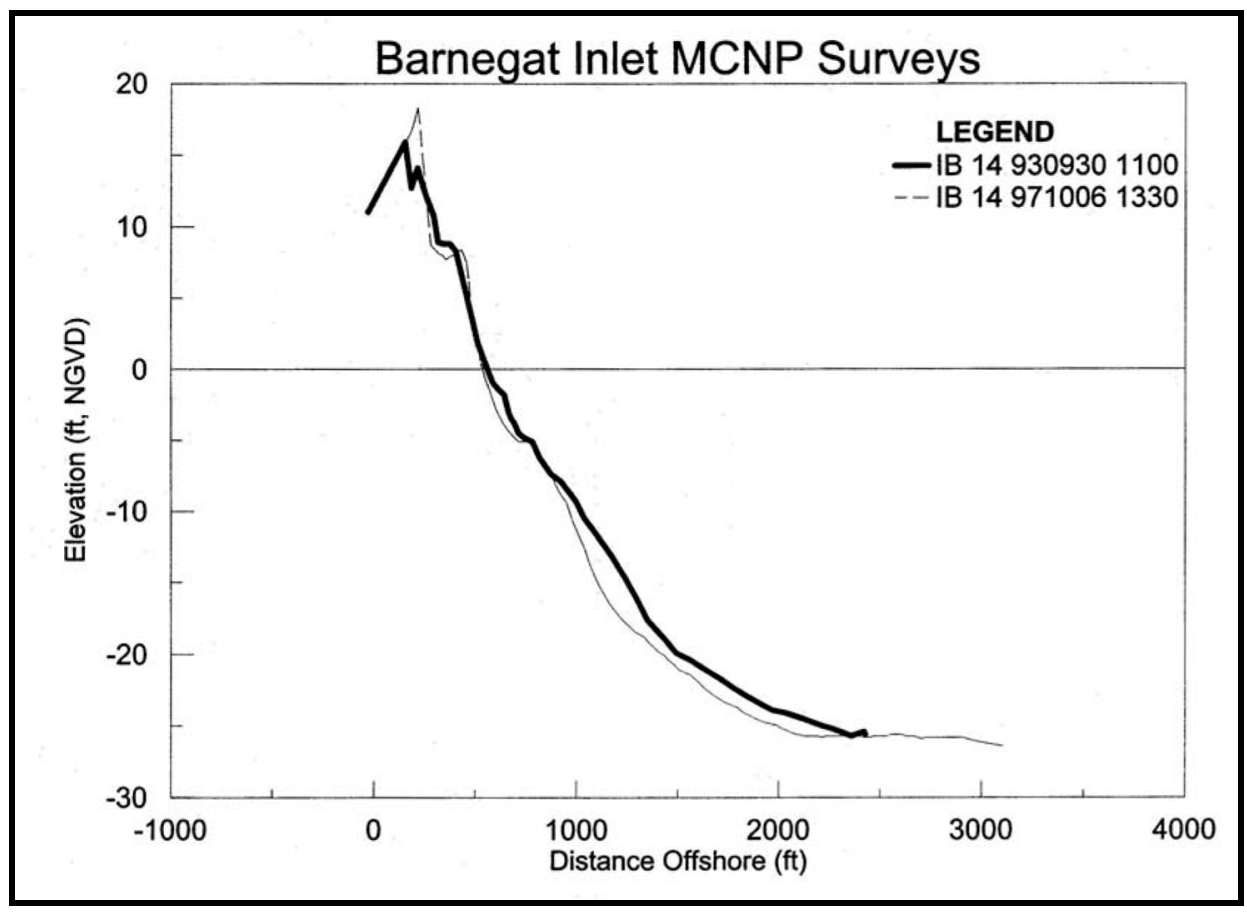

Figure B14. Island Beach State Park Profile No. 14 


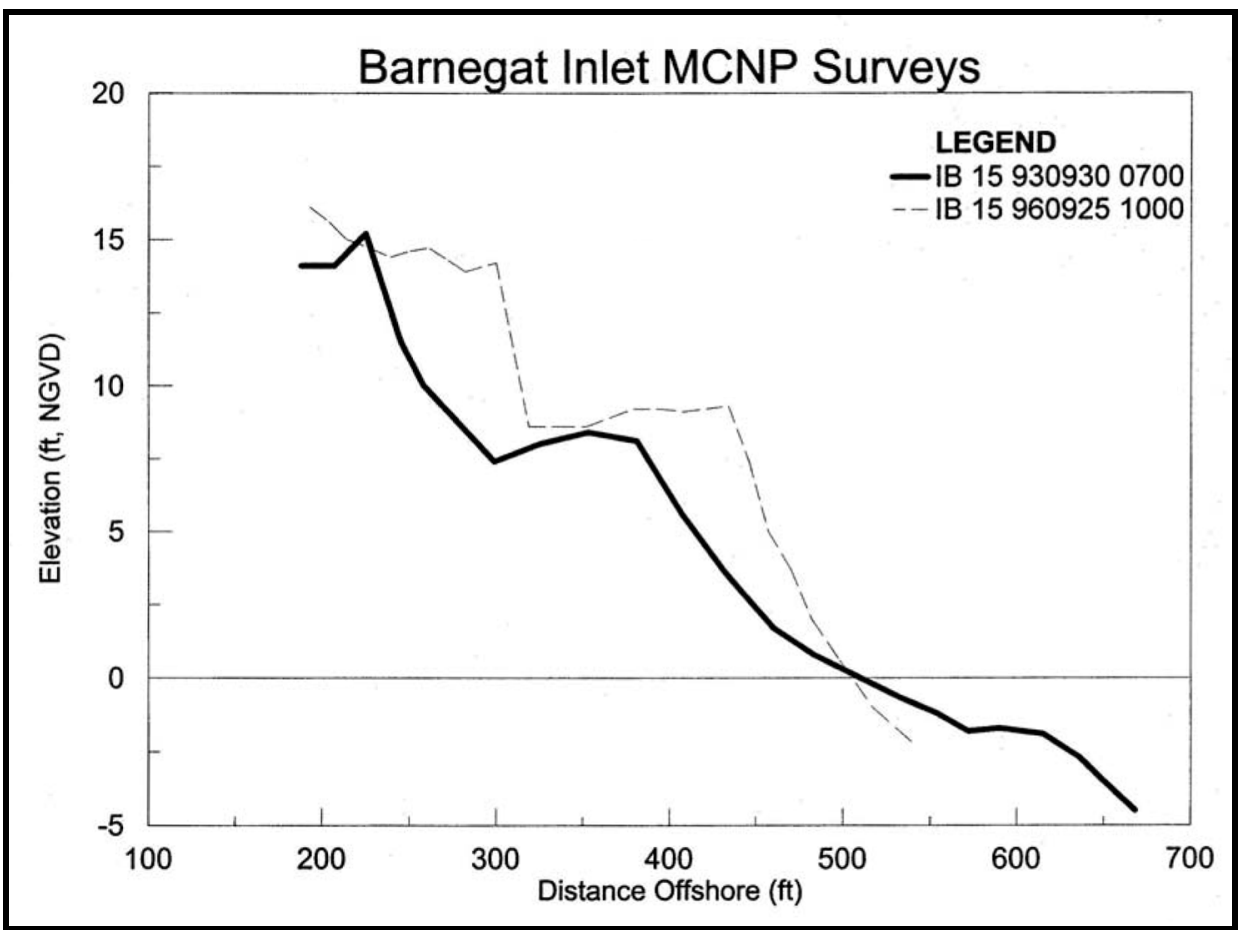

Figure B15. Island Beach State Park Profile No. 15

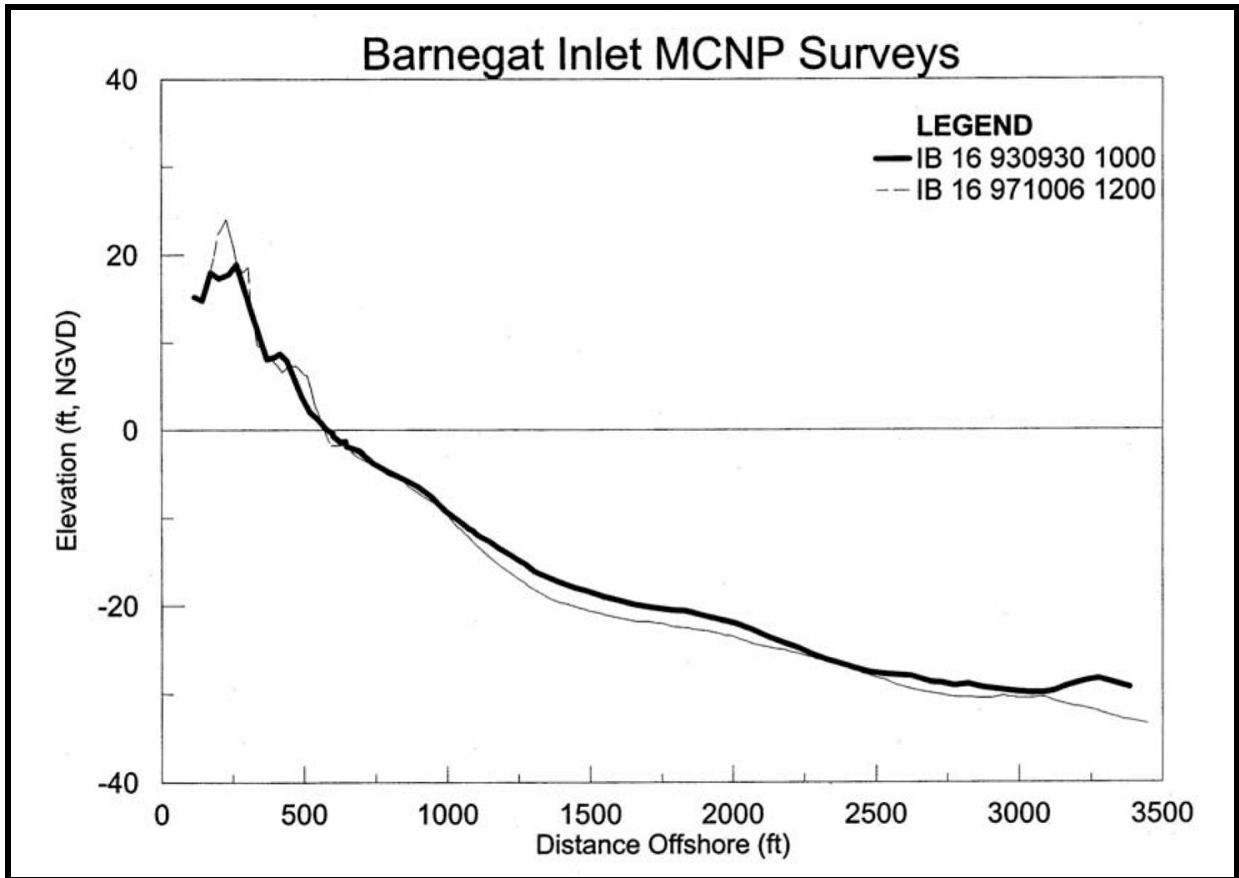

Figure B16. Island Beach State Park Profile No. 16 


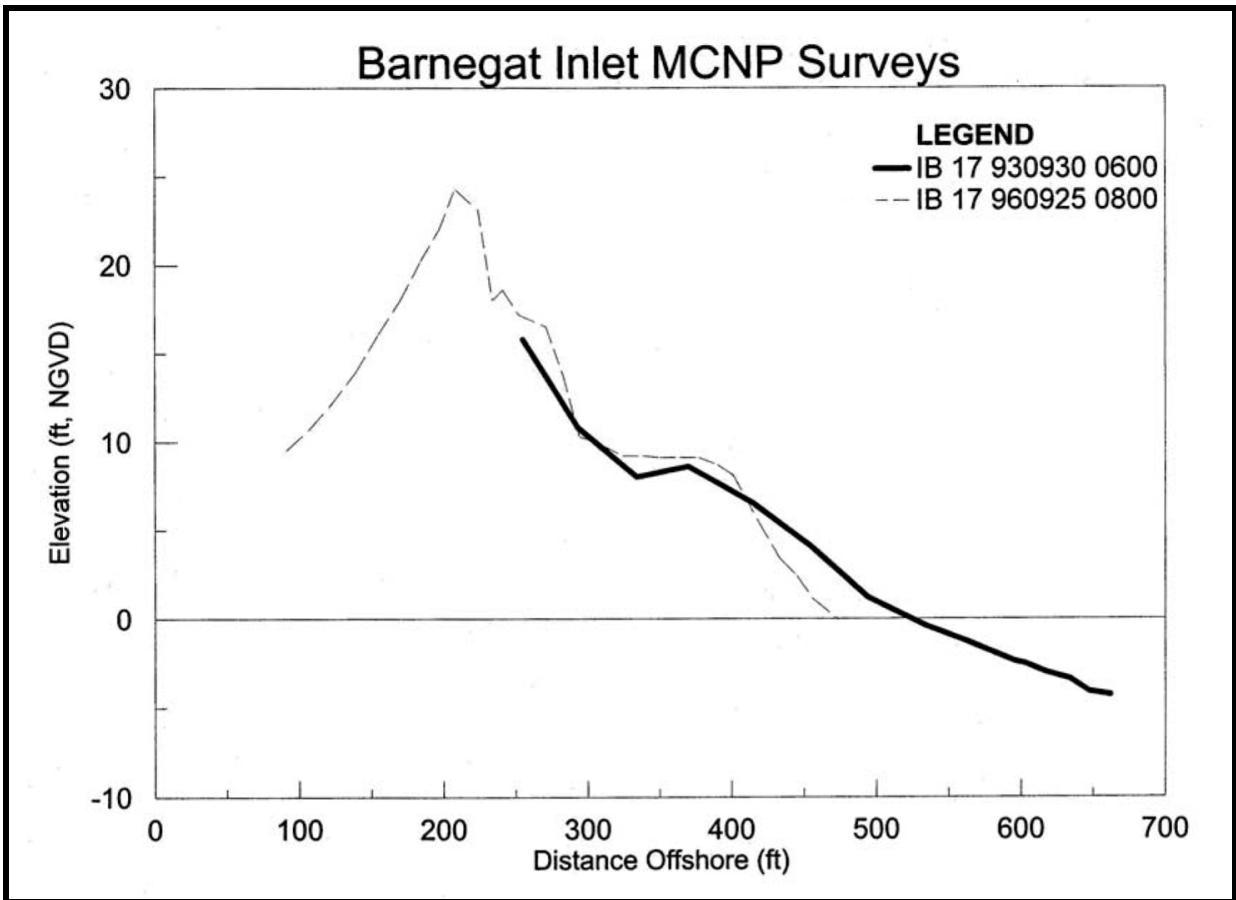

Figure B17. Island Beach State Park Profile No. 17

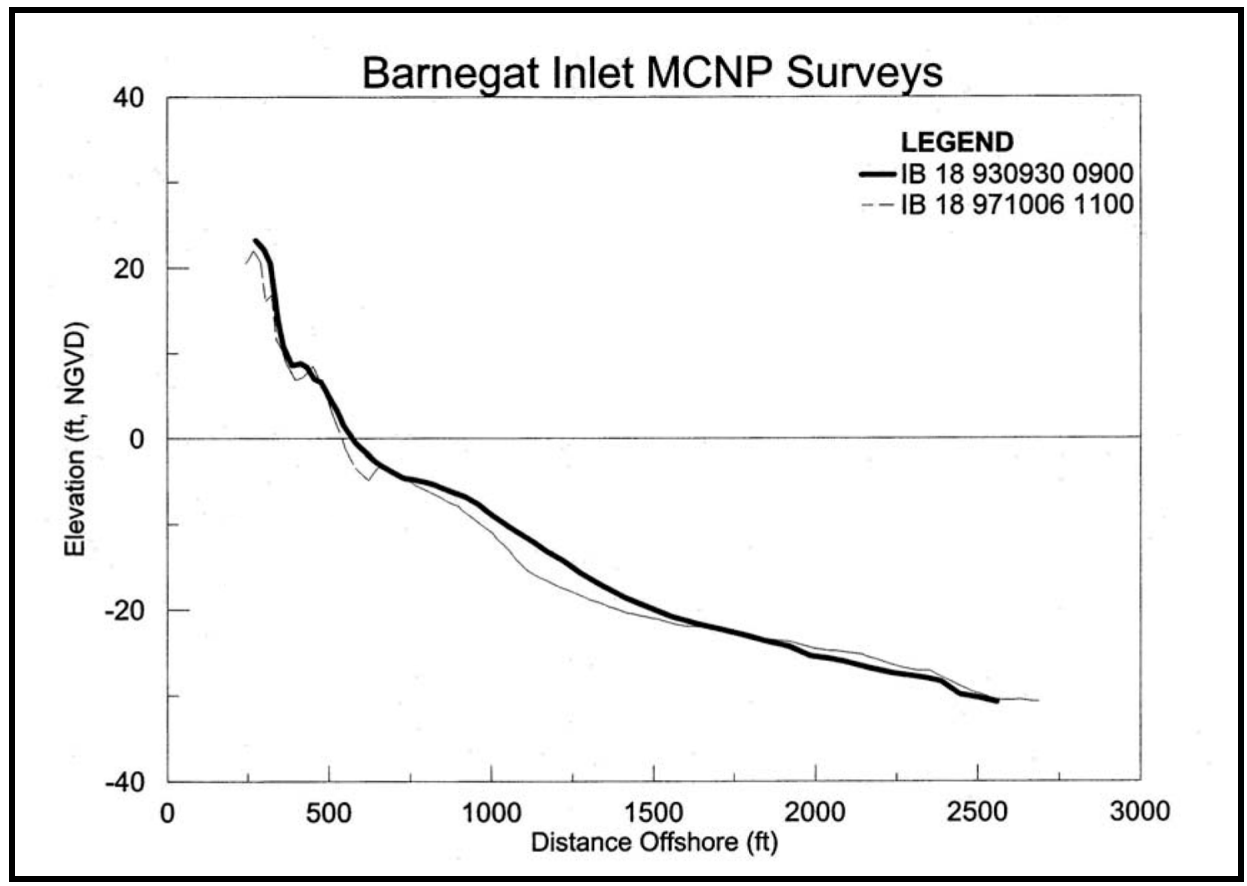

Figure B18. Island Beach State Park Profile No. 18 


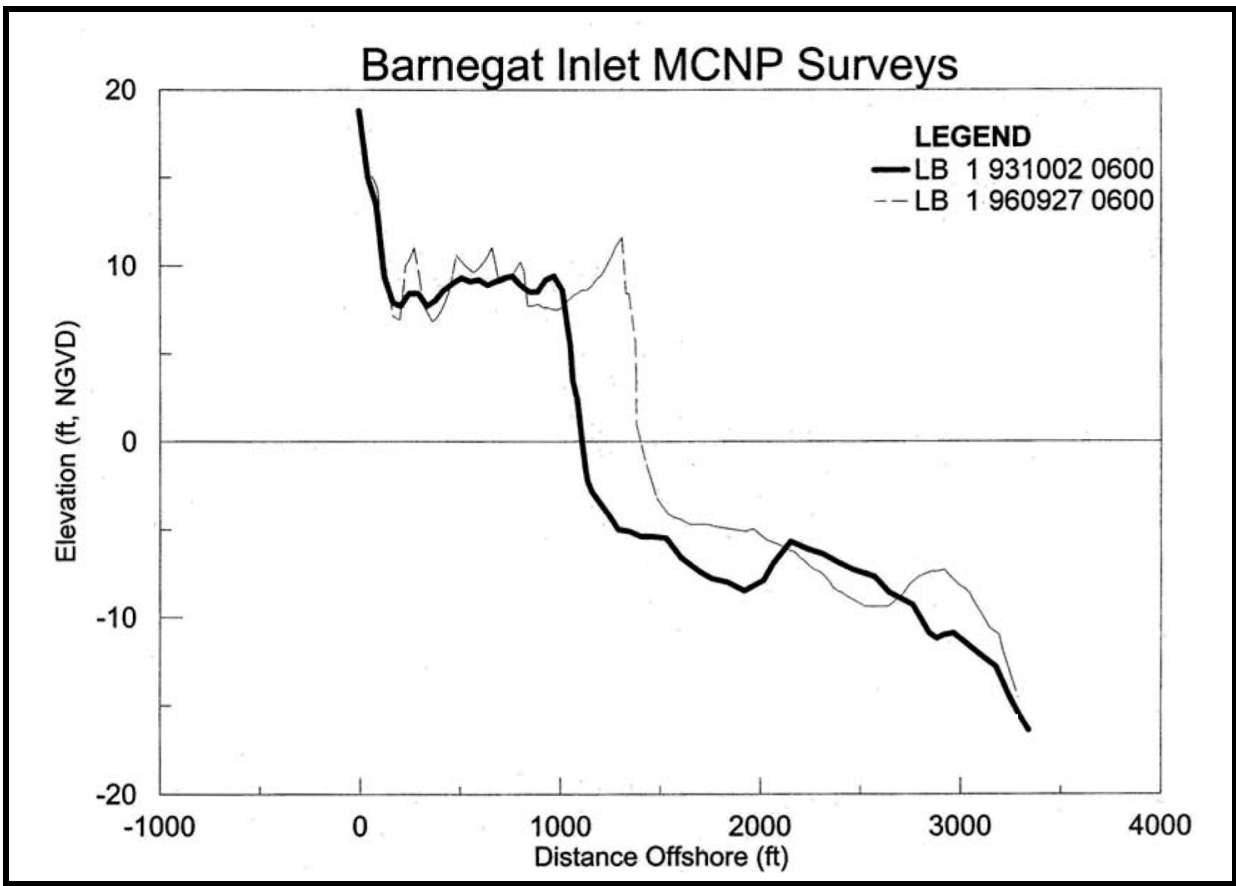

Figure B19. Long Beach Island Profile No. 1

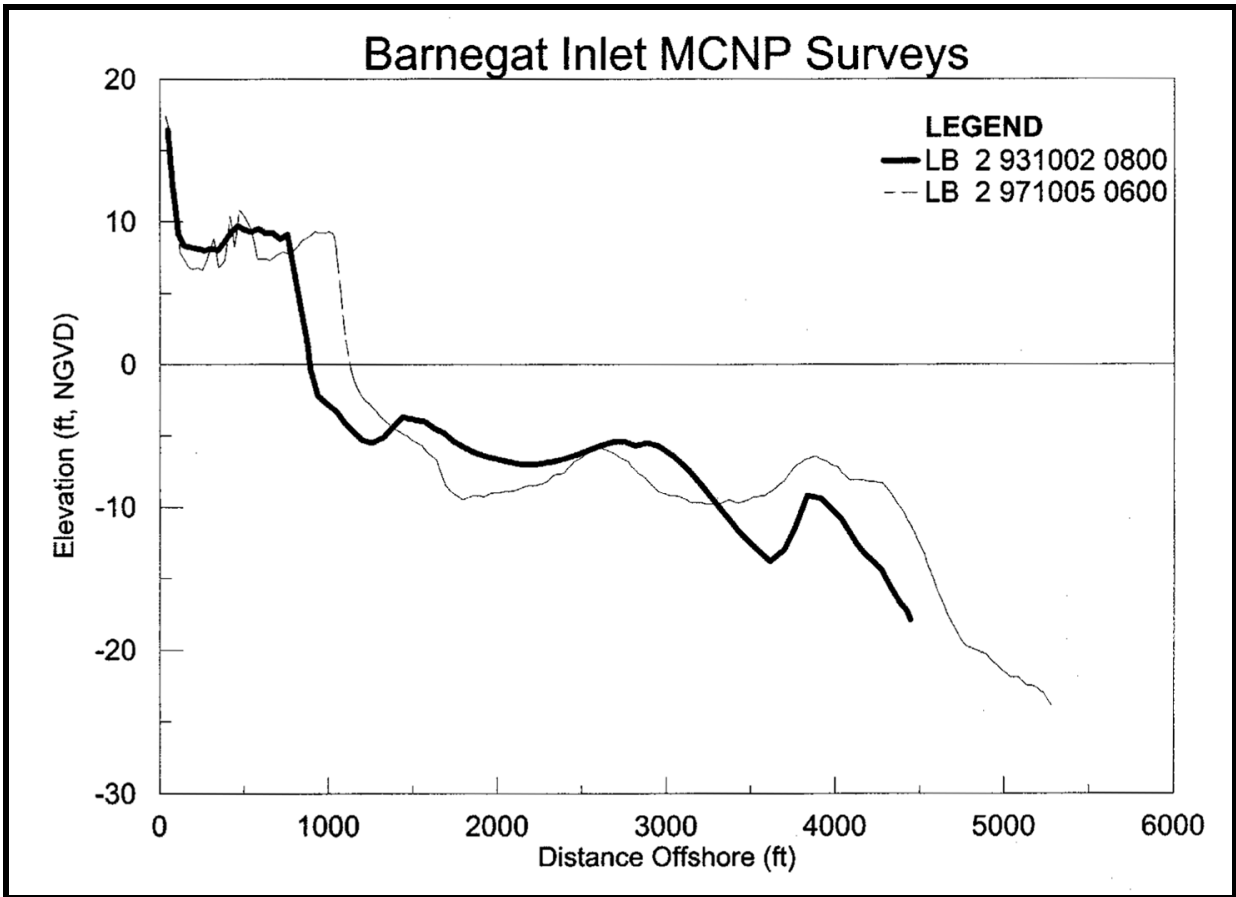

Figure B20. Long Beach Island Profile No. 2 


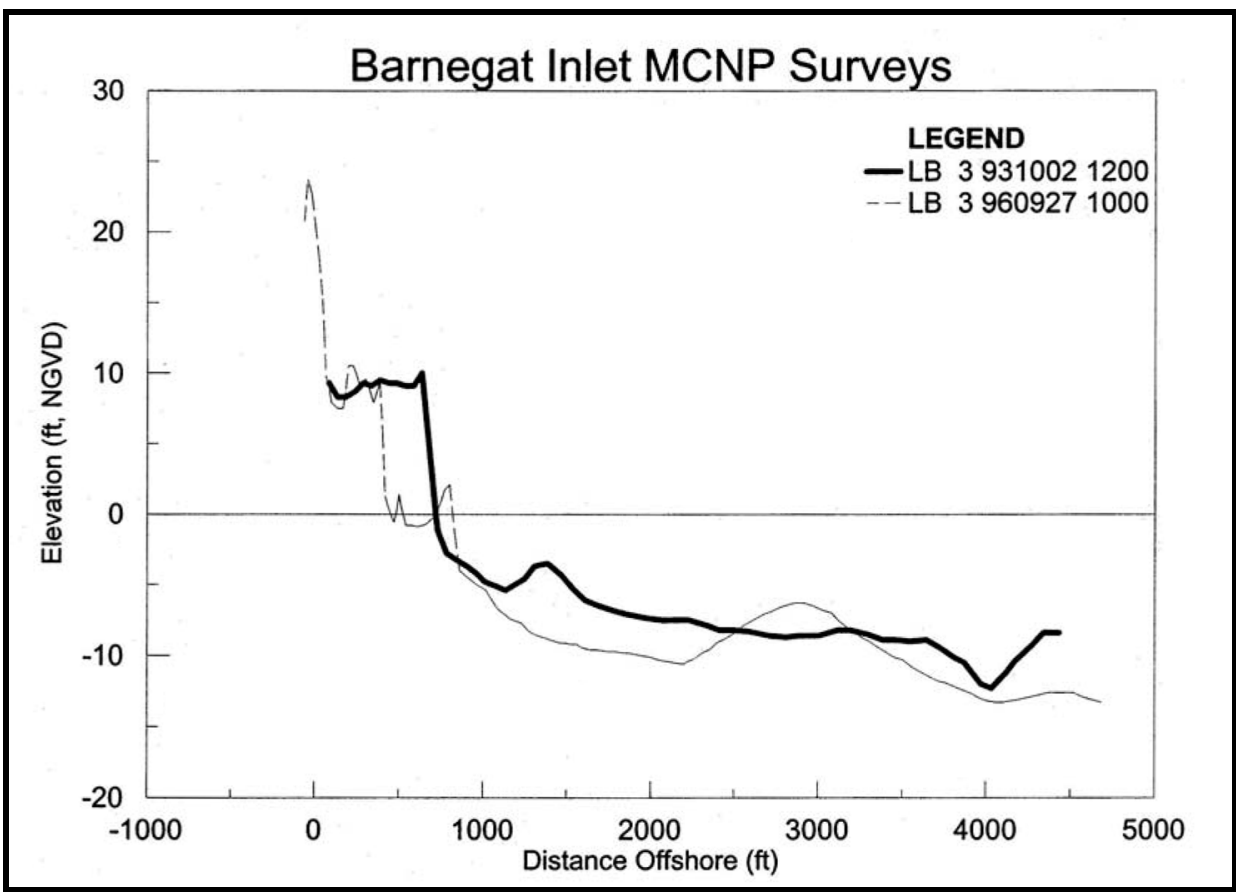

Figure B21. Long Beach Island Profile No. 3

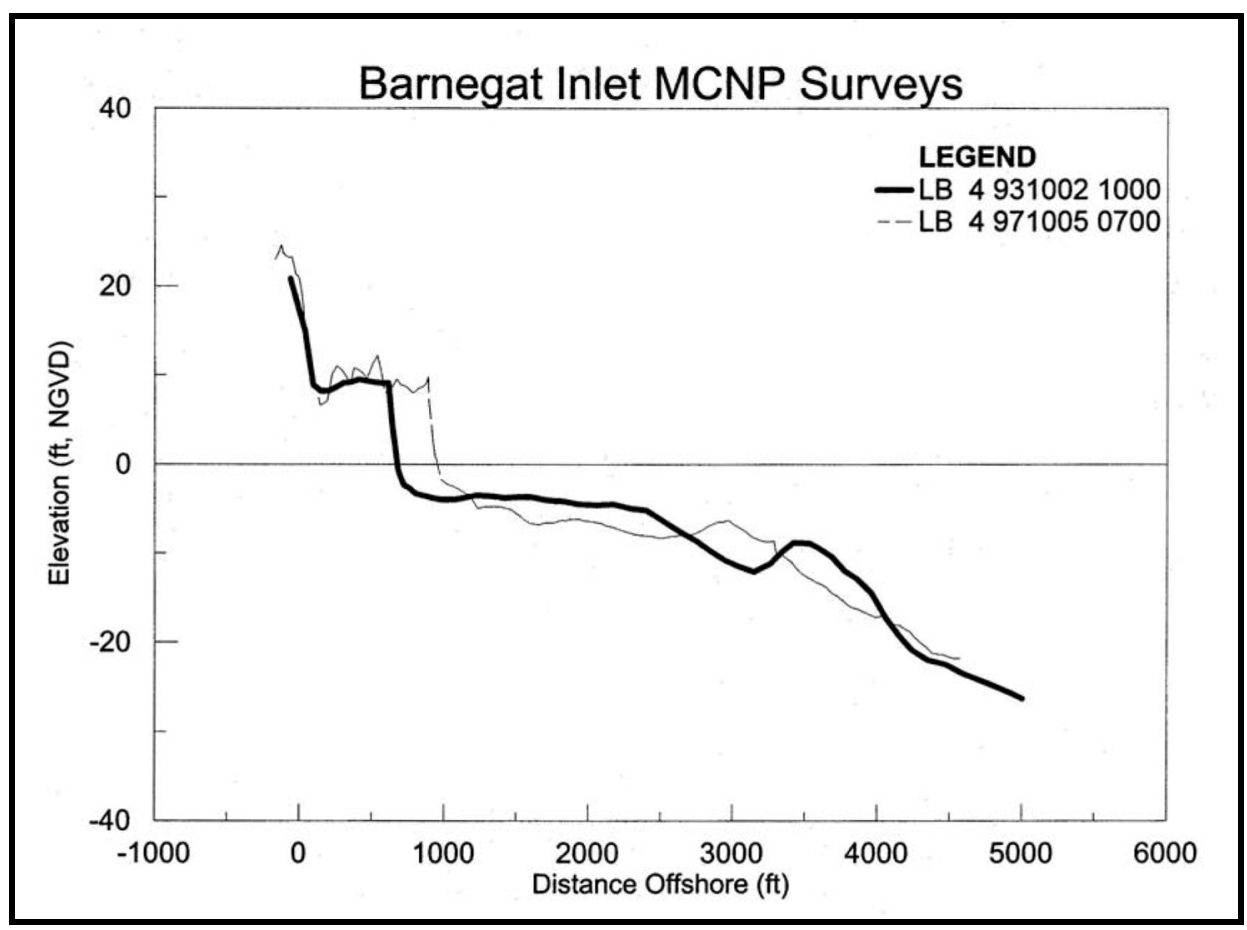

Figure B22. Long Beach Island Profile No. 4 


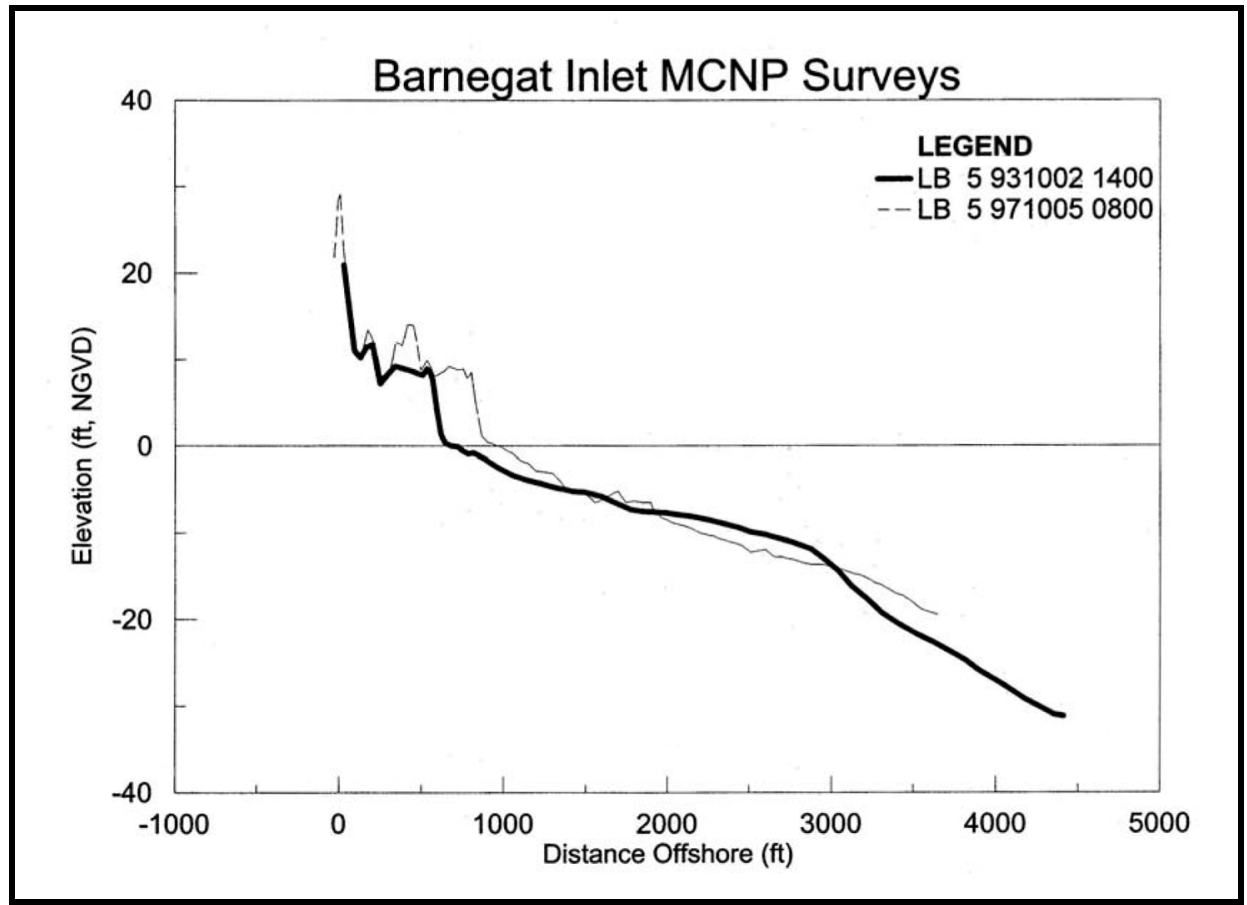

Figure B23. Long Beach Island Profile No. 5

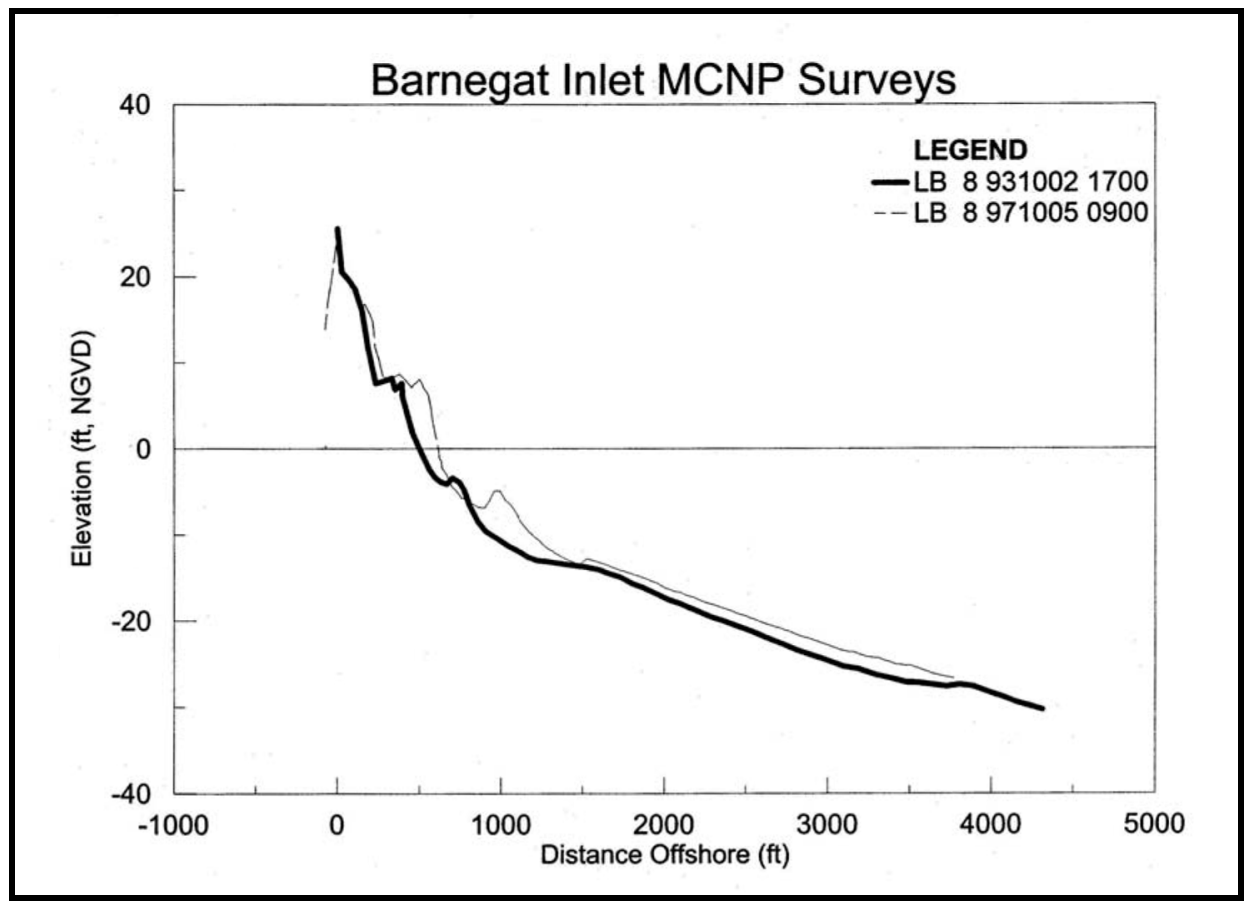

Figure B24. Long Beach Island Profile No. 8 


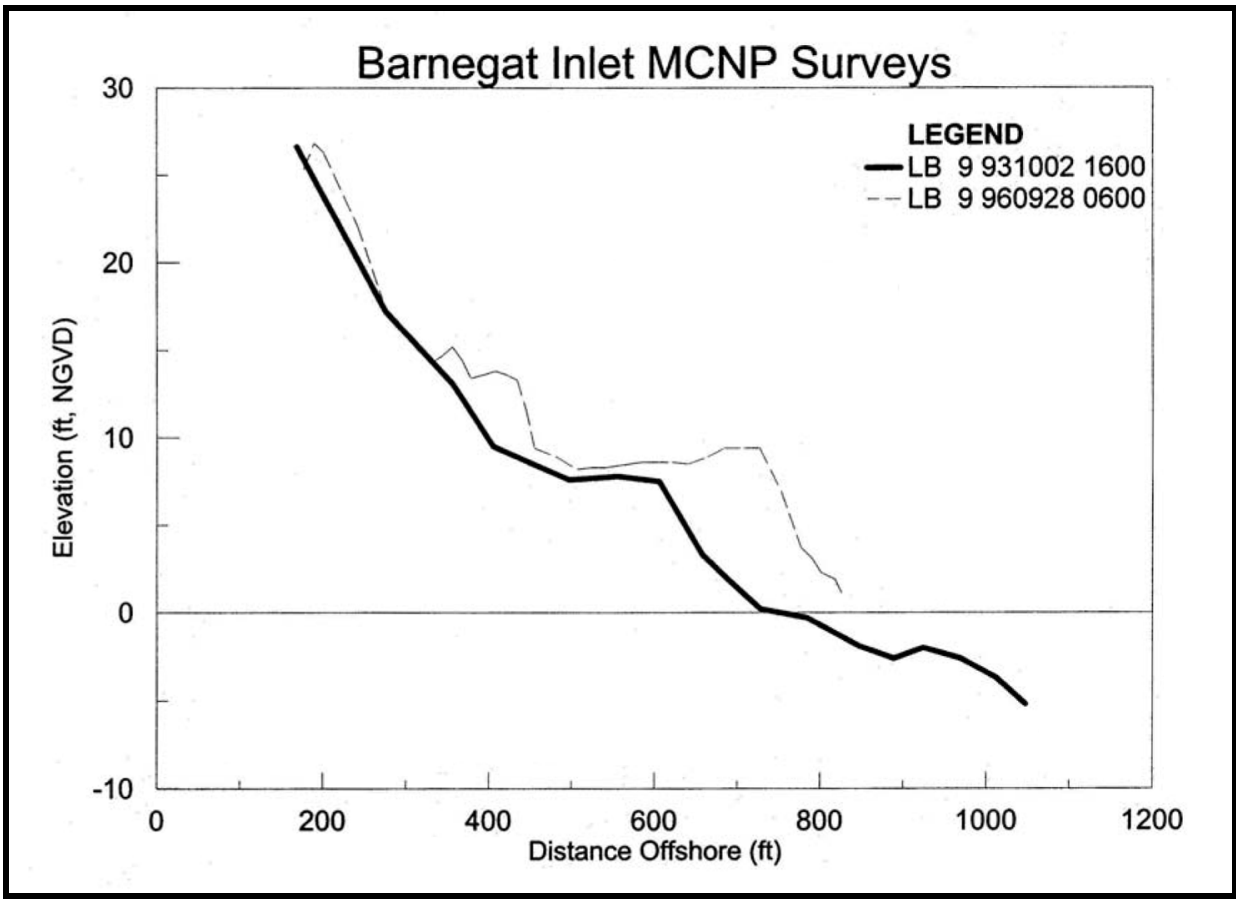

Figure B25. Long Beach Island Profile No. 9

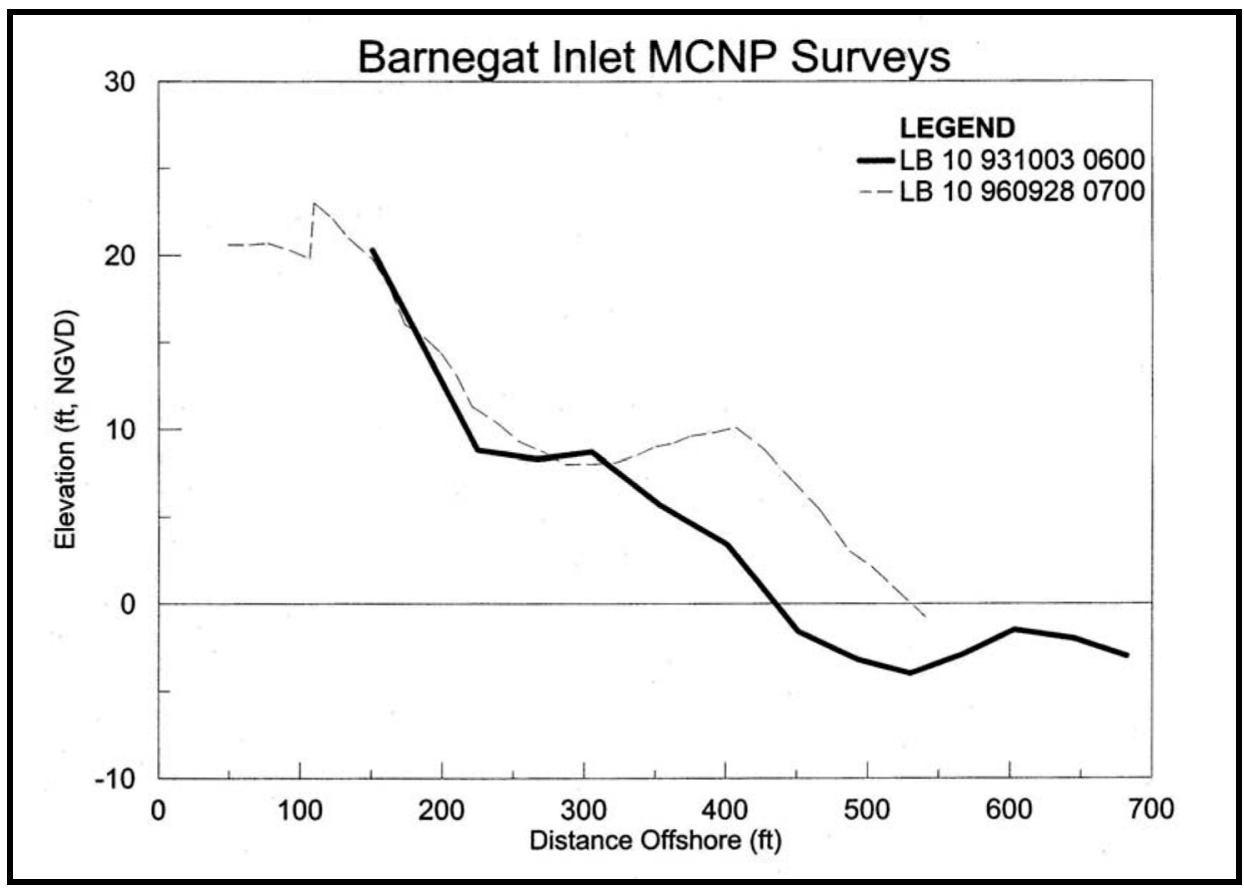

Figure B26. Long Beach Island Profile No. 10 


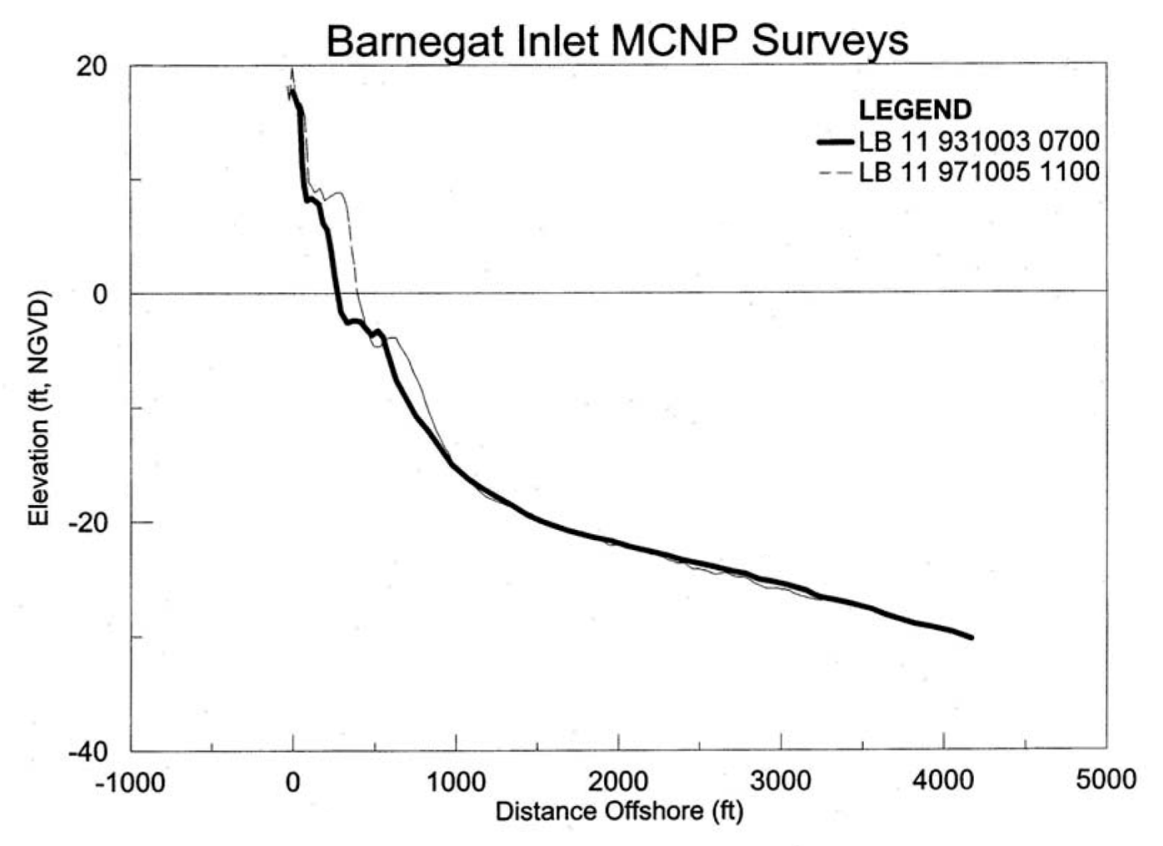

Figure B27. Long Beach Island Profile No. 11

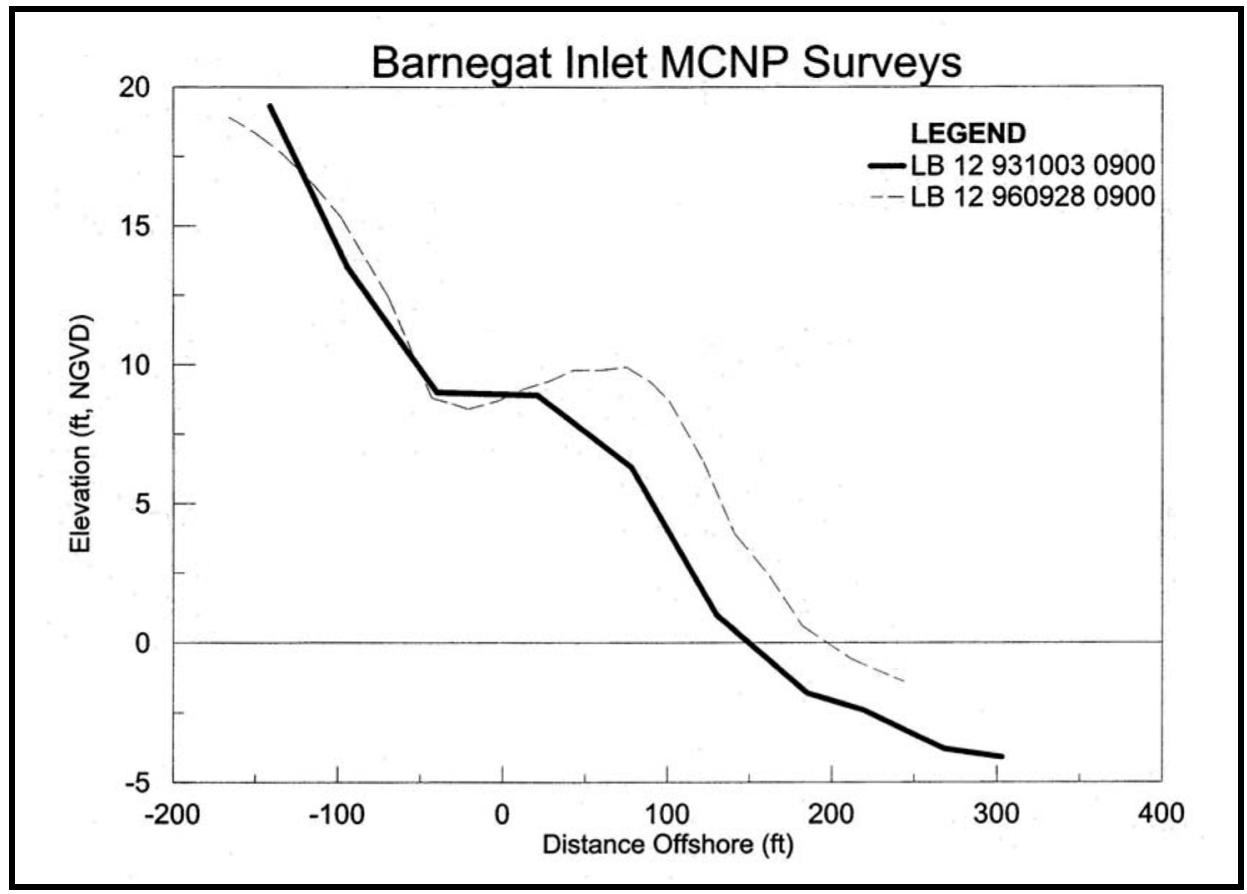

Figure B28. Long Beach Island Profile No. 12 


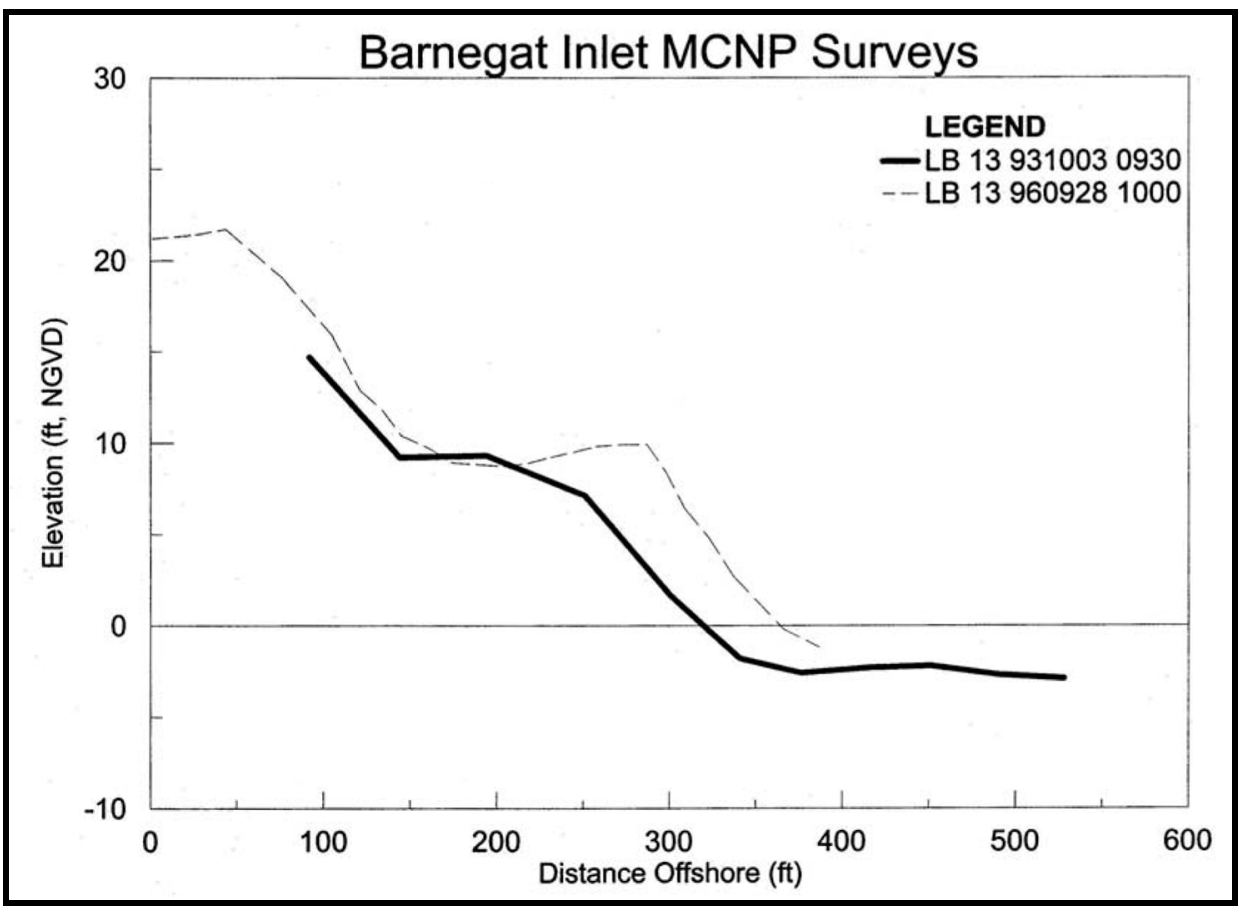

Figure B29. Long Beach Island Profile No. 13

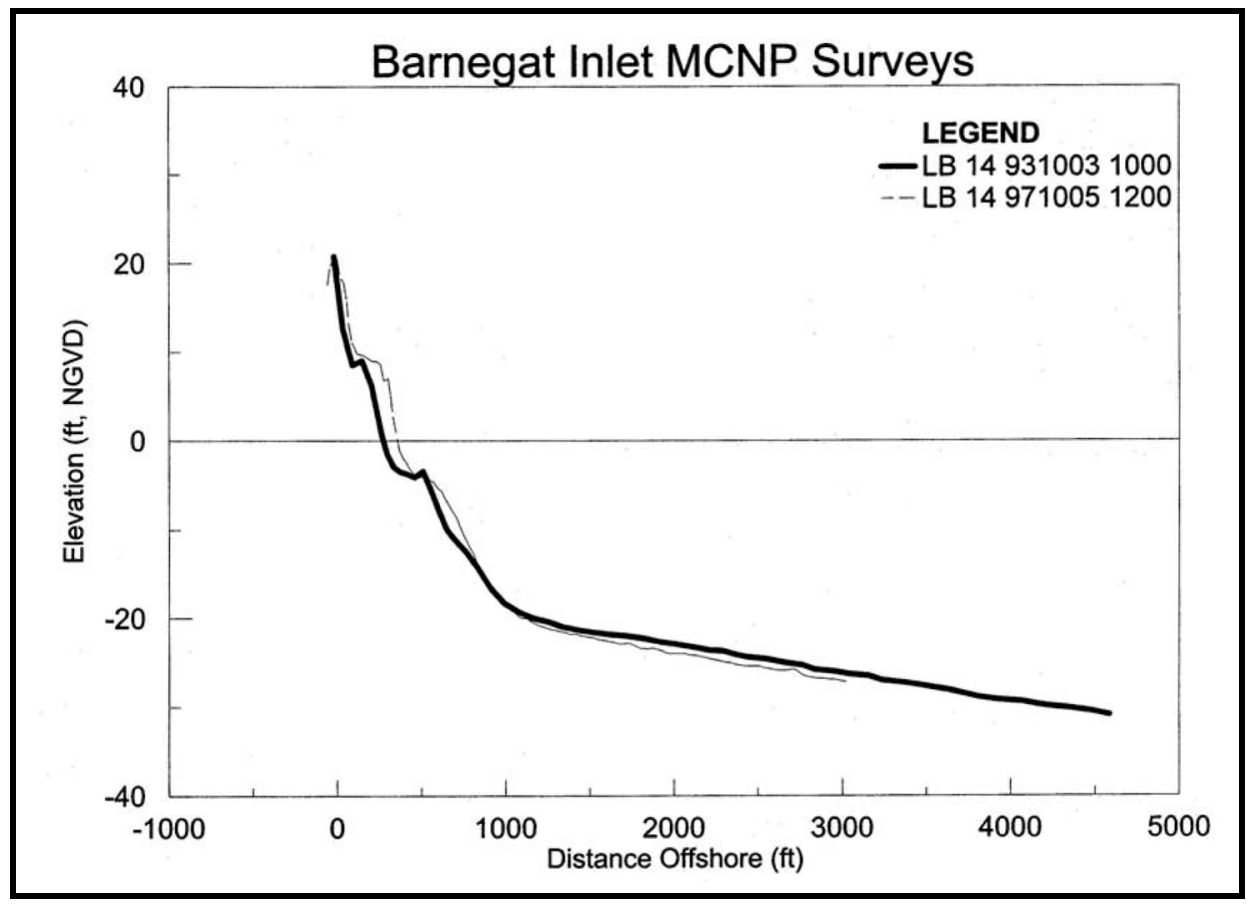

Figure B30. Long Beach Island Profile No. 14 


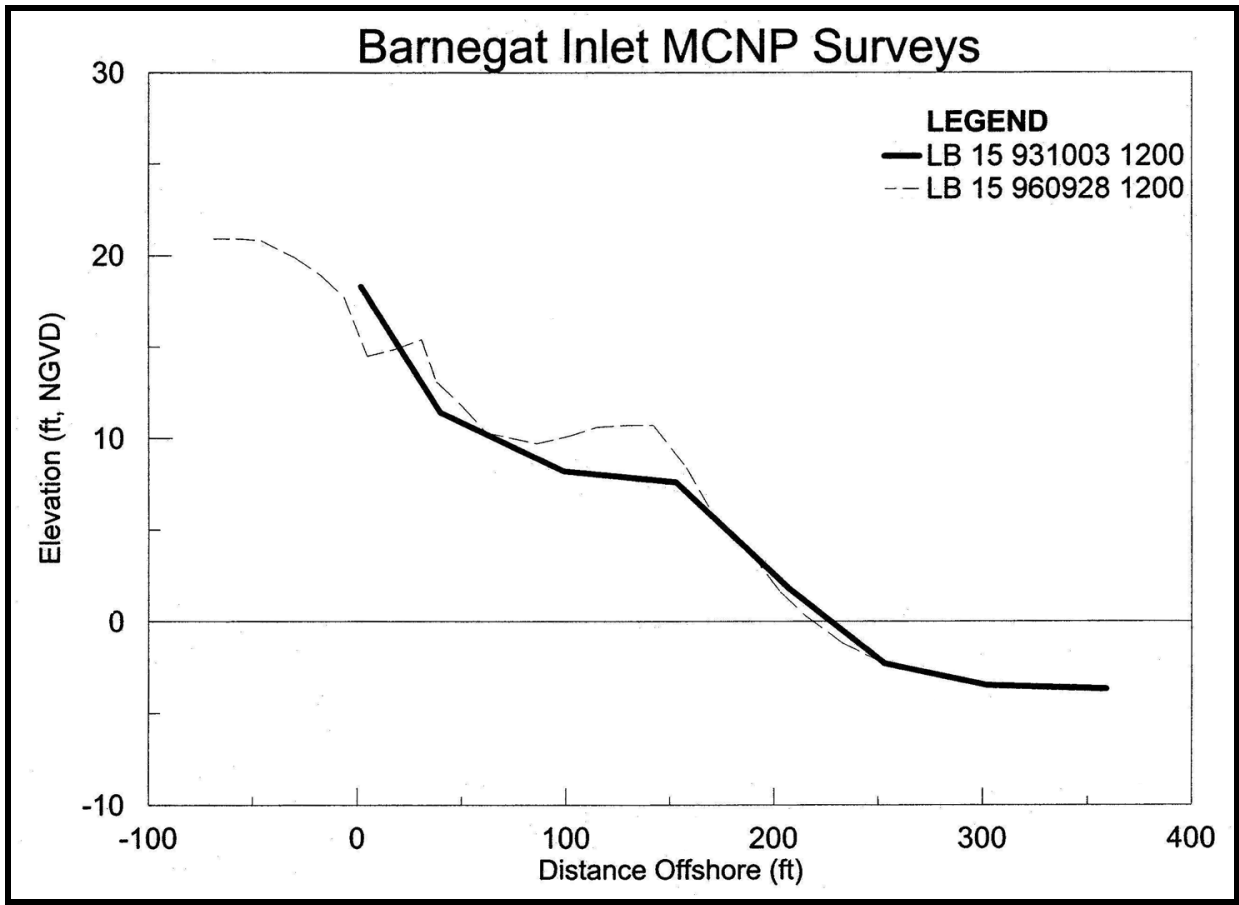

Figure B31. Long Beach Island Profile No. 15

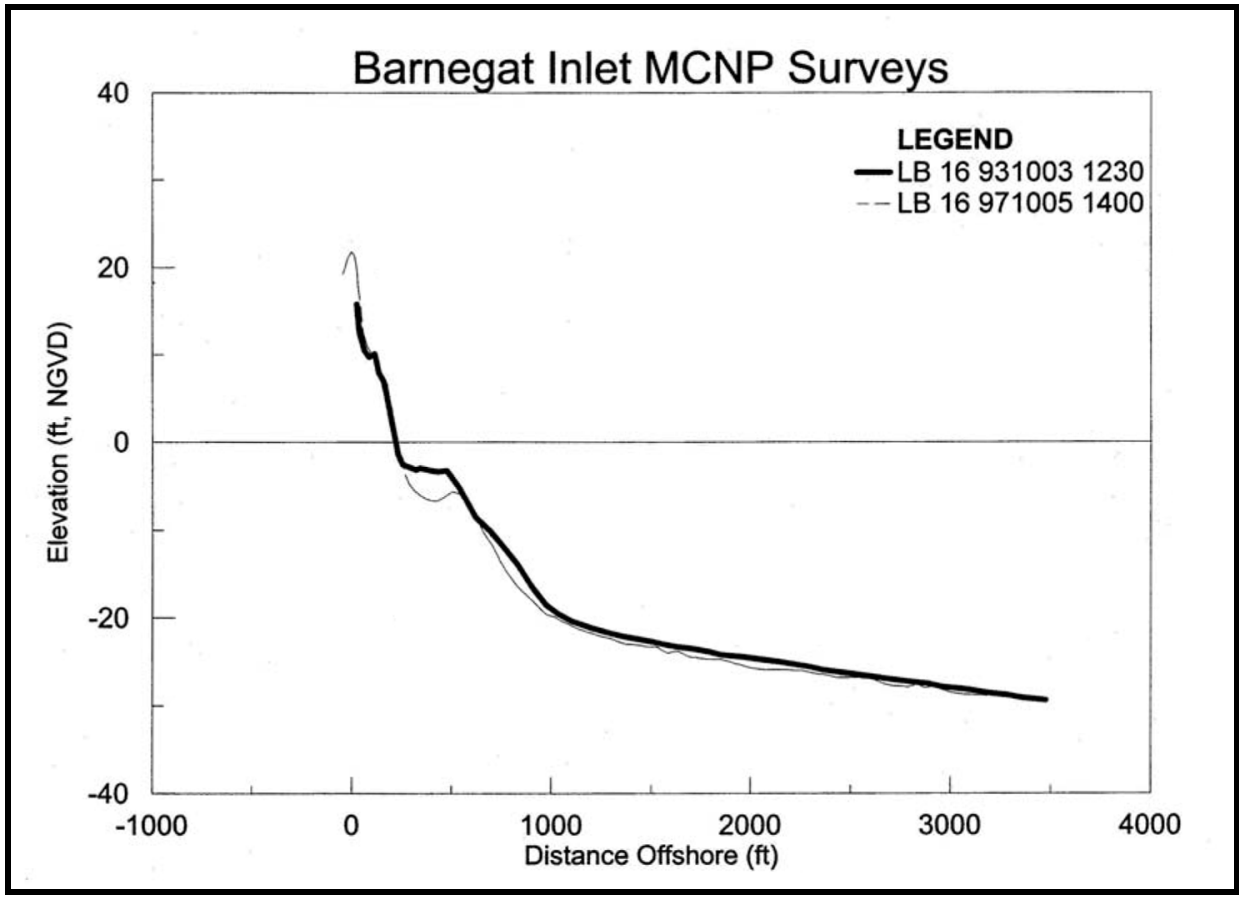

Figure B32. Long Beach Island Profile No. 16 


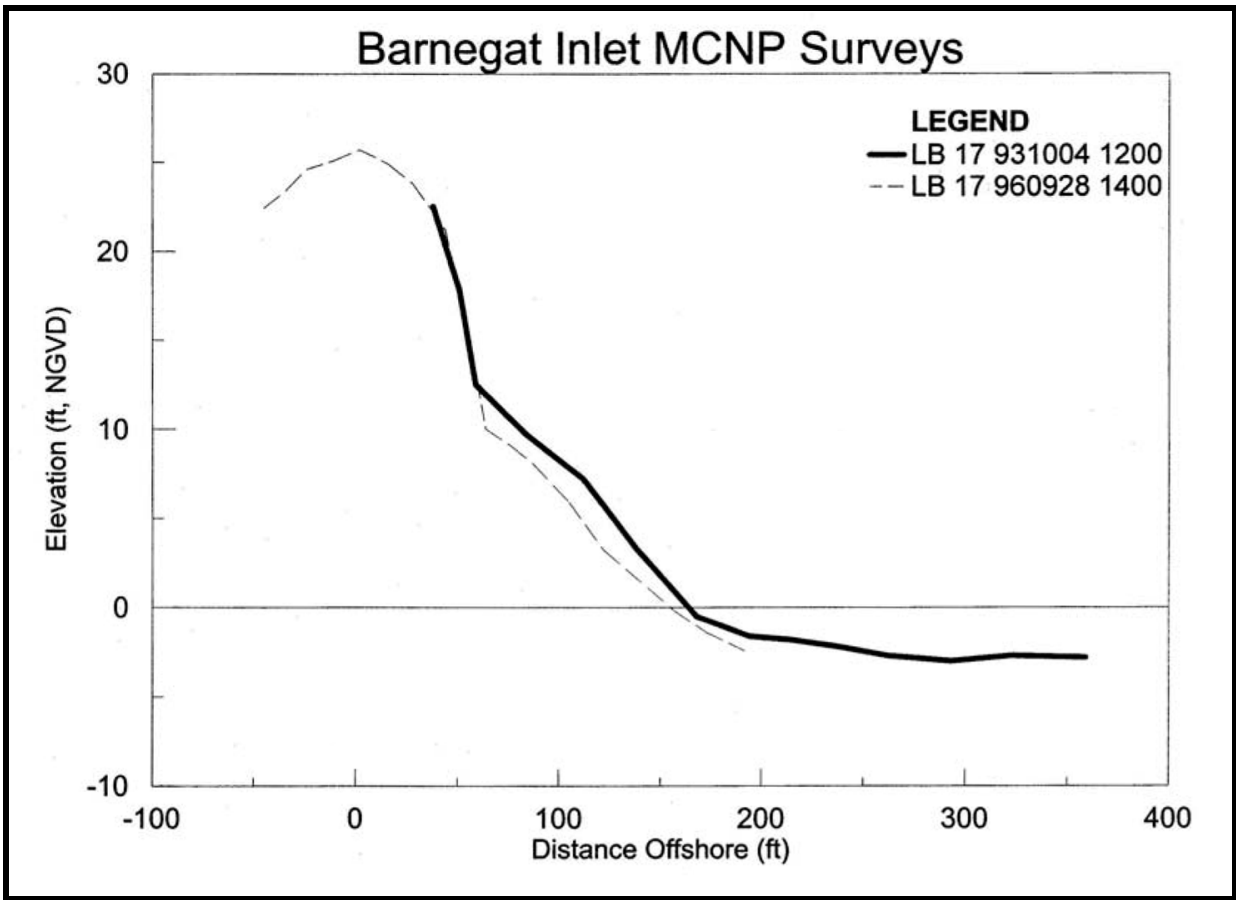

Figure B33. Long Beach Island Profile No. 17

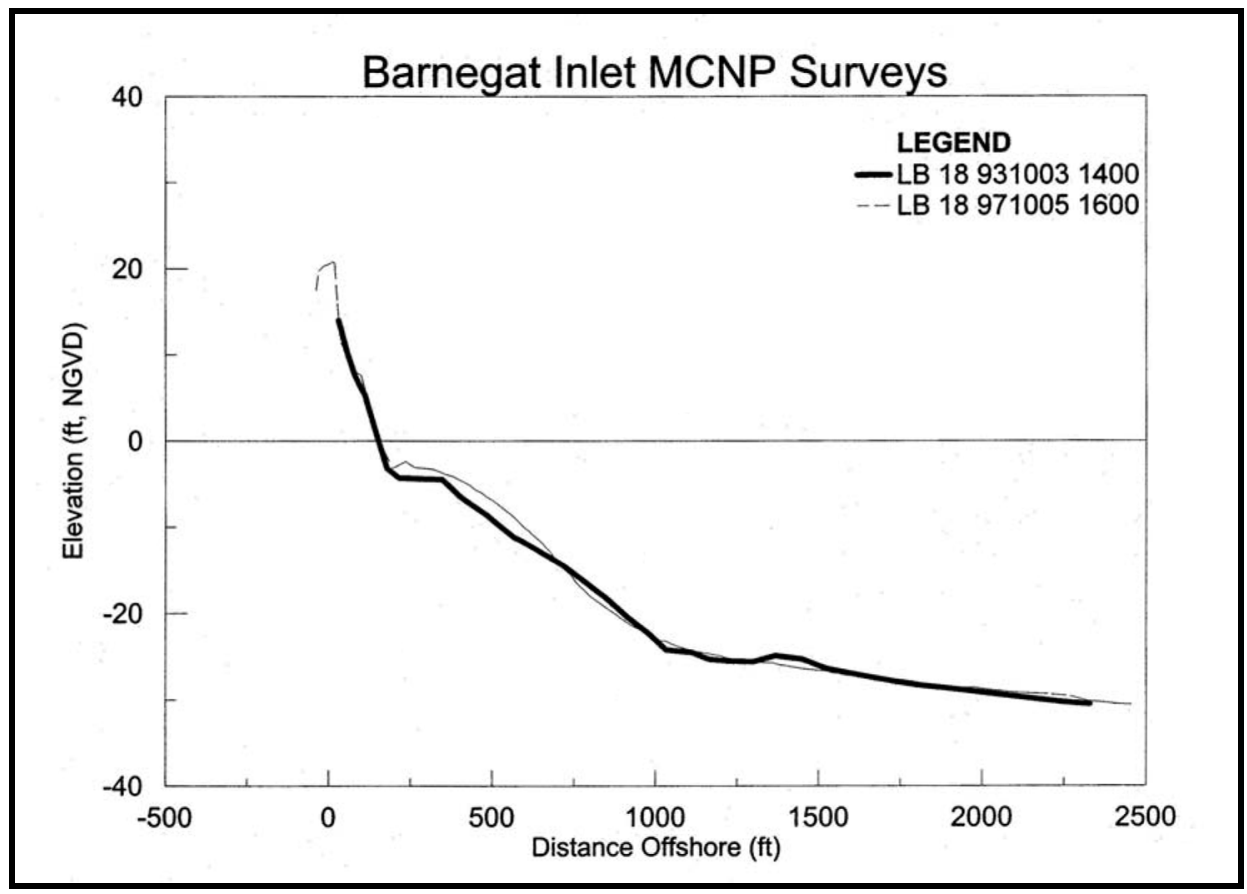

Figure B34. Long Beach Island Profile No. 18 


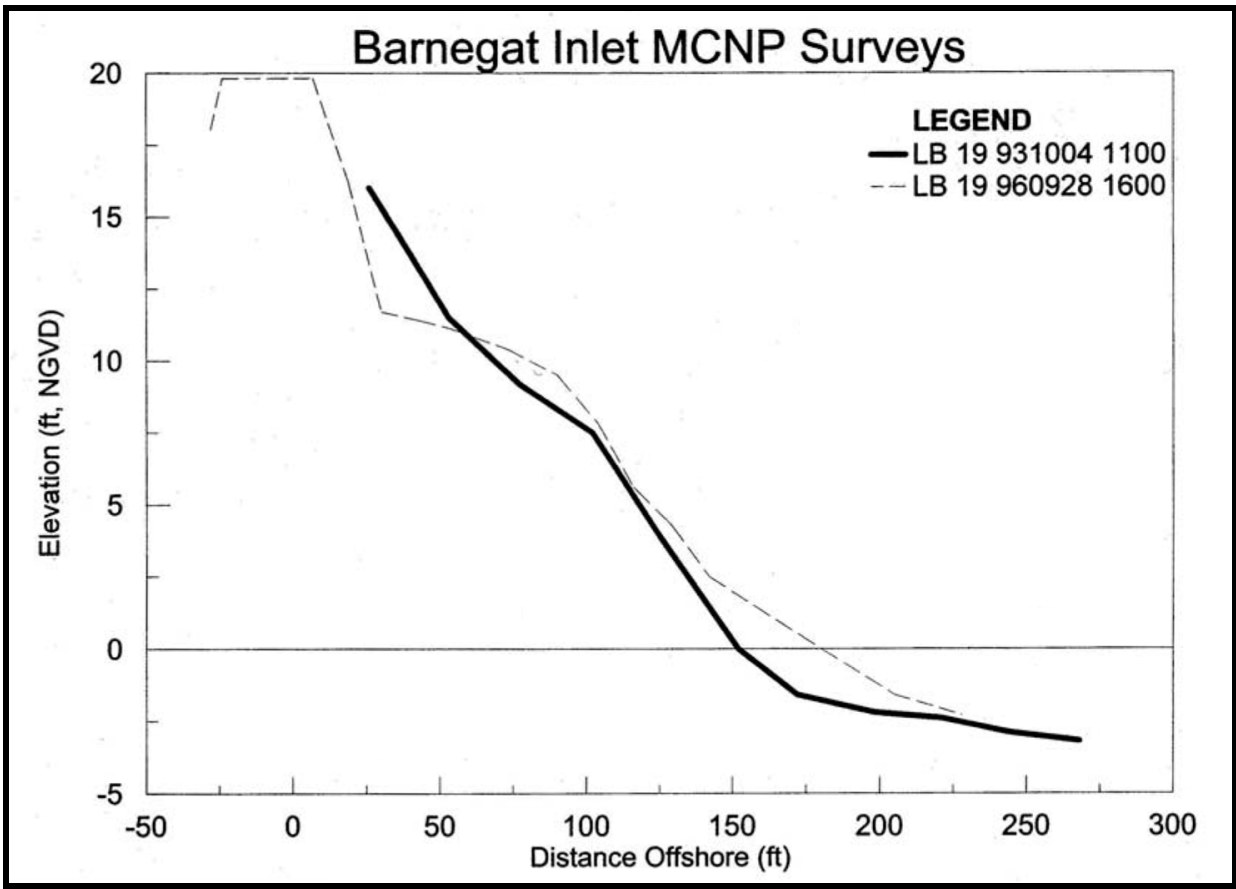

Figure B35. Long Beach Island Profile No. 19

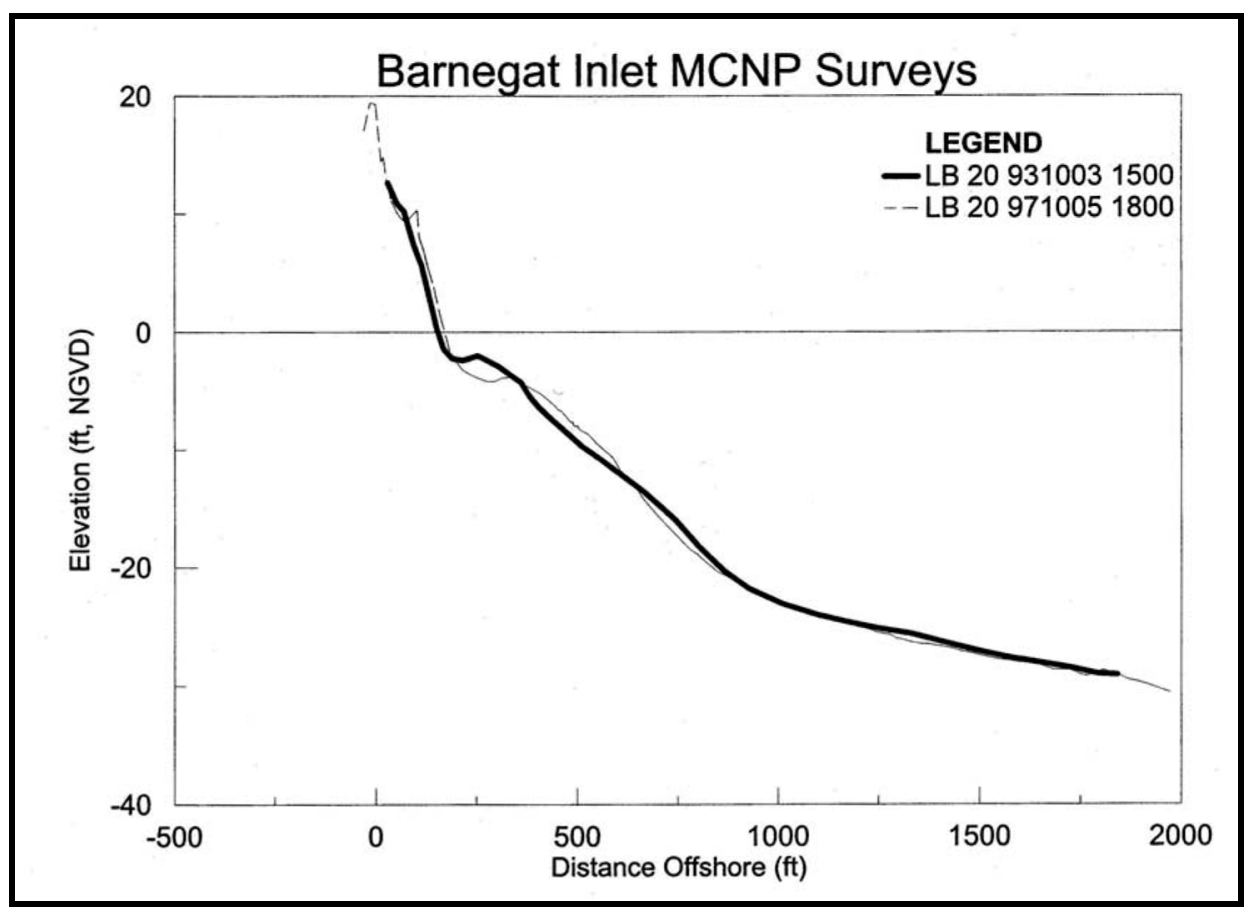

Figure B36. Long Beach Island Profile No. 20 


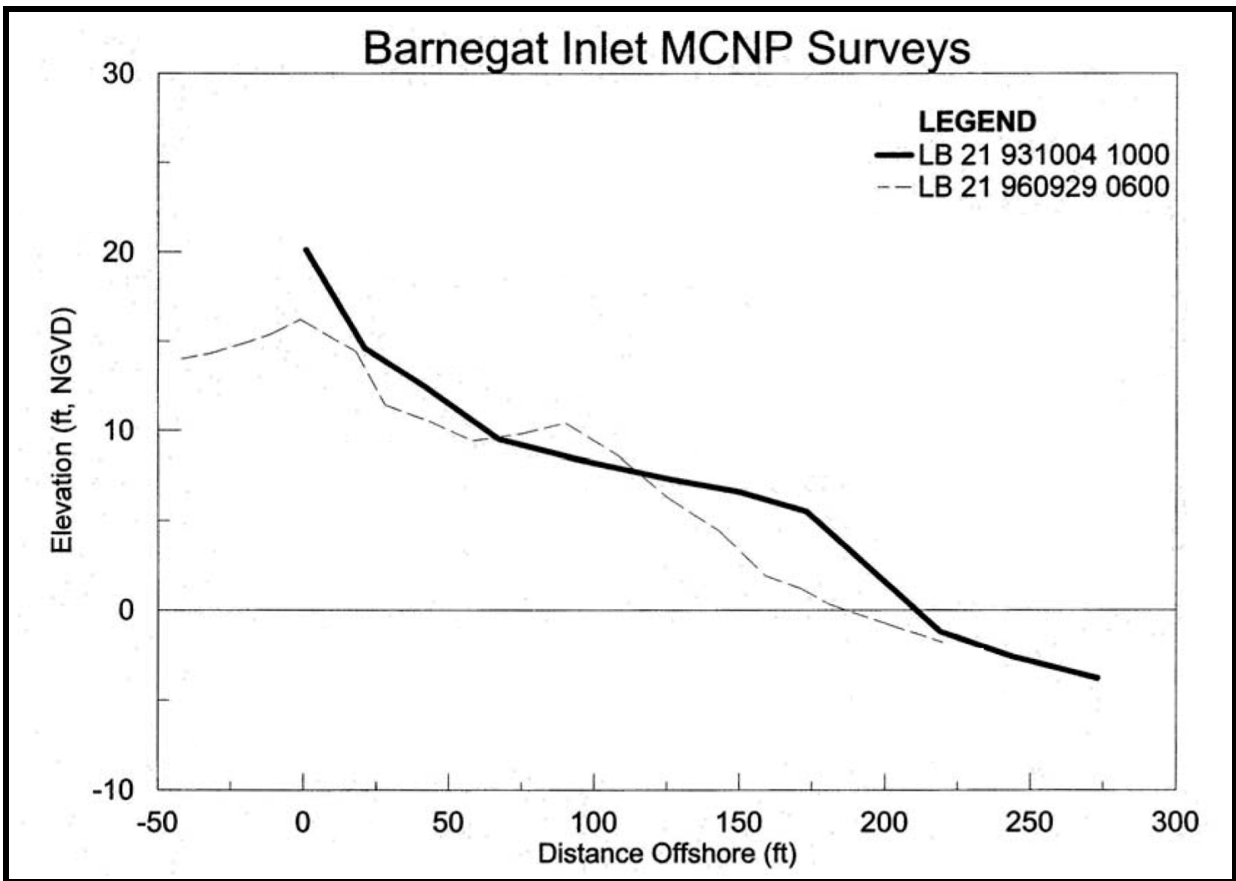

Figure B37. Long Beach Island Profile No. 21

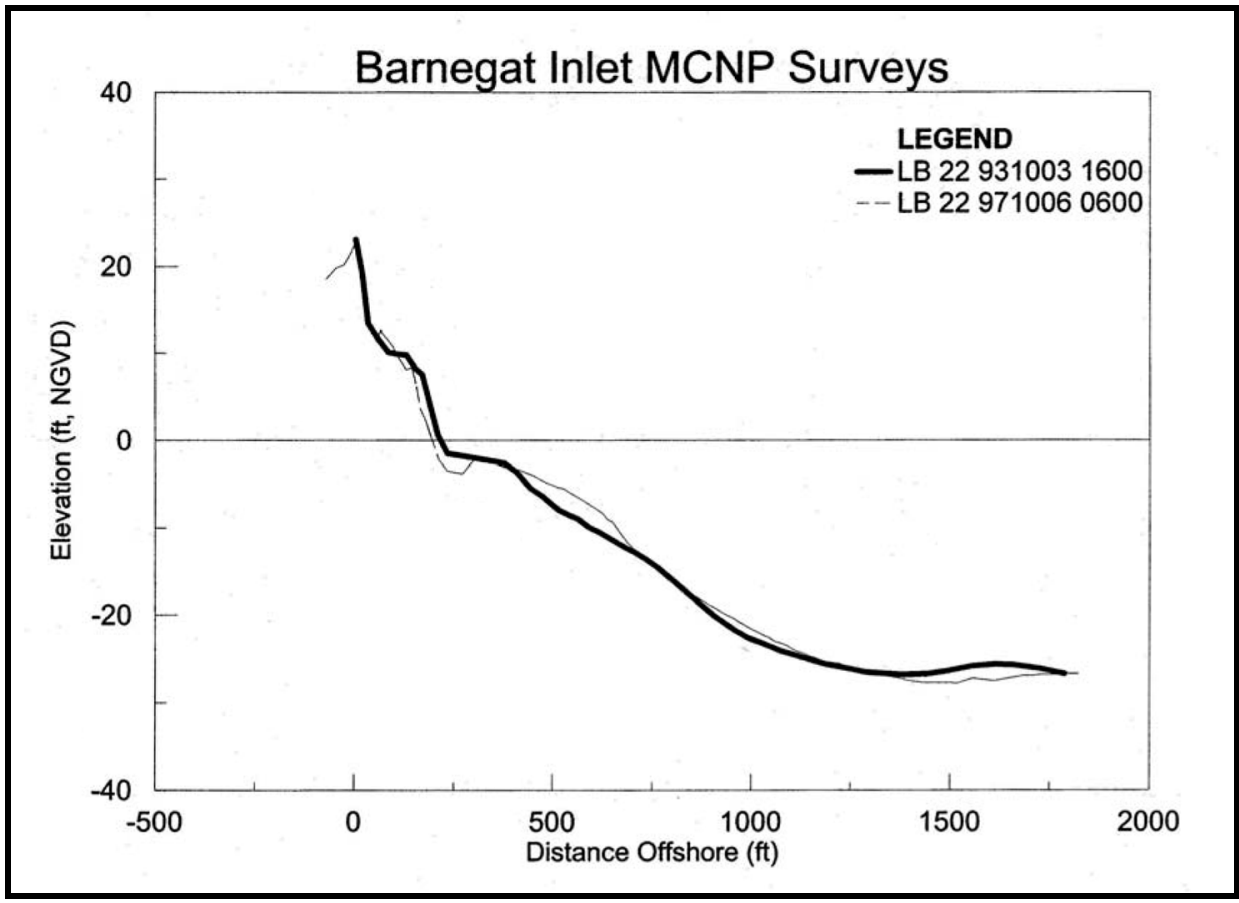

Figure B38. Long Beach Island Profile No. 22 


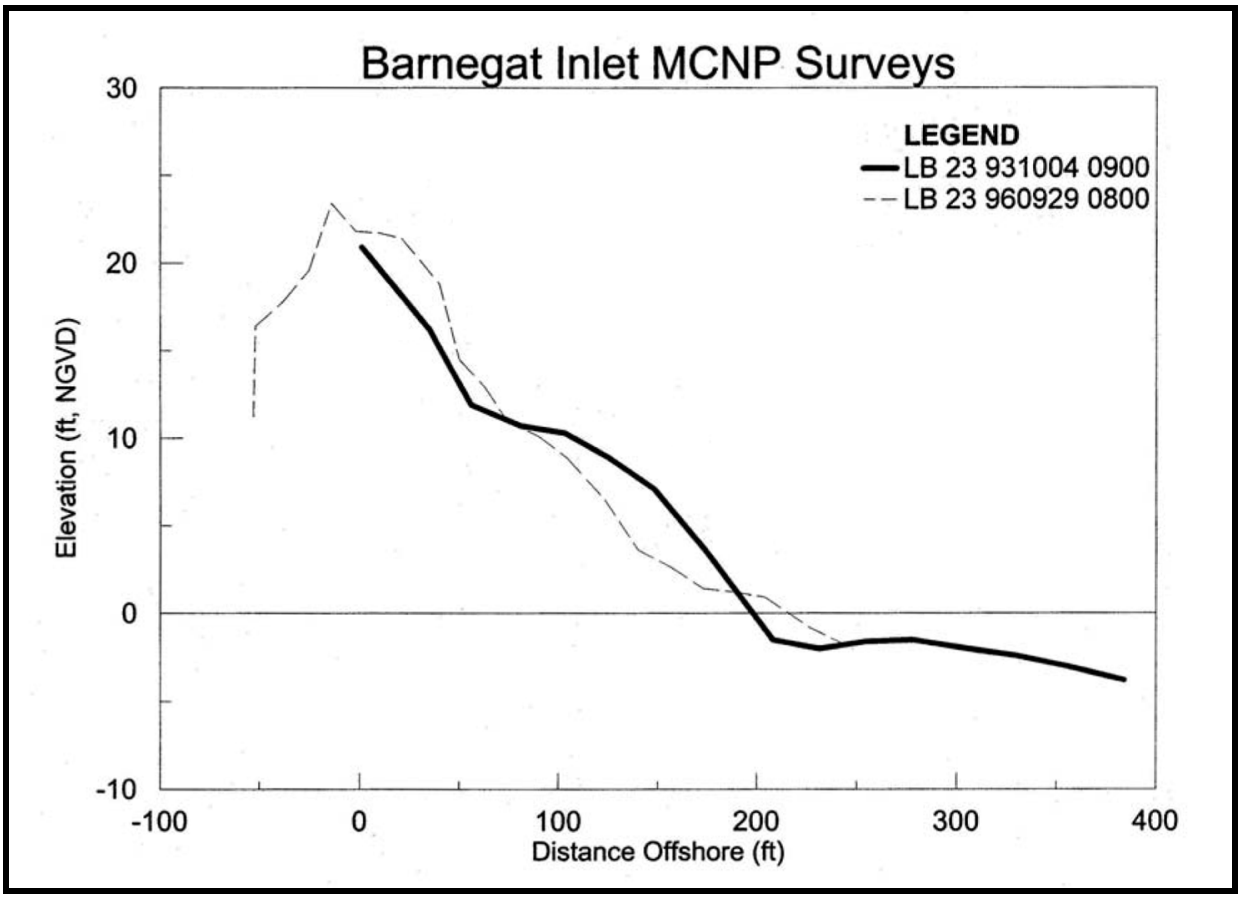

Figure B39. Long Beach Island Profile No. 23

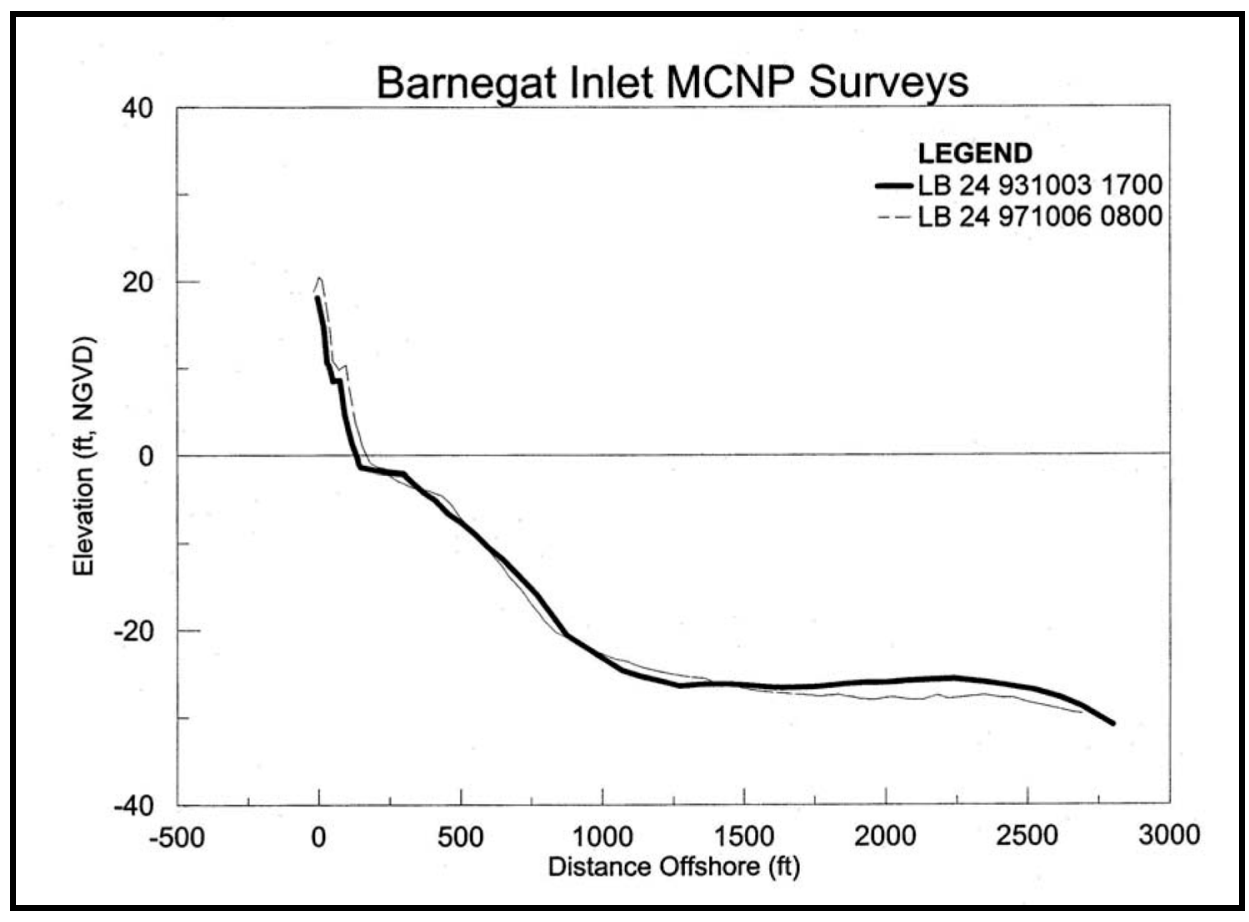

Figure B40. Long Beach Island Profile No. 24 


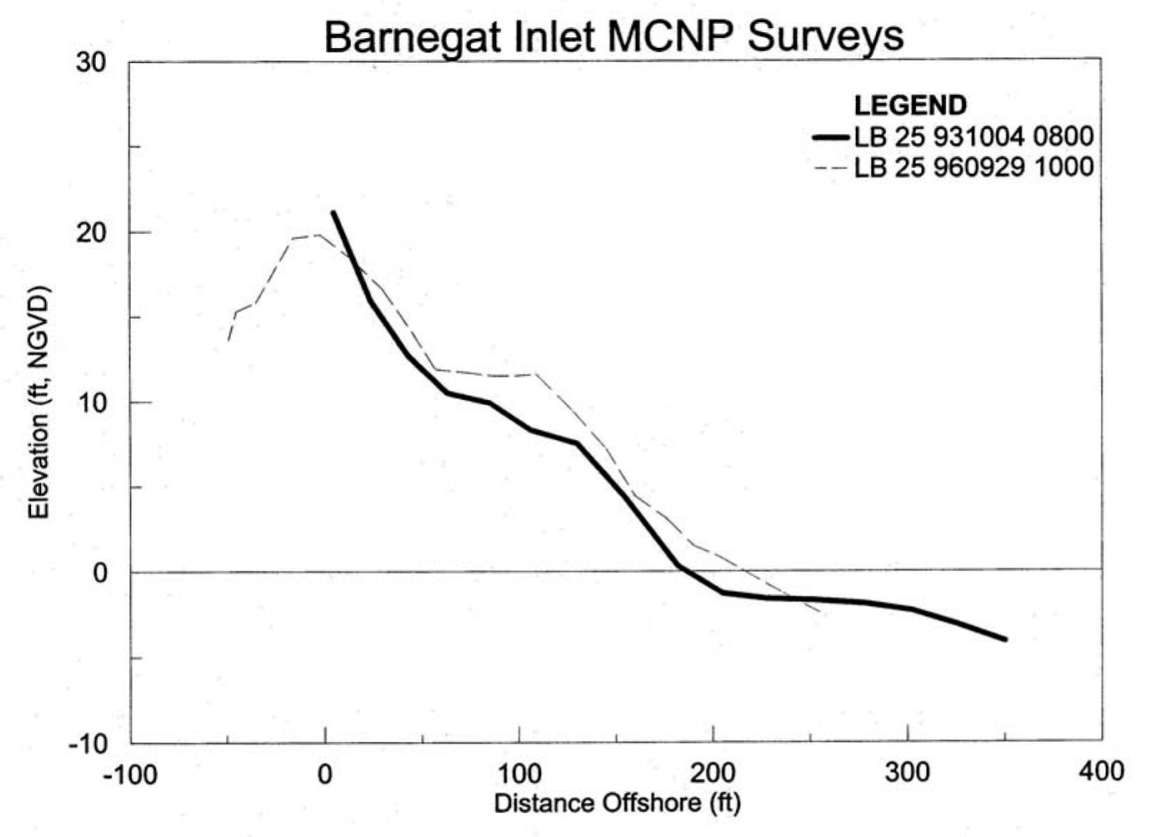

Figure B41. Long Beach Island Profile No. 25

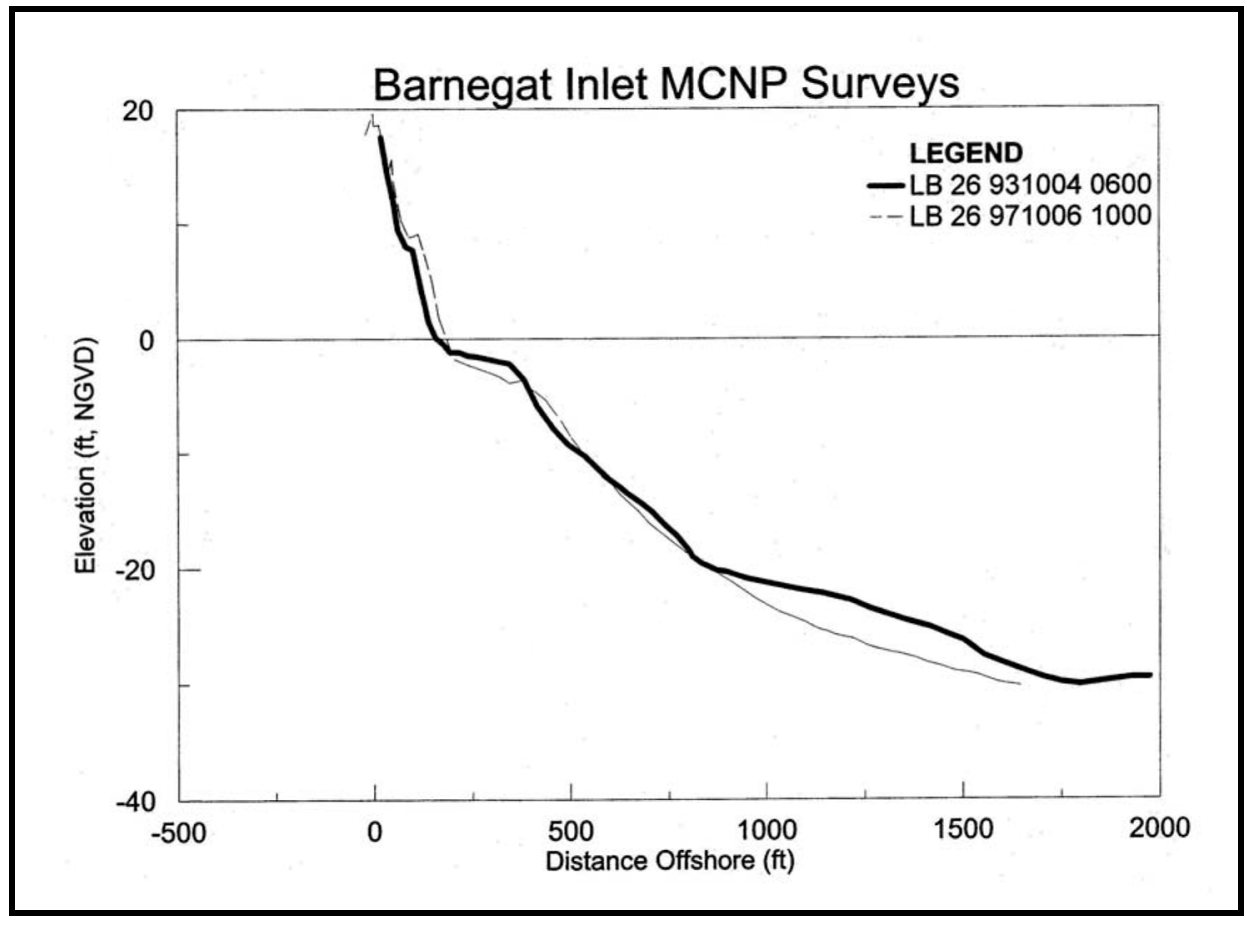

Figure B42. Long Beach Island Profile No. 26 


\section{Appendix C Beach Sand Volume above Various Contours for Island Beach State Park and Long Island Beach Profiles for Years 1993, 1994, 1995, 1996, and 1997}

Note: to convert volumes given in cu $\mathrm{yd} / \mathrm{ft}$ to $\mathrm{cu} \mathrm{m} / \mathrm{m}$, multiply by 2.5 . 
Island Beach-Profile 1: Volume Above Various Contours $\square 1993 \square 1994 \square 1995 \square 1996$

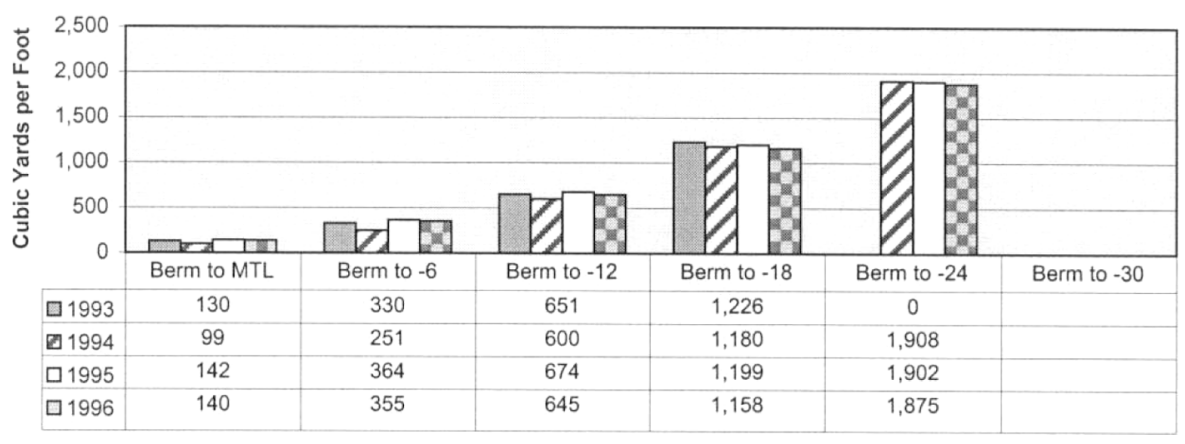

Island Beach-Profile 4: Volume Above Various Contours

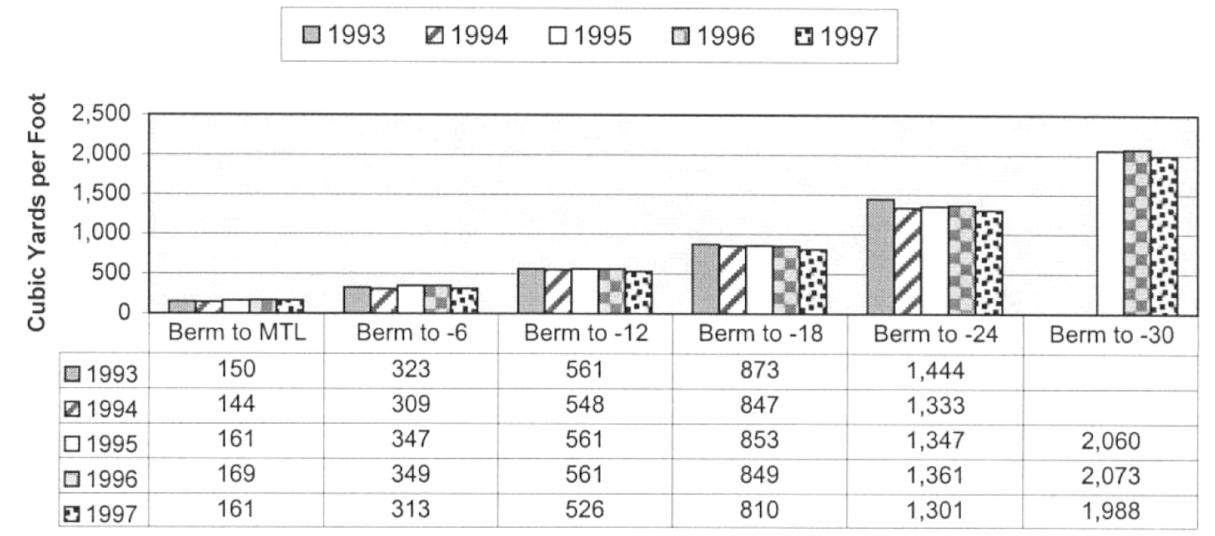

Island Beach-Profile 6: Volume Above Various Contours

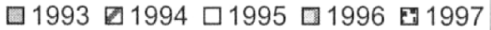

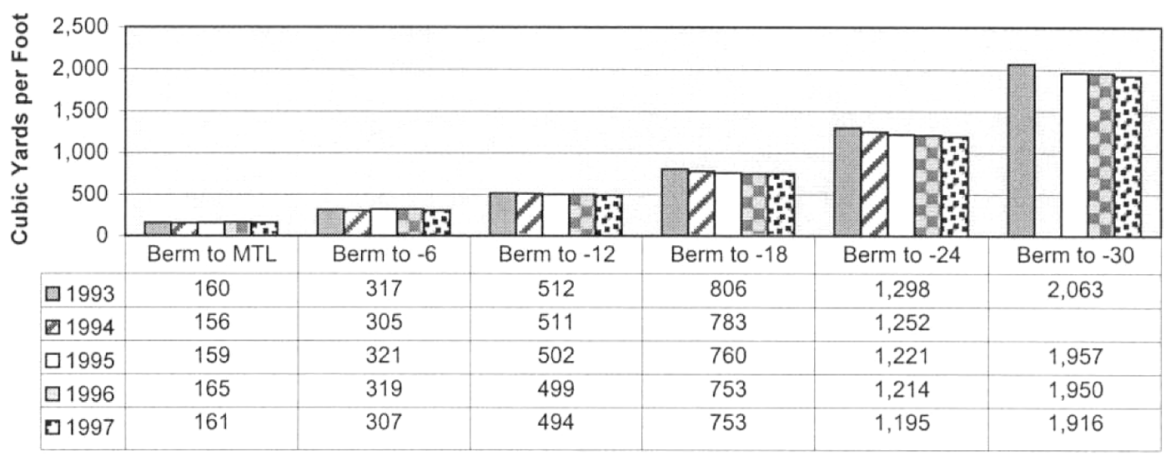


Island Beach-Profile 8: Volume Above Various Contours

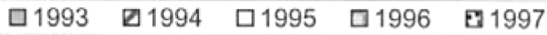

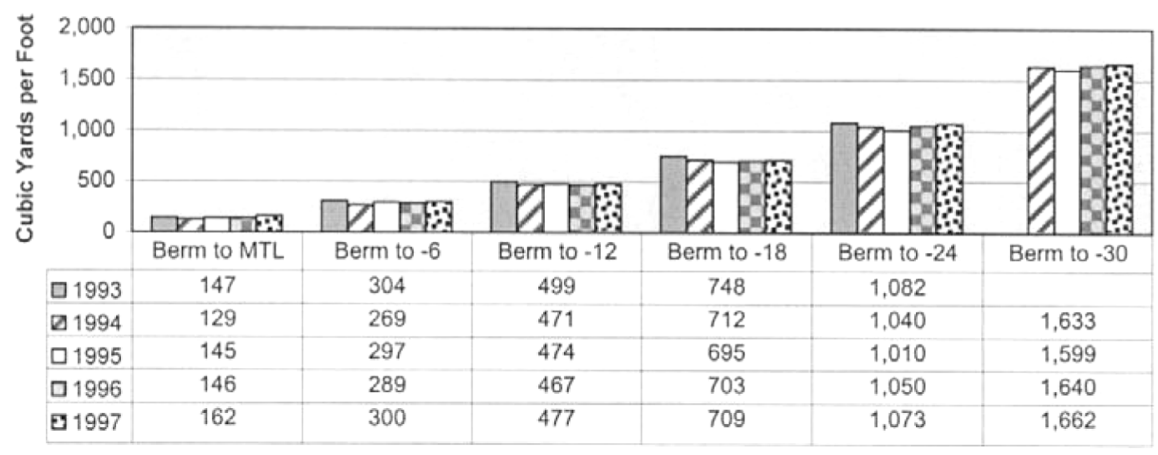

Island Beach-Profile 10: Volume Above Various Contours

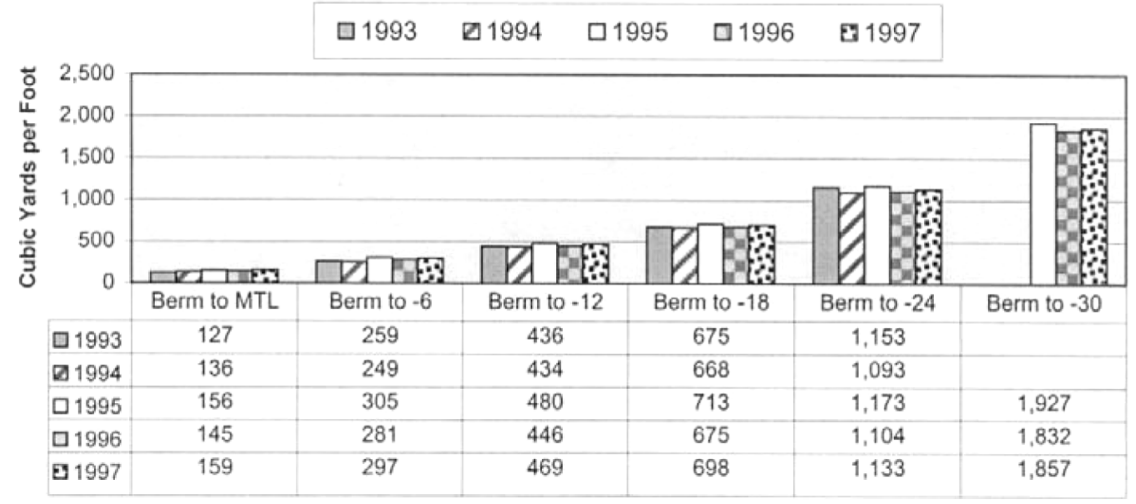

Island Beach-Profile 12: Volume Above Various Contours

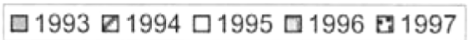

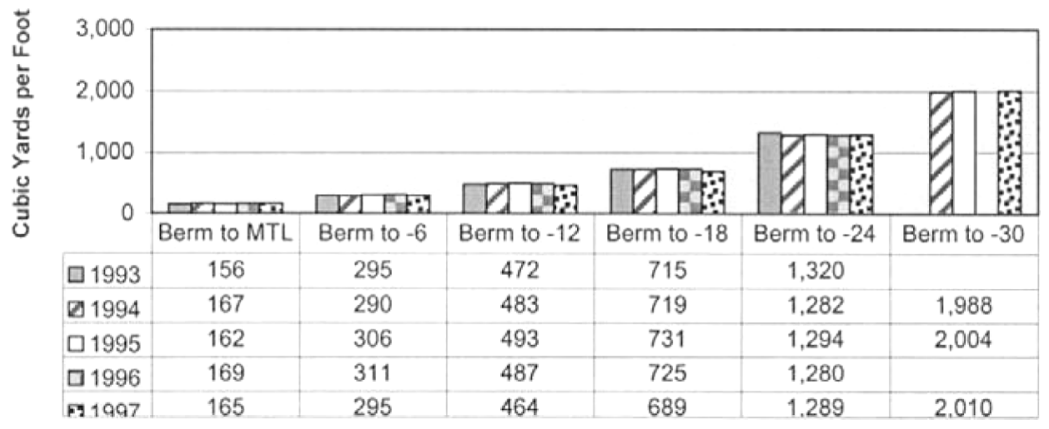


Island Beach-Profile 14: Volume Above Various Contours

\section{$\square 1993 \square 1994 \square 1995 \square 1996 \square 1997$}

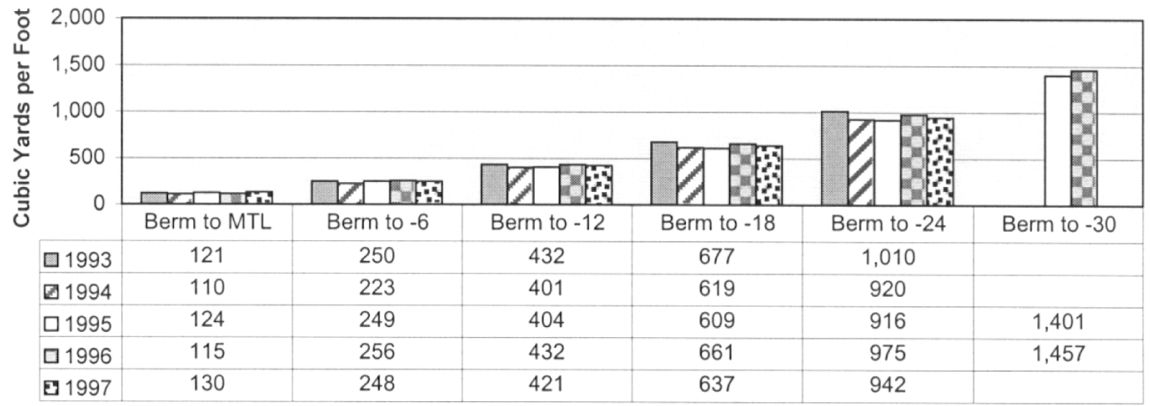

Island Beach-Profile 16: Volume Above Various Contours

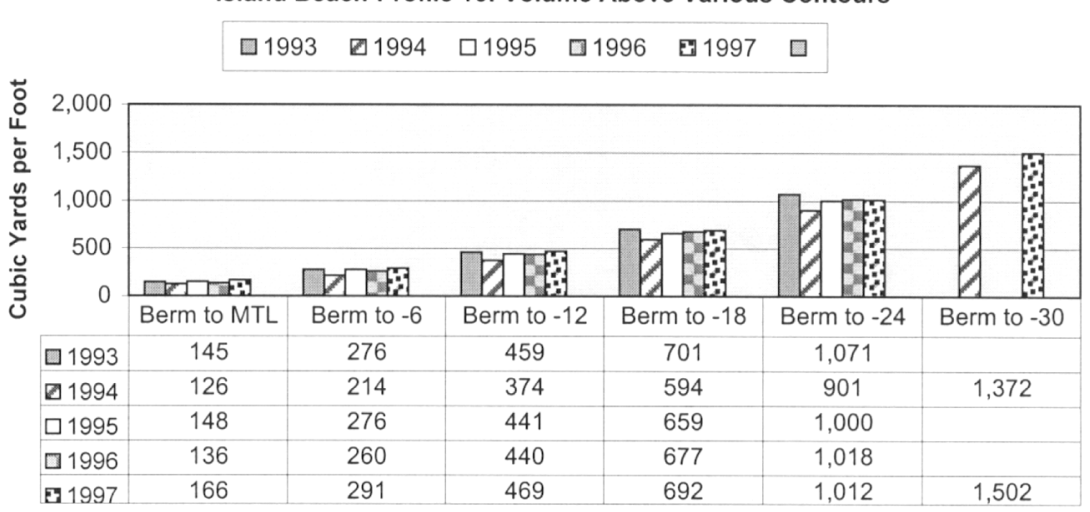

Island Beach-Profile 18: Volume Above Various Contours

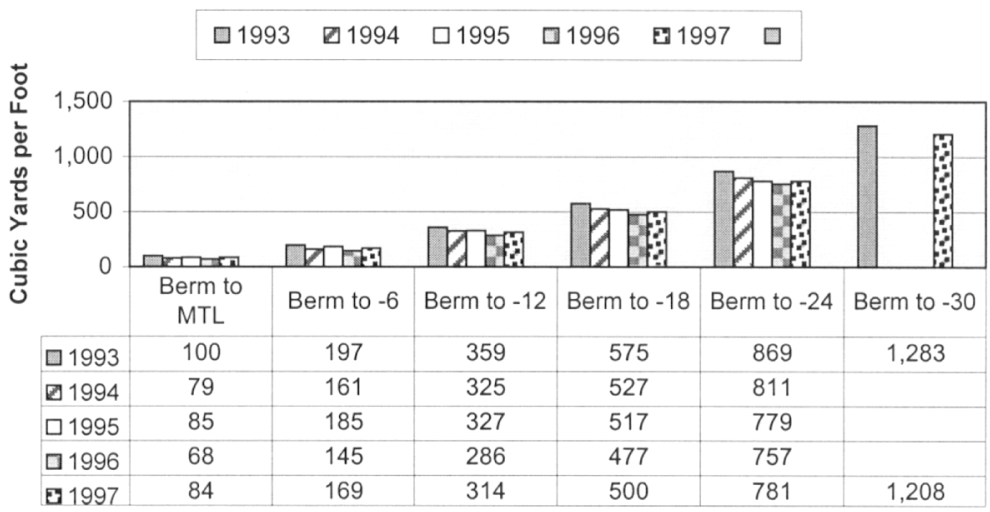


Long Beach-Profile 1: Volume Above Various Contours

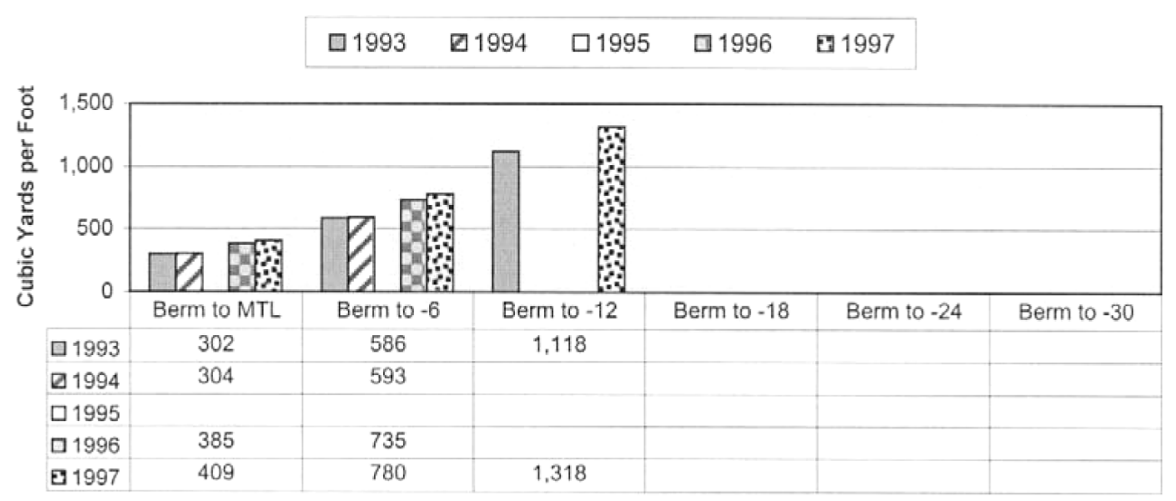

Long Beach-Profile 2: Volume Above Various Contours

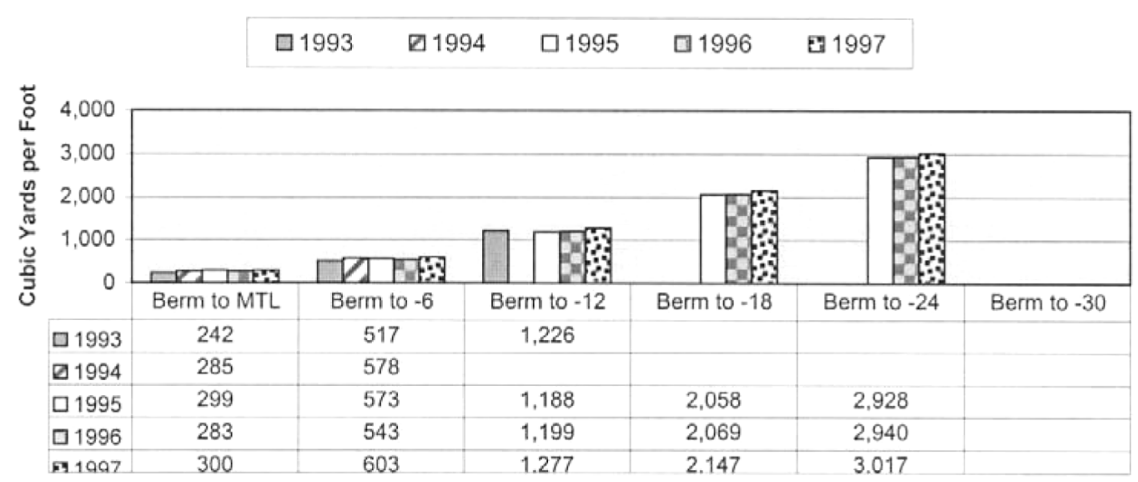

Long Beach-Profile 3: Volume Above Various Contours

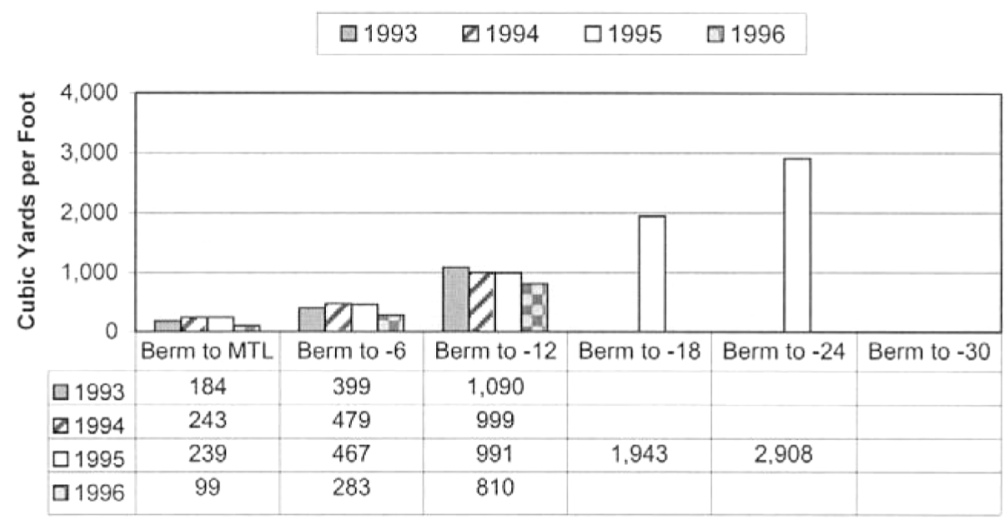


Long Beach-Profile 4: Volume Above Various Contours

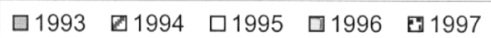

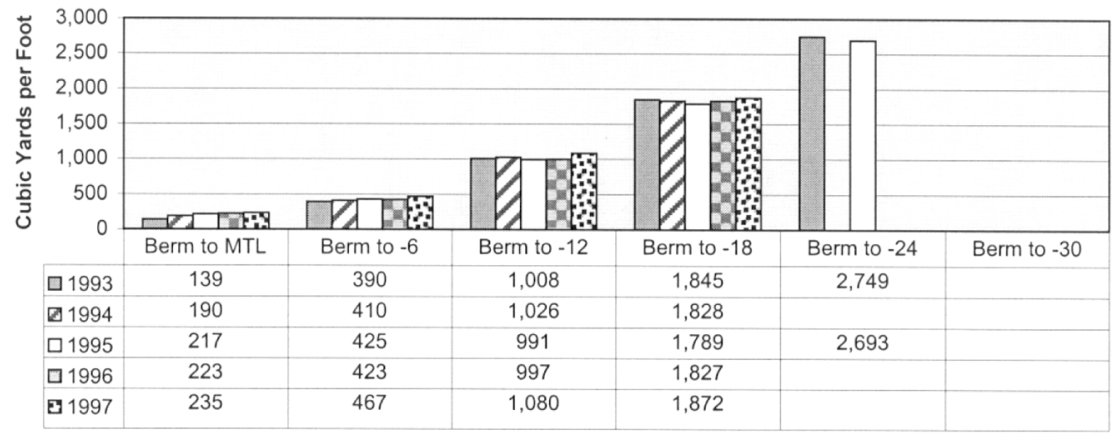

Long Beach-Profile 5: Volume Above Various Contours

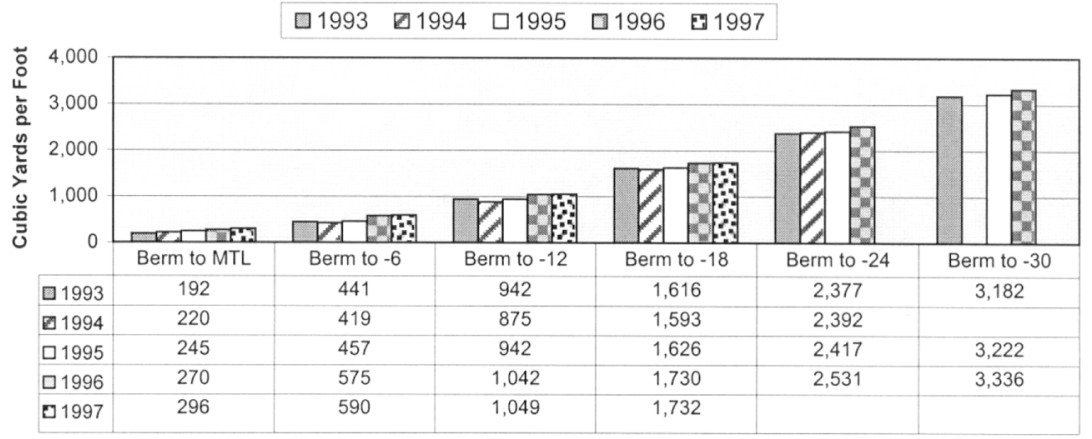

Long Beach-Profile 8: Volume Above Various Contours

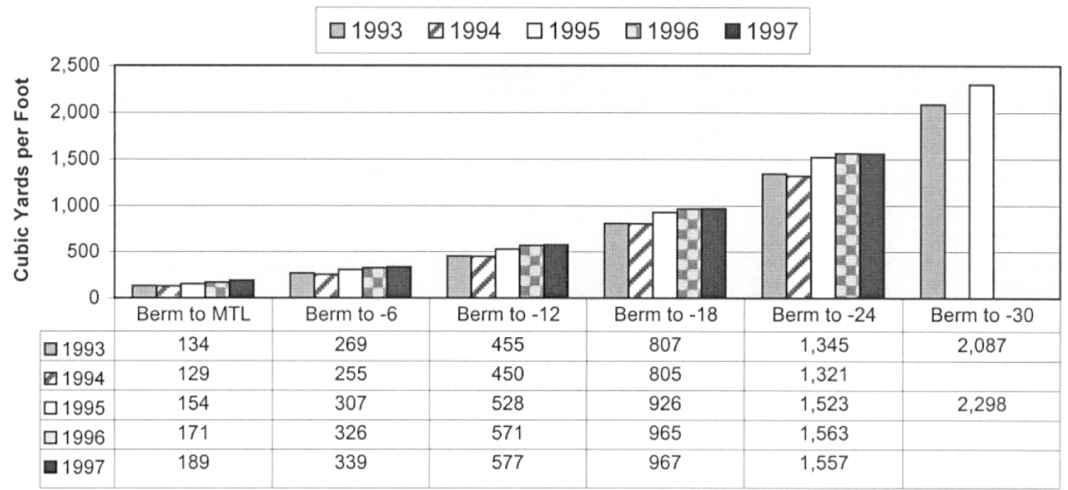


Long Beach-Profile 11: Volume Above Various Contours

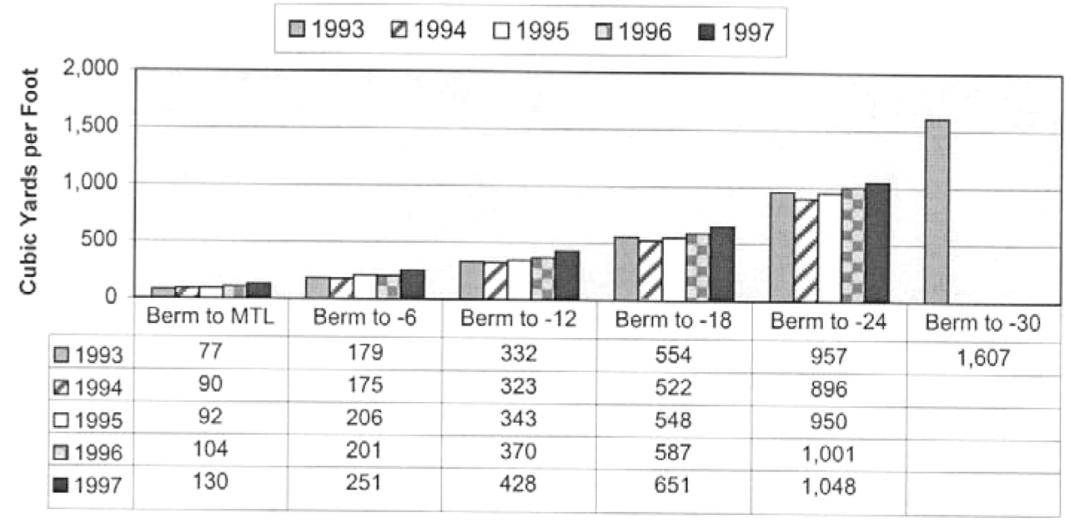

Long Beach-Profile 14: Volume Above Various Contours

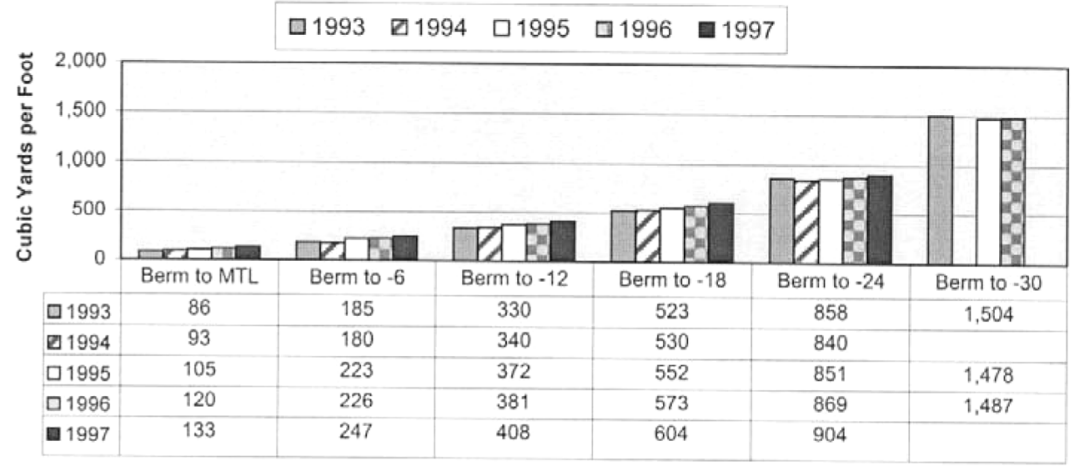

Long Beach-Profile 16: Volume Above Various Contours

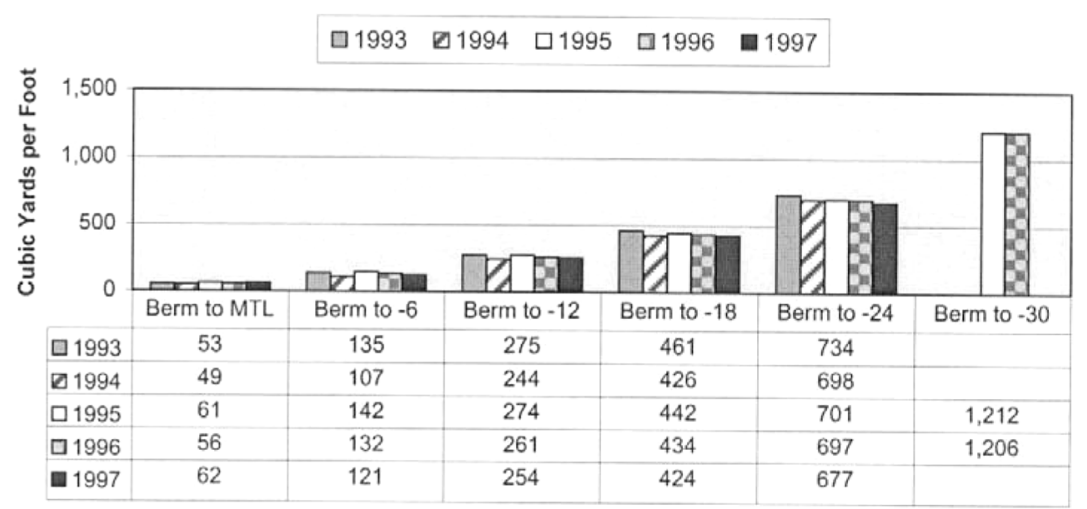


Long Beach-Profile 18: Volume Above Various Contours $\square 1993 \square 1994 \square 1995 \square 1996 \quad \square 1997$

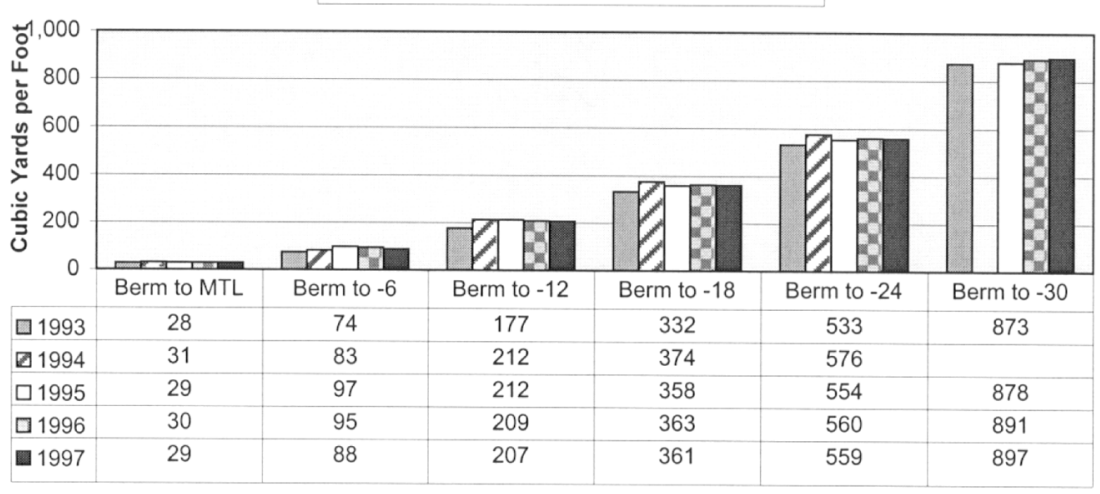

Long Beach-Profile 20: Volume Above Various Contours

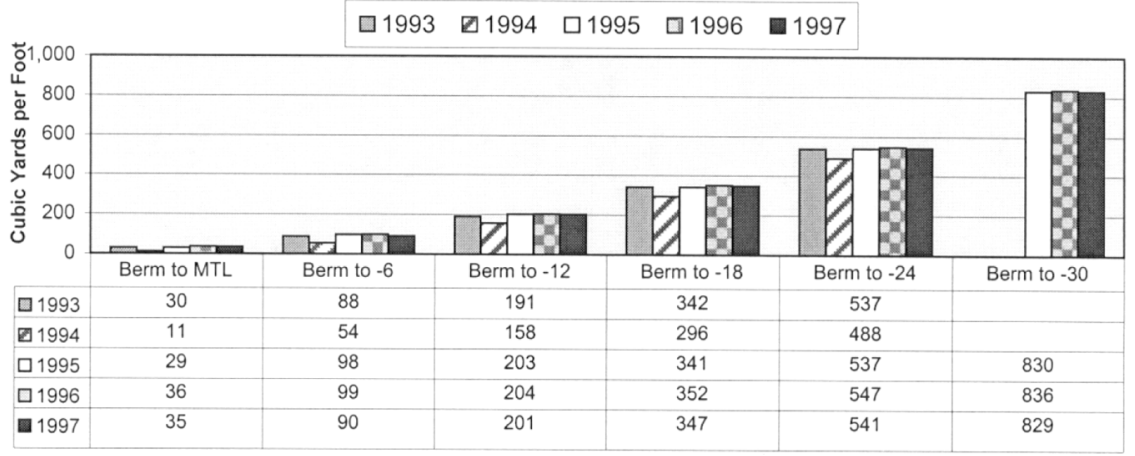

Long Beach-Profile 22: Volume Above Various Contours

$\square 1993 \square 1994 \quad \square 1995 \quad \square 1996 \quad \square 1997$

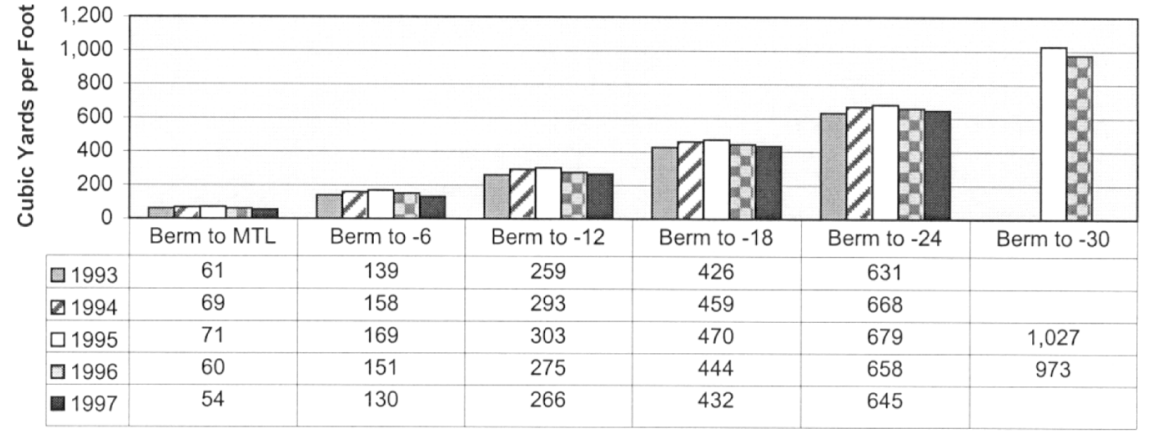


Long Beach-Profile 24: Volume Above Various Contours

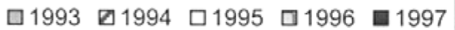

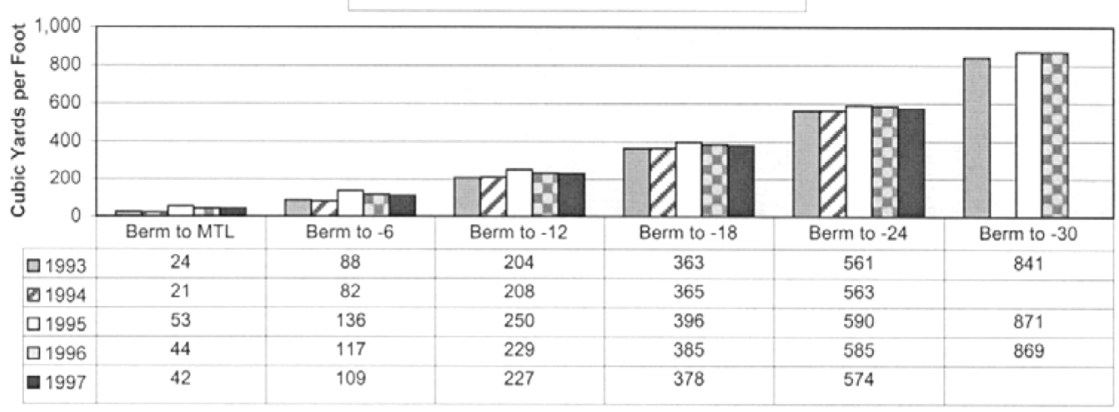

Long Beach-Profile 26: Volume Above Various Contours

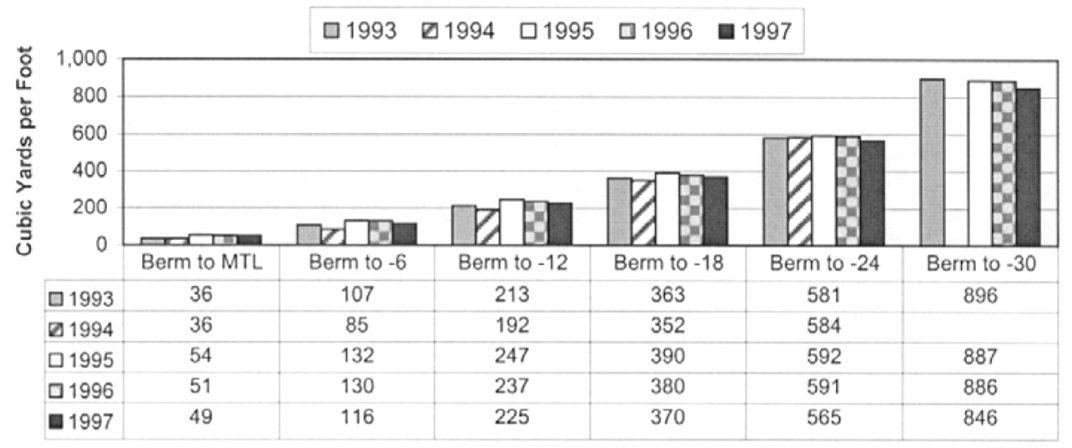




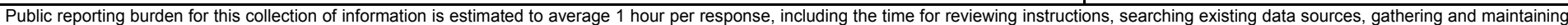

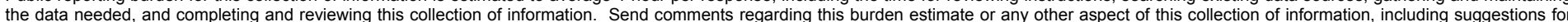

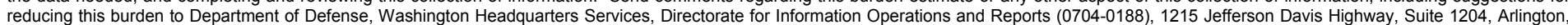

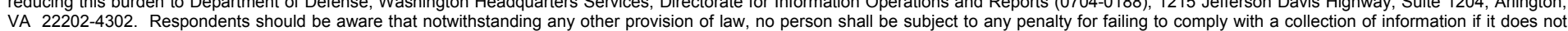
VA 22202-4302. Respondents should be aware that notwithstanding any other provision of law, no person shall be
display a currently valid OMB control number. PLEASE DO NOT RETURN YOUR FORM TO THE ABOVE ADDRESS.

\begin{tabular}{l|c} 
1. REPORT DATE (DD-MM-YYYY) & $\begin{array}{c}\text { 2. REPORT TYPE } \\
\text { August } 2003\end{array}$ \\
\hline
\end{tabular}

\section{TITLE AND SUBTITLE}

Monitoring Barnegat Inlet, New Jersey, South Jetty Realignment

3. DATES COVERED (From - To)

5a. CONTRACT NUMBER

5b. GRANT NUMBER

5c. PROGRAM ELEMENT NUMBER

\section{AUTHOR(S)}

5d. PROJECT NUMBER

William C. Seabergh, Mary A. Cialone, John W. McCormick, Keith D. Watson,

Monica A. Chasten

5e. TASK NUMBER

5f. WORK UNIT NUMBER

IIM-9

\section{PERFORMING ORGANIZATION NAME(S) AND ADDRESS(ES)}

8. PERFORMING ORGANIZATION REPORT NUMBER

See reverse.

ERDC/CHL TR-03-9

9. SPONSORING / MONITORING AGENCY NAME(S) AND ADDRESS(ES)

10. SPONSOR/MONITOR'S ACRONYM(S)

U.S. Army Corps of Engineers

Washington, DC 20314-1000

11. SPONSOR/MONITOR'S REPORT NUMBER(S)

\section{DISTRIBUTION / AVAILABILITY STATEMENT}

Approved for public release; distribution is unlimited.

\section{SUPPLEMENTARY NOTES}

\section{ABSTRACT}

The objective of this monitoring at Barnegat Inlet was to determine the response of the inlet system to a new south jetty completed in 1991 that essentially parallels the existing north jetty. Barnegat Inlet is accessed by a large number of commercial, sport fishing, and recreational vessels each year. An unstable navigation channel and numerous accidents and deaths at Barnegat Inlet led to the construction of the new south jetty. The response of the new south jetty and inlet system was determined by data collection and monitoring and compared with design predictions. This new knowledge will contribute to improved jetty and inlet system design guidance, enhance construction of rubble-mound jetties, and develop better maintenance techniques for tidal inlets. The monitoring plan evaluated four fundamental hypotheses of the project design objectives: (a) the new south jetty and new channel alignment will not adversely affect tidal hydraulic response or high tide level in the inlet by system (i.e., no flooding problem), and prototype hydraulic response will be as predicted by a previous physical model evaluation; (b) the new south jetty realignment will improve navigation safety by stabilizing the navigation channel and depth between the jetties and over the outer bar (ebb tidal shoal), and will eliminate dredging in these regions; (c) the new south jetty will be structurally stable; and (d) the jetty system realignment will not adversely affect upcoast or downcoast beaches.

\section{SUBJECT TERMS}

See reverse.

\section{SECURITY CLASSIFICATION OF:}

\begin{tabular}{|l|l|l|}
\hline $\begin{array}{l}\text { a. } \text { REPORT } \\
\text { UNCLASSIFIED }\end{array}$ & b. ABSTRACT & c. THIS PAGE \\
UNCLASSIFIED & UNCLASSIFIED \\
\hline
\end{tabular}

\begin{tabular}{l|c|} 
17. LIMITATION & $\begin{array}{c}\text { 18. NUMBER } \\
\text { OF ABSTRACT }\end{array}$ \\
& 180 \\
&
\end{tabular}

19a. NAME OF RESPONSIBLE PERSON

19b. TELEPHONE NUMBER (include
area code) 


\section{PERFORMING ORGANIZATION NAMES(S) AND ADDRESS(ED) (Concluded)}

U.S. Army Engineer Research and Development Center, Coastal and Hydraulics Laboratory, 3909 Halls Ferry Road, Vicksburg, MS 39180-6199

U.S. Army Engineer District, Wilmington, 69 Darlington Avenue, Wilmington, NC 28403

U.S. Army Engineer District, Philadelphia, Wanamaker Building, 100 Penn Square East, $2^{\text {nd }}$ and Chestnut Street, Philadelphia, PA 19107-3390

\section{SUBJECT TERMS}

Beach profiles

Condition Index

Ebb shoal

Flood shoal
Inlet

Jetties

Navigation channel

Tidal prism
Tidal range

Tidal velocities

Waves

Wave transformation 